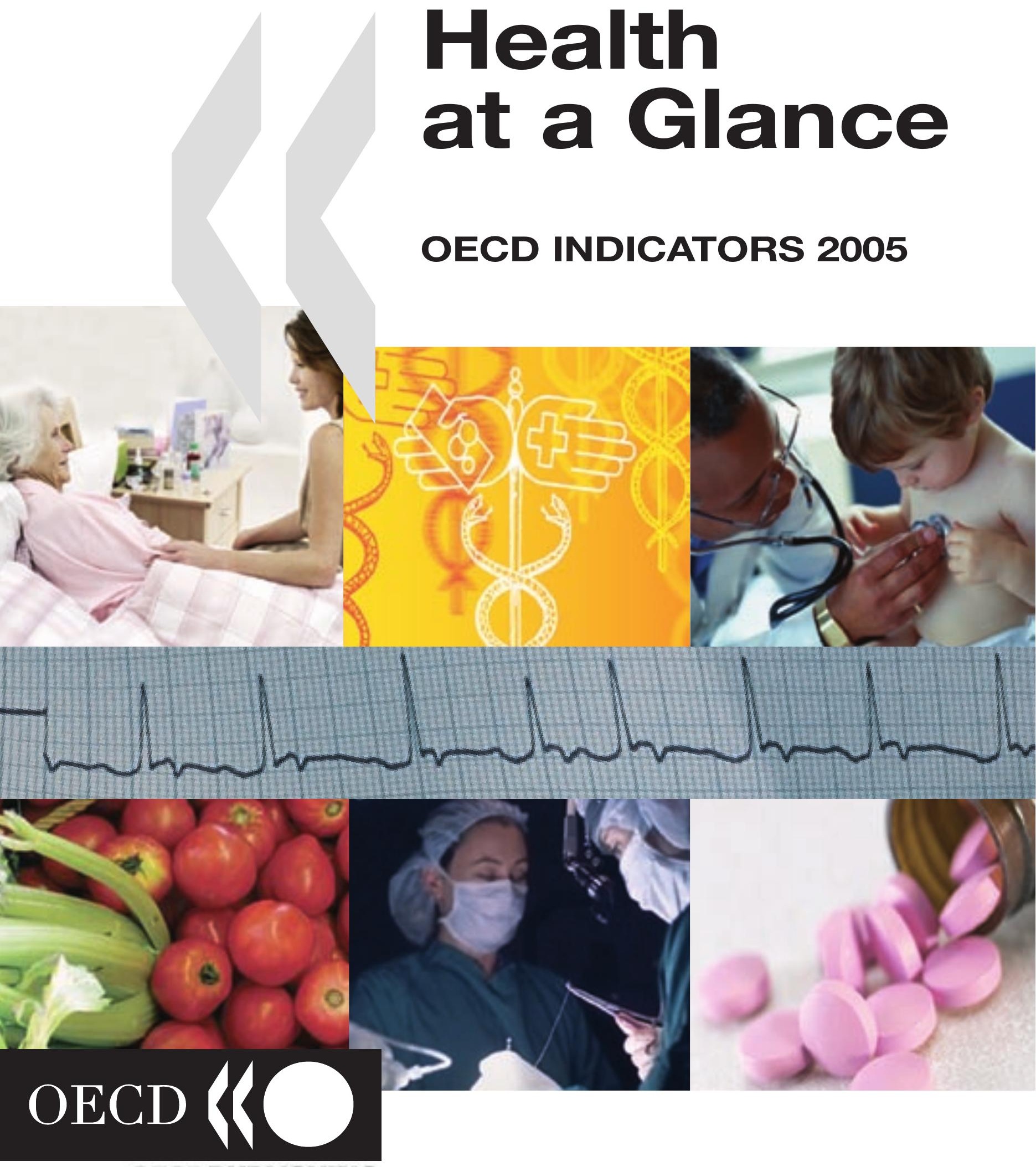

OECDPUBLISHAG

2005 


\title{
Health at a Glance
}

\author{
OECD INDICATORS
}

2005 


\section{ORGANISATION FOR ECONOMIC CO-OPERATION AND DEVELOPMENT}

The OECD is a unique forum where the governments of 30 democracies work together to address the economic, social and environmental challenges of globalisation. The OECD is also at the forefront of efforts to understand and to help governments respond to new developments and concerns, such as corporate governance, the information economy and the challenges of an ageing population. The Organisation provides a setting where governments can compare policy experiences, seek answers to common problems, identify good practice and work to co-ordinate domestic and international policies.

The OECD member countries are: Australia, Austria, Belgium, Canada, the Czech Republic, Denmark, Finland, France, Germany, Greece, Hungary, Iceland, Ireland, Italy, Japan, Korea, Luxembourg, Mexico, the Netherlands, New Zealand, Norway, Poland, Portugal, the Slovak Republic, Spain, Sweden, Switzerland, Turkey, the United Kingdom and the United States. The Commission of the European Communities takes part in the work of the OECD.

OECD Publishing disseminates widely the results of the Organisation's statistics gathering and research on economic, social and environmental issues, as well as the conventions, guidelines and standards agreed by its members.

This work is published on the responsibility of the Secretary-General of the OECD. The opinions expressed and arguments employed herein do not necessarily reflect the official views of the Organisation or of the governments of its member countries.

Publié en français sous le titre:

Panorama de la santé

Les indicateurs de l'OCDE 2005

No reproduction, copy, transmission or translation of this publication may be made without written permission. Applications should be sent to OECD Publishing: rights@oecd.org or by fax (33 1) 452413 91. Permission to photocopy a portion of this work should be addressed to the Centre français d'exploitation du droit de copie, 20, rue des Grands-Augustins, 75006 Paris, France (contact@cfcopies.com). 


\section{Foreword}

$\mathrm{H}$ ealth expenditure now accounts for an average of almost 9\% of GDP in OECD countries, up from just over 5\% in 1970; and more than 70\% of these costs are paid by public sources. In this context, it is understandable that, at the first-ever meeting of OECD Health Ministers in May 2004, there was general agreement that all OECD countries are facing major challenges to improve the efficiency and the financial sustainability of their health systems. Ministers also recognised that countries can only benefit from further experimentation to increase value for money spent on health, combined with performance measurement, benchmarking and sharing of information.

The meeting of OECD Health Ministers concluded with a renewed mandate for the OECD to work with national administrations to ensure that the OECD health database is both timely and accurate. Ministers also supported the continued implementation of health accounts, with the goal being to ensure that national data supplied to all international organisations are based on a consistent health accounts framework.

This third edition of Health at a Glance - OECD Indicators 2005 presents a selection of key indicators on health and health systems contained in OECD Health Data 2005.* It is designed to provide the basis for a better understanding of a range of factors which affect the health of populations and the performance of health systems in OECD countries, in an easily accessible way. This third edition updates a number of core indicators that featured in the first two editions, but also contains some new ones. In particular, it contains an expanded set of indicators related to health promotion and disease prevention, reflecting growing policy interest in these areas. The publication describes the main variations across countries and over time in these key indicators of health, drawing heavily on graphical illustrations. Care has also been taken to indicate precisely the definition of each indicator and to signal data comparability limitations.

Production of OECD Health Data and this publication would not have been possible without the contribution of national data correspondents and health accounts experts in the 30 OECD countries. The OECD gratefully acknowledges their effort to report most of the data and qualitative information contained in this publication. The OECD also acknowledges the contribution of other international organisations, especially the World Health Organisation and Eurostat, for sharing some of the data presented in this publication.

This report was prepared by the OECD Health Division under the coordination of Gaetan Lafortune and David Morgan. Eva Orosz, Gaëlle Balestat, Michael de Looper (from the Australian Institute of Health and Welfare) and Olga Van der Sloot (from the Dutch Ministry of Health, Welfare and Sport) also contributed to this issue of Health at a Glance. Statistical assistance was provided by Gaëlle Balestat and Noura Takrouri. This publication benefited from many comments and suggestions by OECD colleagues, notably Francesca Colombo, Elizabeth Docteur, Martine Durand, Jeremy Hurst and Peter Scherer.

\footnotetext{
* For more than a decade now, OECD Health Data has offered the most comprehensive source of comparable statistics on health and health systems among developed countries. The data collection on health expenditure and financing is increasingly relying on the OECD manual, A System of Health Accounts (OECD, 2000), thereby enhancing the availability and comparability of these data. OECD Health Data is an electronic database released annually on line and on a CD-Rom. Further information on accessing OECD Health Data can be obtained at www.oecd.org/health/healthdata.
} 



\section{Table of Contents}

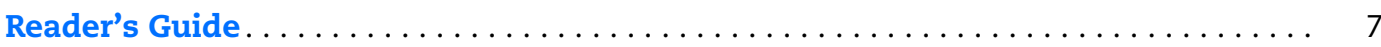

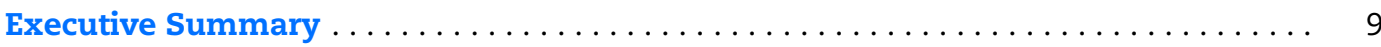

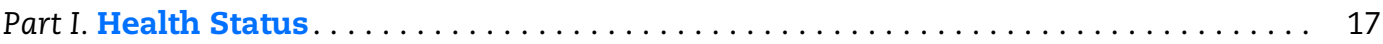

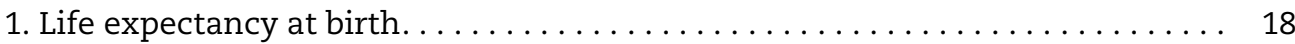

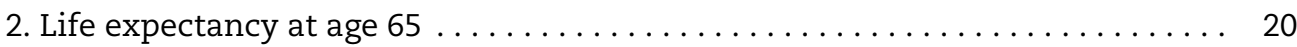

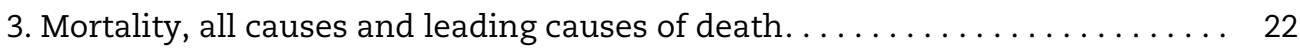

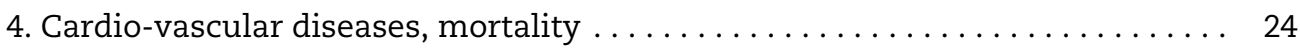

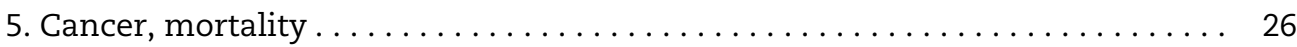

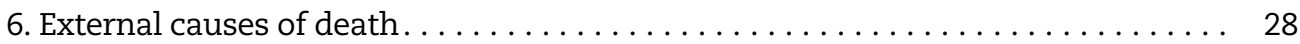

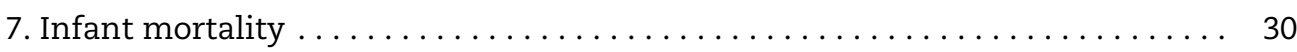

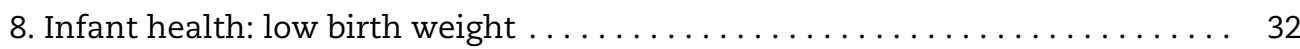

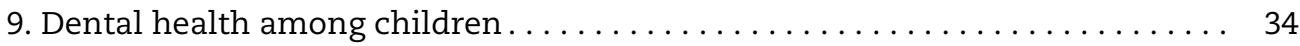

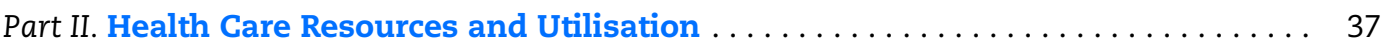

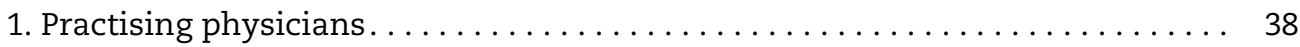

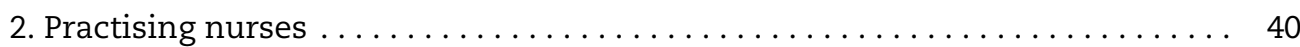

3. Remuneration of health professionals (physicians and nurses) . . . . . . 42

4. Acute care hospital beds, availability and occupancy rates . . . . . . . . . 44

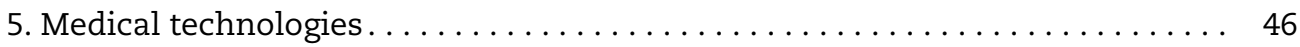

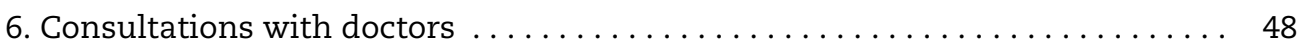

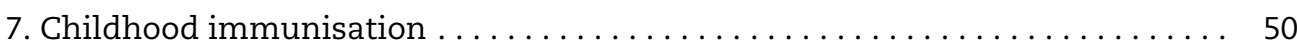

8. Influenza immunisation among elderly people $\ldots \ldots \ldots \ldots \ldots \ldots \ldots \ldots$

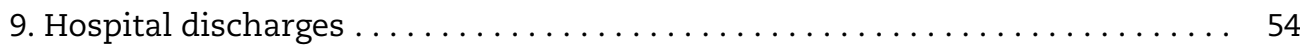

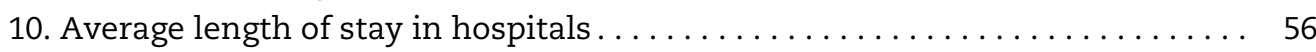

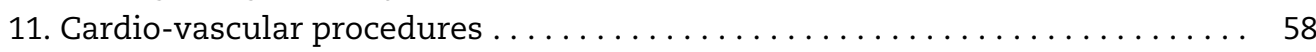

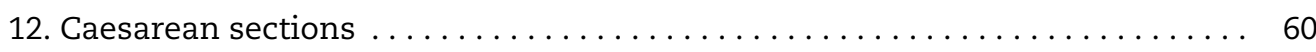

13. Cataract surgeries, ambulatory and inpatient. . . . . . . . . . . 62

Part III. Health Expenditure and Financing $\ldots \ldots \ldots \ldots \ldots \ldots \ldots \ldots \ldots \ldots \ldots \ldots \ldots \ldots \ldots \ldots \ldots$

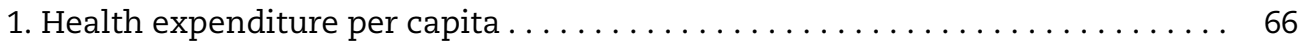

2. Health expenditure per capita, growth trends $\ldots \ldots \ldots \ldots \ldots \ldots \ldots \ldots 6$

3. Health expenditure in relation to gross domestic product (GDP) $\ldots \ldots \ldots \ldots 70$

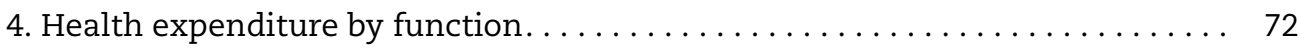

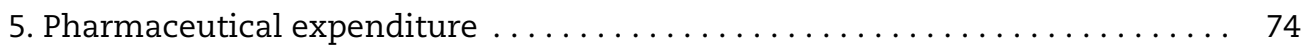

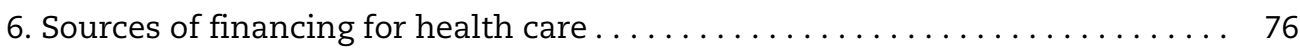


Part IV. Non-medical Determinants of Health . . . . . . . . . . . . . . . . . 79

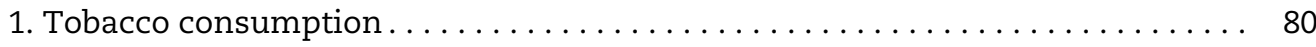

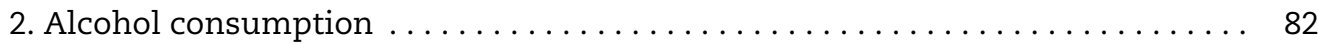

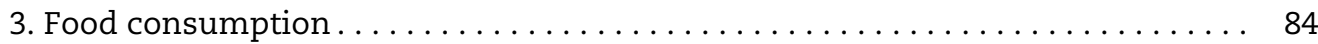

4. Overweight and obesity $\ldots \ldots \ldots \ldots \ldots \ldots \ldots \ldots \ldots \ldots \ldots \ldots \ldots \ldots \ldots \ldots$

Part V. Demographic and Economic Context . . . . . . . . . . . . . . . 89

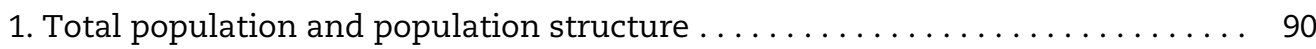

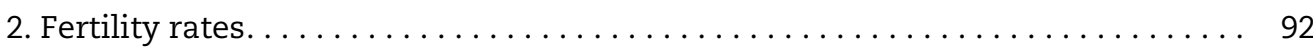

3. Gross domestic product (GDP) and income inequality . . . . . . . . . . . 94

Bibliography .................................... 97

Annex A. Statistical Annex . . . . . . . . . . . . . . . . . . . . . . . . . . . . . . . . 101

Annex B. Definition of Health Expenditure and Methodological Notes

on Data Comparability . . . . . . . . . . . . . . . . . . . . . . . . . . . . . . 168

Annex C. List of Variables in OECD Health Data 2005 . . . . . . . . . . . . . . . . . . . 170

Annex D. Disease and Injury Categories and ICD Codes . . . . . . . . . . . . . . . . 171

\section{This book has...}

\section{StatLinks \\ A service from OECD Publishing that delivers Excel ${ }^{\mathrm{TM}}$ files from the printed page!}

Look for the StatLinks at the bottom right-hand corner of the tables and graphs in this book. To download the matching Excel ${ }^{\mathrm{TM}}$ spreadsheet, just type the link into your internet browser, starting with the http://dx.doi.org prefix.

If you're reading the PDF e-book edition, and your pc is connected to the Internet, simply click on the link. You'll find StatLinks appearing in more OECD books. 


\section{Reader's Guide}

$H_{1}$

ealth at a Glance - OECD Indicators 2005 presents key health indicators in the form of text, charts and tables. The publication shows cross-country variations and trends over time in core indicators of health status, health systems and non-medical determinants of health, as well as background information on the demographic and economic context. It also provides a brief interpretation of these data. The statistical annex at the end of the publication offers additional data on these indicators.

All data presented in this publication are based on OECD Health Data 2005 (final update as of September 2005), allowing users to replicate all the charts and tables. OECD Health Data itself is a comprehensive database covering over 1000 statistical series on health and health systems across OECD countries. The database is the product of a longstanding collaborative effort between the OECD Health Division and national statistical offices. It comes with extensive documentation of indicator definitions, national sources and estimation methods. The structure of Health at a Glance generally follows that of OECD Health Data, although some parts of the database have been combined for the purpose of simplifying this publication. More details on the full content of OECD Health Data 2005 are available in Annex C and at www.oecd.org/health/healthdata.

\section{Text and charts}

Each of the 35 topics covered in this publication is presented over two pages, displaying a brief commentary highlighting the key findings conveyed by the data, and a methodological box with the definition of the indicator and any significant national variations from that definition which might affect data comparability. On the facing page is a series of charts. These charts typically show current levels of the indicator, changes or trends over time. In some cases, these are complemented with an additional chart relating the indicator to another variable. Where an OECD average is included in a chart, it is the unweighted average of the countries presented, unless otherwise specified in the accompanying notes. Users should also refer to the corresponding tables for any further methodological information.

\section{Tables}

All tables are contained in the statistical annex (Annex A) at the end of this publication. Where data for individual countries are not available for the years selected, the tables present the most recent data available, normally up to the previous or following three years.

The tables contain a variety of summary statistics depending on the indicator. For the non-expenditure series, the consistent average refers to the unweighted average of only those countries for which data are available over all the considered time periods, in order to present information for a consistent group of countries over time. The number of 
countries included in the consistent average is noted in brackets, with those countries omitted from the average listed directly under the table. In addition to the consistent average, the latest average is presented in most cases, relating to the average for the latest year available only for as many countries as possible. Unless specified, this should be equal to the average shown in the corresponding bar chart. Finally, the median is also presented. By definition, half the countries have values that are greater than the median, and half have values that are lower than the median. Compared with averages, medians minimize the influence of outliers (countries with values either much greater or much smaller than others). Note that medians relate to the group of countries for which data is available in a given year (so they are not valid for comparisons over time).

The expenditure tables present the unweighted average over time for a group of countries, as defined for the consistent average described above. Where appropriate, a weighted average is shown, taking into account the proportional size of each country, measured either in terms of population or GDP.

Unless otherwise specified, expenditure data are presented in US dollars adjusted for purchasing power parities in order to remove the effect of differences in price levels between countries. For growth rates, nominal expenditures are deflated using suitable price indices. In the absence of widely available and reliable health price indices, an economy-wide (GDP) price index is used in this publication (see Annex B for additional information regarding the use of purchasing power parities and real growth rates).

Missing, not applicable or not available data are noted in the table by ".." and series breaks are marked by a "l" between columns. Any further methodological notes are included directly under the relevant table.

\section{Data limitations}

Limitations in data comparability are indicated both in the text (in the box related to "Definition and deviations") as well as in footnotes to tables and charts. Readers should exercise particular caution when considering time trends for Germany. Data for Germany up to 1990 generally refer to West Germany and data for subsequent years refer to unified Germany.

Readers interested in using the data presented in this publication for further analysis and research are encouraged to consult the full documentation of definitions, sources and methods contained in OECD Health Data 2005. OECD Health Data 2005 can be ordered online at SourceOECD (www.sourceOECD.org) or through the OECD's online bookshop (www.oecd.org/bookshop).

\section{StatLink}

This publication includes OECD's unique Statlink service, enabling the reader to download the exact Excel ${ }^{\mathrm{TM}}$ versions of the tables and charts featured in Health at a Glance. The Statlink address is printed under each table and chart and behaves exactly like an Internet address. By typing or copying the Statlink address into an Internet browser, the user obtains the corresponding data in Excel ${ }^{\mathrm{TM}}$ format allowing further analysis and manipulation. Further information on the Statlink service is available on www.oecd.org/ statistics/statlink. 
ISBN 92-64-01262-1

Health at a Glance: OECD Indicators 2005

(c) OECD 2005

\section{Executive Summary}


$\mathrm{H}$ ealth systems are of growing size and importance in OECD countries. Progress in health care and the development of new medicines have contributed to the steady improvements in health status that OECD countries have enjoyed in recent decades. At the same time, spending on health care has never been higher, consuming an ever-increasing share of national income.

There is obviously more to health than health care and health spending. A large body of evidence shows that population health in developed countries is determined more by socio-economic and lifestyle determinants than by the provision of health care itself. Welldesigned public health programmes may contribute to the prevention of illness and help relieve some of the cost pressures on health care systems. Risk factors to health are also changing. For example, while many OECD countries have achieved remarkable progress over the past few decades in reducing tobacco consumption, obesity rates have increased in all OECD countries, reflecting changes in eating habits and more sedentary lifestyles.

Health at a Glance - OECD Indicators 2005 provides a comparable and up-to-date collection of indicators related to different aspects of the performance of health systems. It takes as its basis OECD Health Data 2005, a comprehensive database containing more than 1000 statistical series on health and health systems across OECD countries. This third edition of Health at a Glance focuses not only on the resources and activities of health care systems, but also includes an increased number of indicators related to health promotion and disease prevention. For instance, the chapter on health status includes more information on children's health, including their dental health. Indicators related to nutrition have also been added to indicators of tobacco consumption, alcohol consumption and overweight and obesity in the chapter on risk factors. Influenza immunisation coverage among elderly people complements the traditional indicators on childhood immunisation, as examples of preventive health services that can reduce ill health and related health care needs. And health spending is now broken down to show spending for organised public health programmes in different OECD countries.

This publication provides striking evidence of large variations across the 30 OECD member countries in indicators of health status, health risks, and in the costs, allocation of resources and outputs of their health systems. While some basic population breakdown by sex and age are presented for a number of indicators, it does not provide in most cases a more detailed breakdown by (sub-national) region, by socio-economic group or by different ethnic/racial group. The reader should therefore bear in mind that for many indicators shown in this publication, there may be as much variation within a country as there is across countries.

The following summarises some of the main findings of this publication as they relate to the performance of health systems. 


\section{Health status has improved dramatically in}

OECD countries

- Life expectancy at birth has increased substantially in OECD countries in recent decades, thanks to rising living standards, improved lifestyle and better education, as well as advances in access to care and the efficacy of medicine. On average across OECD countries, life expectancy at birth reached 77.8 years in 2003, up from 68.5 in 1960. In 2003, Japan enjoyed the highest life expectancy, with 81.8 years for the whole population, followed by Iceland, Spain, Switzerland, Australia and Sweden (Chart 1.1).

- It is difficult to estimate the relative contribution of the numerous non-medical and medical factors that might affect variations in life expectancy across countries and over time. Higher national income is generally associated with higher life expectancy at birth across OECD countries, although the relationship is less pronounced at higher levels of national income. There are also notable differences in life expectancy between OECD countries with similar income per capita. For instance, Japan and Spain have higher life expectancies than would be predicted by their GDP per capita alone, while the United States and Hungary have lower life expectancies than predicted based on income (Chart 1.3).

- Life expectancy at age 65 has also increased substantially over the past few decades in OECD countries. In 2003, life expectancy at age 65 stood, on average across OECD countries, at 19.3 years for women and 15.9 years for men. This is up by more than 3 years since 1970 for both women and men. As with life expectancy at birth, Japan enjoys the longest life expectancy at age 65 in 2003 (Chart 1.5). Life expectancy at age 65 is expected to continue to increase in coming decades. OECD calculations project that, by 2040, life expectancy at age 65 will, on average in OECD countries, reach 21.6 years for women and 18.1 years for men.

- All OECD countries have made remarkable progress in reducing infant mortality rates in recent decades, thanks to overall improvements in economic and social conditions, as well as improvements in health services for post-natal care, including access to childhood immunisation. Portugal has seen its infant mortality rate reduced by over $90 \%$ since 1970, going from the country with the highest rate in Europe to one among the lowest in 2003. Large reductions in infant mortality rates have also been achieved in Mexico, Turkey and in some southern European countries, such as Italy, Spain and Greece. In 2003, Japan and some of the Nordic countries had the lowest infant mortality rates among OECD countries (Chart 1.20).

\section{OECD countries face rising health costs}

- While there have been impressive gains in longevity over the past decades in OECD countries, health costs have also risen over time, and in most countries health expenditure increased at a faster rate than overall economic growth. In 2003, OECD countries devoted, on average, $8.8 \%$ of their GDP to health spending, up from $\mathbf{7 . 1 \%}$ in 1990 and just over 5\% in 1970. However, the share of GDP allocated to health spending varies considerably across countries, ranging from $15 \%$ in the United States to less than $6 \%$ in the Slovak Republic and Korea. Following the United States, in terms of 
highest health spending as a percentage of GDP in 2003, were Switzerland and Germany which spent $11.5 \%$ and $11.1 \%$ of their GDP on health, respectively (Chart 3.7).

- Growth in health spending can be attributed to several factors. In general, OECD countries with higher GDP per capita tend to spend more per capita on health (Chart 3.10). However, there are significant variations across countries, which may partly reflect policy decisions regarding appropriate spending levels, different financing and organisational structures of health systems, and the perceived value of additional spending on health relative to other goods and services. Advances in the capability of medicine to prevent, diagnose and treat health conditions are a major factor driving health cost growth. A variety of factors affect the development and diffusion of new medical technologies and new drugs, including the decision-making process about how to finance new equipment, treatment or drug. Population ageing also contributes to the growth in health spending. The percentage of the population 65 years or older has risen in all OECD countries (Chart 5.3), and this is expected to continue in the years and decades ahead, particularly given the ageing of the "baby-boom" generation (which will begin reaching the age of 65 in 2010 and beyond). Since older populations tend to be in greater need of health and long-term care, population ageing can be expected to increase public expenditure in these areas.

Health costs are putting pressure on public

budgets

- Given the predominance of publicly financed health insurance coverage or direct public financing of care in most OECD countries, the public sector accounts for the greatest part of health spending in all countries, except the United States, Mexico and Korea (Chart 3.17). Even in the United States, where the private sector plays a particularly large role in financing, public spending on health represents $6.6 \%$ of GDP, comparable to the OECD average.

- The last decade can be roughly divided into two periods in terms of the growth in public expenditure on health in OECD countries. The period 1992-1997 saw economic growth matched by a similar or even slower growth in public expenditure on health. In more recent years however, public expenditure on health has increased more rapidly than economic growth in all OECD countries. In some countries such as the United Kingdom and Canada, recent increases in public health spending have reflected deliberate policies to relieve demand pressures arising from cost containment during the mid-1990s (Chart 3.6).

- The rapid rise in drug spending in recent years - more than $5 \%$ per year growth on average since 1997 - has been an important driver in the overall rise in total health spending. In fact, most OECD countries have seen growth in pharmaceutical spending outstrip growth in total health spending over this period. In the United States and Australia, pharmaceutical spending has increased at more than double the rate of growth in total health spending in recent years. Significant growth has also been observed in Ireland and Korea, albeit from a relatively low per capita base at the beginning of the period. The rate of growth was much more moderate in Japan (Chart 3.16). 
- On average across OECD countries, $60 \%$ of the pharmaceutical bill is borne by public funds, the remainder being met basically by out-of-pocket payments and, to a lesser extent, private insurance. However, this average hides a very wide variation, ranging from lows of $11 \%$ in Mexico and $21 \%$ in the United States, to a high of $86 \%$ in Ireland. One reason for this is how and even whether pharmaceuticals are covered by national health programmes and publicly financed insurance (Table A.3.11).

- In 2003, drug expenditure per person was highest in the United States (more than 700 USD per person), followed by France (just over 600 USD), Canada and Italy (about 500 USD). The lowest spending of just over 100 USD was in Mexico and in Turkey. Variations in drug spending across countries reflect differences in volume, structure of consumption and price level. Difference in income levels across countries also affects spending on drugs (Chart 3.14).

Shortages of health care resources could pose a problem in certain countries

- A perceived shortage of physicians is an important concern in many countries. The size, distribution and composition of practising physicians is influenced by a number of factors, including restrictions imposed on entry into the medical profession, choice of speciality, remuneration and other aspects of working conditions, and migration. In 2003, there were large variations in the number of practising doctors per capita across OECD countries. It ranged from highs of more than 4 doctors per 1000 population in Italy and Greece, to lows of less than 2 per 1000 population in Turkey, Mexico and Korea. The number of practising doctors per capita was also relatively low in Japan, Canada, the United Kingdom and New Zealand. This latter group of countries have traditionally controlled medical school intake.

- Foreign-trained physicians account for a substantial share of the physician workforce in certain countries. In 2000 , the share of foreign-trained physicians exceeded $20 \%$ of all practising physicians in English-speaking countries such as New Zealand, the United Kingdom, the United States and Canada. On the other hand, the share of foreign-trained physicians was much lower in Japan, Austria and France (Chart 2.4). International migration can increase the flexibility of labour markets for doctors and other health professionals in receiving countries, but it raises serious concerns about a "brain drain" when there are net long-term flows of staff from lower-income to higher-income countries.

- New data on the remuneration of doctors are presented in this third edition of Health at a Glance - OECD Indicators 2005, for general practitioners (GPs) and specialists (separated into salaried and self-employed physicians). Compared to average national income, the income of physicians varies considerably across countries. For example, the income of self-employed specialists is relatively high in the Netherlands, the United States, Belgium and Canada. On the other hand, specialists in Hungary and the Czech Republic (regardless of whether they are salaried or self-employed) earn relatively less, compared to average national income, than in other countries (Chart 2.9).

- There are also reports of current nurse shortages in all but a few OECD countries. As for doctors, there are substantial variations in the number of nurses across OECD countries, although the comparability of data is limited due to the inclusion of different 
categories of nurses. Ireland, Iceland and the Netherlands report the highest number of nurses per capita, with almost or more than 13 nurses per 1000 population in 2003. At the lower end of the scale, there were less than 4 nurses per 1000 population in Turkey, Korea, Mexico and Greece (Chart 2.5). Looking at trends over time, between 1990 and 2003, the number of nurses per capita continued to increase at least slightly in most countries, but it started to decline in Australia, Canada, New Zealand and Poland (Chart 2.6).

- Data on the remuneration of nurses is available only for salaried hospital nurses. Based on data from a dozen of countries, the relative income of nurses compared to GDP per capita is highest in Portugal, followed by Australia and New Zealand. The relative income is lowest in the Czech Republic and Hungary, as well as in Norway (Chart 2.11).

- There are also concerns in some countries about a shortage of diagnostic or therapeutic equipment to ensure timely access to leading-edge technologies. The availability of diagnostic technologies, such as CT and MRI scanners, has increased over the past decade in all OECD countries. MRI being a newer technology than CT, the number of MRIs has increased particularly rapidly since 1990 (Table A.2.8). Nonetheless, there remain large variations in the diffusion of these medical technologies, with Japan reporting, by far, the highest number of CT and MRI scanners per capita. At the other end of the scale, not surprisingly given the high cost of these equipment, the number of MRI units per capita is the lowest in Mexico, followed by Poland, the Slovak Republic and the Czech Republic (Charts 2.13 and 2.14).

\footnotetext{
A greater focus on prevention might provide

opportunities to further improve health while

reducing pressure on health care systems
}

- Health care systems are sometimes criticised for being overly focused on "sick care": for treating the ill, but not doing enough to prevent illness. In fact, only around $3 \%$ of current health expenditure is spent on prevention and public health programmes on average in OECD countries (Chart 3.12).

- Childhood immunisation has been shown to be one of the most effective preventive measures for reducing childhood disease and mortality. Around two-thirds of OECD countries have achieved DTP (diphtheria, tetanus, pertussis) vaccination coverage of 95\% or more, the level needed to provide general immunity for the population. For measles, around half the OECD countries report the same level of coverage. Some of the wealthier OECD countries, as measured by GDP per capita, such as Ireland, Norway and Austria, report below average vaccination coverage for both diphtheria and measles (Chart 2.21).

- Immunisation against influenza (or flu) among elderly people has become increasingly widespread in OECD countries over the past decade, as a way to prevent illness, hospitalisation and mortality among this population group which has a greater risk of developing serious complications from flu. In 2003, the rate of influenza vaccination among elderly people varied from a low of less than $40 \%$ in the Czech Republic, the Slovak Republic and Hungary, to over $\mathbf{7 5 \%}$ in Australia, Korea and the Netherlands. The rate of influenza vaccination also stood at over $60 \%$ in most G7 countries, with the 
exception of Germany and Japan where less than $50 \%$ of the elderly population reported having been vaccinated against influenza in 2003 (Chart 2.23).

Risk factors to health are changing

- Many OECD countries have achieved remarkable progress over the past two decades in reducing tobacco consumption, though it is still a leading cause of premature mortality. Much of this decline can be attributed to policies aimed at reducing tobacco consumption through public awareness campaigns, advertising bans and increased taxation. Current rates of daily smokers among adults now stand at less than $20 \%$ in Australia, Canada, Sweden and the United States, down from over 33\% in the late 1970s. At the other end of the scale, more than $33 \%$ of adults in Greece, Hungary and Luxembourg continue to smoke on a daily basis (Chart 4.1).

- Average alcohol consumption per adult has also gradually fallen in many OECD countries over the past two decades. Curbs on advertising, sales restrictions and taxation have all proven to be effective measures to reduce alcohol consumption. Traditional wine-producing countries such as Italy and France have seen their alcohol consumption per capita drop substantially since 1980. On the other hand, alcohol consumption per capita rose by more than $40 \%$ in Ireland (Charts 4.6 and 4.7 ).

- In many OECD countries, the growth in overweight and obesity rates among children and adults is rapidly becoming a major public health concern. Obesity is a known risk factor for several health problems, including hypertension, high cholesterol, diabetes, cardiovascular diseases, asthma, arthritis and some forms of cancer. More than $\mathbf{5 0 \%}$ of adults are now defined as either being overweight or obese in ten OECD countries: the United States, Mexico, the United Kingdom, Australia, the Slovak Republic, Greece, New Zealand, Hungary, Luxembourg and the Czech Republic (Table A.4.6).

- Focussing on obesity (which involves greater health risks than simply being overweight), the prevalence of obesity among adults varies from a low of $3 \%$ in Japan and Korea, to a high of $\mathbf{3 1 \%}$ in the United States. However, it should be noted that estimates of overweight and obesity rates in most countries are based on self-reported data, which is not the case for the United States, Australia, New Zealand and the United Kingdom where estimates are based on the actual measurement of people's height and weight. Self-reported data on height and weight are not as reliable as actual measures, usually because of an under-estimation of weight. This means that current estimates of obesity rates in most OECD countries under-estimate the true prevalence of obesity because of such reporting biases (Charts 4.12 and 4.13).

- Because obesity is associated with higher risks of chronic illnesses, it is linked to significant additional health care costs. Estimates from the United States indicate that the cost of health care services is $36 \%$ higher, and the cost of medications $77 \%$ higher, for obese people than for people of normal weight (Sturm, 2002). There is a time lag of several years between the onset of obesity and related health problems, suggesting that the rise in obesity over the past two decades observed in most OECD countries will mean higher health care costs in the future. 



\section{Health Status}

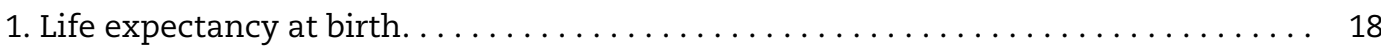

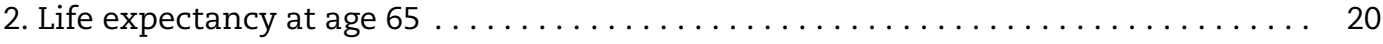

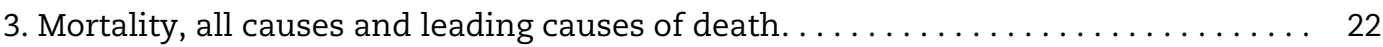

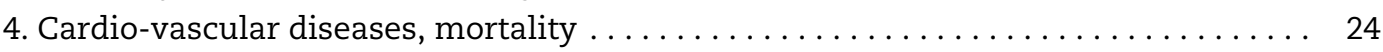

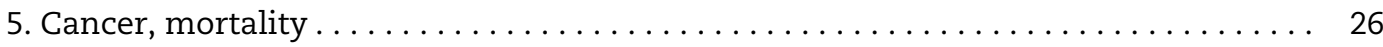

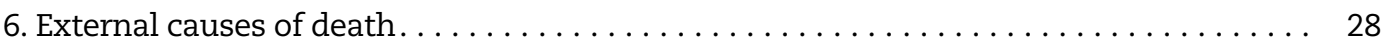

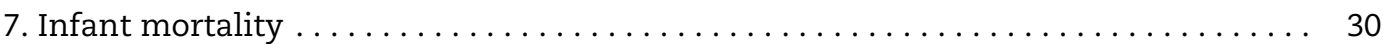

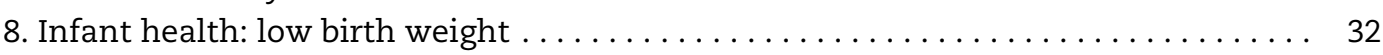

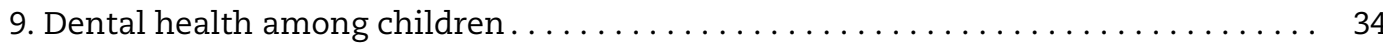




\section{I.1. LIFE EXPECTANCY AT BIRTH}

Life expectancy at birth has increased substantially in OECD countries in recent decades (Chart 1.1). These gains in longevity have been due to a number of important factors affecting mortality rates, including rising living standards, improved lifestyle and better education, as well as advances in access to care and the efficacy of medicine. Other factors, such as better nutrition, sanitation and housing also played a role, particularly in countries with developing economies (OECD, 2004a).

In 2003, the country with the highest life expectancy was Japan, with 81.8 years for the whole population, followed by Iceland, Spain, Switzerland, Australia and Sweden, whose life expectancy also reached 80 years or more (Chart 1.1). On average across OECD countries, life expectancy at birth for the whole population reached 77.8 years in 2003 , up from 68.5 in 1960.

Gains in life expectancy were steady over the past four decades in most countries, averaging 1.8 year in the $1960 \mathrm{~s}$, and 2.3 years in the $1970 \mathrm{~s}$, 1980s and 1990s (Table A.1.1). Increases in life expectancy have been particularly pronounced in countries that started with relatively low levels. In Turkey, life expectancy at birth increased by over 20 years between 1960 and 2003, rapidly catching up with the OECD average. Similarly, in Mexico, life expectancy increased by more than 17 years since 1960. A significant reduction in infant mortality rates has contributed to these gains (see indicator "Infant mortality").

The gender gap in life expectancy stood at 5.8 years on average across OECD countries in 2003 , with life expectancy reaching 74.9 years for men and 80.7 years for women (Chart 1.2). This gender gap increased by less than one year on average across countries over the entire period from 1960 to 2003 (Tables A.1.2 and A.1.3). But this result hides different trends between earlier and later decades. While the gender gap in life expectancy increased substantially in many countries during the 1960s and the 1970s, it narrowed during the past two decades, as gains in life expectancy for men exceeded those for women in several OECD countries. The narrowing of the gender gap in life expectancy in many countries over the past two decades has been attributed partly to the narrowing in risk factor behaviours, such as smoking, between men and women, accompanied by falls in mortality rates from cardiovascular disease among men (Max Planck Institute, 1999; Statistics Netherlands, 2004).

It is difficult to estimate the relative contribution of the numerous non-medical and medical factors that might affect variations in life expectancy over time and across countries. Higher national income (as measured by GDP per capita) is generally associated with higher life expectancy at birth across OECD countries, although the relationship is less pronounced at higher levels of national income (Chart 1.3). There are also notable differences in life expectancy between OECD countries with similar income per capita. Japan and Spain have higher life expectancies than would be predicted by their GDP per capita alone, while the United States, Hungary and Turkey have lower life expectancies than would be predicted based on income.

Chart 1.4 shows the relationship between life expectancy at birth and health expenditure per capita across OECD countries. As for GDP per capita, higher health spending per capita is generally associated with higher life expectancy at birth, although this relationship tends to be less pronounced in countries with higher health spending per capita. Again, Japan and Spain stand out as having relatively high life expectancies, and the United States, Hungary and Turkey relatively low life expectancies, given their levels of health spending.

These simple correlations are interesting but deeper analysis is required. Variations in GDP per capita may influence both life expectancy and health expenditure per capita. Many other factors, beyond national income and total health spending, also need to be taken into account to explain variations in life expectancy across countries.

\section{Definition and deviations}

Life expectancy measures how long on average people would live based on a given set of age-specific death rates. However, the actual age-specific death rates of any particular birth cohort cannot be known in advance. If agespecific death rates are falling (as has been the case over the past decades in OECD countries), actual life spans will be higher than life expectancy calculated with current death rates.

Each country calculates its life expectancy according to methodologies that can vary somewhat. These differences in methodology can affect the comparability of reported life expectancy estimates, as different methods can change a country's life expectancy estimates by a fraction of a year. Life expectancy at birth for the total population is calculated by the OECD Secretariat for all countries, using the unweighted average of life expectancy of men and women. 
Chart 1.1. Life expectancy at birth, total population, 1960 and 2003

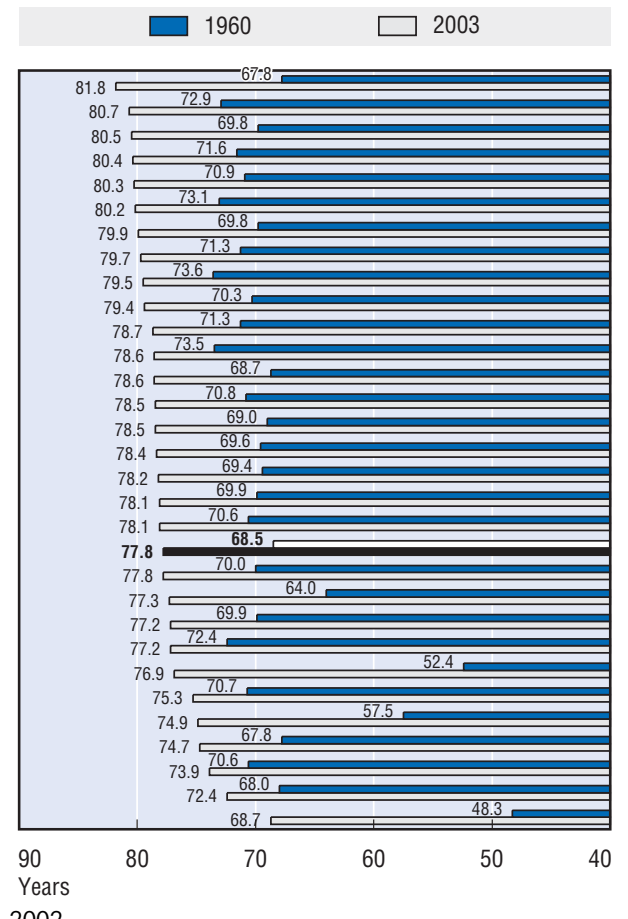

Chart 1.3. Life expectancy at birth and GDP per capita, 2003

Life expectancy, years

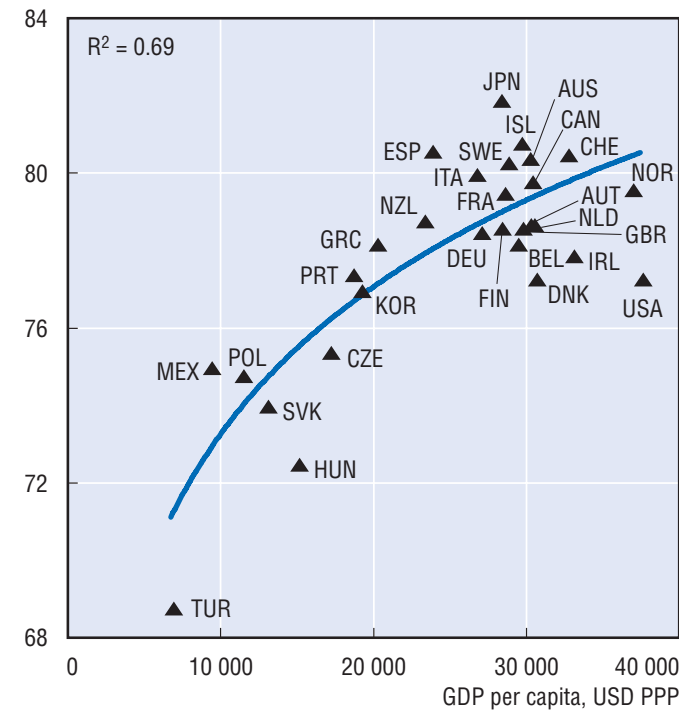

Source: OECD Health Data 2005.
Chart 1.2. Life expectancy at birth, by gender, 2003

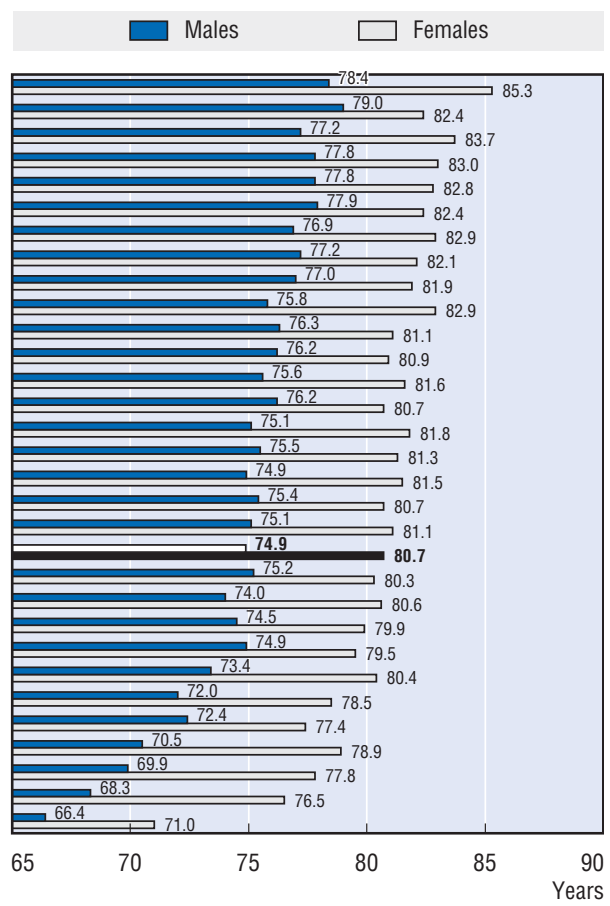

Chart 1.4. Life expectancy at birth and health spending per capita, 2003

Life expectancy, years

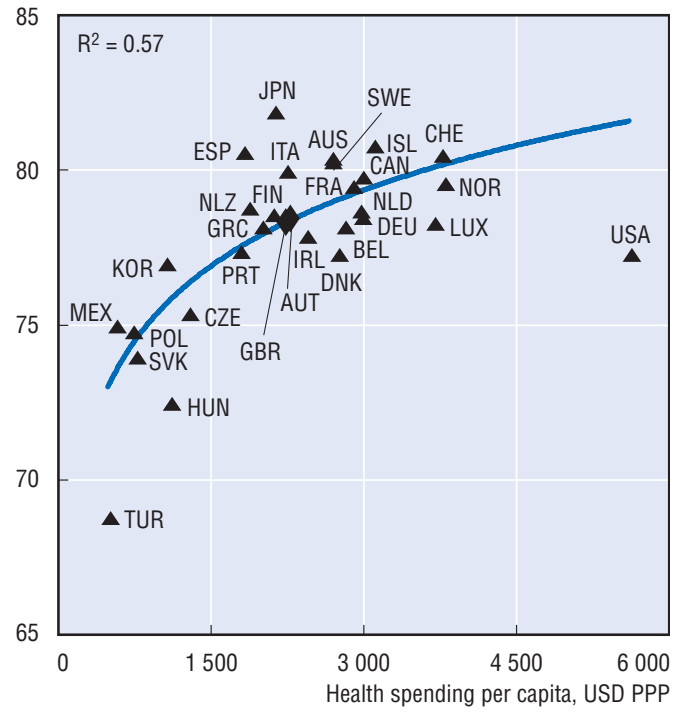

StatLink: http://dx.doi.org/10.1787/760335706673 
Life expectancy at age 65 has increased for both men and women over the past few decades in all OECD countries. Some of the factors explaining the gains in life expectancy at age 65 include advances in medical care combined with greater access to health care, healthier lifestyles and improved living conditions before and after people reach 65 .

In 2003, life expectancy at age 65 in OECD countries stood, on average, at 19.3 years (that is, living to 84.3) for women and 15.9 years (80.9) for men (Chart 1.5; Tables A.1.4 and A.1.5). This is a gain of 3.7 years for women and 3.2 years for men on average across OECD countries since 1970. The gender gap in longevity at age 65 therefore widened slightly in many countries between 1970 and 2003.

Similarly, life expectancy at age 80 has also increased slightly more rapidly among women than for men on average in OECD countries over the past three decades (Chart 1.6). In 2003, life expectancy for women at age 80 was 8.6 years (up from 6.5 years in 1970) on average in OECD countries, while for men at age 80 it was 7.1 years (up from 5.7 years in 1970).

Japan registered particularly strong gains in life expectancy at age 65 in recent decades, with an increase of 7.7 years for women and 5.5 for men between 1970 and 2003. As a result, among all OECD countries Japanese women and men enjoyed the longest life expectancy at age 65 in 2003, with respectively 23 and 18 remaining years of life (Chart 1.5). These gains can be explained at least partly by a marked reduction in death rates from coronary heart disease and cerebro-vascular disease (stroke) among elderly people in Japan. Many other
OECD countries have also registered significant reductions in mortality from cardio-vascular and cerebro-vascular diseases among elderly populations over the past decades (OECD, 2003a; Moïse et al., 2003; Moon et al., 2003).

Following Japan in terms of the longest life expectancy at age 65 in 2003 are France, Switzerland and Australia for women, and Iceland, Australia and Switzerland for men. At the other end of the scale, life expectancy at age 65 was the lowest in Turkey, followed by Hungary, the Slovak and Czech Republics, and Poland.

The gains in longevity at older ages in recent decades in all OECD countries, combined with the trend reduction in fertility rates, are contributing to a steady rise in the proportion of older persons in most OECD countries (see indicators "Fertility rates" and "Population structure"). Life expectancy at age 65 is expected to continue to increase in coming decades. OECD calculations (based on projections from the United Nations/World Bank population database) project that, in 2040, life expectancy at age 65 will reach 21.6 years for women and 18.1 years for men on average in OECD countries (OECD, 2005).

Whether longer life expectancy is accompanied by good health and functional status for ageing populations has important implications for healthcare systems. OECD countries are increasingly focusing their research and policy attention on conditions that affect the elderly disproportionately, including stroke, heart disease and dementia (OECD, 2003a; and OECD, 2004).

\section{Definition and deviations}

Life expectancy measures how long on average people at a particular age would live based on a given set of agespecific death rates. However, the actual age-specific death rates of any particular birth cohort cannot be known in advance. If age-specific death rates are falling (as has been the case over the past decades in OECD countries), actual life spans will be higher than life expectancy calculated with current death rates.

Each country calculates its life expectancy according to methodologies that can vary somewhat. These differences in methodology can affect the comparability of reported life expectancy estimates, as different methods can change a country's life expectancy estimates by a fraction of a year. 


\section{Chart 1.5. Life expectancy at age 65 by gender, 1970 and 2003}

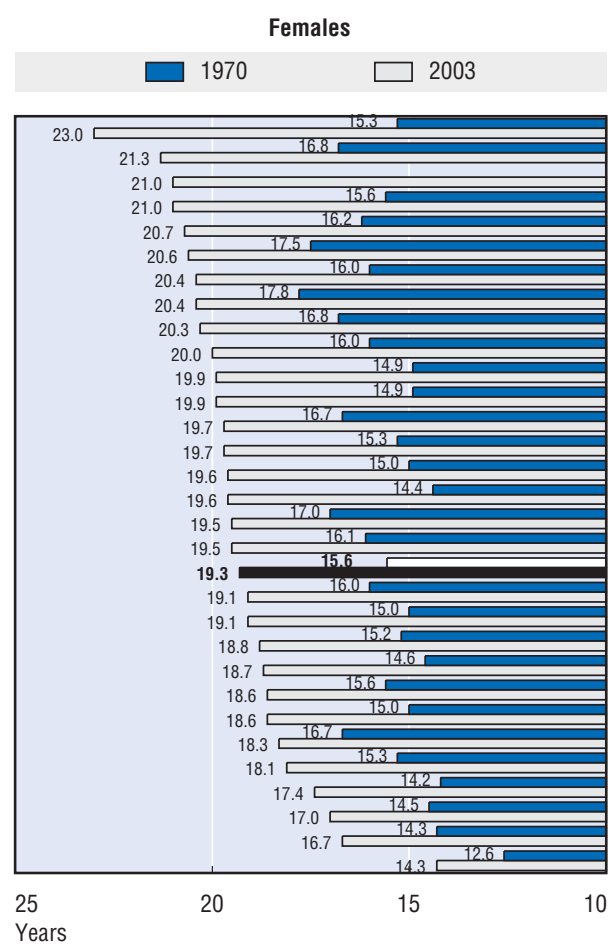

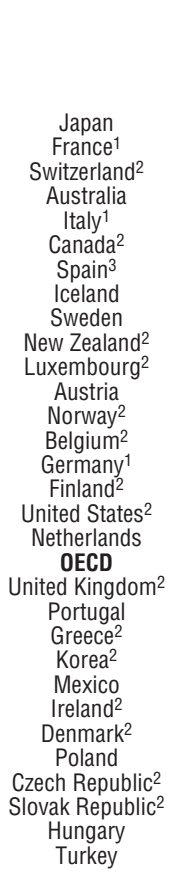

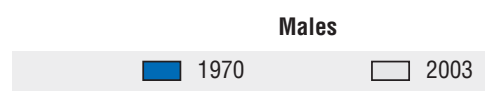

2001.

2. 2002 .

3. 2000 .

\section{Chart 1.6. Trends in life expectancy at age 65 and at age 80, males and females, OECD average,} 1970-2003

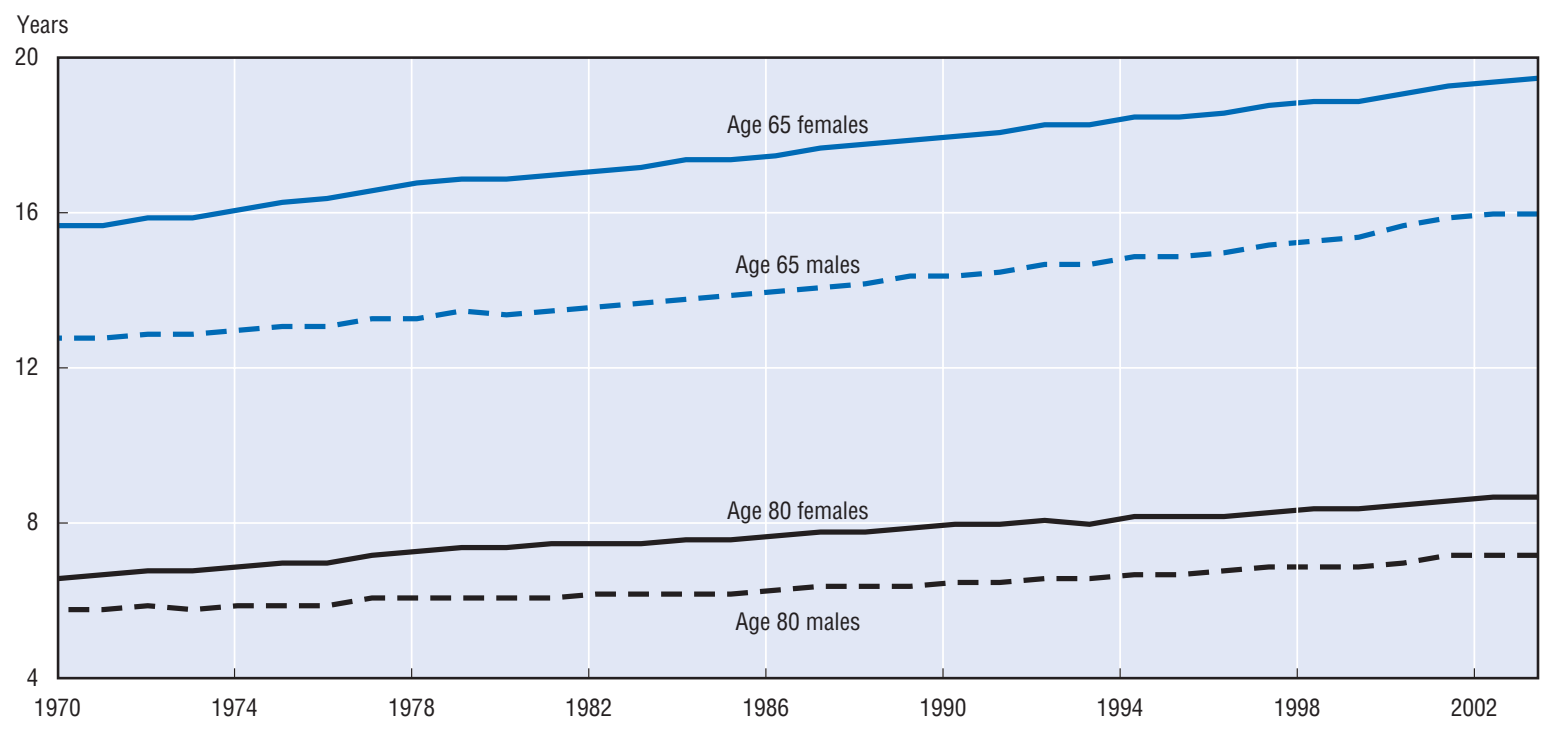

Source: OECD Health Data 2005. 


\section{I.3. MORTALITY, ALL CAUSES AND LEADING CAUSES OF DEATH}

Mortality rates are, paradoxically, the most common measures of a population's health, since mortality statistics remain the most widely available and comparable source of information on health problems. Age standardising death rates remove the effect of variations in the age structure of populations across countries and over time.

In 2001-2002 (the most recent data available from the WHO Mortality Database), there were large variations in age-standardised overall mortality rates across OECD countries. Death rates were the lowest in Japan, followed by Australia, Switzerland and Iceland (Chart 1.7). They were the highest in Hungary, the Slovak Republic, Poland and the Czech Republic (no recent data were available for Mexico and Turkey). Overall mortality rates have decreased substantially over the past few decades in most countries. Between 1970 and 2000, they were cut by more than half in Japan and Australia (Table A.1.6).

The leading causes of death in OECD countries in 2001-2002 were related to cardio-vascular diseases (such as heart attack and stroke), cancer, diseases of the respiratory system (such as asthma, emphysema and bronchitis), and external causes of death (such as road accidents, accidental falls, suicides and homicides).

Cardio-vascular diseases are the leading cause of death in all OECD countries, with the exception of Japan and France where cancer has become the main cause of mortality (Chart 1.8). In most OECD countries, between a third and a half of all deaths is attributed to cardio-vascular diseases. Mortality from cardio-vascular diseases is particularly high in Central and Eastern European countries, accounting for about $50 \%$ or more of all deaths in the Slovak
Republic, the Czech Republic, Hungary and Poland. At the other end of the scale, less than one-third of all deaths nowadays are due to cardio-vascular diseases in Korea, Japan, France, Spain and Canada.

Cancer is the second leading cause of death in most OECD countries, accounting for between 22-33\% of all deaths in 2002 (see indicator "Cancer mortality" for more information). The third and fourth main causes of mortality are related to diseases of the respiratory system and external causes of death. Diseases of the respiratory system account for $4-14 \%$ of all deaths in different OECD countries. The share of mortality attributable to respiratory diseases is particularly high in Ireland, Japan and the United Kingdom. Smoking and environmental factors, such as pollution, are among the risk factors for respiratory diseases. External causes of death accounted for another $4-10 \%$ of deaths in OECD countries in 2002, with the share being the highest in Finland and Japan (see indicator "External causes of death").

Looking at trends over time, the proportion of deaths due to cardio-vascular diseases has decreased substantially since 1980 on average in OECD countries (Chart 1.9), although it continues to be the main cause of death in most countries. While cardio-vascular diseases accounted for nearly half (48\%) of all deaths in OECD countries in 1980, this share decreased to $38 \%$ in 2002 . During that period, the proportion of deaths due to cancer increased on average in OECD countries.

The next three indicators examine more closely cross-country variations, trends and gender differences in three of these four leading causes of mortality.

\section{Definition and deviations}

Mortality rates are estimated based on the crude number of deaths according to selected causes as provided in the WHO Mortality Database. A general assessment of the coverage, completeness and reliability of cause of death data was recently published by WHO (Mathers et al., 2005). Mortality rates have been age-standardised to the 1980 OECD population structure to remove variations arising from differences in age structures across countries and over time within each country. 


\section{I.3. MORTALITY, ALL CAUSES AND LEADING CAUSES OF DEATH}

\section{Chart 1.7. Total mortality rates per 100000 population, 2002}

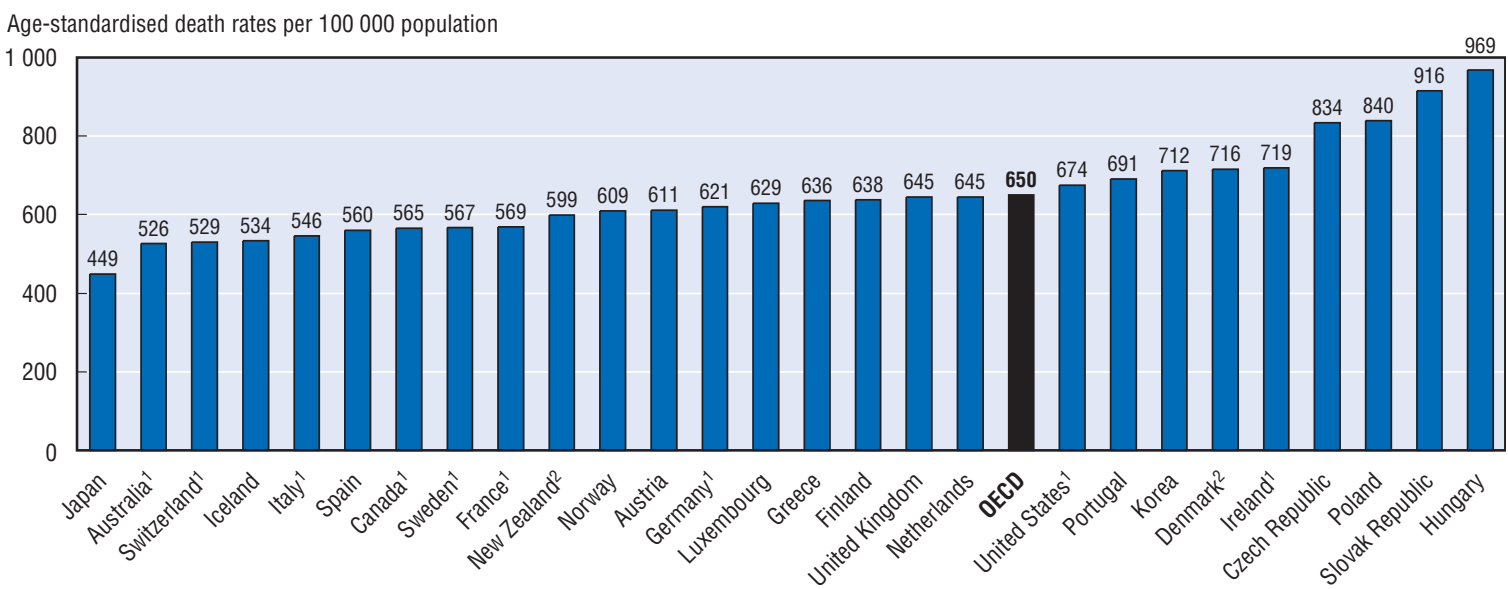

1. 2001.

2. 2000 .

Chart 1.8. Percentage of mortality attributable to leading causes of death, 2002 (ranked from lowest to highest overall mortality rates)

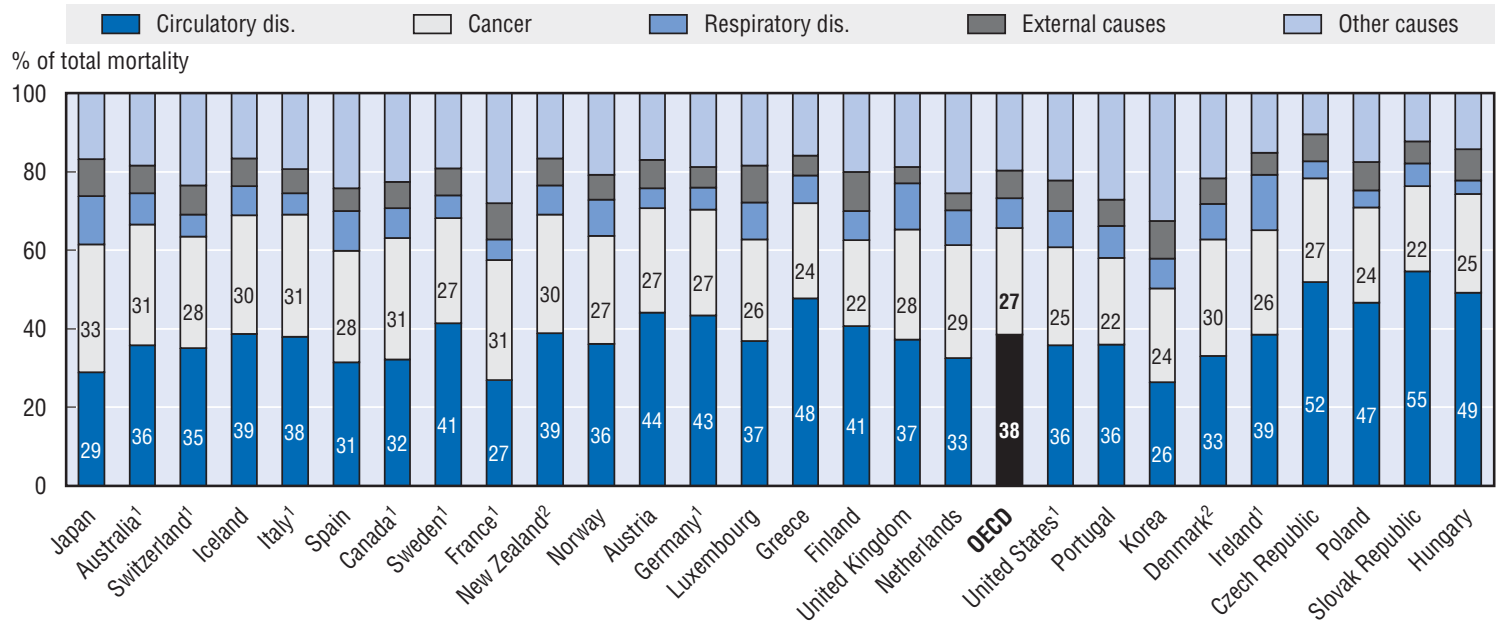

1. 2001.

2. 2000

Chart 1.9. Percentage of mortality attributable to leading causes of death, OECD average, 1960-2002

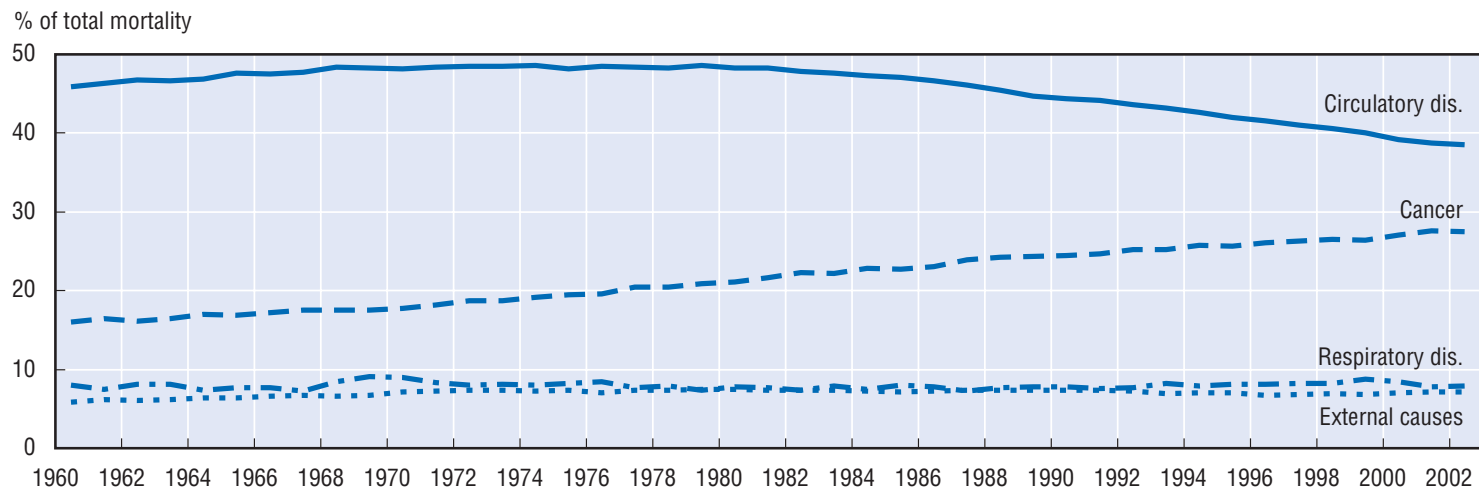

Source: OECD Health Data 2005. The raw mortality data is extracted from the WHO mortality database (March 2005), and age-standardised to the 1980 OECD population. 
Cardio-vascular diseases are the main cause of mortality in most OECD countries, accounting for $38 \%$ of all deaths on average in OECD countries in 2002. Cardio-vascular diseases cover a range of diseases related to the circulatory system, including ischaemic heart disease (or heart attack) and cerebro-vascular disease (or stroke). Together, ischaemic heart disease and stroke account for more than half of the deaths from cardio-vascular diseases in all OECD countries (Table A.1.8).

Ischaemic heart disease (IHD) is caused by the accumulation of fatty deposits lining the inner wall of a coronary artery, restricting blood flow to the heart. IHD alone was responsible for $17 \%$ of all deaths on average in OECD countries in 2002. Mortality from IHD varies considerably however across OECD countries (Chart 1.10). In 2002, the Slovak Republic had the highest IHD mortality rate for both males and females, followed by Hungary and the Czech Republic. IHD mortality rates were also relatively high in Finland, the United States and Ireland, with rates several times higher than those in Japan and Korea, the countries with the lowest IHD mortality rates. There is a clear regional pattern to the variability in IHD mortality rates. Following the two OECD's Asian countries with the lowest IHD mortality rates are four countries located in Southern Europe: France, Spain, Portugal and Italy. This suggests that there are underlying risk factors, such as diet, which explain differences in mortality across countries.

A significant gender gap exists in IHD mortality; death rates are much higher for men than for women in all countries (Chart 1.10). On average across OECD countries, IHD mortality rates in 2002 were about two times greater for men than for women. This gap has persisted since the 1960s.
From 1960 to 1980, the gender gap in IHD mortality rates increased in many countries, but in recent years it has narrowed (Table A.1.9).

Since 1980, IHD mortality rates have declined in almost all OECD countries. The decline has been most remarkable in Denmark, Sweden, Australia, the Netherlands and Canada, with IHD mortality rates falling by more than $55 \%$. A number of factors are responsible for declining IHD mortality rates. Declining tobacco consumption has contributed to reducing the incidence of IHD, consequently reducing IHD mortality rates. Significant improvements in medical care for treating IHD have also contributed to reducing IHD mortality rates (see indicator "Cardio-vascular procedures").

Stroke is another important cause of mortality in OECD countries, accounting for about $10 \%$ of all deaths in 2002. Stroke is caused by the disruption of the blood supply to the brain. In addition to being an important cause of mortality, the disability burden from stroke is substantial (Moon et al., 2003). There are large variations in stroke mortality rates across countries (Chart 1.11). The rates are highest in the Czech Republic and Hungary. They are the lowest in Switzerland, France, Canada, the United States, Iceland and Australia.

Looking at trends over time, stroke mortality has strongly decreased in all OECD countries (except Poland) since 1980 (Table A.1.10). As for IHD, the reduction in stroke mortality can be attributed at least partly to a reduction in risk factors. Tobacco smoking and hypertension are the main modifiable risk factors for stroke (Stegmayr et al., 1997). Other risk factors (beyond age itself) include blood cholesterol, overweight and obesity, and heavy alcohol consumption.

\section{Definition and deviations}

Mortality rates are estimated based on the crude number of deaths according to selected causes as provided in the WHO Mortality Database. A general assessment of the coverage, completeness and reliability of causes of death data was recently published by WHO (Mathers et al., 2005). Mortality rates have been age-standardised to the 1980 OECD population structure to remove variations arising from differences in age structures across countries and over time within each country. 
Chart 1.10. Ischaemic heart disease, mortality rates, 2002
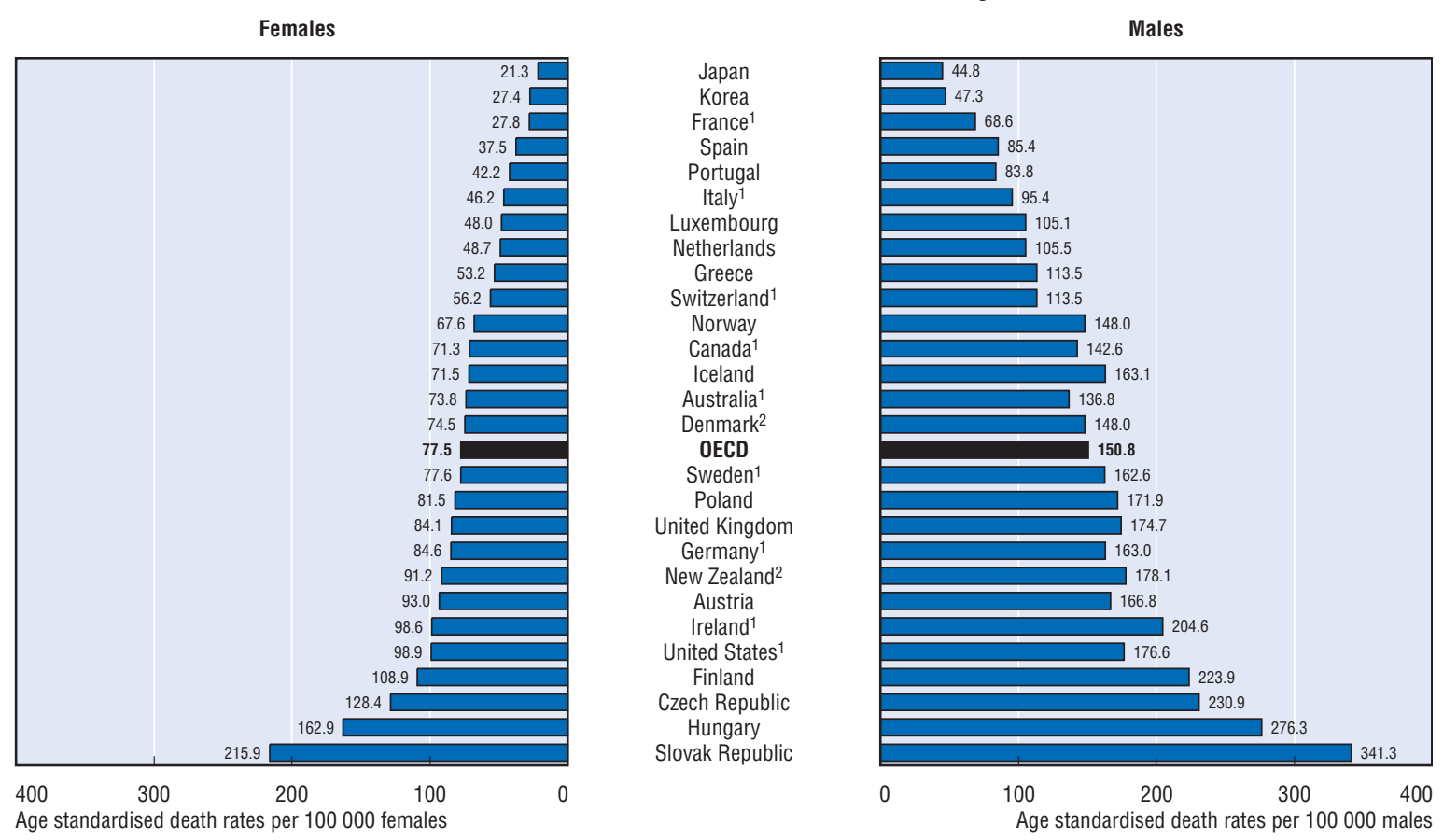

1. 2001.

2. 2000 .

Chart 1.11. Cerebro-vascular disease, mortality rates, 2002

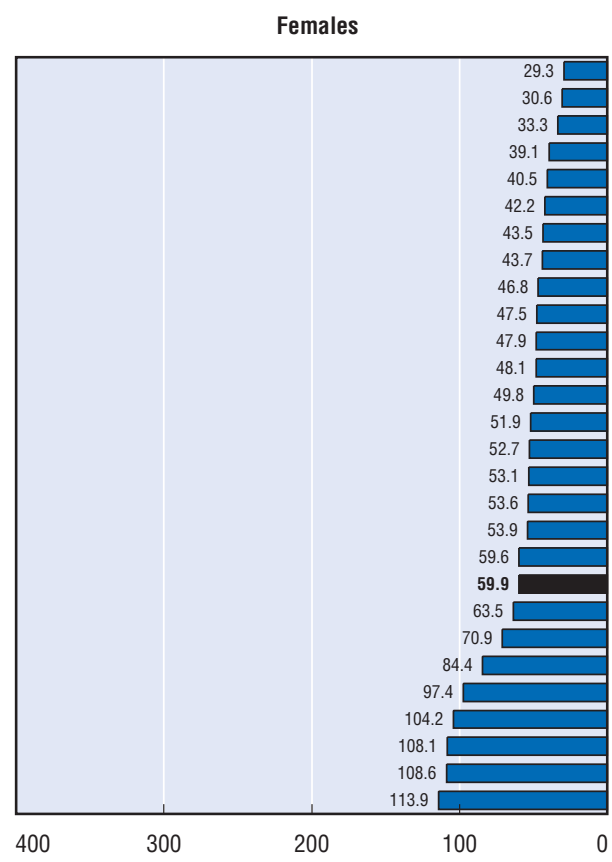

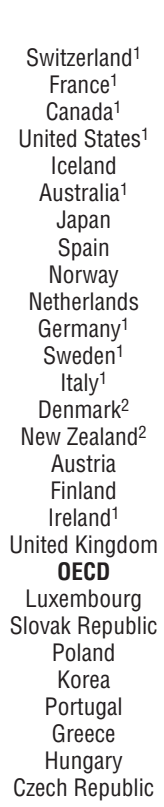

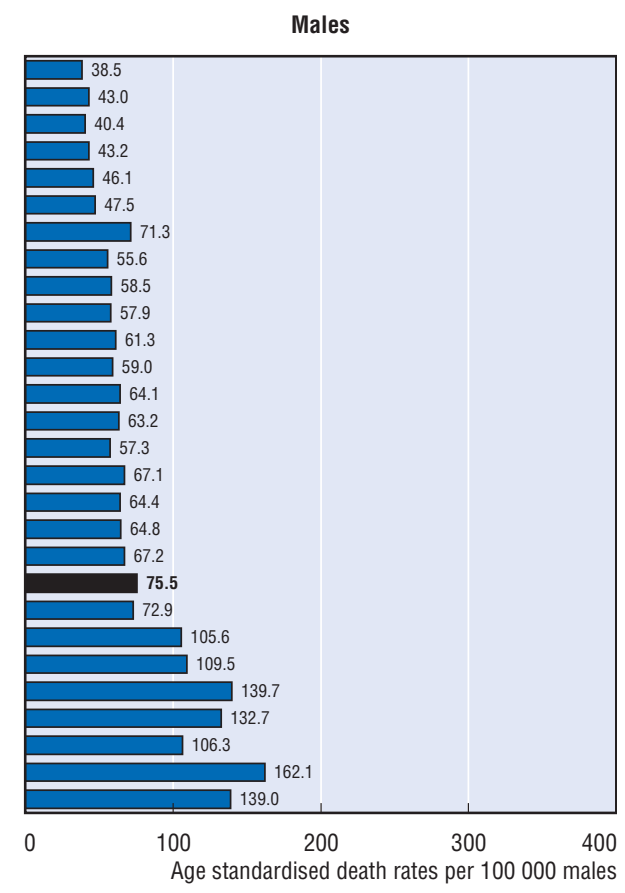

1. 2001.

2. 2000.

Source: OECD Health Data 2005. The raw mortality data is extracted from the WHO mortality database (March 2005), and age-standardised to the 1980 OECD population. 
Cancer is the second leading cause of mortality in most OECD countries (after cardio-vascular diseases), accounting for $27 \%$ of all deaths on average in 2002.

In 2002, cancer mortality rates, for males and females taken together, were the lowest in Finland, Japan (although there is a wide gender gap), Switzerland, Sweden, Portugal and Greece (Table A.1.11). They were the highest in Hungary, the Czech Republic, Poland and the Slovak Republic. Denmark also reports relatively high mortality rates from cancer for both males and females. Differences in (age-standardised) death rates from cancer across countries can be explained both by non-medical factors, including the population's exposure to risk factors (such as smoking), and medical factors, including early diagnosis and effective treatment of different types of cancer.

Cancer mortality rates are higher for men than for women in all OECD countries (Chart 1.12). In 2002, the gender gap in death rates from cancer was particularly wide in Japan, Korea, France, Spain and the Slovak Republic, with mortality rates more than two times higher for men than for women in these countries. The gender gap in cancer mortality rates can be explained at least partly by the greater prevalence of risk factors among men and the lesser availability or use of screening programmes for different types of cancers affecting men, leading to lower survival rates after diagnosis.

Focussing on specific types of cancer, lung cancer still accounts for the greatest number of cancer deaths among men in all OECD countries (except Sweden and Iceland), while it is one of the main causes of cancer mortality among women. Tobacco smoking is the most important risk factor for lung cancer. In 2002, death rates from lung cancer among men were the highest in Central and Eastern European countries (Hungary, Poland, the Czech and Slovak Republics), the Netherlands and Korea (Chart 1.13). These are all countries where smoking rates among men have traditionally been, and continue to be, relatively high. Death rates from lung cancer among men are the lowest in Sweden, one of the countries with the lowest male smoking rate (see indicator "Tobacco consumption").

Breast cancer is the most common cancer among women in all OECD countries (IARC, 2004). In many countries, it accounts for $30 \%$ or more of cancer incidence among women, and $15 \%$ to $20 \%$ of cancer deaths. While there has been an increase in incidence rates of breast cancer in most countries over the past decade, death rates from breast cancer have declined or remained stable in most countries. Declining mortality rates reflect increased rates of breast cancer screening (resulting in significant increases in the percentage of less advanced cases) and better treatments. In 2002, breast cancer mortality rates varied significantly across countries (Chart 1.14). The lowest mortality rates from breast cancer are in Korea and Japan, while the highest mortality rates are in Denmark, Ireland, the Netherlands, Hungary and the United Kingdom.

Prostate cancer has become the most common cancer among males in many OECD countries (IARC, 2004), particularly those over 65 years of age, although death rates from prostate cancer remain lower than for lung cancer in all countries except Sweden and Iceland. The rise in the reported incidence of prostate cancer in many countries during the 1990s is due to a large extent to the greater use of prostate-specific antigen (PSA) diagnostic tests. Death rates from prostate cancer in 2002 varied from lows of less than 10 per 100000 males in Korea and Japan, to highs of more than 33 per 100000 males in Iceland, Norway, Sweden and Denmark (Chart 1.15). The causes of prostate cancer are not well-understood. Some evidence suggests that environmental and dietary factors might influence the risk of prostate cancer (Institute of Cancer Research, 2003).

Overall death rates from all types of cancer for males and females have declined at least slightly in most OECD countries since 1980, although the decline has been more modest than for cardiovascular diseases (which explains why cancer accounts now for a larger share of all deaths). The decline in death rates from cancer over the past two decades was particularly pronounced in Luxembourg, Finland and Austria, with a reduction in cancer mortality rates of more than $20 \%$ in these countries during that period. The exceptions to this declining pattern are Korea (which started with the lowest level among all OECD countries in the 1980s), Spain, Hungary and Poland, where death rates from cancer increased between 1980 and 2002 (Table A.1.11).

\section{Definition and deviations}

Cancer mortality rates are estimated based on the crude number of deaths according to selected causes as provided in the WHO Mortality Database. A general assessment of the coverage, completeness and reliability of causes-of-death data was recently published by WHO (Mathers et al., 2005). The international comparability of cancer mortality data can be affected by differences in medical training and practices as well as in death certification procedures across countries. Mortality rates have been age-standardised to the 1980 OECD population structure to remove variations arising from differences in age structures across countries and over time within each country. 


\section{Chart 1.12. All cancers, mortality rates,} males and females, 2002

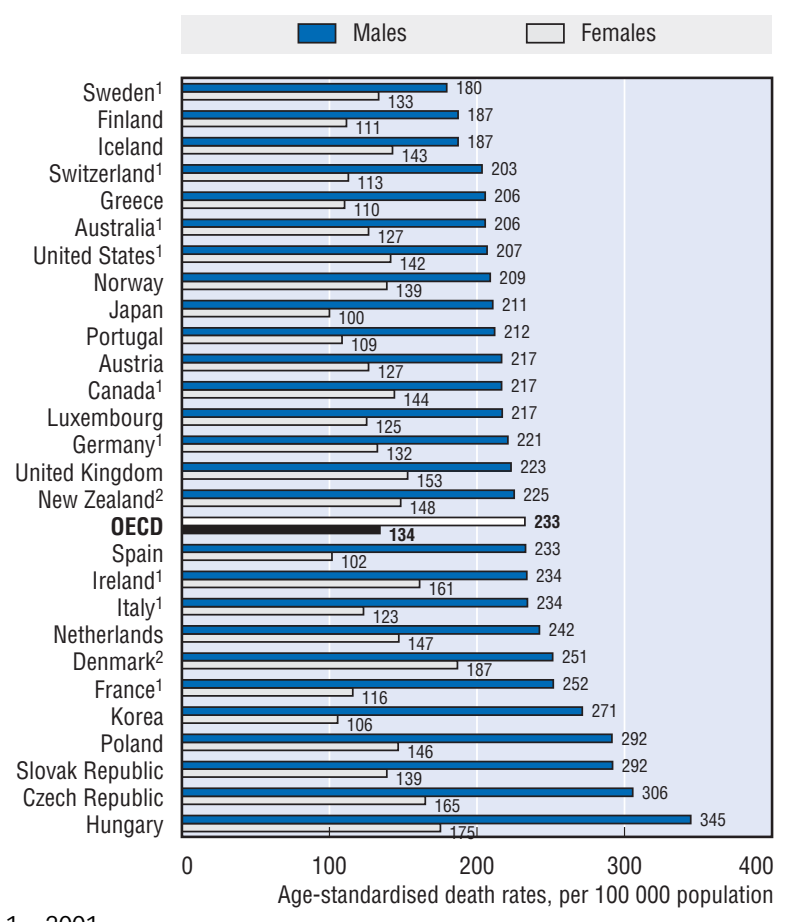

1. 2001.

2. 2000 .

\section{Chart 1.14. Breast cancers, mortality rates, females, 2002}

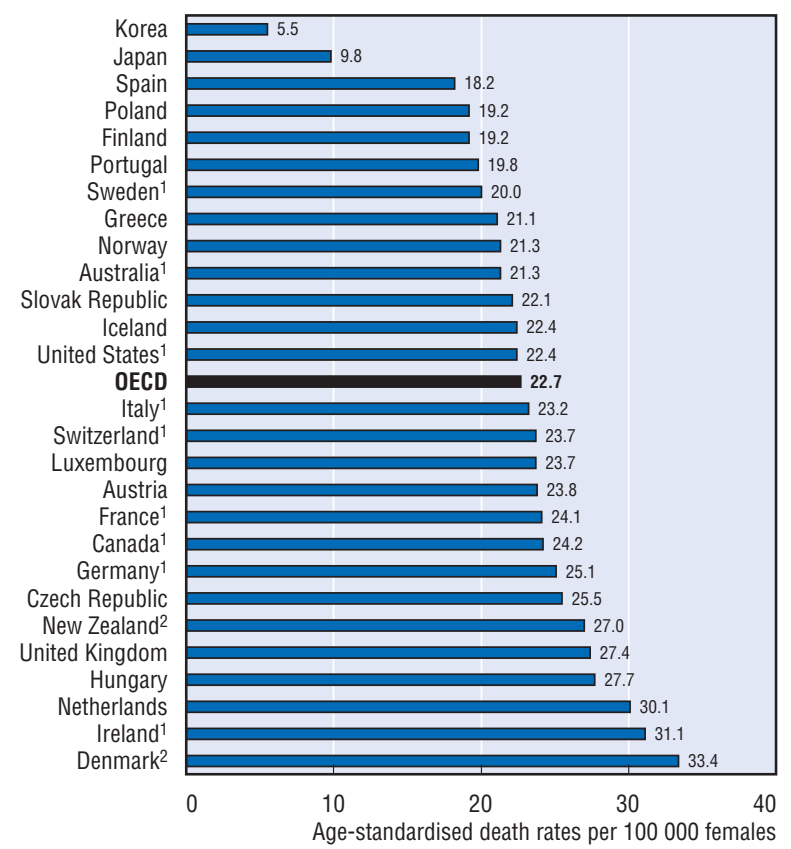

\section{Chart 1.13. Lung cancers, mortality rates, males and females, 2002}

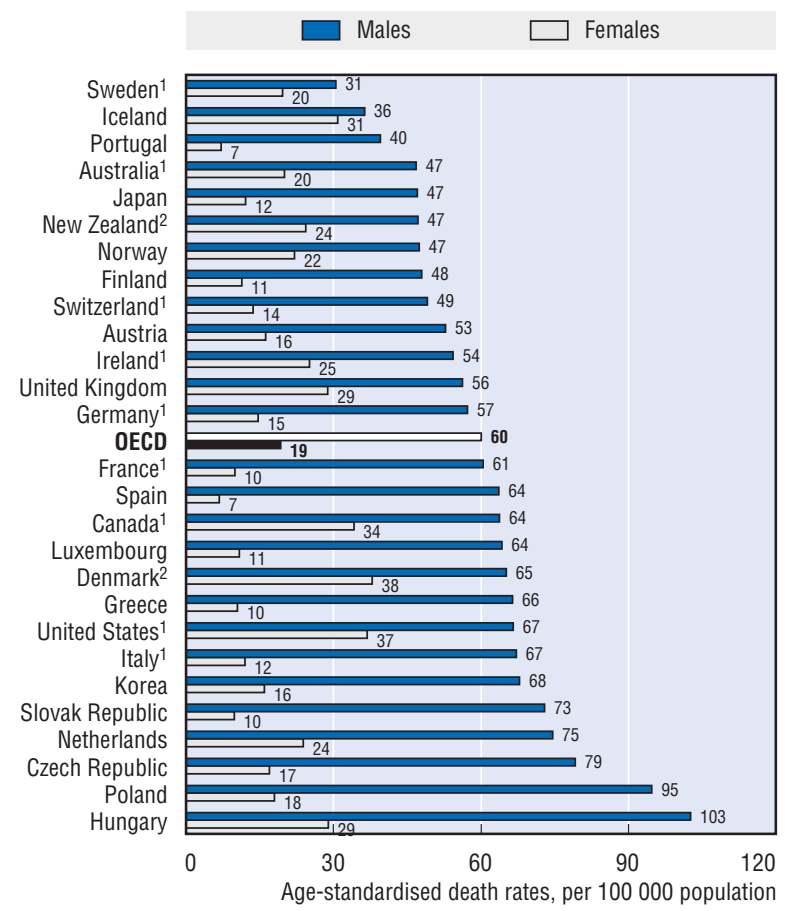

Chart 1.15. Prostate cancers, mortality rates, males, 2002

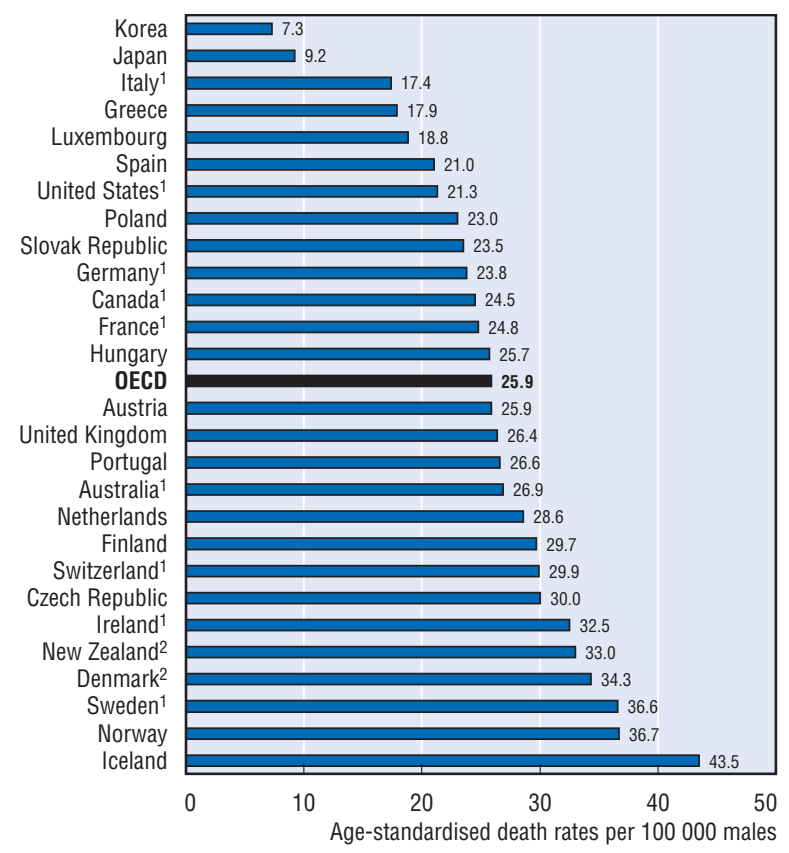

1. 2001.

2. 2000.

Source: OECD Health Data 2005. The raw mortality data is extracted from the WHO mortality database (March 2005), and age-standardised to the 1980 OECD population. 
External causes of death, taken together, account for $4-10 \%$ of all deaths in OECD countries. Road accidents, accidental falls, suicides and homicides are among the main external causes of death.

Road accidents were responsible for more than 120000 deaths in OECD countries in 2002. Death rates from road accidents vary a lot across countries. Taking together death rates for males and females, they were the highest in 2002 in Korea and Portugal, followed by the United States, Hungary, Poland and Greece. They were the lowest in the United Kingdom, Sweden, the Netherlands, Japan and Norway. Deaths from road accidents are much higher for men than for women in nearly all countries (Chart 1.16). Road security has seriously improved over the past decades in many countries through improvements of road systems, education and prevention campaigns, the adoption of new laws and regulations and the enforcement of these new laws through more traffic controls. As a result, deaths rates due to road accidents have been cut by half on average in OECD countries since 1970 (Table A.1.15).

Deaths from accidental falls affect mainly young children and elderly people. Some of the main risk factors for falls among elderly people include the use of some types of medication, poor nutritional status, poor vision, balance or gait, insufficient exercise and environmental hazards (OECD, 2003). In 2002, death rates from accidental falls were particularly high in Hungary, Finland and the Czech Republic. They were the lowest in Australia, Spain, Japan, the United Kingdom,
Sweden and the Netherlands (Chart 1.17). Death rates from falls have strongly decreased over the past decades in most OECD countries, and the reduction has been particularly pronounced among women (Table A.1.16).

Suicides are a significant cause of death in many OECD countries, accounting for over 130000 deaths in OECD countries in 2002. The number of suicides may be under-estimated because of the stigma that might still be associated with it in certain countries. Suicide rates vary considerably across countries. In 2002, they were the lowest in Southern European countries (Greece, Italy and Spain) and in the United Kingdom (Chart 1.18). They were the highest in Hungary, Finland, Japan and Korea. Since 1990, suicides rates have decreased in many OECD countries, but not in Japan and Ireland where they have increased substantially over the past decade or so, among men in particular (Table A.1.17). In general, death rates from suicides are three to four times greater for men than for women in OECD countries, and this gender gap has been fairly stable over time. The gender gap is narrower for attempted suicides, reflecting the fact that women tend to use less fatal methods than men.

Homicides account for a relatively small number of deaths in OECD countries (Chart 1.19). Death rates from homicides are the highest in the United States, with rates five times greater than the OECD average. In all countries, men are more likely to be killed than women. Death rates from homicides have decreased in most OECD countries since 1990, including in the United States (Table A.1.18).

\section{Definition and deviations}

Mortality rates are estimated based on the crude number of deaths according to selected causes as provided in the WHO Mortality Database. A general assessment of the coverage, completeness and reliability of cause of death data was recently published by WHO (Mathers et al., 2005). Mortality rates have been age-standardised to the 1980 OECD population structure to remove variations arising from differences in age structures across countries and over time within each country.

The international comparability of death rates from suicide can be affected by reporting differences across countries. A stigma is associated with suicide in many countries, and those recording causes of death may come under pressure to record deaths from suicide as "unknown" or due to other causes. Caution is required therefore in interpreting variations across countries.

Mortality rates from road traffic accidents in Luxembourg are biased upward because of the large volume of traffic in transit, resulting in a significant proportion of non-residents killed in road accidents in Luxembourg. 
Chart 1.16. Road accidents, mortality rates, males and females, 2002

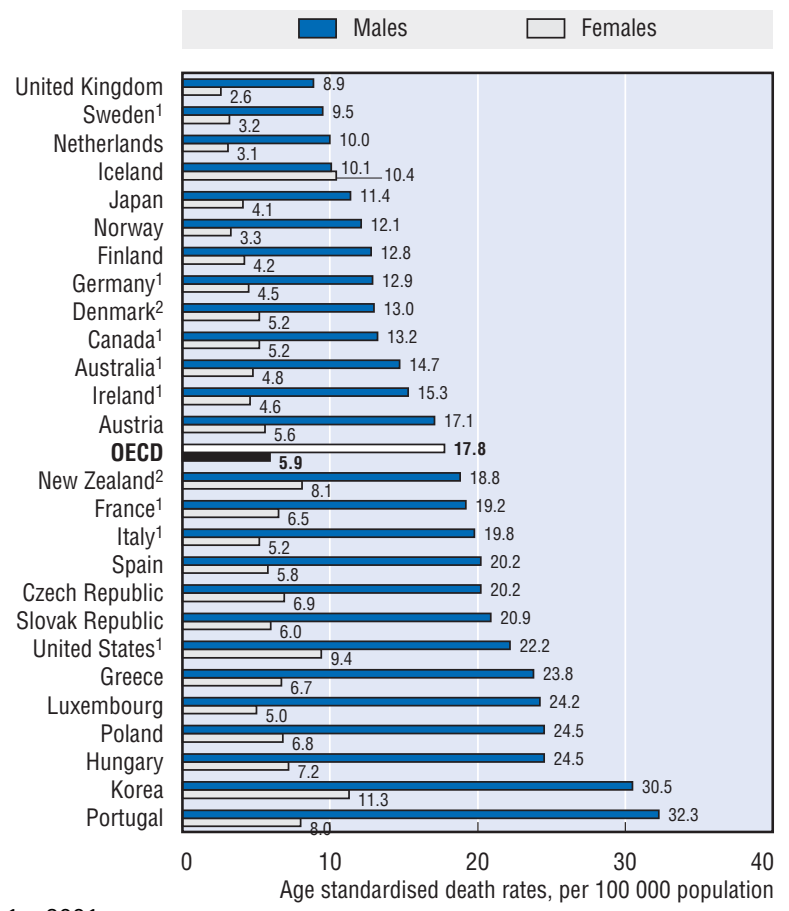

1. 2001.

\section{Chart 1.18. Suicides, mortality rates, males and females, 2002}

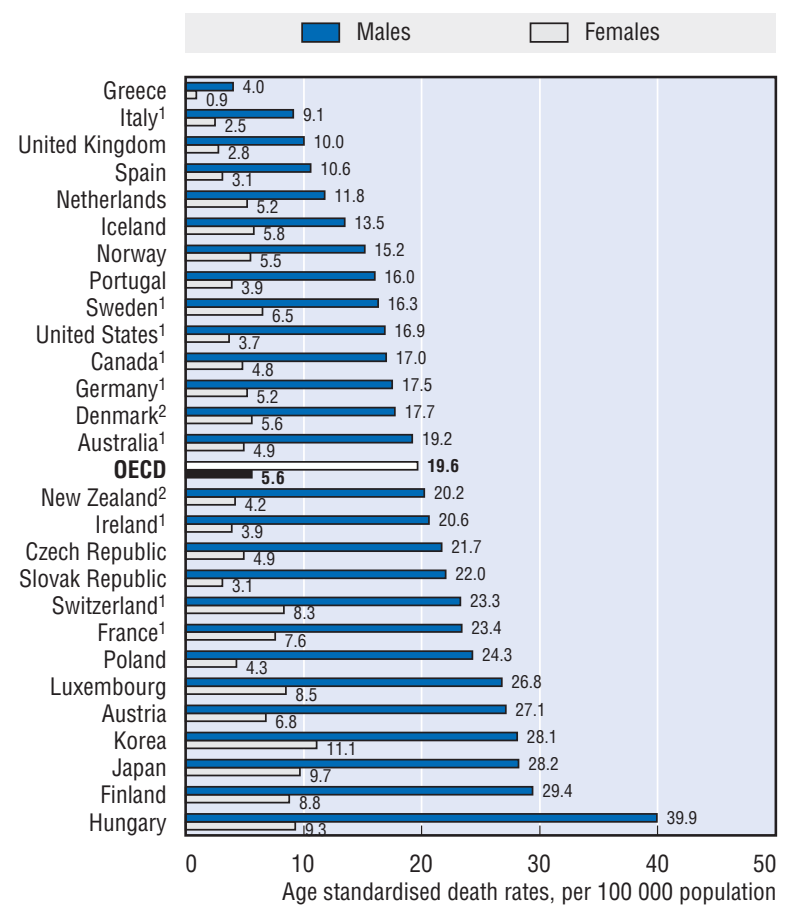

\section{Chart 1.17. Accidental falls, mortality rates, males and females, 2002}

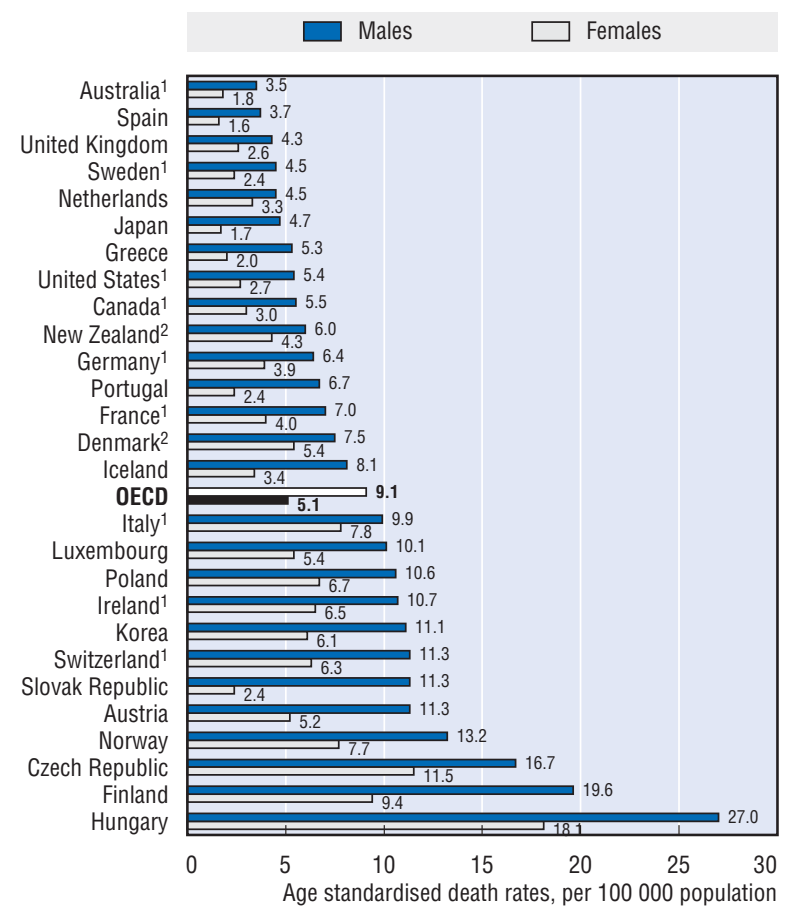

\section{Chart 1.19. Homicides, mortality rates, males and females, 2002}

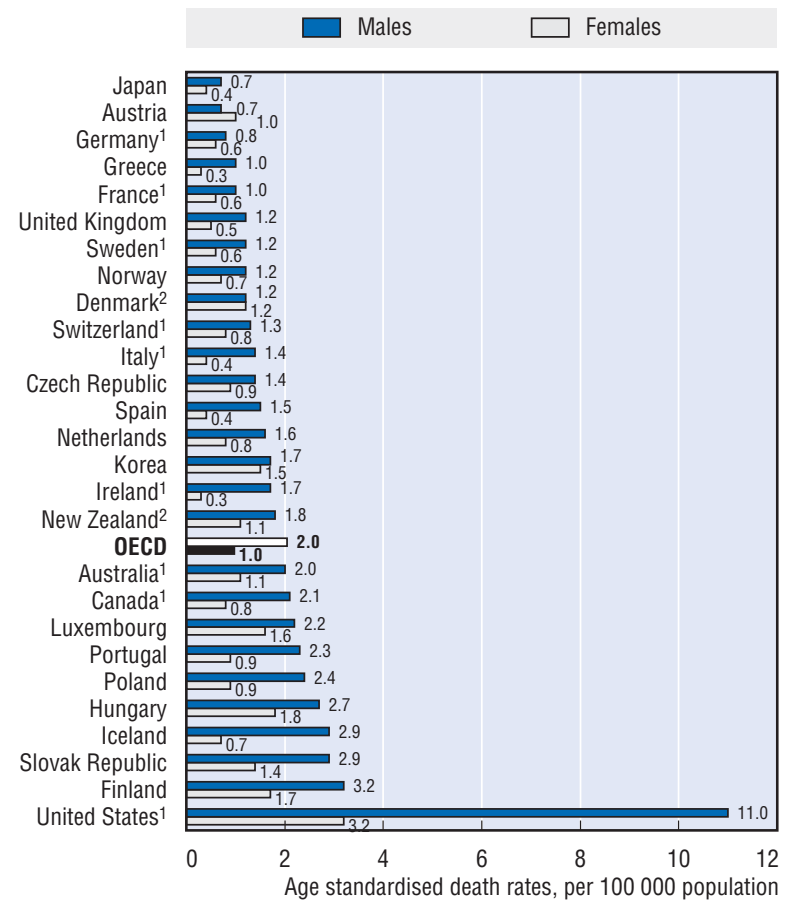

1. 2001.

Source: OECD Health Data 2005. The raw mortality data is extracted from the WHO mortality database (March 2005), and age-standardised to the 1980 OECD population. 
Infant mortality rates, the rate at which babies of less than one year of age die, reflect the effect of economic and social conditions on the health of mothers and newborns as well as the effectiveness of health systems.

Figures for 2003 show that most OECD countries report infant mortality rates in a range from around three deaths per 1000 live births, in the case of Japan and some of the Nordic countries, up to around seven or more for the United States and some Eastern European members (Chart 1.20 and Table A.1.19). Outside of this band, fall Mexico and Turkey which report considerably higher rates of 20 and 29 deaths per 1000 live births respectively.

Around two-thirds of the deaths that occur during the first year of life are neonatal deaths (i.e. during the first four weeks). Congenital malformations, low birth weight of pre-term infants and other conditions arising during pregnancy are the principal factors contributing to neonatal mortality in developed countries. With an increasing number of women deferring childbearing and the rise in multiple births linked with fertility treatments, the number of pre-term births has tended to increase (see indicator "Low birth weight"). For some countries with historically low infant mortality rates, such as the Nordic countries and Western Europe, this has contributed to a leveling-off or reversal of the downward trend in infant mortality rates over the past few years. The increase in the birth of very small infants was also cited as the major reason for the first increase since the 1950s in infant mortality rates in the United States between 2001 and 2002 (CDC, 2005). For deaths beyond a month (post neonatal mortality), there tends to be a greater range of causes - the most common being birth defects,
SIDS (Sudden Infant Death Syndrome), infections and accidents.

All OECD countries, including Mexico and Turkey, have seen remarkable progress in reducing infant mortality rates from the levels of 1970, when the average was approaching 30 deaths per 1000 live births (Chart 1.22). This equates to an average reduction of over $75 \%$ (Chart 1.21). Portugal has seen its infant mortality rate reduced by over $90 \%$ since 1970, going from the country with the highest rate in Europe to one with an infant mortality rate among the lowest in the OECD in 2003. Large reductions in infant mortality rates are also seen in some of the other southern European countries, such as Italy, Spain and Greece.

Numerous studies have focused on infant mortality rates as a health outcome to examine the effect of a variety of medical and non-medical determinants of health. Although most analyses show an overall negative relationship between infant mortality and health spending, more weight has been placed on how health care resources are allocated and the balance between healthcare and non-healthcare spending to explain differences observed between developed countries (Babazano and Hillman, 1994). The fact that some countries with a high level of health expenditure, such as the United States, do not necessarily exhibit low levels of infant mortality, has led to the conclusion that more health spending is not necessarily required to obtain better results (Retzlaff-Roberts et al., 2004). A whole body of research suggests that many factors outside of the quality and efficiency of the health system, such as income inequality, the social environment, and individual lifestyles and attitudes are all factors influencing infant mortality rates (Kiely et al., 1995).

\section{Definition and deviations}

The infant mortality rate is the number of deaths of children under one year of age in a given year, expressed per 1000 live births. Neonatal mortality refers to the death of children under 28 days.

Some of the international variation in infant and neonatal mortality rates may be due to variations among countries in registering practices of premature infants (whether they are reported as live births or fetal deaths). In several countries, such as in the United States, Canada and the Nordic countries, very premature babies with relatively low odds of survival are registered as live births, which increases mortality rates compared with other countries that do not register them as live births (Sachs et al., 1995). 


\section{Chart 1.20. Infant and neonatal mortality rates, 2003}

$\square$ Infant mortality $\quad \square$ Neonatal mortality

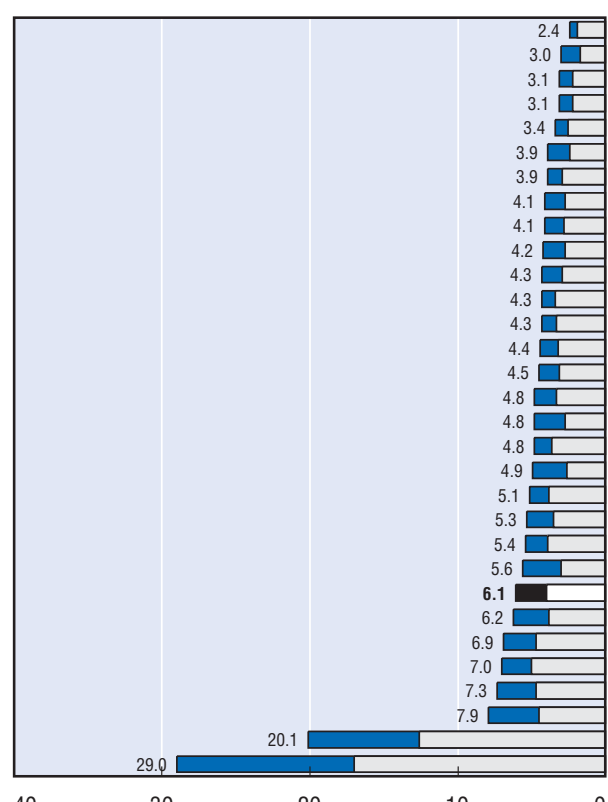

Deaths per 1000 live births

1. 2002.

2. 2001.

3. 1999.

Note: In the United States, Canada and some Nordic countries, very premature babies with a low chance of survival are registered as live births which may not be the case in other countries.

\section{Chart 1.22. Infant mortality rates, $\mathbf{1 9 7 0 - 2 0 0 3}$}

OECD average, Portugal and United States

Deaths per 1000 live births

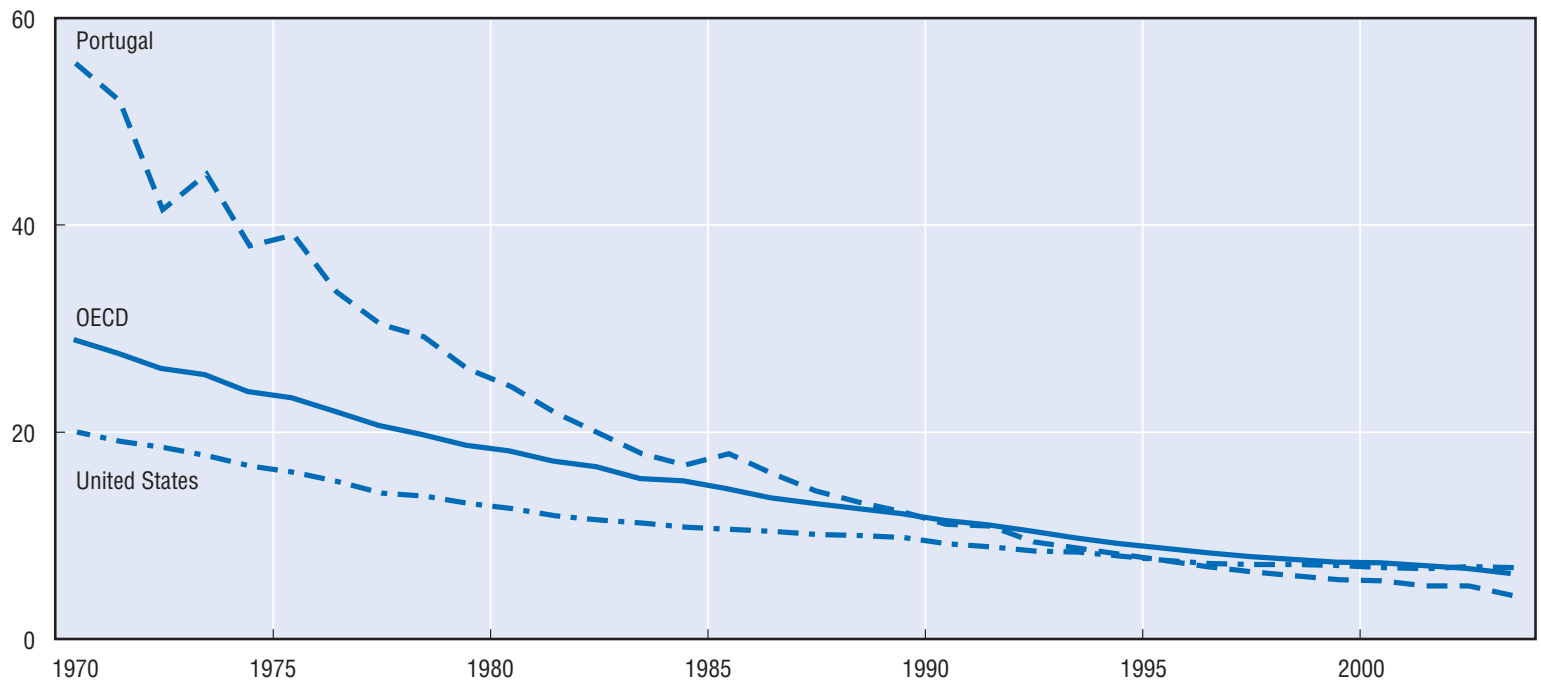

Note: In the United States, Canada and some Nordic countries, very premature babies with a low chance of survival are registered as live births which may not be the case in other countries.

Source: OECD Health Data 2005. 
Low birth weight is an important indicator of infant health because of the relationship between birth weight and infant mortality and morbidity. There are two categories of low birth weight babies: those resulting from pre-term birth and those as a result of inhibited foetal growth or IUGR (intra uterine growth retardation). Low birth weight infants have a greater risk of poor health or death, require a longer period of hospitalisation after birth, and are more likely to develop significant disabilities (UNICEF and WHO, 2004). Possible determinants of low birth weight cover socio-economic status, demographic factors (maternal age, multiple fertility, etc), individual behavioural, such as smoking and alcohol consumption, as well as the level of pre-natal care.

In 2003 (or the latest year available), Iceland, Finland, Korea and Sweden reported the smallest proportions of low weight births with $4.5 \%$ or less of live births defined as low birth weight (less than 2 500g). Japan, Hungary and Greece are at the other end of the scale, with rates of low birth weight infants above $8 \%$ (Chart 1.23). Turkey, the United States and the United Kingdom are close behind with nearly $8 \%$ of all live births reported as low birth weight infants. These figures compare with an overall OECD average of $6.5 \%$.

There may be a number of reasons for the observed increase of low birth weight infants in many OECD countries in recent years (Chart 1.24 and Table A.1.20). First, the number of multiple births, with the increased risks of pre-term births and low birth weight has risen steadily, partly as a result of the increase in fertility treatments. Additionally, during the past 20 years there has been a tendency in many OECD countries for women to delay childbearing until their thirties or later, again shown to increase the risk of low birth weight infants. A third factor is that new medical technology and improved pre-natal care is giving very small foetuses an increased chance of being born alive.

Chart 1.26 shows a positive correlation between the percentage of low birth weight infants and infant mortality rates. In general, countries reporting a low proportion of low birth weight infants also report relatively low infant mortality rates. This is the case for instance for the Nordic countries. Japan, however, is an exception, reporting the highest proportion of low birth weight infants but one of the lowest infant mortality rates.

Japan, historically amongst the group of countries with a low proportion of low birth weight, has seen one of the greatest increases, rising from around $5 \%$ of newborns in the late 1970 s to over $9 \%$ by 2003. A number of risk factors in the Japanese society have been cited as contributing to this increase. The rising prevalence in smoking among younger Japanese women from the 1970s onwards is seen as one of the causes together with a significant move towards later motherhood amongst Japanese women (Jeong and Hurst, 2001; and Ohmi et al., 2001). On the other hand, it has been suggested that Japanese medical care for newborns has been particularly successful in reducing infant mortality, despite the increase in low birth weight babies.

Comparisons of different population groups within countries suggest that the proportion of low birth weight infants might also be influenced by differences in education, income and ethnicity/race. In the United States, marked differences between ethnic groups in the proportion of low birth weight infants have been observed, with black infants having a rate almost double that of white infants (CDC, 2003). Similar differences have also been observed among the indigenous and nonindigenous populations in Australia (AIHW, 2005) and Mexico.

\section{Definition and deviations}

Low birth weight is measured by the number of live births weighing less than 2500 grams as a percentage of total live births. The majority of the data comes from birth registers; however, in the case of the Netherlands the source is a national health interview survey. 


\section{Chart 1.23. Low birth weight infants,} 2003

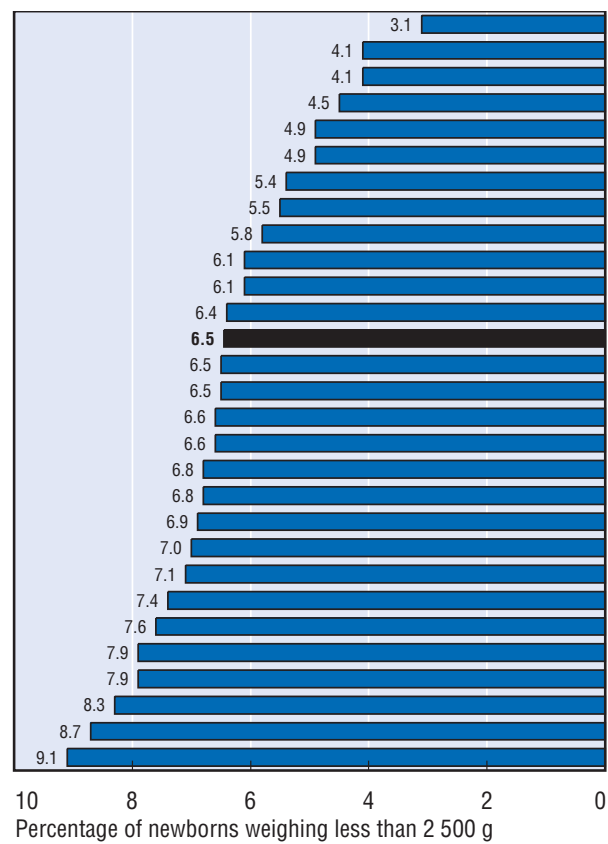

1. 2002.

2. 2001.
Chart 1.24. Change in percentage of low birth weight infants, 1980 to 2003

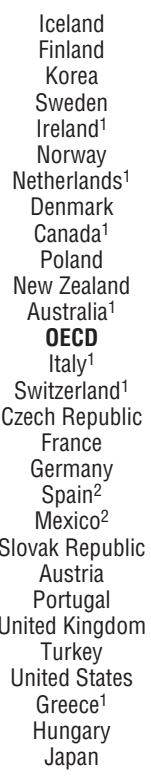

\section{Chart 1.26. Low birth weight and infant mortality, 2003}

Infant mortality (deaths per 1000 live births)

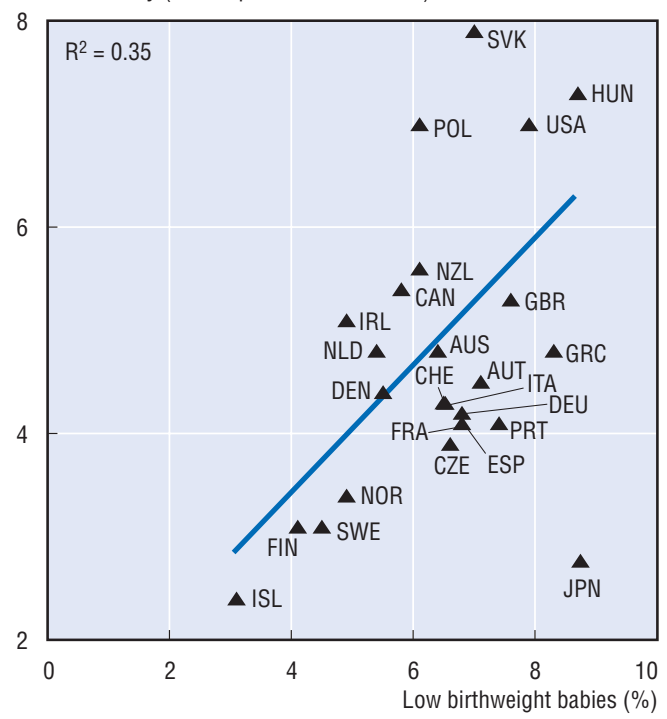

Source: OECD Health Data 2005. 


\section{I.9. DENTAL HEALTH AMONG CHILDREN}

Dental problems, mostly in the form of caries (tooth decay) and gum disease, are common in developed countries, affecting $60-90 \%$ of school children and the majority of adults (WHO, 2003). Dental and other oral diseases thus represent a major public health problem. Dental diseases are highly related to lifestyle factors, which include a high sugar diet, while also reflecting whether or not protective influences such as exposure to fluoride and good oral hygiene are present. Persons with poor oral health may experience pain and discomfort, functional impairment, low self-esteem and dissatisfaction with their appearance. Much of the burden of dental disease falls on disadvantaged and socially marginalised populations (WHO, 2003). Treatment of dental disease in developed countries is often costly.

In 2000 , or the closest available year, 12 year old children in Australia, the United Kingdom and Switzerland had an average of less than one decayed, missing or filled permanent tooth (DMFT) (Chart 1.27). In contrast, Poland, Hungary, Korea, the Czech and Slovak Republics and Portugal had a moderate three DMFT or more. Most OECD countries had between one and three DMFT for 12-year-old children, but no OECD country had high DMFT (more than 4.4).

The past several decades have seen substantial falls in DMFT across OECD countries, from an average 4.7 in 1980, to 2.7 in 1990, and 1.5 in 2000 for a consistent group of countries with long time series (Table A.1.21). In the same 20 year period, 18 of the 20 OECD countries for which data are available saw declines in DMFT of $50 \%$ or more (Chart 1.28). This is a substantial public health achievement. A majority of countries were able to meet the World Health Organization target of no more than three DMFT by the year 2000 (WHO, 2003).

Successes in the decline of caries and other dental problems were achieved through numerous public health measures such as community water fluoridation, along with changing living conditions, disease management and improving oral hygiene.

Chart 1.29 shows a weak negative association between the number of DMFT among children and the number of dentists per capita. There are substantial differences in DMFT among countries that have the same number of dentists per capita, indicating that many other factors affect dental health beyond only the availability of dentists.

Challenges remain in maintaining current low DMFT in OECD countries. There is cause for concern among some countries which have seen a slowing of the decline, or even an increase in DMFT in recent years (Table A.1.21).

\section{Definition and deviations}

A common measure of dental health is the DMFT index. It describes the amount of dental caries in an individual through calculating the number of decayed (D), missing (M) or filled (F) permanent teeth. The sum of these three figures forms the DMFT index. In this instance, the data are for 12-year-old children. A DMFT of less than 1.2 is judged to be very low, $1.2-2.6$ is low, $2.7-4.4$ is moderate, and 4.5 or more is high.

Norway provides an MFT index, which does not include decayed teeth. Sweden provides a DFT index, excluding a measure of missing teeth. The average age for New Zealand children may be slightly above 12, since Year 8 school children are surveyed. 
Chart 1.27. Average number of decayed, missing or filled teeth, 12-year-old children, 2000 or nearest year

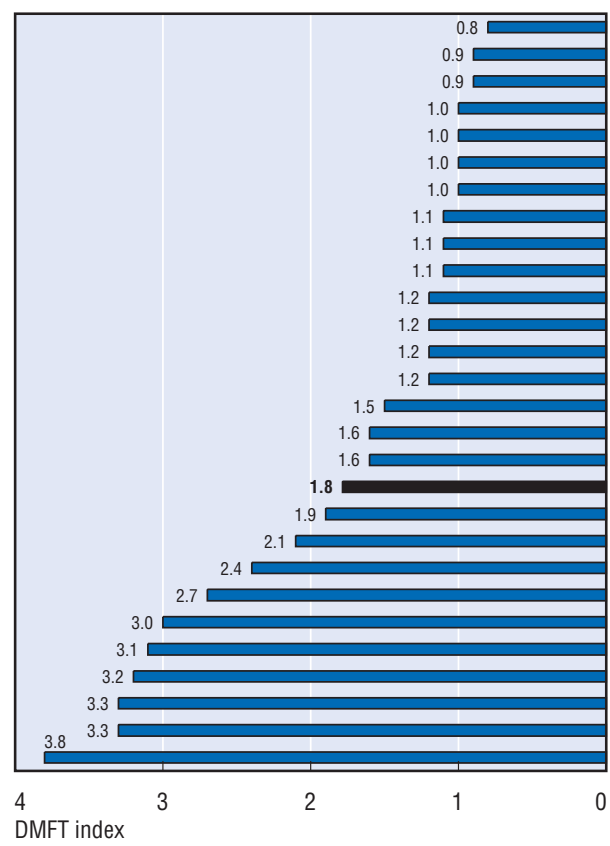

Chart 1.28. Decline in average number of decayed, missing or filled teeth, 12-year-old children, 1980 to 2000

Australia (2000) United Kingdom (2000)

Switzerland (2000)

Sweden (2000)

Netherlands (1999)

Denmark (2000)

Austria (2002)

Spain (2000)

Ireland (2002)

Iceland (1997)

United States (1999)

Luxembourg (2001)

Germany (2000)

Finland (2000)

Norway (2000)

New Zealand (2000)

Belgium (1998)

$$
\text { OECD }
$$

France (1998)

Italy (1996)

Japan (1999)

Greece (1998)

Portugal (2000)

Czech Republic (2000)

Slovak Republic (2001)

Korea (2000)

Hungary (2001)

Poland (2000)

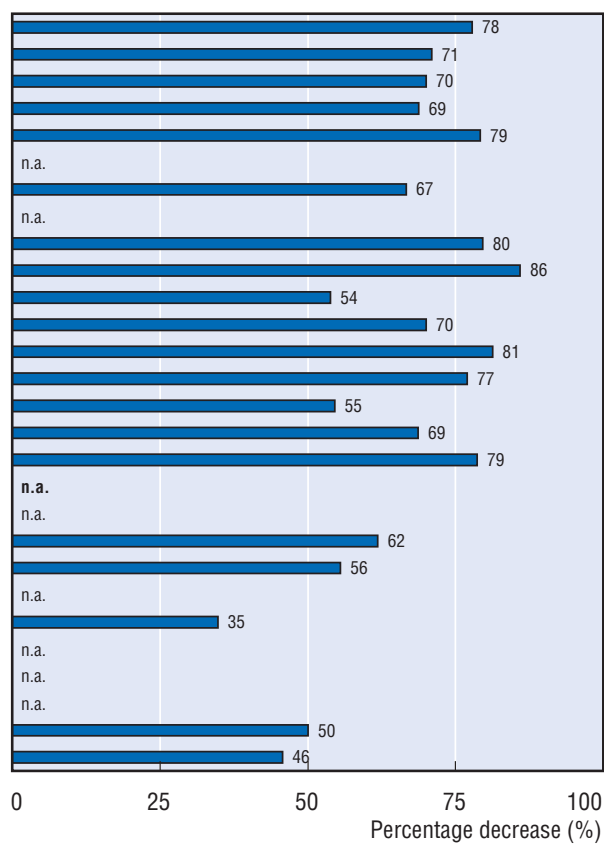

Chart 1.29. Average number of decayed, missing or filled teeth, 12-year-old children, and dentists per 1000 population, 2000

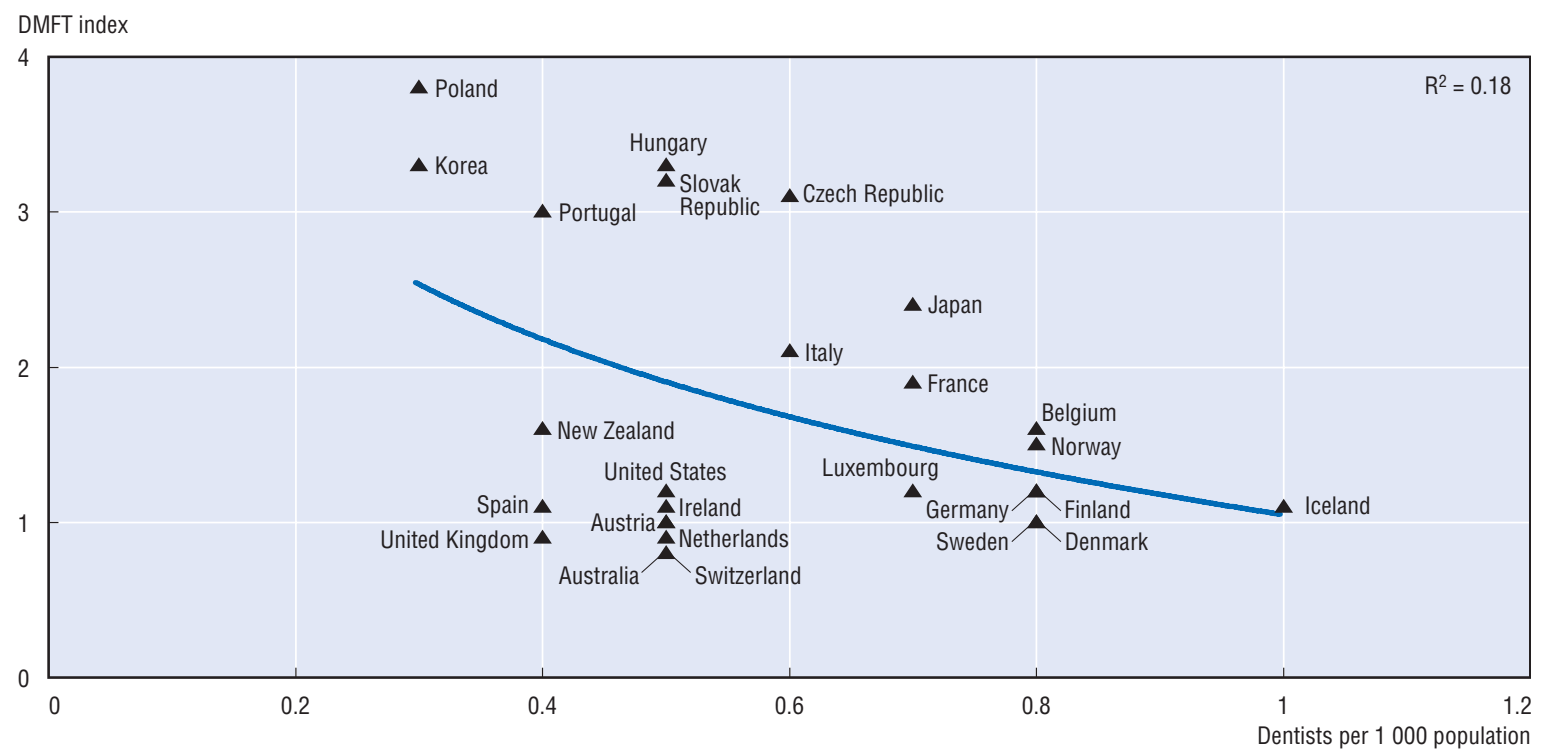

Note: DMFT: decayed, missing or filled permanent tooth.

Source: OECD Health Data 2005. 



\section{Health Care Resources and Utilisation}

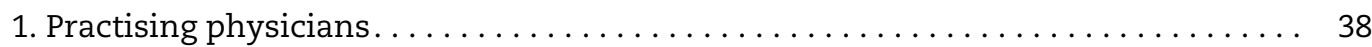

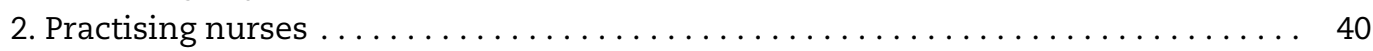

3. Remuneration of health professionals (physicians and nurses) $\ldots \ldots \ldots \ldots \ldots \ldots 42$

4. Acute care hospital beds, availability and occupancy rates $\ldots \ldots \ldots \ldots \ldots \ldots . \ldots 4$

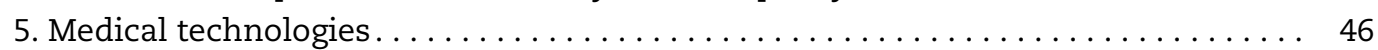

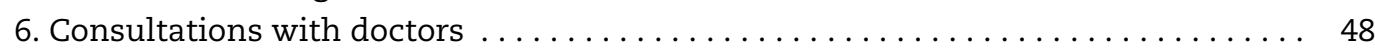

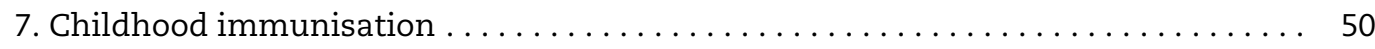

8. Influenza immunisation among elderly people $\ldots \ldots \ldots \ldots \ldots \ldots \ldots \ldots \ldots \ldots \ldots \ldots \ldots \ldots$

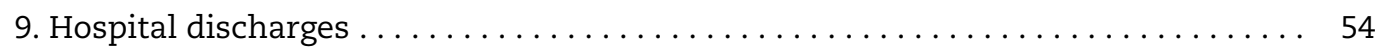

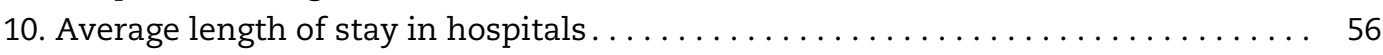

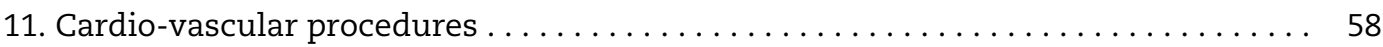

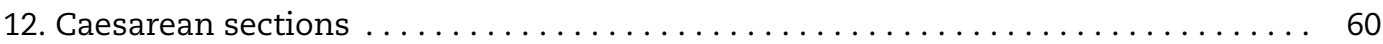

13. Cataract surgeries, ambulatory and inpatient. . . . . . . . . . . . . 62 


\section{II.1. PRACTISING PHYSICIANS}

A perceived shortage of physicians is an important concern in many OECD countries. The size, distribution and composition of practising physicians is influenced by a number of factors, including restrictions imposed on entry into the medical profession, choice of speciality, demographic characteristics of doctors (e.g., age and gender), remuneration, working conditions, and international migration.

In 2003, there were large variations in the number of practising doctors per capita across OECD countries. It ranged from highs of more than four doctors per 1000 population in Italy and Greece, to lows of less than two per 1000 population in Turkey, Mexico and Korea (Chart 2.1). The number of practising doctors per capita was also relatively low in Japan, Canada, the United Kingdom and New Zealand. The OECD average was 2.9 doctors per 1000 population.

In all countries for which trend data is available, the doctor-to-population ratio has increased since 1990, with the exception of Canada where it has remained stable (Chart 2.2). The ratio has increased particularly rapidly since 1990 in those countries where it was relatively low, like Korea, Mexico and Turkey. In Korea, the ratio has increased at a rate of $5 \%$ per year on average since 1990. It is expected to continue to increase rapidly over the coming years as a result of newly established medical schools and a higher number of medical students (OECD, 2003b). In Mexico, there has also been a large increase in the number of doctors operating in the government health system in the second half of the 1990s, following the introduction of a programme designed to improve access to health services (OECD, 2005c).

An important factor affecting the supply of doctors in different countries is whether public authorities impose restrictions on entry into medical schools, or leave it to medical schools to determine total student places in any given year. In general, the growth rate of the doctor-to-population ratio has been much lower in those OECD countries that have controlled medical school intake (e.g., Canada, Japan and New Zealand) than in countries that have not imposed such control (Simoens and Hurst, 2004).
An important source of new doctor supply in many OECD countries has been the increasing number of women who have joined the medical profession in recent decades. The share of doctors who are women has increased steadily over the past two decades in all OECD countries. Nonetheless, in 2003, there remained large variations in the share of female doctors across countries, ranging from lows of $16 \%$ in Japan and $23 \%$ in the United States, to highs of over $50 \%$ in Poland, Finland, the Czech Republic and Hungary (Chart 2.3). Changes in female participation in the medical profession need to be taken into account in any planning of health human resources not only because attracting more women to the profession may provide a valuable source of new recruits, but also because women tend to differ from men in how they participate in the medical workforce. Evidence from Australia and Canada suggests that women have a greater tendency than men to choose primary care and certain specialities such as paediatrics, psychiatry, obstetrics and gynaecology (AMWAC, 1996; AIHW, 1996; and Tyrrell and Dauphinee, 1999). Evidence from a number of European countries (e.g., Austria, France, Germany and the United Kingdom) also suggests that women tend to work fewer hours, particularly during childbearing age (Simoens and Hurst, 2004).

Although OECD countries generally favour policies of national self-sufficiency for their physician workforces, such policies often co-exist with short-term or medium-term policies to attract physicians from abroad, on a temporary or permanent basis. Foreign-trained physicians can account for a substantial share of the physician workforce in certain countries. In 2000, the share of foreign-trained physicians exceeded $20 \%$ of all practising physicians in English-speaking countries such as New Zealand, the United Kingdom (England), the United States and Canada (Chart 2.4). On the other hand, the share of foreign-trained physicians was much lower in Japan, Austria and France. International migration can increase the flexibility of labour markets for doctors and other health professionals in receiving countries, but it raises serious concerns about a "brain drain" when there are net, long-term flows of staff from lowerincome to higher-income countries.

\section{Definition and deviations}

Practising physicians are defined as the number of doctors who are actively practising medicine in public and private institutions. The numbers are based on head counts, except in the Czech Republic, Mexico and Norway which report full-time equivalents (resulting in a small downward bias). Ireland and the Netherlands provide the number of physicians entitled to practise rather than actually practising (resulting in an upward bias). 


\section{II.1. PRACTISING PHYSICIANS}

\section{Chart 2.1. Practising physicians per 1000 population, 2003}

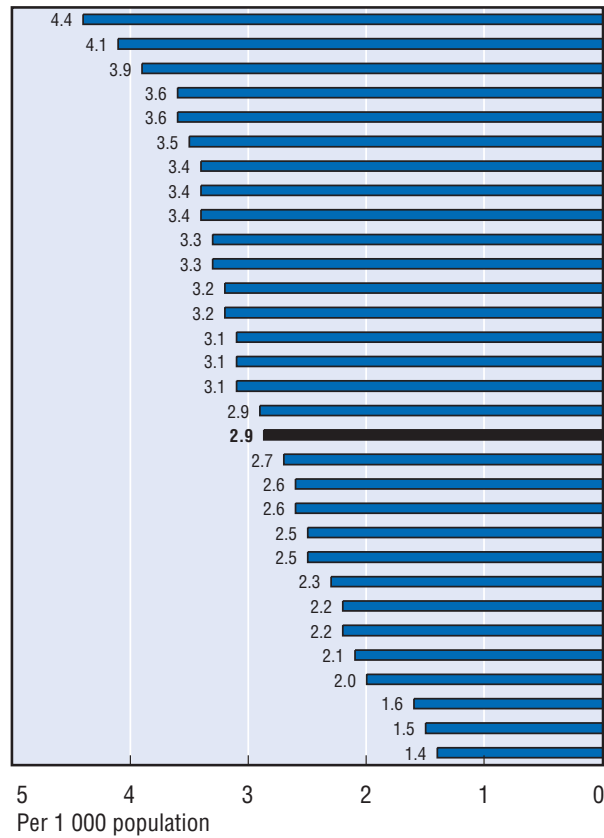

1. 2001. 2. 2002.

3. Data for Ireland and the Netherlands refer to physicians entitled to practise rather than actually practising.

Chart 2.3. Female physicians as a percentage of total physicians, 1980 and 2003 (or latest year)

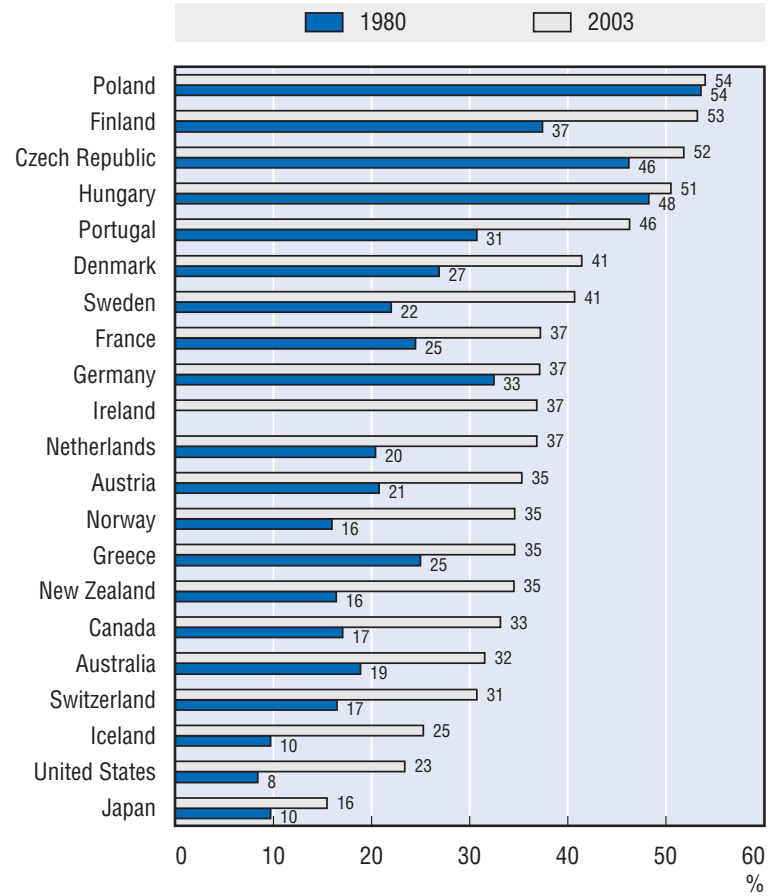

Note: Finland 1990-2003, France 1984-2003, Germany 1991-2003, Greece 1981-2001, Iceland 1985-2003.

See footnotes to Table A.2.1.

Source: OECD Health Data 2005
Chart 2.2. Average annual growth rate in number of practising physicians per 1000 population, 1990 to 2003

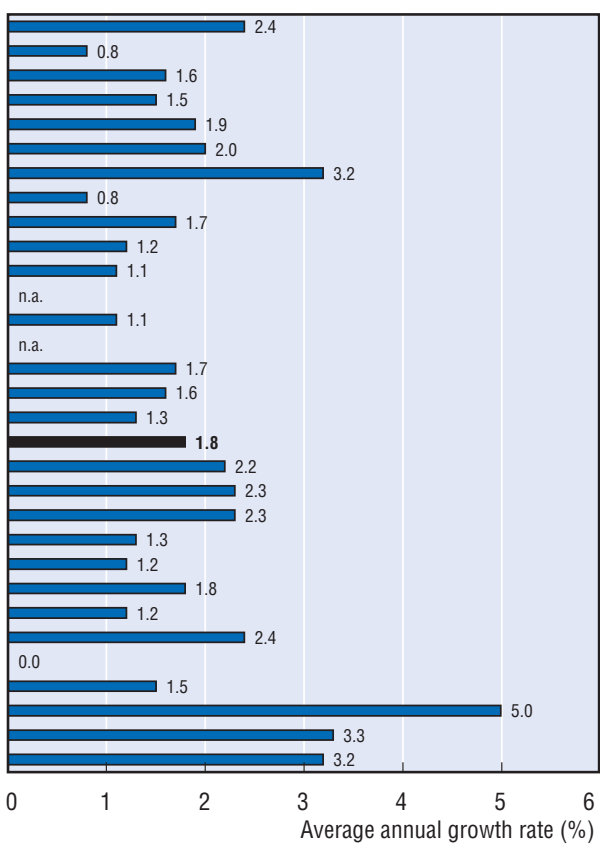

Greece $^{1}$

Italy

Belgium²

Switzerland ${ }^{2}$

Iceland

Czech Republic

Austria

France

Germany

Portugal

Sweden ${ }^{2}$

Spain

Hungary

Slovak Republic

Netherlands ${ }^{3}$

Norway

Denmark

OECD

Luxembourg

Finland

Ireland ${ }^{3}$

Australia²

Poland

United States

New Zealand

ited Kingdom

Canada

Japan ${ }^{2}$

Korea

Mexico

Turkey
Chart 2.4. Foreign-trained physicians as a percentage of practising physicians, selected OECD countries, 2000

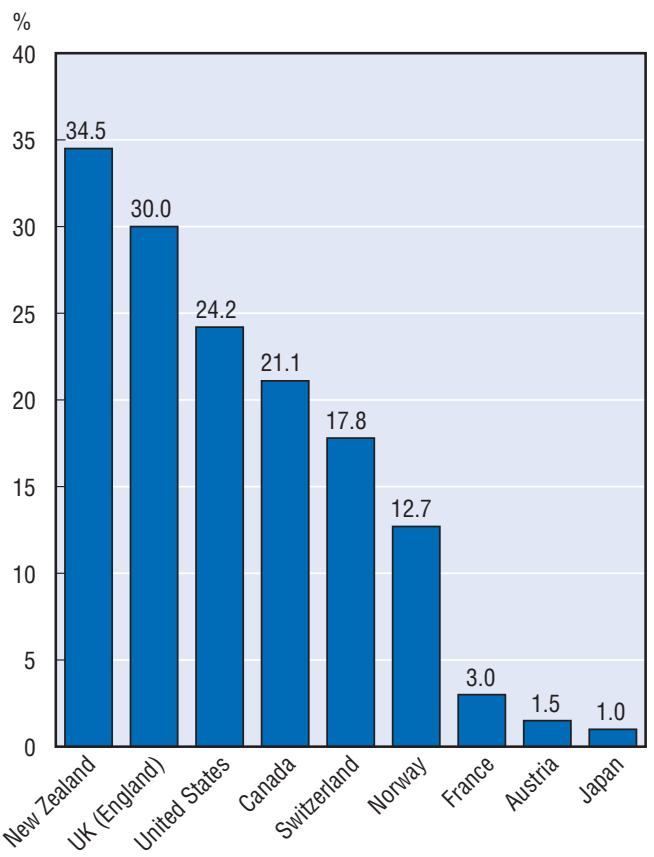

Source: OECD (2004b), Chapter 4. 


\section{II.2. PRACTISING NURSES}

There are reports of current nurse shortages in all but a few OECD countries. Given anticipated increases in the demand for nurses combined with a reduction in the supply of nurses due to workforce ageing and retirement, shortages of nurses are expected to persist or become even more acute in the future unless action is taken to increase recruitment and retention in the profession.

In 2003, there were substantial variations in the number of nurses per 1000 population across OECD countries, although it is important to note the limitations in the comparability of data related to the inclusion of different categories of nurses, incomplete coverage of health care settings and other differences in methodologies (see the box on "Definition and deviations"). Ireland, Iceland and the Netherlands reported the highest number of nurses per capita, with more than 12 nurses per 1000 population in 2003 (Chart 2.5). At the lower end of the scale, there were less than four nurses per 1000 population in Turkey, Korea, Mexico and Greece.

Looking at trends over time, the number of nurses per 1000 population has increased in all OECD countries for which data are available during the 1970s and the 1980s (Table A.2.2). Between 1990 and 2003 , the number of nurses per capita continued to increase at least slightly in most countries, but it started to decline in Australia, Canada, New Zealand and Poland (Chart 2.6). In Canada, the reduction in the number of nurses per capita was linked to a reduction in enrolment and graduation from nursing schools during the 1990s, together with a reduction in health expenditure (in the mid-1990s) and the number of hospital beds (throughout this period).

In all OECD countries, the nurse profession continues to be predominantly a female profession. The share of female nurses exceeds $85 \%$ in all but two countries (Chart 2.8).

Not much is known about the cost-effectiveness of different policies to ensure an adequate supply of nurses. Pay has been shown to influence entry into nursing school as well as workforce participation and retention of qualified nurses, although it is clearly not the only factor influencing the supply of nurses. Available evidence on the remuneration of hospital nurses compared with the average remuneration of all workers in the economy shows significant variations across countries (see indicator "Remuneration of health professionals"). Improvements in other aspects of working conditions can also play an important role in recruiting and retaining nurses. These include offering flexible work and retirement arrangements, improving workforce management policies, and enhancing career advancement prospects (Simoens et al., 2005).

There are large differences in reported nurseto-physician ratios across OECD countries (Chart 2.7), raising questions as to whether countries are adopting an appropriate skill mix between physicians and nurses in the delivery of health care. These range from more than five nurses per physician in Ireland to less than 1 nurse per physician in Greece. The nurse-to-physician ratio continues to be relatively high in Canada and Australia, despite the reduction in nurses per capita since 1990 in these two countries. More than half of OECD countries report nurse-to-physician ratios which lie in the range of two to four.

A recent review of potential changes in skill mix and substitution between physicians and nurses (including the emergence of "advanced practice nurses" and "nurse practitioners", in both primary care and hospital settings) found that nurses can provide care which is equivalent to that provided by doctors, and which is often preferred by patients, when they take on certain medical tasks once the diagnosis has been established. This review focused specifically on experiences in the United States and the United Kingdom (Buchan and Calman, 2004).

\section{Definition and deviations}

Practising nurses are defined as the number of actively practising nurses employed in public and private hospitals, clinics and other health facilities, including self-employed nurses. The data should normally include fully-qualified nurses (with post-secondary education in nursing) and vocational/associate/auxiliary/practical nurses (with a lower level of nursing skills but also usually registered). Auxiliary/practical nurses are not included however in France and Norway, resulting in an under-estimation. Most countries report head counts, while Hungary, Mexico and Norway report full-time equivalents (also resulting in an under-estimation compared with the head-count data provided by other countries). Austria and Italy report only nurses employed in hospitals; they do not include those working in other health facilities or self-employed nurses (leading to an under-estimation). 


\section{Chart 2.5. Practising nurses per 1000 population, 2003}

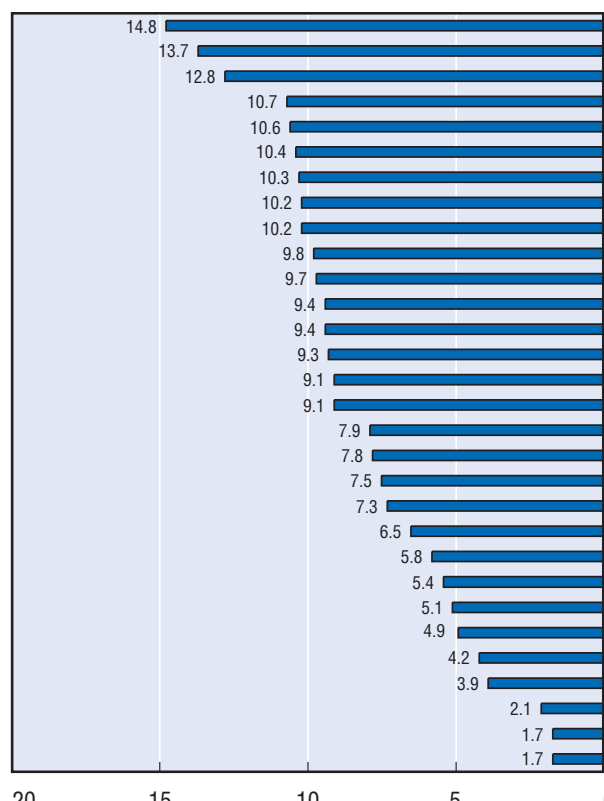

Per 1000 population

\section{Chart 2.6. Change in the number of practising nurses \\ per 1000 population, 1990 to 2003}

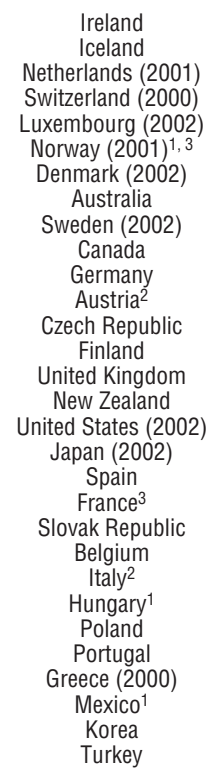

1. Hungary, Norway and Mexico report full-time equivalents rather than head counts (under-estimation).

2. Austria and Italy report only nurses employed in hospitals (under-estimation).

3. France and Norway do not include auxiliary/practical nurses (under-estimation).

\section{Chart 2.7. Ratio of practising nurses to practising physicians, 2003}

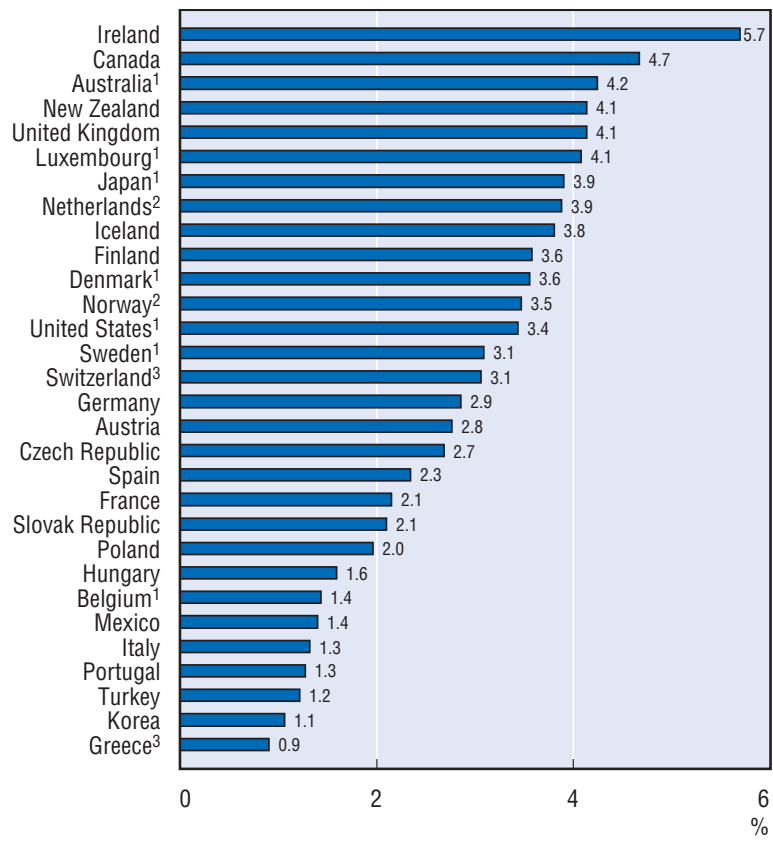

Chart 2.8. Female participation in the nurse workforce, 2000

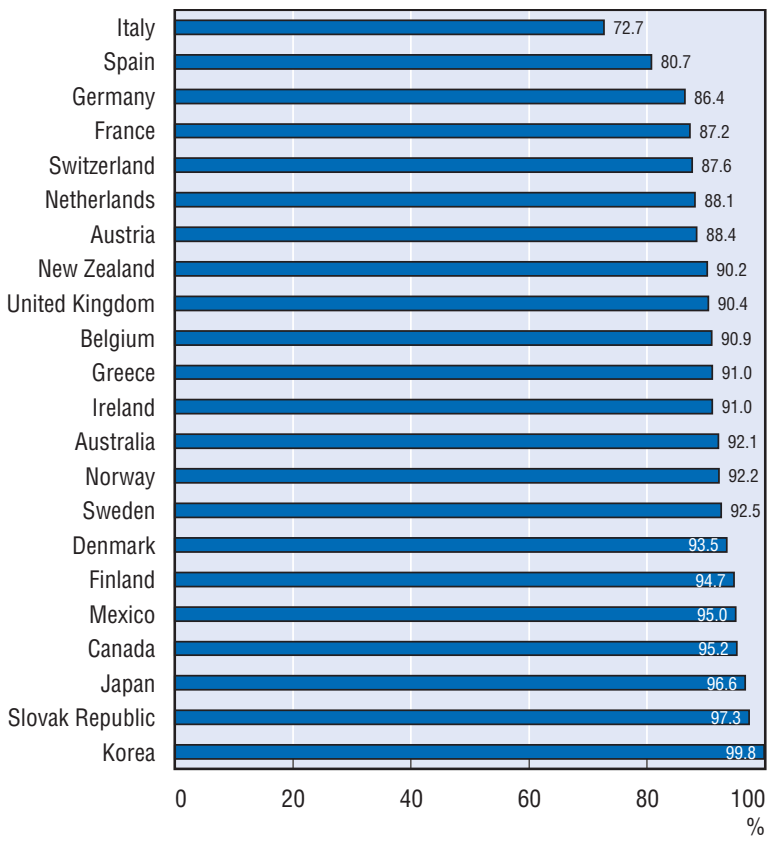

1. 2002.

2. 2001.

3. 2000 .

Source: OECD Health Data 2005.

Source: OECD (2004b) and Eurostat Labour Force Survey. 


\section{II.3. REMUNERATION OF HEALTH PROFESSIONALS}

Information on remuneration levels of health professionals such as physicians and nurses is useful for a number of reasons. Health care is a service-based industry. Accordingly, labour and professional costs are important determinants of total health expenditure, with cross-country differences influenced by the number of service providers, as well as their productivity and remuneration. At the national level, remuneration levels, as one of the determinants of labour supply, may explain at least partly possible shortages or surpluses of different categories of health professionals. At the international level, information on remuneration levels might be useful in understanding migration of health professionals across countries. Finally, information on remuneration levels can also help to inform national policies on payments and reimbursements of physician services.

However, gathering comparable data on the remunerations of health professionals across countries is difficult, because different countries collect data on different types of remunerations, for different categories of physicians and nurses, using a variety of data sources and calculation methods. Hence, cross-country variations in remuneration levels should be interpreted with a lot of caution (see the box below on "Definition and deviations").

Data on the remuneration of doctors is available for general practitioners (GPs) and specialists, separated into salaried and self-employed physicians. Compared to average national income per capita, the income of physicians varies considerably across countries. Looking first at the income of self-employed specialists, it is relatively high in the Netherlands, the United States, Belgium and Canada. The relative income of salaried specialists tends to be somewhat lower than that of self-employed specialists (taking into account as much as possible business expenses). The income of salaried specialists relative to the average national income is highest in the United Kingdom, the Netherlands and Ireland. On the other hand, specialists in Hungary and the Czech Republic (regardless of whether they are salaried or selfemployed) earn relatively less (compared with the national income per capita) than in other countries (Chart 2.9; left panel).

Turning to the remuneration of GPs, as expected, their remuneration levels are lower than for specialists in all countries, with the exception of Portugal where it is equal (Chart 2.9; right panel). In Belgium, GPs earn much less than specialists (more than three times less). As for specialists, the United States and the Netherlands report the highest remunerations for GPs in relation to GDP per capita.

In the Netherlands and Canada, the relatively high remuneration levels of both specialists and GPs are accompanied by reports of shortages for a number of specialties. This might be explained by the fact that medical school intake has been subject to strict "numerus clauses", limiting entry into the profession. In general across countries, lower numbers of specialists per capita tend to be associated with higher relative remuneration. Nonetheless, for a given level of specialists per capita, there may be very different levels of relative remuneration (Chart 2.10).

For all countries, the data refer to the average compensation of doctors in the country; they do not provide information on the distribution of income. There may be large differences in income among doctors within countries, with income levels depending on age, experience, specialty, type of hospital and region. In the United States, for example, specialists' income varies greatly among specialties and regions (Kane and Loeblich, 2003).

Regarding nurses, data on remuneration is available only for salaried hospital nurses (Chart 2.11). Based on data from 12 countries, the relative income of nurses compared to GDP per capita, is highest in Portugal, followed by Australia and New Zealand. The relative income is lowest in the Czech Republic and Hungary, as well as in Norway.

\section{Definition and deviations}

Data on health professionals' remuneration refers to average gross annual income, which includes social security contributions and income taxes payable by the employee. Remunerations should also normally include all extra formal payments, like bonuses, payments for night on-call and overtime compensation (although this is not the case for all countries; for instance, overtime payments for hospital nurses are not included in countries such as Ireland and Mexico, resulting in an under-estimation). Informal payments, which are common in countries like Hungary and Greece, are not included. In the case of self-employed physicians, practice expenses are excluded (although the methodology for deducting these business expenses varies across countries).

The comparability of data is also limited because they might relate to slightly different categories of doctors or nurses. This is particularly an issue for the Czech Republic, where the figures on salaried "specialists" include some general practitioners working as employees, who represent about $15 \%$ of all GPs (resulting therefore in a slight under-estimation of the remuneration of specialists); and the figures for nurses relate to all paramedical personnel (resulting in an over-estimation of the remuneration of nurses). Health professionals in training are generally excluded. For salaried health professionals, figures are for full-time equivalent. For self-employed physicians however, most figures refer to head counts. It is also important to note that the figures for salaried specialists do not include any additional income derived from private practice (resulting in an under-estimation in countries such as Finland, Ireland and the United Kingdom).

Data on GDP per capita come from the OECD National Accounts. 


\section{Chart 2.9. Remuneration of physicians, ratio to GDP per capita, latest year available Specialists General practitioners (GPs)}
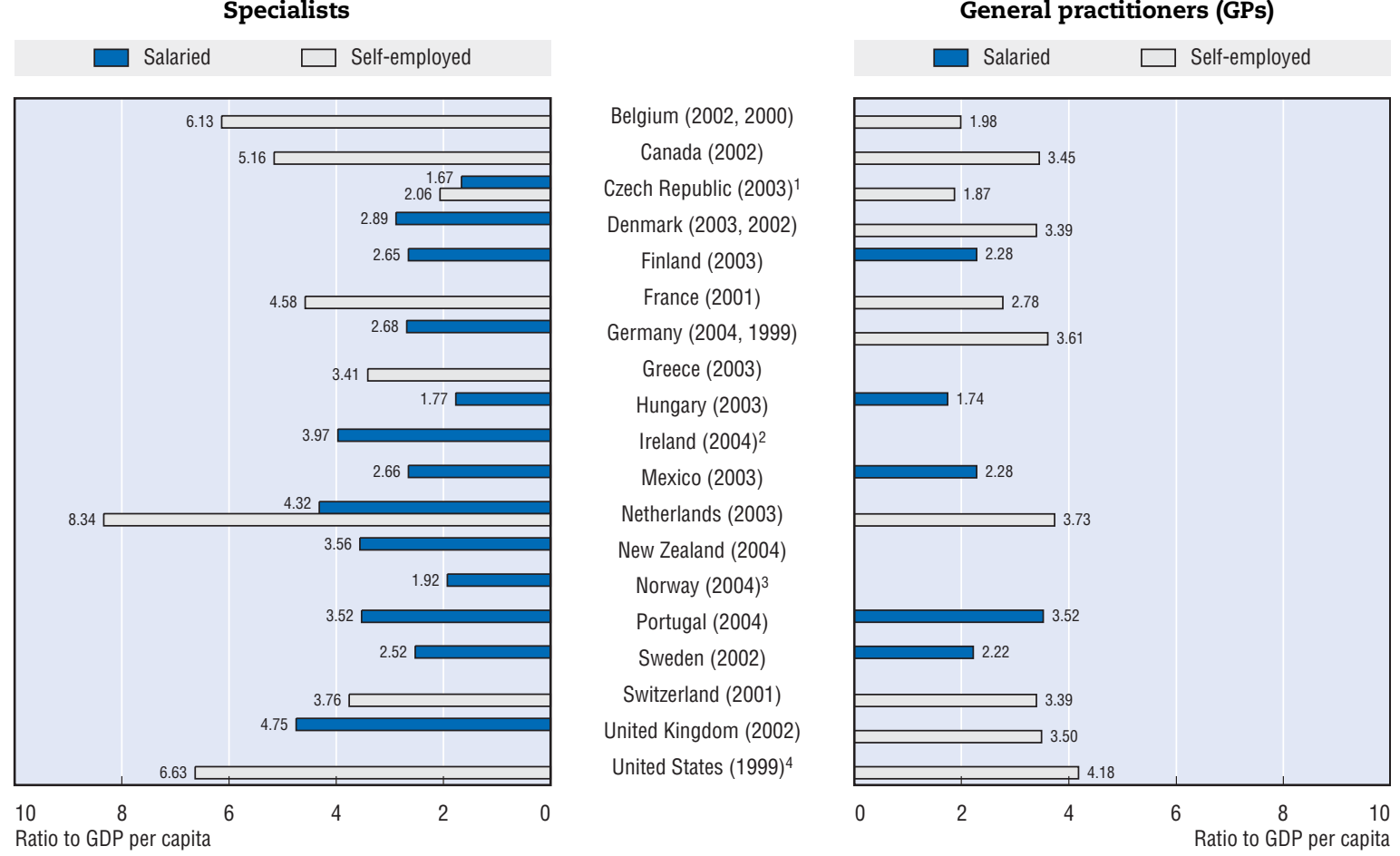

Ratio to GDP per capita

Belgium $(2002,2000)$

Canada (2002)

Czech Republic (2003)

Denmark $(2003,2002)$

Finland (2003)

France (2001)

Germany $(2004,1999)$

Greece (2003)

Hungary (2003)

Ireland (2004) ${ }^{2}$

Mexico (2003)

Netherlands (2003)

New Zealand (2004)

Norway $(2004)^{3}$

Portugal (2004)

Sweden (2002)

Switzerland (2001)

United Kingdom (2002)

United States (1999) ${ }^{4}$

1. Salaried specialists in the Czech Republic also include general practitioners (GPs) working as employees (about $15 \%$ of all GPs).

2. Given that GDP per capita overstates the average income in Ireland, the ratio under-estimates the relative income of doctors.

3. Salaried specialists in Norway also include assistant doctors.

4. Data include both self-employed and salaried physicians (salaried physicians account for about one-third of all physicians). See footnotes to Tables A.2.3 and A.2.4 for more information about sources and methods.

\section{Chart 2.10. Relative remuneration of specialists and specialists per 1000 population, latest year available ${ }^{1}$}

Ratio to GDP per capita

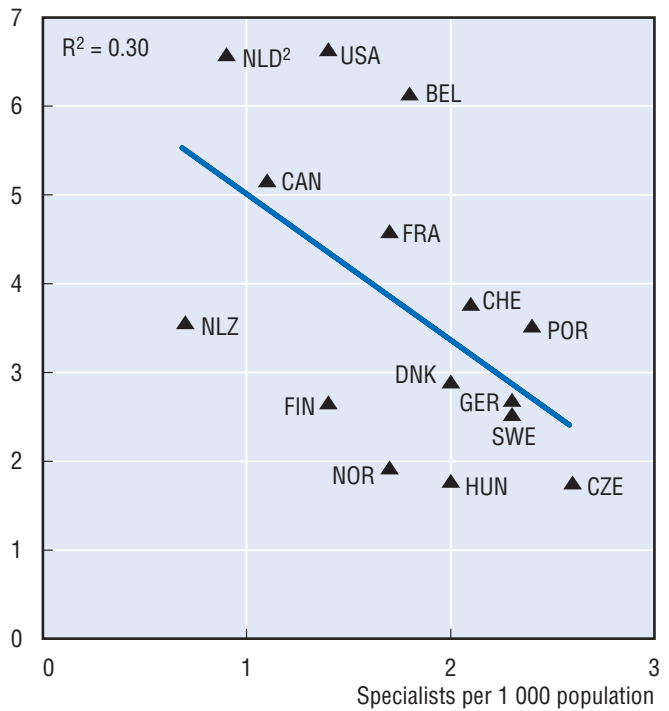

1. The year for the number of specialists per 1000 population is the same as for the remuneration or, if not available, the latest year available.

2. Includes non-practising specialists.
Chart 2.11. Remuneration of salaried hospital nurses, ratio to GDP per capita, latest year available

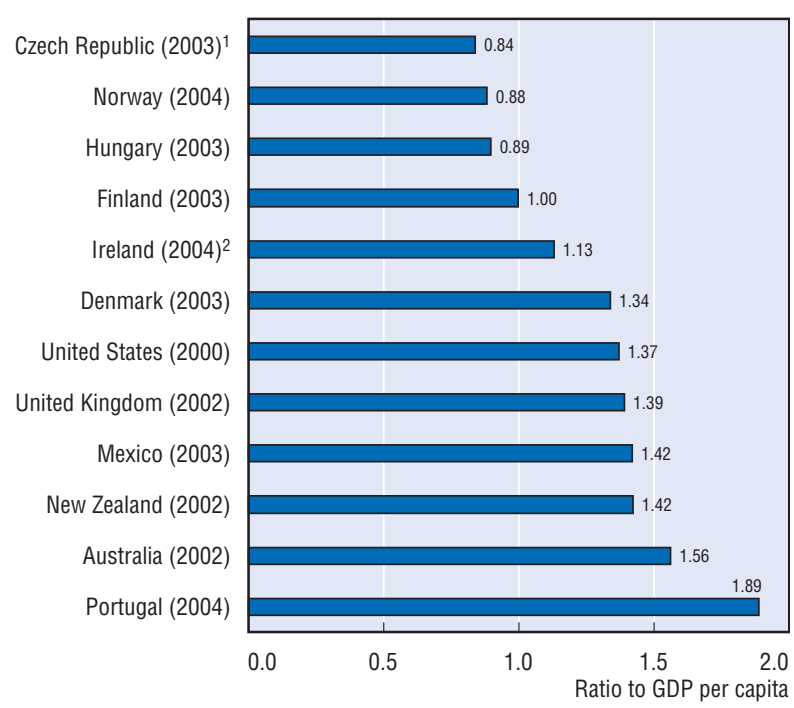

1. Included are wages of all paramedical personnel.

2. Given that GDP per capita overstates the average income in Ireland, the ratio under-estimates the relative income of nurses. See footnotes to Table A.2.5 for more information on sources and methods.

Source: OECD Health Data 2005.

StatLink: http://dx.doi.org/10.1787/753873300856 


\section{II.4. ACUTE CARE HOSPITAL BEDS, AVAILABILITY AND OCCUPANCY RATES}

The number of acute care hospital beds provides a measure of the resources available for delivering health services in hospitals. It does not provide however a comprehensive measure of capacity since it does not capture the capacity of hospitals to furnish services for non-admitted patients receiving emergency or elective interventions which do not require overnight stays. Also, it is not intended to take into account beds allocated for non-acute care purposes (e.g., for long-term care).

In 2002, there were large variations in the number of acute care beds across OECD countries. Bearing in mind that variations remain in the definition of "acute care" across countries which limit to a certain extent data comparability, the number of acute care beds per capita was highest in Japan, followed by Germany, the Czech and Slovak Republics and Austria, with all these countries reporting 6 acute care beds or more per 1000 population (Chart 2.12). It was the lowest (less than 3 per 1000 ) in Mexico, Turkey, Finland, Sweden and the United States. Many "acute care" beds are devoted to long-term care in Japan (Jeong and Hurst, 2001).

There has been a substantial reduction in the number of acute care hospital beds per capita in most OECD countries since 1990, continuing a trend which started in the 1980s. On average across a consistent group of countries, the number of acute care hospital beds has come down from 5.3 per 1000 population in 1990 to 4.2 in 2002. In a few countries that started with a less developed hospital sector, the number of acute care hospital beds has increased since 1990. This has been the case particularly in Korea, where the number of acute care beds per capita has more than doubled between 1990 and 2002.

The reduction in acute care hospital beds per capita in most countries has been driven at least partly by attempts to contain the growth of in-patient costs, which remain the largest health spending category in nearly all OECD countries (see indicator "Health expenditure by function"). The reduction of hospital beds per capita might have been associated with three possible changes in terms of activity: 1) a reduction in the number of hospital admissions/ discharges requiring overnight stays; 2) a reduction in the average length of stay for admitted patients; and/ or 3) an increase in occupancy rates of available beds (Kroneman and Siegers, 2004). The reduction in the number of acute care beds per capita has reflected these three factors differentially across countries. In some countries, hospital discharge rates have declined at least slightly over the past decade (see indicator "Hospital discharges"). In nearly all countries, the average length of stay for acute care patients has decreased significantly since 1990 (see indicator "Average length of stay in hospitals"). And in several countries, bed occupancy rates have increased as the number of acute care beds per capita has decreased (Chart 2.13).

The average occupancy rate of acute care beds in OECD countries was $75 \%$ in 2002, about the same level as in 1990. There are however considerable variations in occupancy rates across countries (Chart 2.13). In 2002, Norway, Canada, Switzerland, Ireland and the United Kingdom had the highest occupancy rates (at around $85 \%$ ). These are all countries where acute care beds per capita are below the OECD average, although they are not the lowest. On the other hand, following Turkey with the lowest occupancy rates in 2002 are Korea, the United States and the Netherlands (at 65-66\%). These three countries show very different trends however in the availability of hospital beds per capita and their occupancy rates. In Korea, the number of acute care hospital beds has grown very rapidly over the past decade, and now stands well above the OECD average. The occupancy rate of available beds has decreased sharply during that period. In both the United States and the Netherlands, the number of acute care beds per capita has decreased over time, and now stands below the OECD average. But while bed occupancy rates have remained relatively stable in the United States between 1990 and 2002, the occupancy rate has decreased significantly in the Netherlands. The Netherlands, Germany and Luxembourg are the only countries featuring both a reduction in the number of acute care beds per capita combined with a significant reduction in occupancy rates since 1990.

\section{Definition and deviations}

Acute care hospital beds should in theory only include beds available for "curative care" as defined in the SHA Manual (OECD, 2000a). However, there are variations across countries in the functions of care included/excluded in "acute care" which limits data comparability (e.g., the extent to which beds designated for long-term care, rehabilitation and palliative care are excluded). Several countries (e.g., Austria, Canada, Czech Republic, Denmark, Finland, Germany, Ireland, Poland, Spain, Switzerland and the United States) report all beds in "general" or "acute care" hospitals. Some of these beds may be used for purposes such as long-term care (e.g., in Japan).

The occupancy rate for acute care beds is defined as the number of hospital beddays related to acute care divided by the number of available acute care beds multiplied by the number of days (365). 


\section{Chart 2.12. Acute care hospital beds per 1000 population, 1990 and 2002}

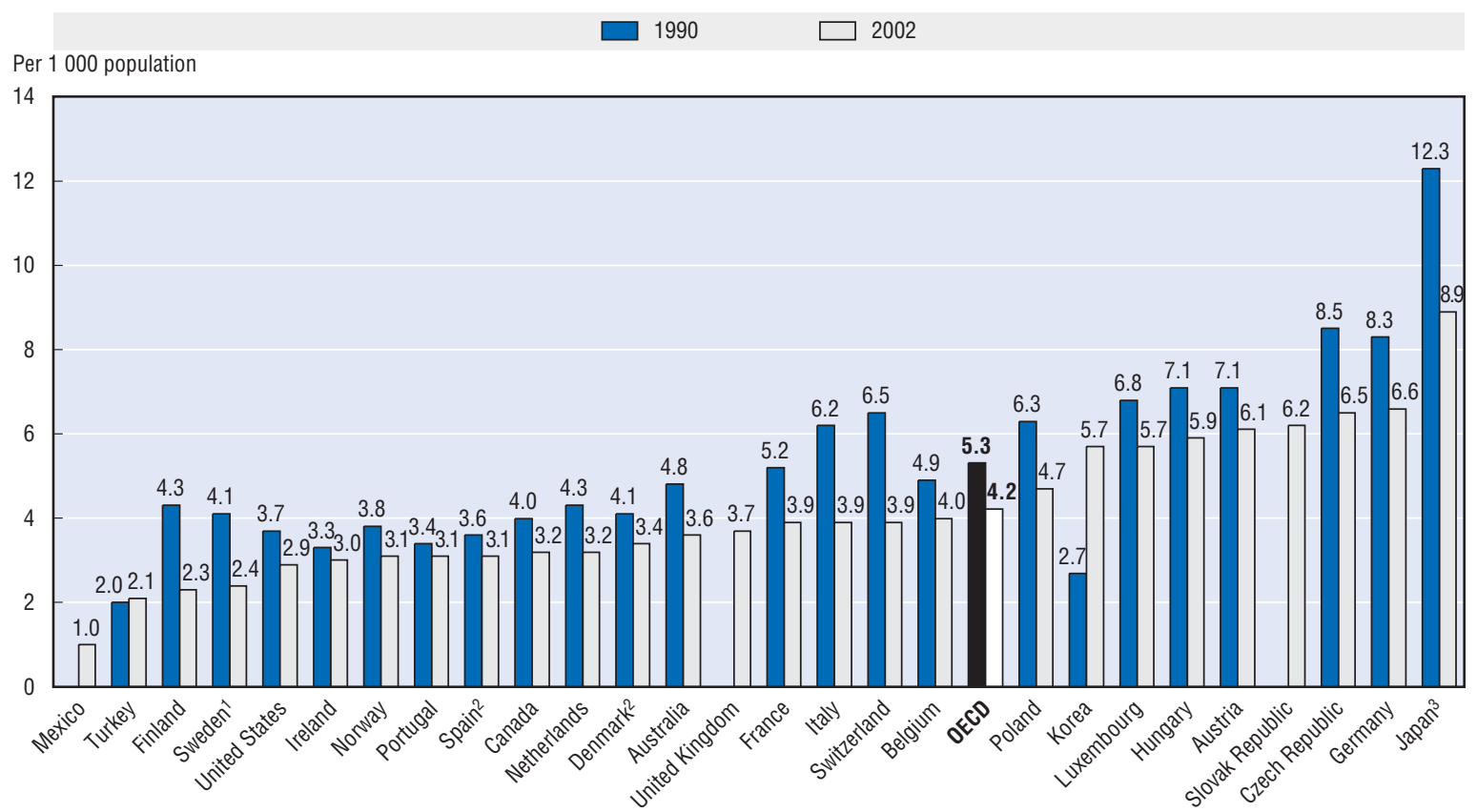

Note: The definition of "acute care" beds may vary from one country to the other. In Japan, many "acute care" beds are devoted to longterm care. Cross-country variations should therefore be interpreted with caution.

1. 2000 .

2. 2001 .

3. 1993.

Chart 2.13. Occupancy rate of acute care hospital beds, 1990 and 2002

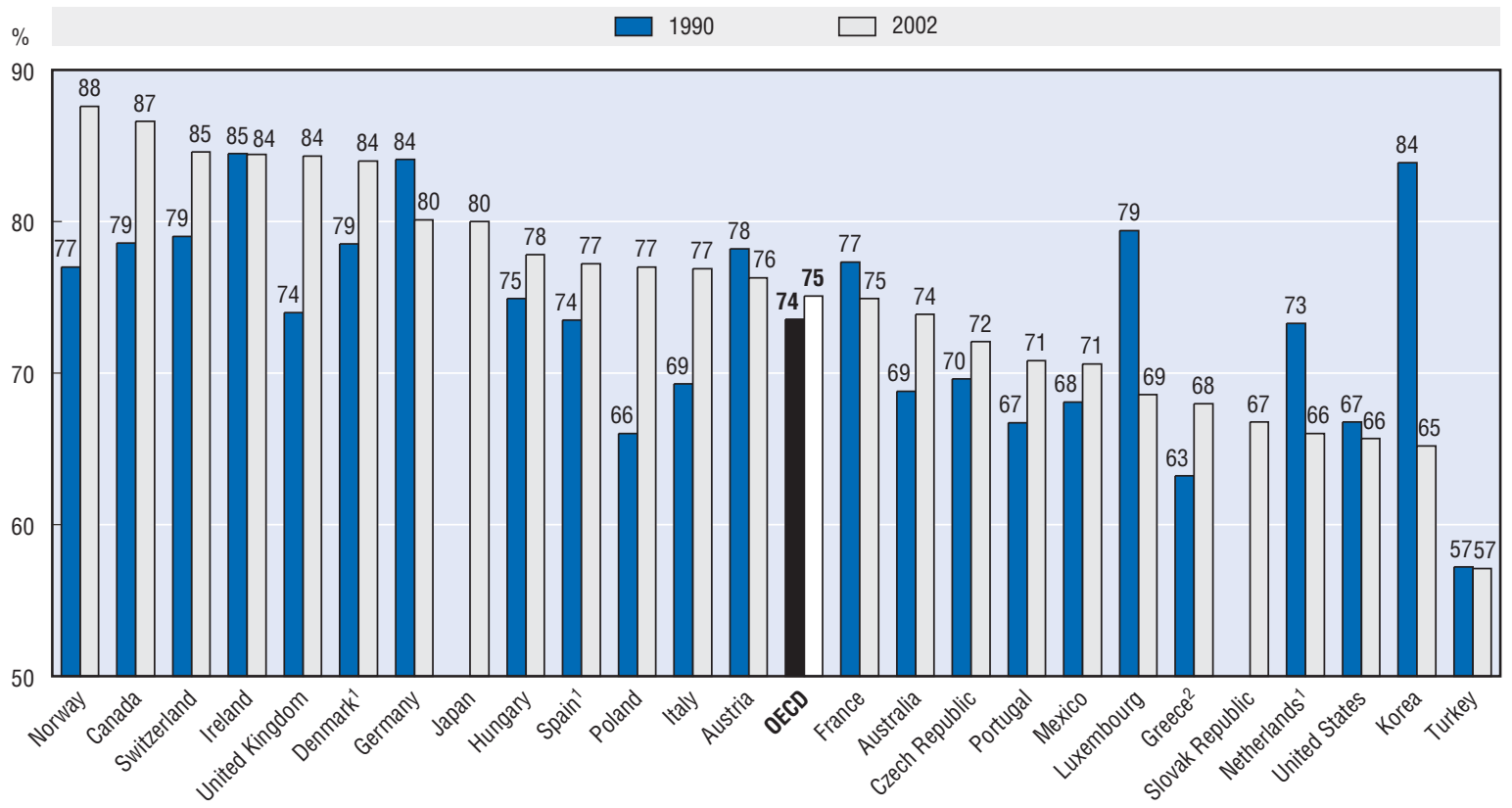

1. 2001.

2. 1999.

Source: OECD Health Data 2005 
The diffusion of modern medical technologies is one of the main drivers of rising health expenditures across OECD countries. This section presents data on the availability of three specific diagnostic technologies - computed tomography (CT) scanners, magnetic resonance imaging (MRI) units and mammographs - and one therapeutic technology, radiation therapy equipment. While these data provide an indication of the overall availability of such equipment, they do not indicate the extent to which the equipment are actually used. It is also important to note that the figures for the United States under-estimate considerably the availability of these devices, because they refer to the number of hospitals reporting to have at least one of these types of equipment rather than the total number in all locations (including clinics).

CT scanners (also known as "CAT" scans, for computed axial tomography) and MRI units are used to diagnose a wide range of diseases. An advantage of MRI over conventional radiography or CT is that it does not expose patients to ionising radiation. The availability of CT and MRI scanners has increased in most OECD countries over the past decade or so. MRI being a newer technology than CT, the number of MRIs has increased particularly rapidly since 1990 (Table A.2.8).

In 2002, Japan was the country with by far the highest number of CT and MRI scanners per capita, with $93 \mathrm{CT}$ scanners per million population and 35 MRI units (Charts 2.14 and 2.15). Some analysts have attributed the rapid increase in the number of MRI scanners in Japan at least partly to the lack of any formal assessment of efficiency or effectiveness before making decisions to purchase such equipment (Hisashige, 1992). European countries such as Iceland, Switzerland, Austria, Finland and Italy also have a relatively high number of MRI units per capita. At the other end of the scale, not surprisingly given the high cost of these types of equipment, the number of MRI units per capita was the lowest in Mexico, followed by Poland, the Slovak Republic and the Czech Republic.

Mammography plays an important role in the early diagnosis of breast cancer, the most common cancer among women (see indicator "Cancer, mortality"). Early diagnosis and intervention significantly increase survival rates from breast cancer (OECD, 2003a). Among those countries for which data is available, the number of mammographs per capita in 2002 was the highest in France and Finland, followed by Greece, New Zealand, Luxembourg and Belgium (Chart 2.16). Mexico, Turkey and the United Kingdom reported the lowest number of mammographs per capita. The availability of mammographs has rapidly increased in several countries in the 1990s (Table A.2.9). This rapid diffusion has coincided with the development of organised mammography screening programmes in many countries.

Radiation therapy (also called radiotherapy) is used for the treatment of many types of cancer. More than half of patients with cancer are treated with radiation therapy (National Cancer Institute, 2004; DREES, 2005). In 2002, the number of radiation therapy equipment per capita was the highest in Iceland (the absolute number of machines was very small however; the high rate per capita is due to the very small population base), followed by Switzerland and Finland (Chart 2.17). It was relatively low not only in Mexico and Turkey, but also in Hungary, Portugal, Spain and the United Kingdom. While the relatively low number of radiation therapy equipment in Portugal and Spain is associated with relatively low cancer incidence and mortality rates, this is not the case in Hungary and the United Kingdom, where cancer incidence and cancer mortality rates are above the OECD average (see indicator "Cancer, mortality").

National income and total health spending are important factors influencing the diffusion of medical technologies. A recent analysis focussing on the diffusion of CT and MRI scanners across OECD countries, controlling for a number of possible explanatory variables, confirmed that "purchasing power" (as measured by health expenditure per capita) is positively correlated with the diffusion of these technologies. This study also found that differences in payment methods to hospitals can also play an important role, with certain payment methods (e.g., those based on reimbursements on a per case or per diem basis) associated with a greater diffusion of CT and MRI scanners (Eun-Hwan Oh et al., 2005).

\section{Definition and deviations}

The figures relate to the number of medical technology devices per million population. Data on radiation therapy equipment include linear accelerators, cobalt-60 units, caesium-137 therapy units and low to orthovoltage x-ray units (brachytherapy units are normally excluded).

For the United States, the data refer to the number of short-term general hospitals reporting to have at least one of these equipments. They therefore under-estimate considerably the real number of devices available. For the United Kingdom, the data refer only to devices in the public sector; they do not include equipment in the private sector (also resulting in an under-estimation). For Spain, the data relate only to devices available in hospitals; they do not include equipment in other health care facilities (also leading to an under-estimation). For Australia, the data on the number of MRI units include only those that are eligible for public insurance (only 60\% of the total in 1999). 
Chart 2.14. MRI units, number per million population, 2002

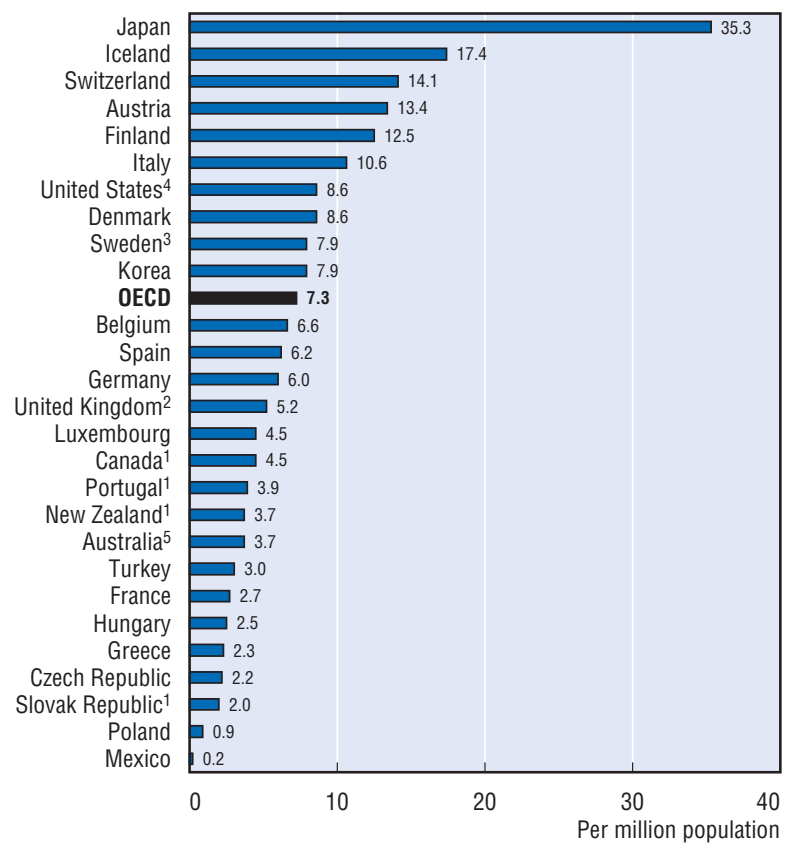

Chart 2.16. Mammographs, number per million population, 2002

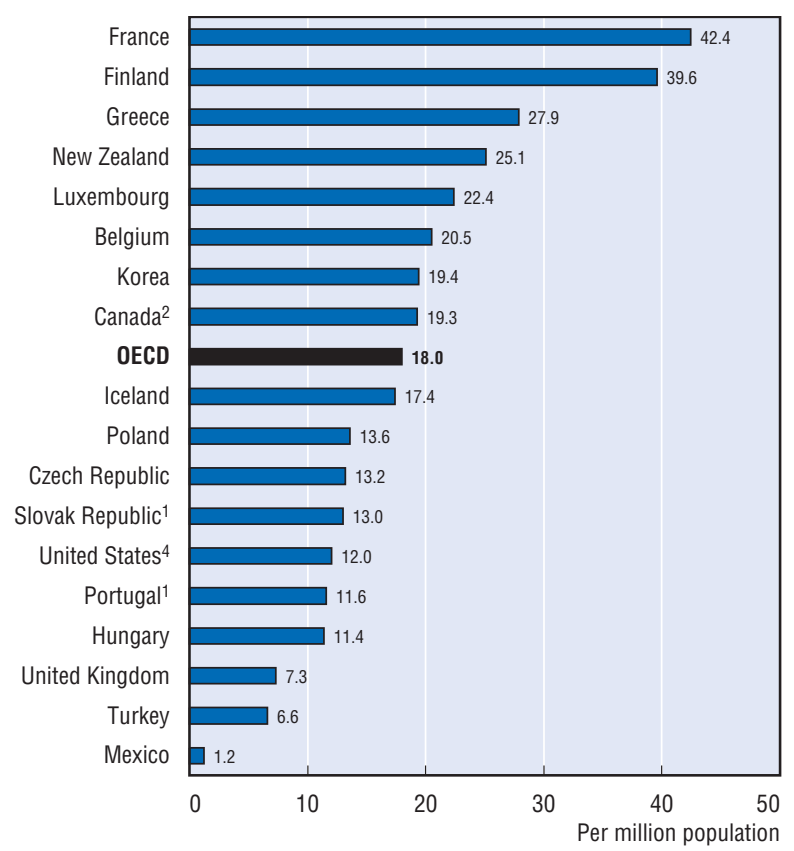

Chart 2.15. CT scanners, number per million population, 2002

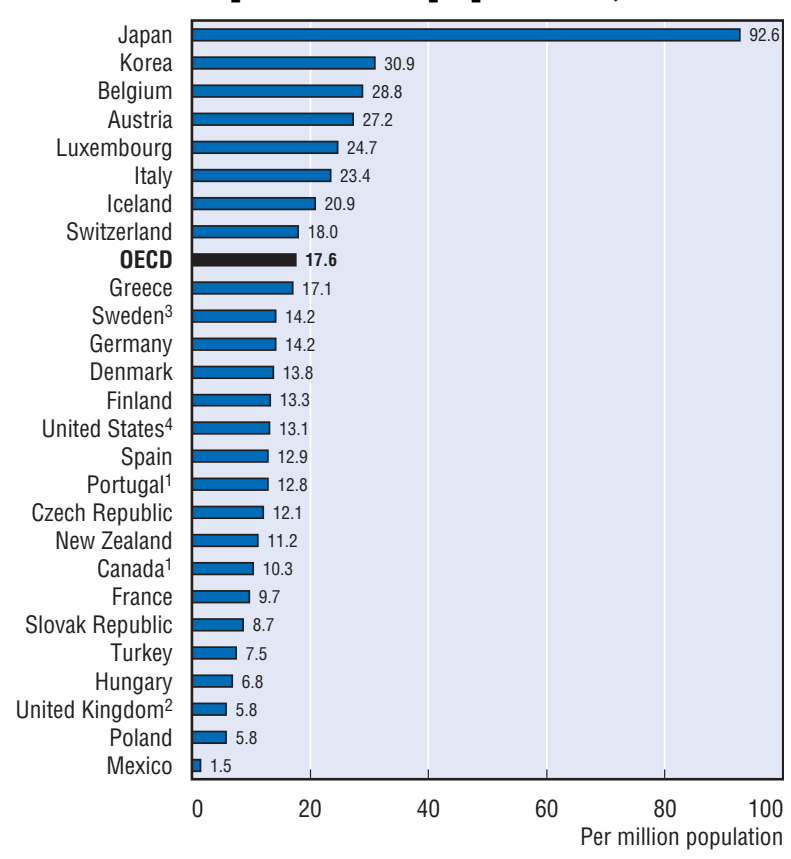

Chart 2.17. Radiation therapy equipment, number per million population, 2002

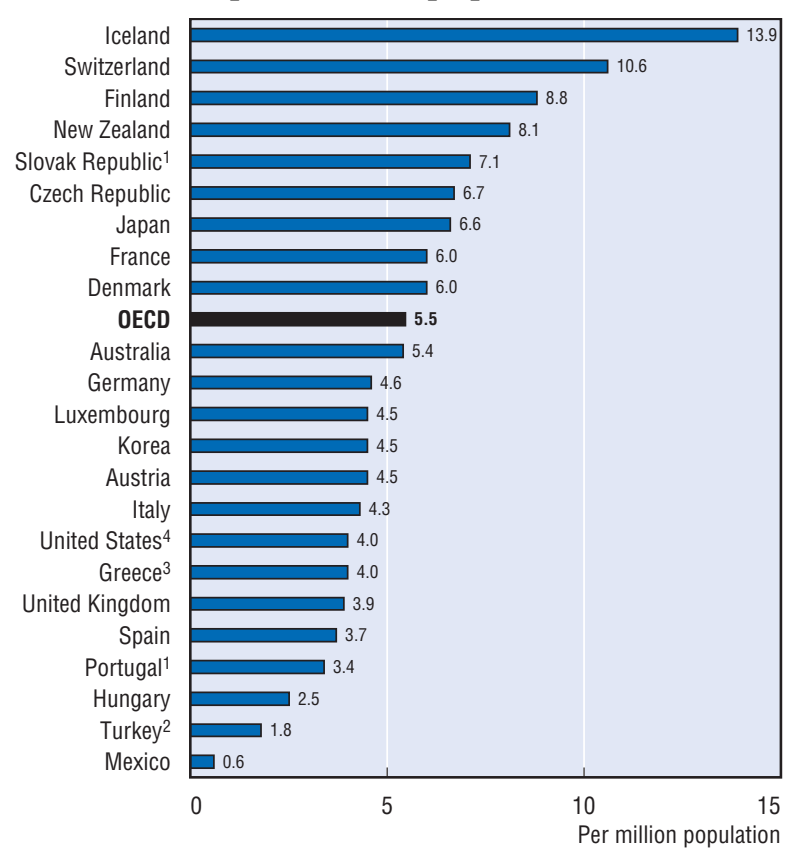

1. 2003.

2. 2001.

3. 1999.

4. The figures for the United States under-estimate considerably the real number of devices in that country, because they refer to the number of hospitals reporting to have at least one of these equipment rather than the total number of equipment in hospitals and in other locations (e.g., specialised clinics).

5. For Australia, the data on the number of MRI are only for those that are Medicare-eligible (60\% of the total in 1999$)$.

Source: OECD Health Data 2005. 


\section{II.6. CONSULTATIONS WITH DOCTORS}

A large proportion of patient contacts with health care systems involves a consultation with a doctor either in a doctor's office, in a primary care clinic or in a hospital outpatient department. The average number of physician contacts in a given year is influenced, among other things, by the population's health status, the availability of doctors and the cost of consultations to individuals. Ways of accessing specialists can also play a role. In some countries (e.g., Belgium, Germany, Greece), patients can approach a specialist directly while in others (e.g., Austria, Canada, the Netherlands, the United Kingdom and in France as of 2005) they are either required or encouraged to approach a general practitioner "gatekeeper" who decides whether they need referral to a specialist. The total number of physician contacts is only a crude measure of the volume of services provided, as services are counted regardless of their duration and complexities.

There are two main sources of data on doctor consultations: administrative data (such as medical registrations used for payment purposes) and selfreported data based on health interview surveys. Both sources have advantages and disadvantages (Van der Heyden et al., 2003). Usually, administrative data are more accurate and reliable than results from health interview surveys, because of reporting errors and biases in surveys arising from incorrect recall and non-response rates. An advantage of survey data over administrative data is the possibility of linking healthcare utilisation data (such as doctor consultations) with other variables such as socioeconomic status (income, education, occupational status) to examine distributional issues.

A comparison of estimates of doctor consultations per capita between administrative data and survey data shows that while they are reasonably consistent in some countries (e.g., Austria, Belgium, France), in other countries the results vary substantially according to the data source (e.g., Canada, Denmark, Hungary and the United States). In general, estimates from administrative sources are higher than those obtained from health interview surveys (Chart 2.18).

Focussing on administrative data (the main data source used for OECD Health Data), there were considerable differences reported across countries in the average number of consultations with doctors per capita in 2003 (Chart 2.19). It ranged from a low of less than three visits per person per year in Mexico, Turkey and Sweden, to over 10 visits per year in the OECD's two Asian countries (Japan and Korea), and in the Czech Republic, the Slovak Republic and Hungary. The average across OECD countries was nearly seven visits per person per year in 2003. In Japan, the number of doctor visits has steadily been much higher than in other OECD countries, which is related at least partly to the fact that doctors not only prescribe but also dispense drugs.

The number of doctor consultations per capita has increased at least slightly in most countries between 1990 and 2003 (Chart 2.19). The increase in the number of doctor consultations per capita in Turkey and Mexico (which started with low levels) is related at least partly to the increase in the total number of doctors per capita during that period, which has increased access to doctor services (see indicator "Practising physicians").

Many OECD countries aim to achieve equal care for equal need. Evidence from a comparative analysis of health interview surveys conducted around 2000 in a number of OECD countries suggests that most countries covered under this study had achieved this aim in the number of physician visits across different income groups, after standardising for need differences (Van Doorslaer et al., 2004). Significant disparity in doctor consultations between the lowest and highest income groups (after need standardisation) emerged in only a few countries, including the United States, Portugal and Finland (Chart 2.20).

\section{Definition and deviations}

Consultations with doctors per capita refer to the number of ambulatory contacts with physicians (both generalists and specialists) divided by the entire population. The number of contacts normally includes: consultations of patients at the physician's office, in primary care clinics and in outpatient departments of hospitals, and visits made to the patient's home.

Estimates reported in OECD Health Data generally come from administrative sources for most countries, with the exception of Italy, the Netherlands, New Zealand (for the 2003 estimate), Spain, Switzerland and the United Kingdom (for consultation with general practitioners) where they come from health interview surveys. Estimates of doctor consultations from administrative sources tend to be higher than those obtained from health interview surveys, because of incorrect recall and non-response rates in surveys.

The estimates for the United States and Denmark include consultations by telephone; they are therefore not limited to physician visits. The figures for the United Kingdom do not include private consultations with specialists. Data for the Netherlands do not include contacts for maternal and child care. Those for Portugal and Turkey exclude visits to private practitioners. 


\section{II.6. CONSULTATIONS WITH DOCTORS}

Chart 2.18. Doctors consultations per capita, estimates from administrative data and health interview surveys, 2000

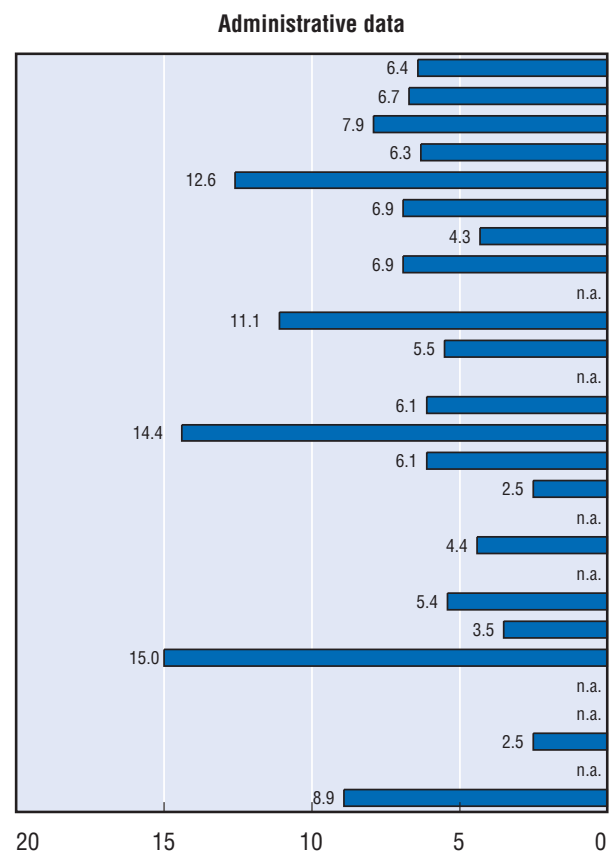

Australia
Austria
Belgium
Canada
Czech Republic
Denmark
Finland
France
Greece
Hungary
Iceland
Ireland
Italy
Japan
Luxembourg
Mexico
Netherlands
New Zealand ${ }^{1}$
Norway
Poland
Portugal
Slovak Republic
Spain
Switzerland
Turkey
United Kingdom
United States

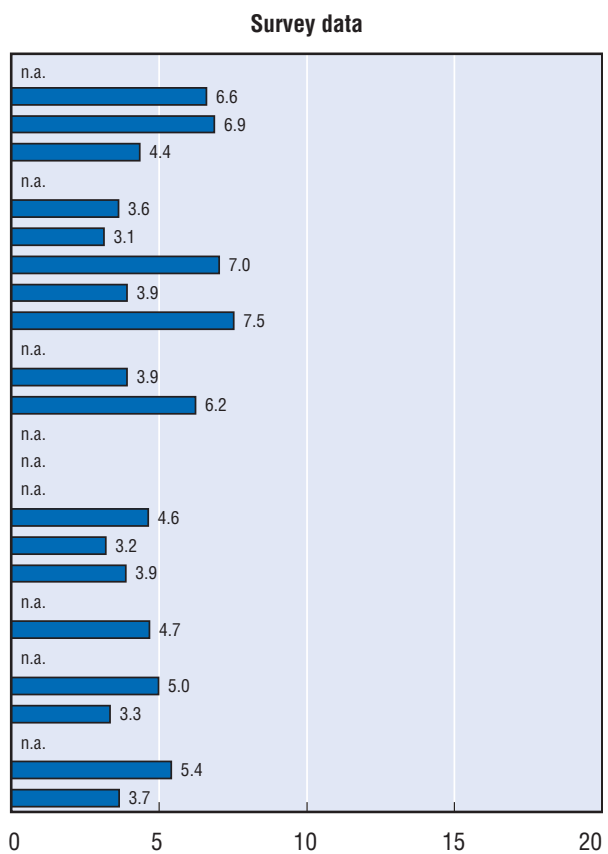

1. For New Zealand, administrative data refer to 2001 and survey data to 2003

Source: OECD Health Data 2005 and Van Doorslaer et al. (2004).

\section{Chart 2.19. Doctor consultations per capita, 1990 to 2003}

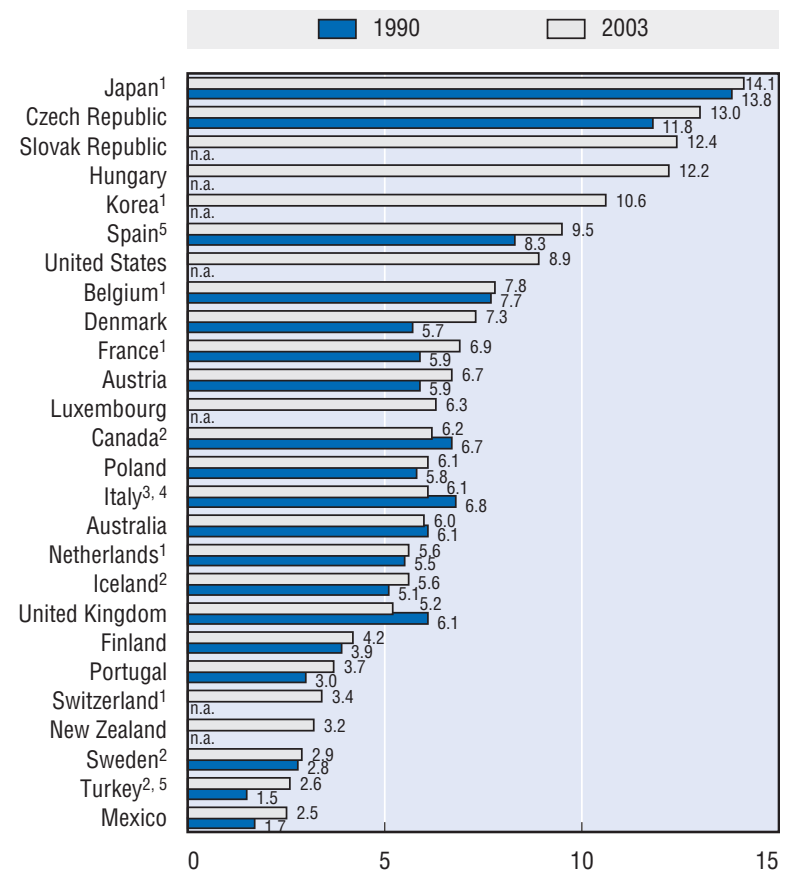

1. 2002. 2. 2001. 3. 2000. 4. 1991. 5. 1993.

Source: OECD Health Data 2005.
Chart 2.20. Doctor consultations by income level, adjusted for need differences, survey data around 2000

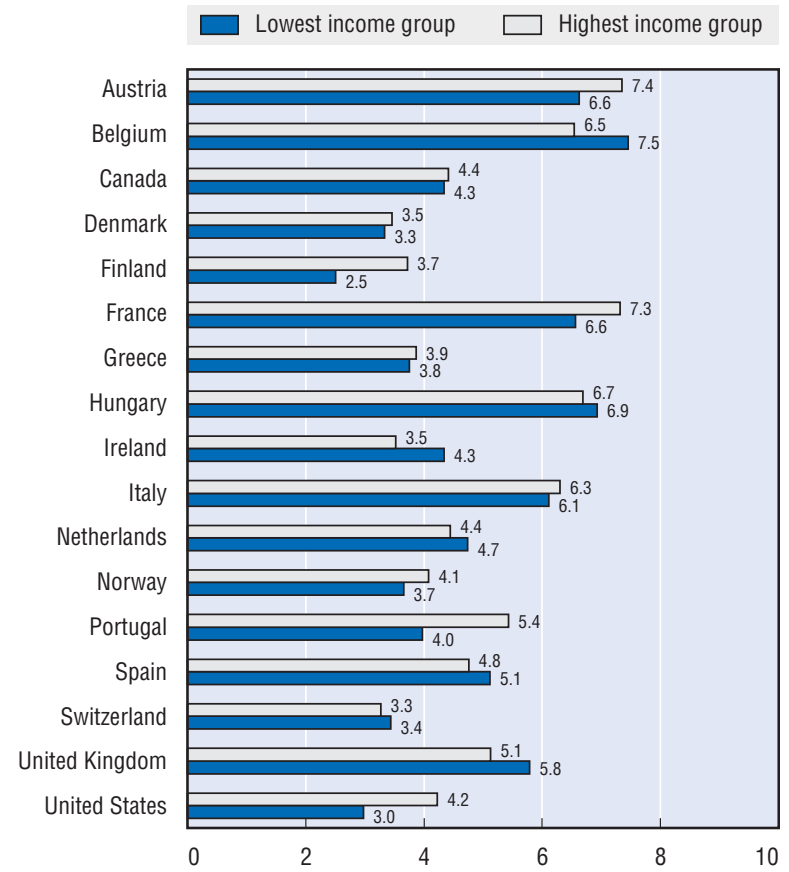

Source: Van Doorslaer et al. (2004). 
Childhood immunisation has been shown to be one of the most effective preventive measures for reducing childhood disease and mortality. Widespread use of vaccines has drastically reduced the incidences of many childhood communicable diseases in many countries, meaning they no longer feature as a major cause of infant mortality. However, despite the strong evidence of the cost-effectiveness of such programmes in tackling diseases such as measles and diphtheria, some countries have still not attained target levels of childhood immunisation. This can be due to a variety of reasons, such as a lack of comprehensive nationallevel immunisation programme, instability of public health funding, individual complacency about the effectiveness of immunisation, or concern about perceived adverse effects.

Through mass vaccination, polio and diphtheria have been, to all intents and purposes, eradicated as childhood diseases across the OECD; the last case of polio in Turkey having been reported in 1998. Globally, measles remains an important cause of childhood mortality and the leading cause of vaccinepreventable deaths in childhood, causing an estimated 530000 deaths around the world in 2003 according to WHO/UNICEF (WHO, 2005). In Europe, as a whole, the gradual uptake of the measles vaccine has meant that measles incidence is around ten times less than the rate of the early 1990s. However, while some countries have reported measles incidence rates of less than 1 per 100000 inhabitants, indicating they are nearing elimination, there are other countries in which measles vaccination coverage remains below the level required to interrupt indigenous transmission. Between 1999 and 2003, there were major measles outbreaks in Italy, Germany, Ireland, Switzerland and France.

Chart 2.21 shows that around two-thirds of OECD countries achieve DTP (diphtheria, tetanus, pertussis) vaccination coverage of $95 \%$ or more, the level needed to provide general immunity for the population. For measles, around half the OECD countries report the same level of coverage (Chart 2.22). Some countries, for example in Central and Eastern Europe, Scandinavia and Japan have achieved almost universal coverage for many years through long established and effective vaccination programmes. It is interesting to note, however, that some of the wealthier OECD countries, as measured by GDP per capita, such as Ireland, Norway and Austria, report below average vaccination coverage for both diphtheria and measles. Adverse publicity surrounding possible links between a combined MMR (mumps-measles-rubella) vaccine and autism has led to a significant reduction in measles vaccination coverage in the United Kingdom, which now reports levels similar to those at the beginning of the 1990s (Chart 2.23).

Although Turkey had the lowest reported coverage rate for measles in 2003, national targets have been set to eliminate the disease by 2010. In December 2003, as part of a "catch-up campaign", around 11 million school children between the ages 6 and 14 years were vaccinated, an immunisation coverage of $97 \%$, with the remaining pre-school children to be targeted during 2005 (WHO/EURO, 2005).

A successful national immunisation programme can be structured in various ways. In certain countries, immunisation may be almost obligatory; childhood vaccination being required in order to gain access to future medical care, childcare facilities or schooling. Other countries may adopt a thorough follow-up campaign by health service staff. Mass media communication and promotion can also be a useful tool in any immunisation campaign.

\section{Definition and deviations}

Childhood immunisation refers to two measures: the percentage of 1-year-old children vaccinated against diphtheria, tetanus and pertussis combined (DTP), and the proportion of 1-year-old children vaccinated against measles. In some countries diphteria and tetanus, and pertussis vaccines are administered separately. In a few countries however (Germany, Greece, Italy, Luxemburg), immunisation rates against pertussis are somewhat lower than vaccination rates against the two other diseases. In these cases, the data are those referring to immunisation against diphteria and tetanus.

The age of complete immunisation may also differ across countries due to different immunisation policies. The aim is to achieve complete immunisation for 2-year-olds in Australia for measles; for ages 18-24 months in Belgium for DTP; for 2-year-olds in Canada and Finland, for ages 14-15 months in the Netherlands and for ages 19-35 months in the United States, for both DTP and measles. 


\section{II.7. CHILDHOOD IMMUNISATION}

Chart 2.21. Diphtheria, tetanus and pertussis immunisation coverage for young children, 2003

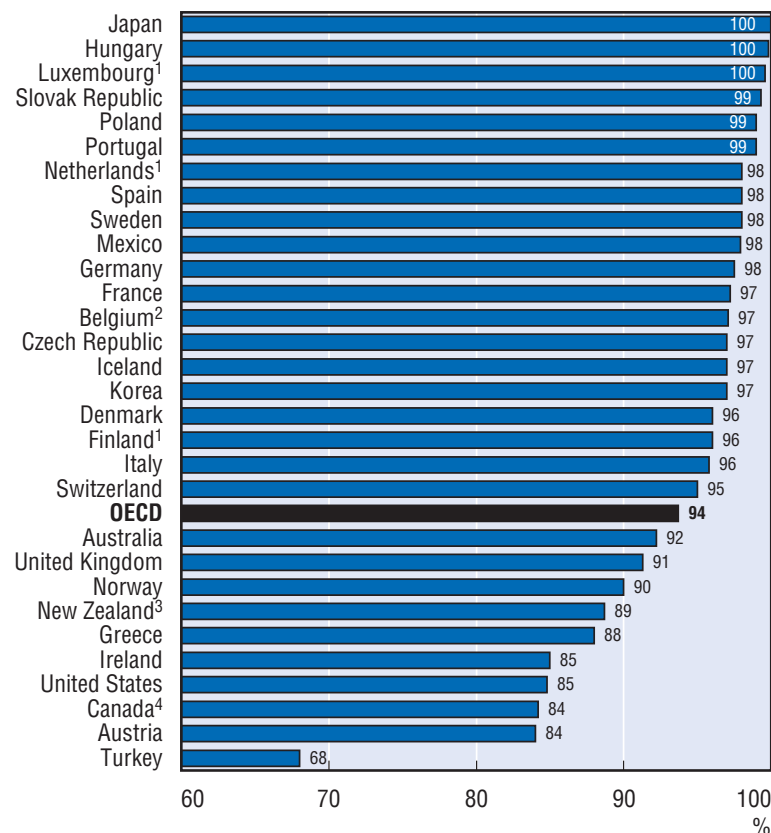

1. 2002

2. 1999 .

3. 2000 .

4. 1998

\section{Chart 2.22. Measles immunisation coverage for young children, 2003}

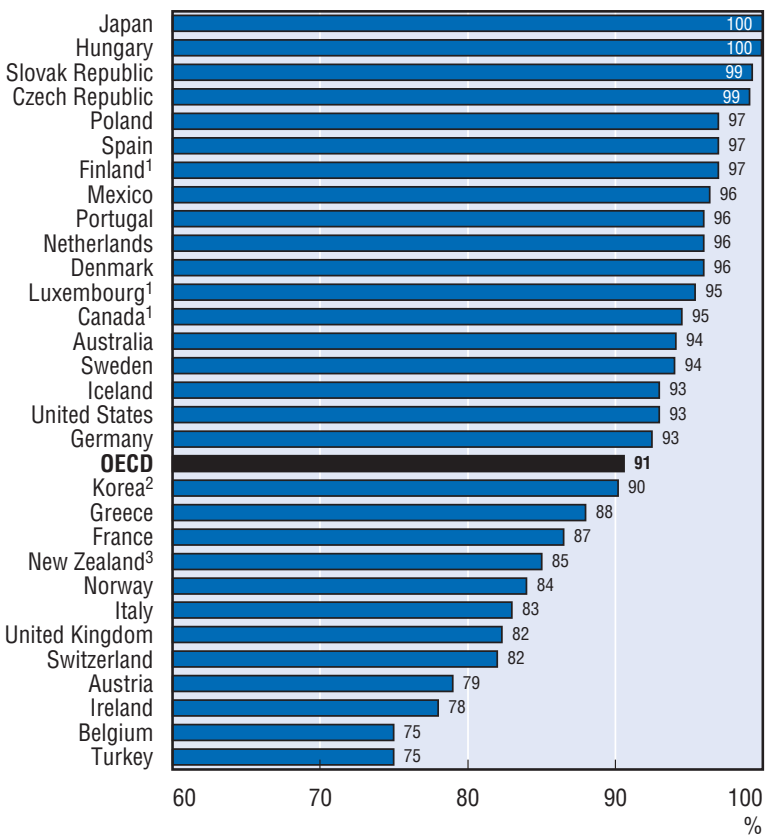

1. 2002 .

2. 2000

3. 1999.

Chart 2.23. Trends in immunisation coverage for measles, 1985 to 2003

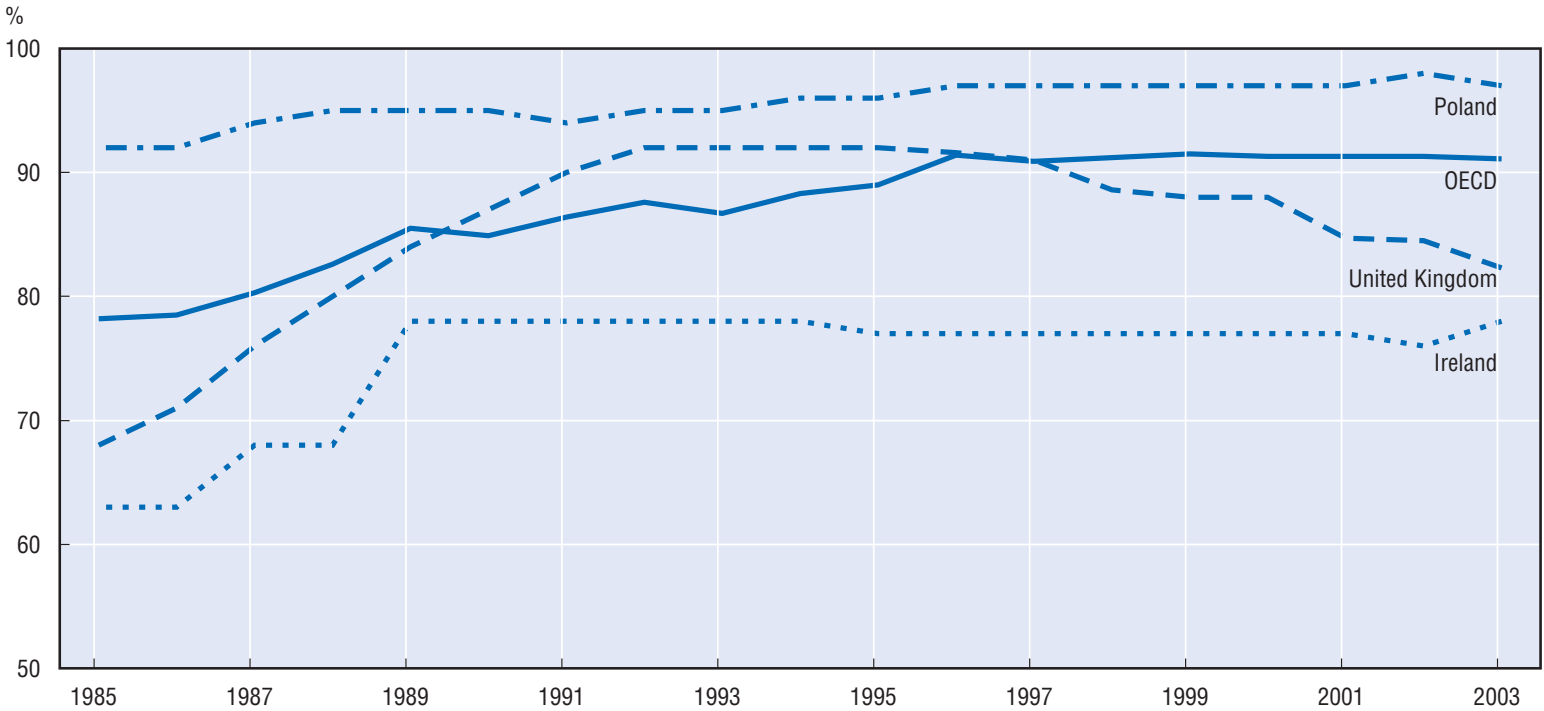

Source: OECD Health Data 2005. 


\section{II.8. INFLUENZA IMMUNISATION AMONG ELDERLY PEOPLE}

Immunisation against influenza (or flu) among elderly people has become increasingly widespread in OECD countries over the past decade, as a way to prevent illness, hospitalisation and mortality among this population group which has a greater risk of developing serious complications from flu. Annual influenza vaccination of elderly people has been demonstrated as safe and effective in reducing the risks of illness, hospitalisation and death in the United States and in other countries (e.g., US Preventive Services Task Force, 1996).

In 2003 (or for the latest year available), the rate of influenza vaccination among elderly people varied from a low of less than $40 \%$ in the Czech Republic, the Slovak Republic and Hungary, to over $75 \%$ in Australia, Korea and the Netherlands among those countries for which data is available (Chart 2.24). The rate of influenza vaccination among people aged 65 years and over was over $60 \%$ in most G7 countries (Canada, France, Italy, the United Kingdom and the United States), with the exception of Germany and Japan where less than $50 \%$ of the elderly population reported to have received vaccination against influenza in 2003.

In all countries reporting data over the past five to ten years, the share of the elderly population receiving annual influenza immunisation has increased over time (Chart 2.25). This is particularly true in the case of the Netherlands, where the immunisation coverage increased from 37\% in 1993 to $79 \%$ in 2003. This strong rise in the Netherlands is due to the launch of annual national vaccination campaigns, which include mass media information, the involvement of general practitioners in reminding high-risk patients to get vaccinated and the reimbursement of vaccination. In Italy and Switzerland, the rate of influenza immunisation also increased significantly over the past five years, although they remain below the rates in Australia, the United Kingdom, France and the United States, which started earlier than most other OECD countries in organising mass influenza vaccination campaigns for elderly people.

A number of factors have contributed to the increase in influenza immunisation rates in OECD countries, including: greater acceptance of preventive health services by patients and practitioners, improved public insurance coverage for such vaccines, and wider delivery of this service by health care providers other than physicians (Singleton et al., 2000). A number of barriers however need to be overcome to further increase coverage rates. In the United States, the reasons most frequently cited by elderly people for not receiving influenza vaccine were, firstly, ignorance that influenza vaccination was needed and, secondly, concerns that vaccination might cause influenza or side effects (CDC, 2004). Vaccine shortage or unavailability may also be an important reason for non-vaccination in the United States and in other countries in a given year.

Policy interventions may therefore be needed to further increase vaccine coverage, particularly in those countries where the overall coverage rate is relatively low and in those countries where it may be relatively low for certain segments of the population over 65. Following the example of the Netherlands, such policy interventions might include: community-based initiatives (e.g., mass media campaigns to increase awareness and reduce any concerns regarding the safety of the vaccine), individual-based interventions such as patient reminder systems, primary care interventions to improve incentives for practitioners to inform and educate their patients of the benefits of influenza vaccination, and public health interventions to improve access to vaccination in different settings (Marshall et al., 2002; CDC, 2000).

\section{Definition and deviations}

Influenza immunisation rate refers to the number of people aged 65 and over who have received an annual influenza vaccination, divided by the total number of people over 65 years of age. The main limitation in terms of data comparability arises because of the use of different data sources which are susceptible to different types of errors and biases. In many countries, the data come from population-based surveys, which may suffer from incorrect recall. Survey data may also exclude the institutionalised population in certain countries. In some countries (e.g., Denmark, Hungary, Italy, New Zealand and the United Kingdom), the data come from administrative sources, which may only capture vaccination delivered under the payment system covered by the data. It is unknown to what extent the use of administrative data in certain countries may bias downward (or upward) the reported immunisation rates compared with those countries using survey data. 


\section{Chart 2.24. Influenza vaccination coverage among people aged 65 years and over, 2003}

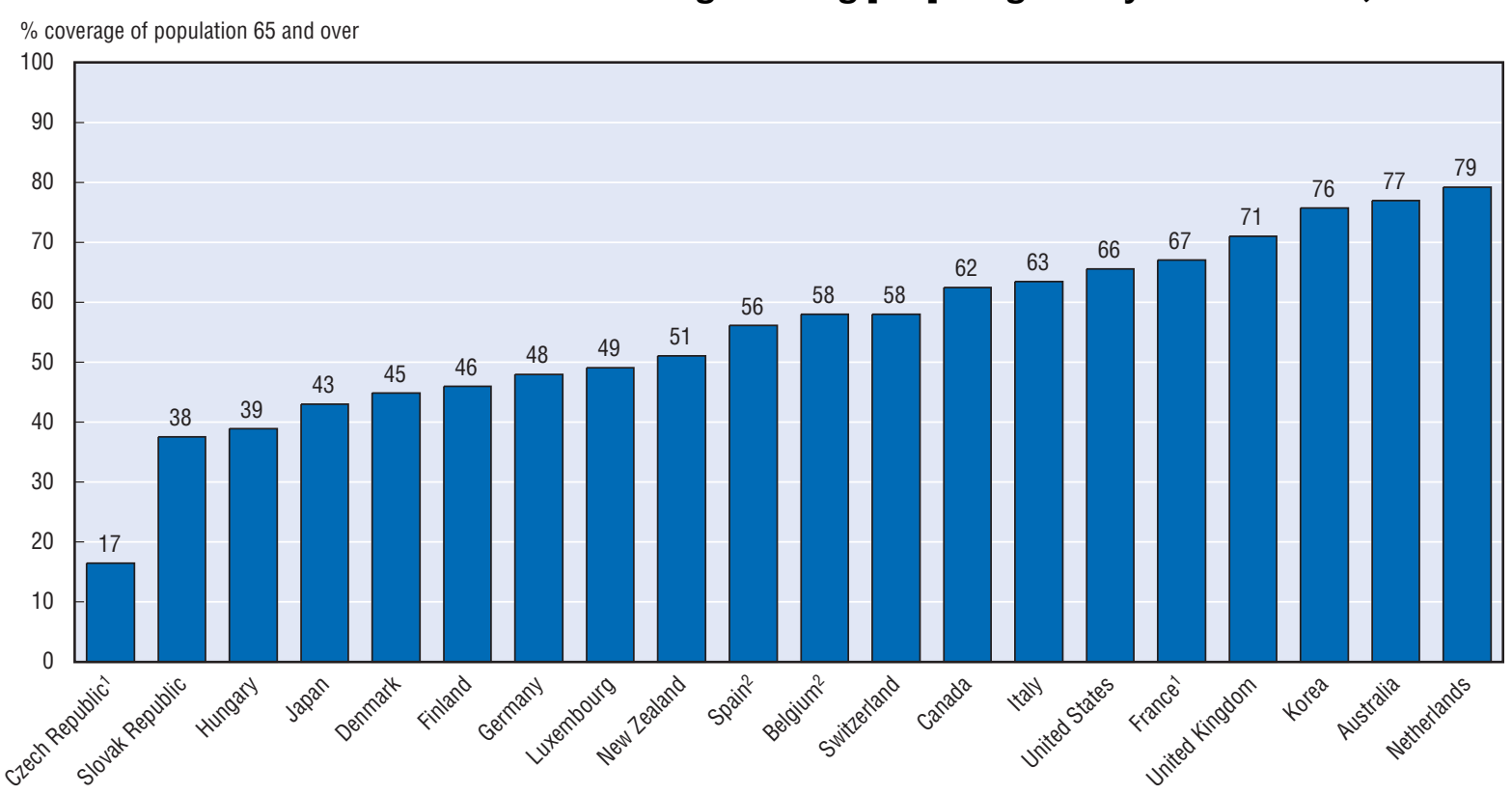

1. 2002.

2. 2001.

Chart 2.25. Increasing rates of influenza vaccination among people aged 65 years and over, 1993 to 2003

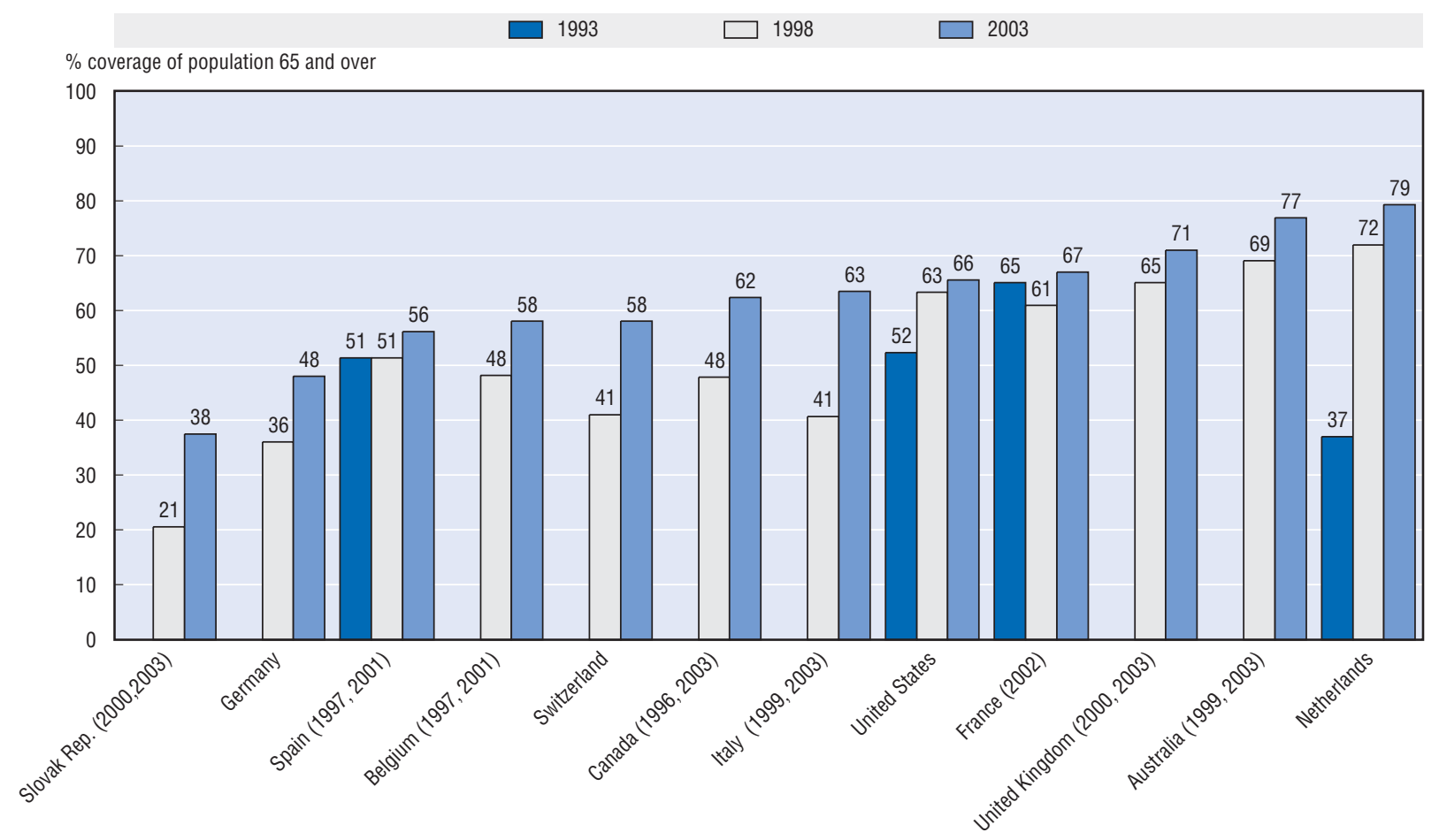

Source: OECD Health Data 2005. 
Discharge rates are an important measure of hospital activity. However, they provide only a partial measure of activity in hospitals since, in most countries, discharge rates do not include treatments which do not require overnight stays (same-day separations). In addition, hospital discharge rates do not take into account differences in case-mix (the mix of the conditions leading to hospitalization).

Caution is required in making cross-country comparisons of hospital discharge rates, since some countries include same-day separations while the majority do not. Finland also reports data which include transfers from one hospital unit to another, while these are excluded in other countries (see the box below on "Definition and deviations").

Not surprisingly, those countries including same-day separations (Austria, Hungary, the Czech Republic, France and New Zealand), with the exception of the United States, tend to rank higher in overall hospital discharge rates than those countries which exclude them (Chart 2.26 and Table A.2.13). This is also the case for Finland which includes transfers from one hospital unit to another. Among those countries which do not include either same-day separations or transfers within the hospital, discharge rates in 2002 were highest in the United Kingdom and Germany, and lowest in Mexico, Portugal and Turkey, followed by Canada and the Netherlands.

In all those countries reporting same-day separations, discharge rates increased between 1995 and 2002, again with the exception of the United States where they remained relatively stable (Chart 2.27 and Table A.2.13). The increase in discharge rates in these countries can be attributed partly to a rising number of patients receiving treatments not requiring overnight stays, as well as shorter average length of stay for hospitalised patients (see section on "Average length of stay in hospitals").

In countries where same-day separations are excluded from discharge rates, there is no consistent pattern in trends over time in discharge rates. In about half of these countries, discharge rates increased at least slightly between 1995 and 2002.
The increase was particularly strong in some of the countries which started with relative low levels in 1995 (e.g., Korea and Turkey). It was also relatively strong in Germany, Greece, Norway and the United Kingdom. Discharge rates remained fairly stable between 1995 and 2002 in a number of countries (e.g., in Belgium, Finland, Japan, Spain), while they fell in Canada, the Netherlands, Portugal and Sweden. The reduction in discharge rates in this latter group of countries does not necessarily indicate a fall in hospital activity, since the decline in patients staying overnight may have been accompanied by a rise in same-day separations.

Looking at the breakdown of discharges by diagnostic category, the main conditions leading to hospital discharges on average in OECD countries in 2002 were circulatory (cardio-vascular) diseases, diseases of the digestive system, external causes (e.g., accidents, violence and poisoning), pregnancy and childbirth, and diseases of the respiratory system (Chart 2.28 and Table A.2.14). Discharge rates for circulatory diseases have increased since 1990 in several countries (Chart 2.29). In countries where discharges for circulatory diseases increased, this can be explained at least partly by the diffusion of new treatments for heart diseases, such as revascularisation procedures (see section on "Cardio-vascular procedures").

Elderly populations account for a disproportionately high percentage of overall hospital discharges in all countries. In the United States, 38\% of all hospital discharges in 2002 concerned people aged 65 years and over, up from $34 \%$ in 1990 (NCHS, 2004). Since the share of the population aged 65 and over was stable in the United States during that period, this rising share must be explained by other factors, including the diffusion of new treatments for specific diseases and greater access to hospital services for this population group. For example, hospital stays with at least one coronary bypass or angioplasty performed on persons 75 years or age and over increased from 7.3 to 12.4 per 1000 population between 1991-92 and 2001-02 in the United States (NCHS, 2004).

\section{Definition and deviations}

Discharge is the release of an inpatient from an acute care institution after admission for a period of hospitalisation. It normally includes deaths in hospital following inpatient care, but in most countries excludes same-day separations (with the exceptions of Austria, the Czech Republic, France, Hungary, New Zealand and the United States which include same-day separations). Transfers to other care units within the same institution are generally excluded, with the exception of Finland where these are included.

There are a few other limitations in the cross-country comparability of data on hospital discharges. Some countries do not cover the whole of the health service. For instance, data for Mexico are restricted to public hospitals only. Data for Portugal relate only to hospitals in Mainland (excluding the Islands of Azores and Madeira). Some countries include discharges related to pregnancy and childbirth while others do not. The source of the information can also differ, although most data come from hospital administrative records. 
Chart 2.26. Hospital discharges, per 1000 population, 2002

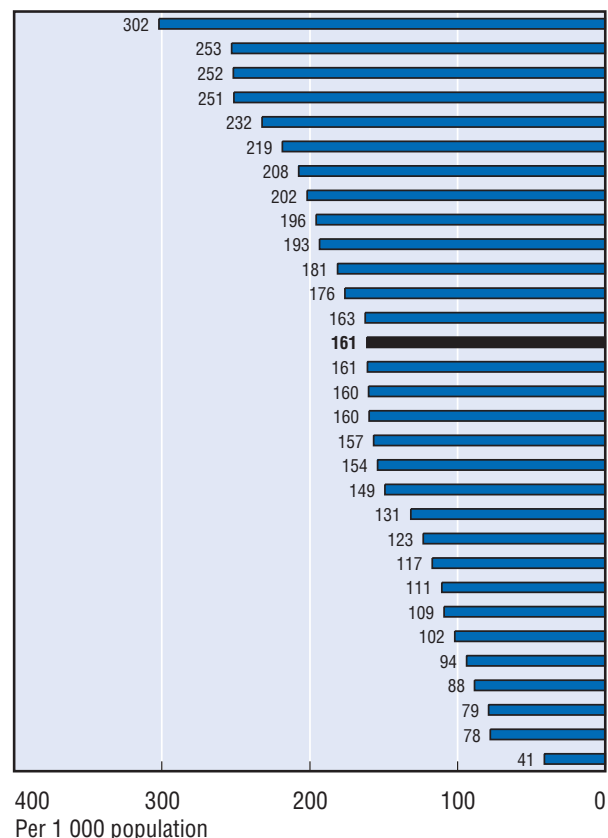

1. Includes same day separations.

2. Includes transfers from one hospital unit to another.

3. 2000 .

4. 1999.

Chart 2.28. Hospital discharges by diagnostic category, OECD average, 2002

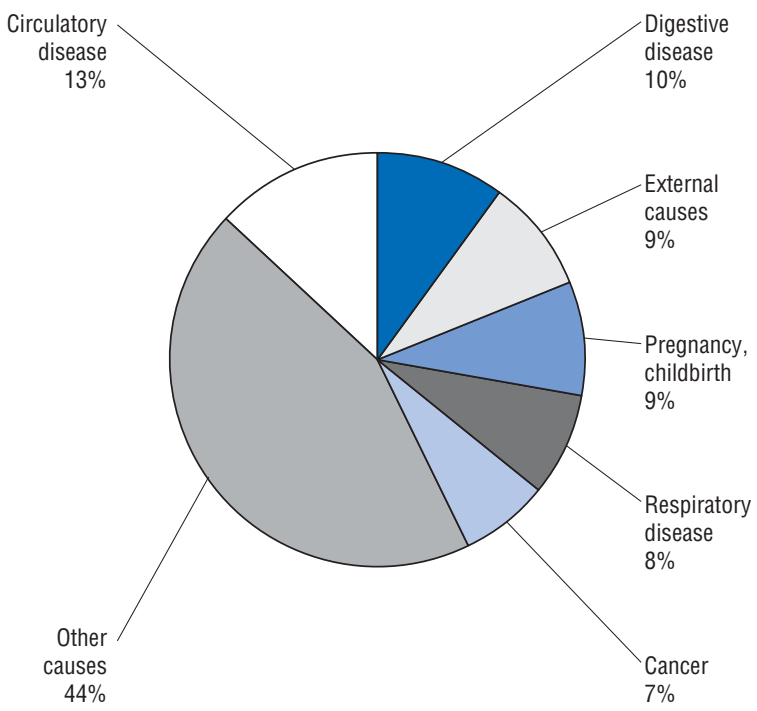

Source: OECD Health Data 2005

\section{Chart 2.27. Percentage change in hospital discharges, per 1000 population, 1995 to 2002}
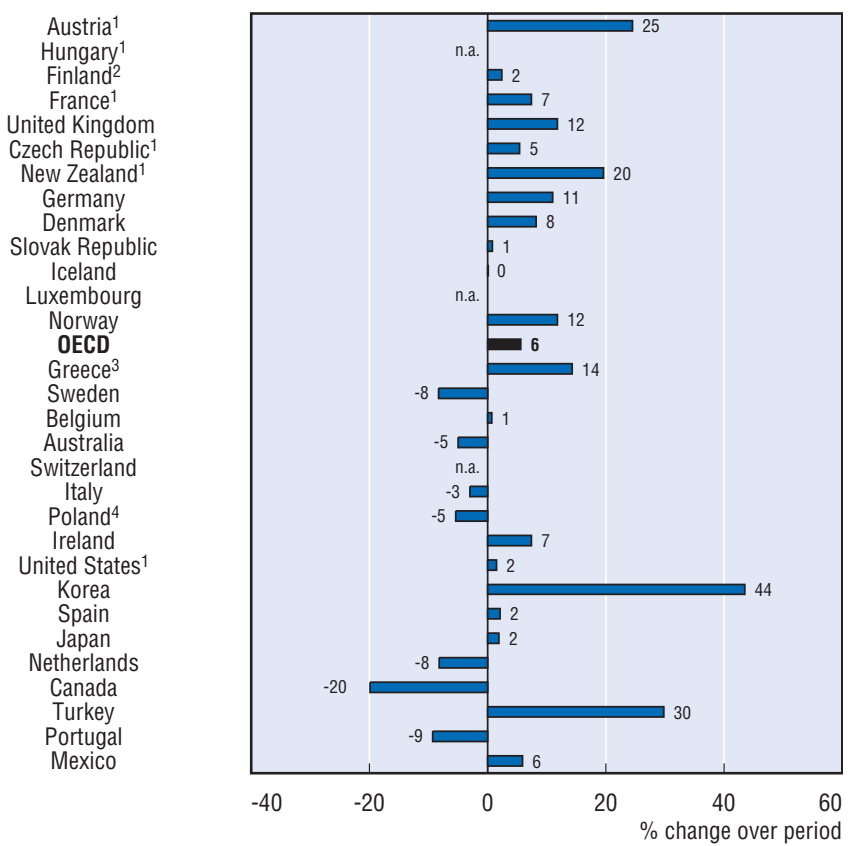

Chart 2.29. Hospital discharges for circulatory disease per 1000 population, 1990 and 2002

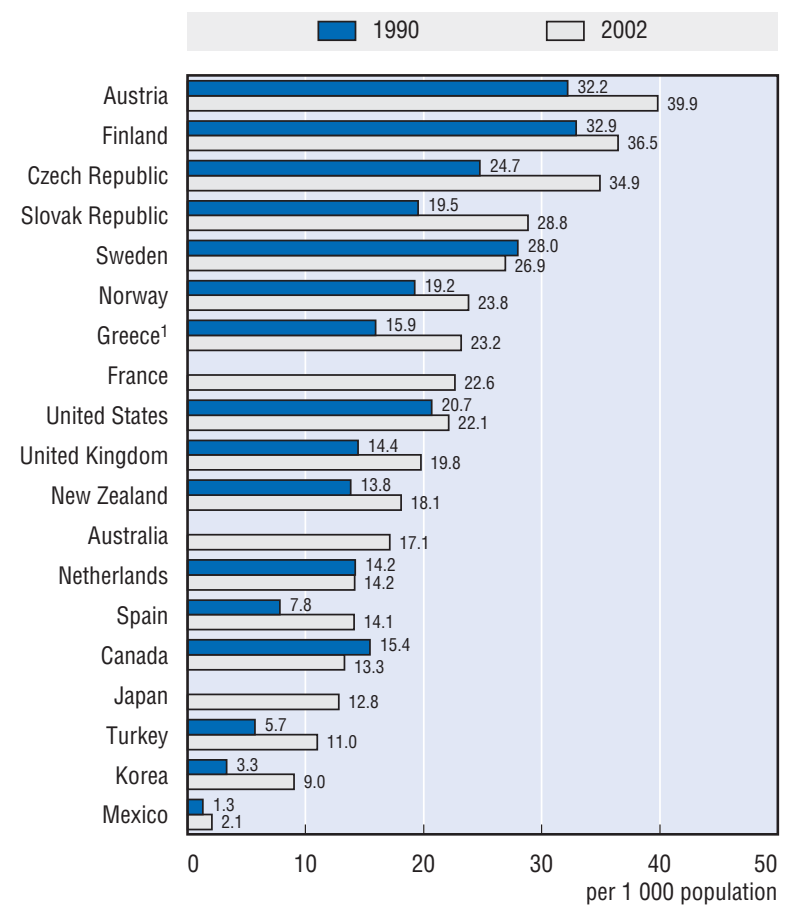

1. 2000 . 


\section{II.10. AVERAGE LENGTH OF STAY IN HOSPITALS}

The average length of stay in hospitals has often been treated as an indicator of efficiency. All other things being equal, a shorter stay will reduce the cost per episode. However, length of stay should only be used with caution as a measure of efficiency. Shorter stays tend to be more service intensive and more costly per day. Also, if the stay is too short, there may be adverse effect on health outcomes or for the comfort and recovery of the patient. If a falling length of stay leads to a rising readmission rate, costs per episode of illness may fall little or even rise.

Average length of stay (ALOS) for acute care has fallen between 1990 and 2002 in all countries for which consistent data over time is available (Chart 2.30), with the exception of Canada where it has remained stable between 1994 and 2002. The decline in ALOS can be attributed to several factors, including the use of less invasive surgical procedures and the expansion of early discharge programmes, enabling patients to return to their home to receive follow-up care. On average across OECD countries, ALOS for acute care decreased from 8.8 days in 1990 to 6.7 days in 2002. ALOS fell particularly quickly during that period in countries which started with relatively high levels in 1990, such as Germany, Switzerland, the Netherlands, the Czech Republic and Poland.

In 2002, there remained large variations across OECD countries in ALOS for acute care. It was relatively low (less than five days) in a number of Nordic countries (Denmark, Finland, Sweden) and in Mexico. It was relatively high (more than 9 days) in Korea, Germany and Switzerland. In Korea, ALOS for acute care in hospitals has been consistently higher than the OECD average, and it has not decreased much over time. The high ALOS in Korea can be explained partly by the lack of beds for long-term care; hence "acute care" beds may also be used for chronically ill patients (OECD, 2003b). The rapidly growing number of hospital beds in Korea during the 1990s might also have given hospitals incentives to keep patients longer (see indicator "Acute care hospital beds").

In Japan, ALOS in hospitals are much longer than in all other countries, reaching more than 20 days in 2002 and 2003 (data not shown in the chart). The comparability of estimates of ALOS for acute care in Japan is limited however, because it is based on a broader definition of "acute care" than the definition used in most other OECD countries (it includes, for instance, beds for rehabilitation and palliative care). This definitional difference does not however explain completely the much higher ALOS in hospitals in Japan compared with other countries. As for Korea, the abundant supply of hospital beds in Japan in the 1990s might have given hospitals an incentive to fill these beds by keeping patients for long periods (Jeong, 1994).

Focusing on ALOS for specific diseases or conditions can remove some of the heterogeneity arising from potentially different mix and severity of acute care conditions across countries. Chart 2.32 shows large variations across countries in ALOS following a normal delivery. It was the lowest in Mexico and Turkey, followed by the United States, the United Kingdom, Canada and New Zealand, where ALOS for a normal delivery is about two days. At the other end of the scale, it was the highest (5.5 days or more) in the Slovak Republic, Hungary, Switzerland, the Czech Republic and Austria. The average across a group of 22 OECD countries was 3.6 days in 2002, down from 4.8 days in 1990. In all countries, ALOS for normal delivery has become shorter over the past decade or so (Table A.2.16). The length of hospitalisation for maternity care has become an important issue in some countries because of concerns about premature discharge.

There has also been a gradual decline in lengths of stay following acute myocardial infarction (heart attack) over the past decades for all countries reporting consistent trend data. In 2002, ALOS following AMI was lowest in the United States with 5.6 days, followed by several Nordic countries (Denmark, Sweden, Norway and Iceland) and Australia, with ALOS of less than seven days. On the other hand, ALOS following AMI stood at over 10 days in Finland, Austria, Ireland and Germany (Chart 2.31). Care is required however in making such cross-country comparisons since, in countries like Finland, ALOS may include patients originally admitted for AMI but who are no longer receiving acute care, and might therefore be considered longterm care patients (Moïse et al., 2003).

ALOS has also continued to decline in nearly all countries for other important conditions leading to hospitalisation, such as cerebro-vascular diseases and pneumonia and influenza (Table A.2.16).

\section{Definition and deviations}

Average length of stay (ALOS) for acute care refers to the average number of days (with an overnight stay) that patients spend in an acute-care inpatient institution. It is generally measured by dividing the total number of days stayed for all patients in acute-care inpatient institutions during a year by the number of admissions or discharges.

The proposed definition of "acute care" includes all the functions of care covered under "curative care" as defined in the SHA Manual (OECD, 2000a). However, there are variations across countries in the functions of care included/ excluded in "acute care" which limits data comparability (e.g., whether or not beds for rehabilitation, palliative care and long-term care are included). Cross-country comparisons should therefore be interpreted with caution. 


\section{Chart 2.30. Average length of stay for acute care, 1990 and 2002}

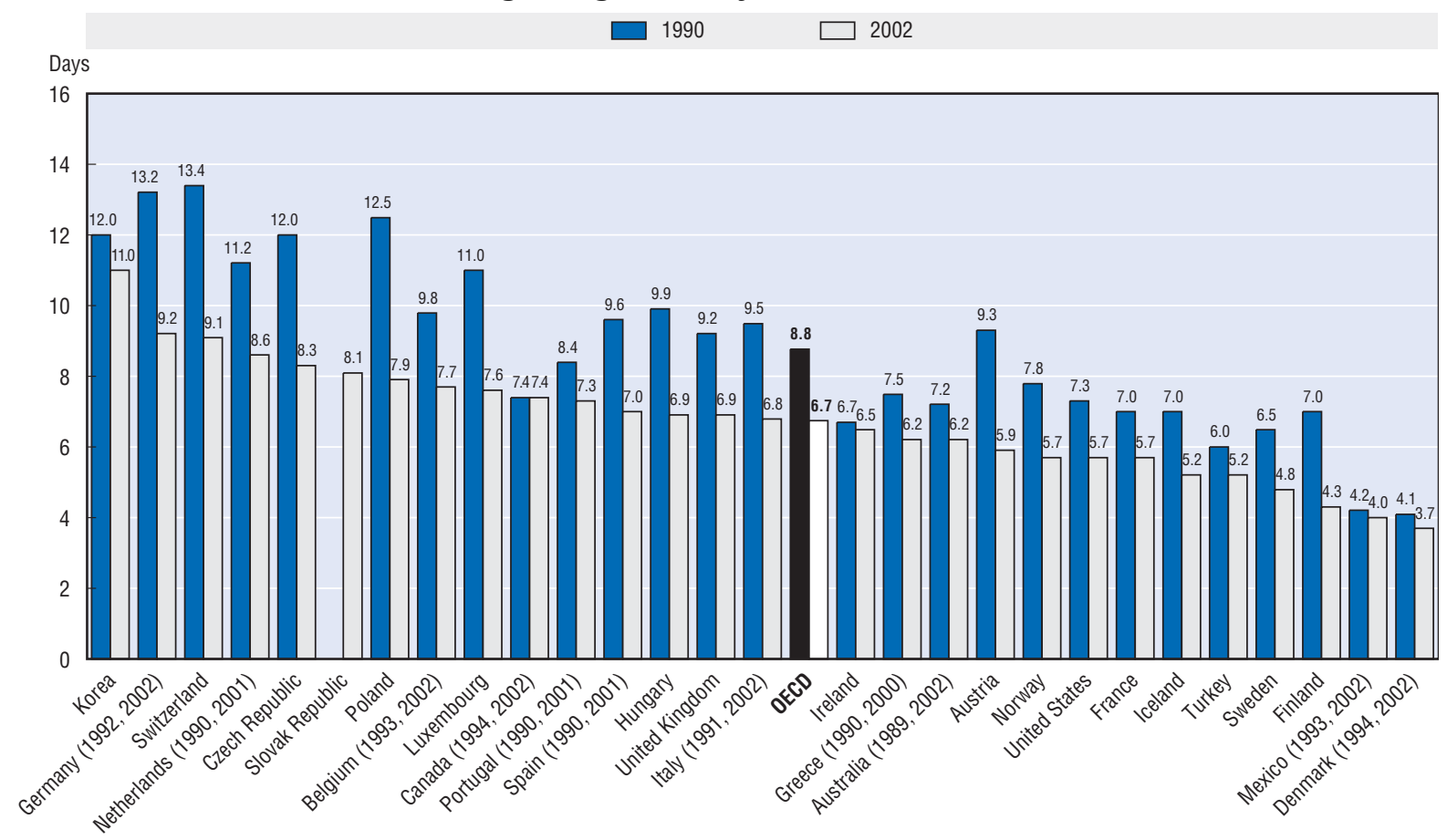

\section{Chart 2.31. Average length of stay following acute myocardial infarction (AMI), 2002}

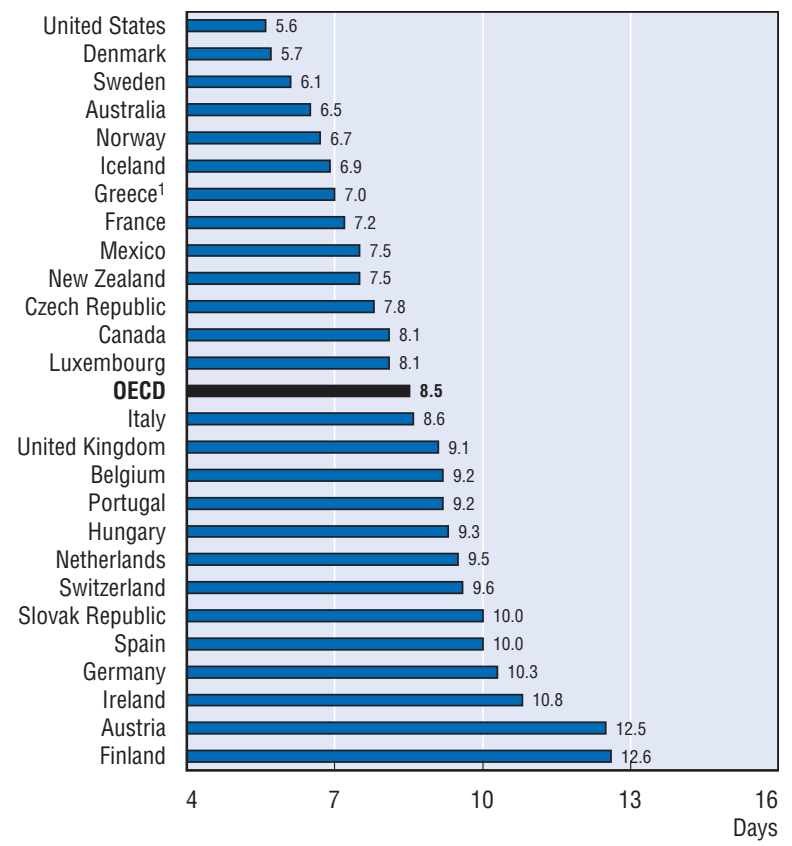

\section{Chart 2.32. Average length of stay for normal delivery, 2002}

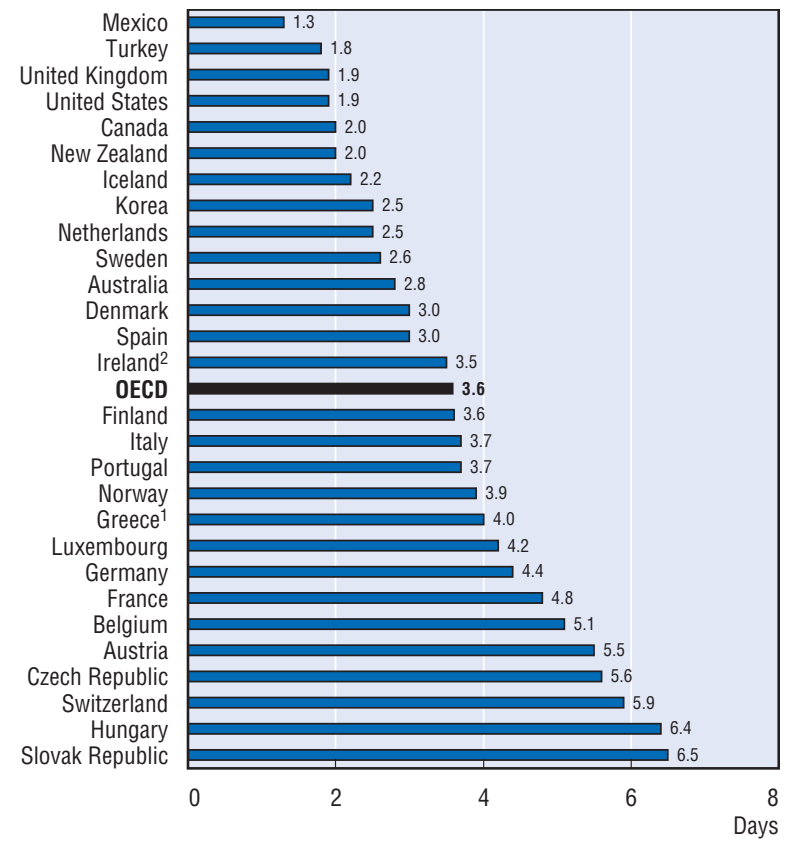

1. 2000 .

2. 2001.

Source: OECD Health Data 2005. 


\section{II.11. CARDIO-VASCULAR PROCEDURES}

Heart diseases are a leading cause of hospitalisation and death in OECD countries (see indicator "Cardio-vascular diseases"). Coronary artery bypass graft (CABG) and coronary angioplasty (PTCA, for percutaneous transluminal coronary angioplasty) are two revascularisation procedures that have revolutionized the treatment of heart diseases in recent decades.

There is considerable variation across countries in the use of both coronary bypasses and coronary angioplasties (Charts 2.33 and 2.34). The United States is the country which makes the heaviest use of these two procedures, with 161 coronary bypasses and 426 coronary angioplasties per 100000 population performed in 2003. Following the United States is Belgium, which also reports high utilisation rates of both types of revascularisation procedures, followed by Hungary and Canada for CABG, and by Germany and Iceland for PTCA. At the other extreme, there were only two coronary bypasses and one coronary angioplasty performed for every 100000 population in Mexico in 2003. Spain and Portugal also report relatively low use of these two procedures (although the data for Spain relate only to public hospitals and do not include activities in private hospitals).

The utilisation of coronary angioplasties has increased rapidly in the past ten years in most OECD countries (Table A.2.17). The advent of the intracoronary stent, a wire mesh that greatly reduces the chances of arterial obstruction following angioplasty, has been the major factor in coronary angioplasty replacing coronary bypass as the most widely used means of revascularisation (Moïse, 2003). Coronary angioplasty began to replace coronary bypass around the mid-1990s, around the same time as the first published trials on the efficacy of stents began to appear. As a result, in some countries (e.g., Australia, Canada, Germany and the United States), the utilisation rate of coronary bypass has in fact decreased in recent years.
As shown in Chart 2.35, there is a great discrepancy across countries in the rate of use of these two revascularisation procedures (combining both coronary bypasses and angioplasties) and the incidence of heart disease (as measured by agestandardised death rates from ischaemic heart disease). Such a discrepancy suggests that some countries could probably reduce mortality rates from heart disease by increasing their intervention rates, while others are probably carrying out interventions which have little benefit in terms of reducing mortality rates.

Despite the proven efficacy in clinical trials of revascularisation for treating ischaemic heart disease (IHD), it is unclear to what extent the increased use of revascularisation procedures has contributed to lowering IHD mortality rates. The WHO-MONICA project found that improvements in acute coronary care were one of the main factors behind declining IHD mortality (Tunstall-Pedoe et al., 2000). But, at an aggregate level, IHD mortality rates are lower in countries like Australia and Canada than in the United States, despite the United States having the highest utilisation rate of revascularisation procedures of any OECD country, almost three times greater than Australia and Canada. Utilisation rates for revascularisations have also been growing faster in the United States than in Australia and Canada, without larger reductions in IHD mortality rates (Moïse, 2003; Moïse et al., 2003).

A recent study found that the use of betablockers (a relatively cheap drug) seems to be the most important factor in explaining regional differences in one-year mortality rates following heart attacks in Finland. Differences in the use of coronary bypasses, coronary angioplasties, total costs for cardiac care or the number of cardiologists, did not seem to be directly related to mortality outcomes (Häkkinen et al., 2004). However, as noted by Cutler and Huckman (2003), the benefit of PTCA over other treatments may not appear as a significant decrease in mortality, but rather as an improvement in the quality of life of patients.

\section{Definition and deviations}

A coronary bypass (CABG) is the grafting of veins and/or arteries to bypass an obstructed coronary artery. It may involve bypassing the obstruction of only one coronary artery, but multiple coronary artery bypasses are most common. Coronary angioplasty (percutaneous transluminal coronary angioplasty or PTCA) involves the threading of a catheter with a balloon attached to the tip through the arterial system, usually started in the femoral artery in the leg, into the diseased coronary artery. The balloon is inflated to distend the coronary artery at the point of obstruction. A support, called a stent, is frequently put in place to make sure that the artery remains open.

The data relate to the number of inpatient procedures, normally counting all procedures per inpatient stay (although some countries might report only the main procedure or the number of patients receiving one or more procedures). The data do not include coronary angioplasties performed on an ambulatory basis (a growing share of overall activity rates in many countries). 
Chart 2.33. Coronary bypass procedures, per 100000 population, 2003

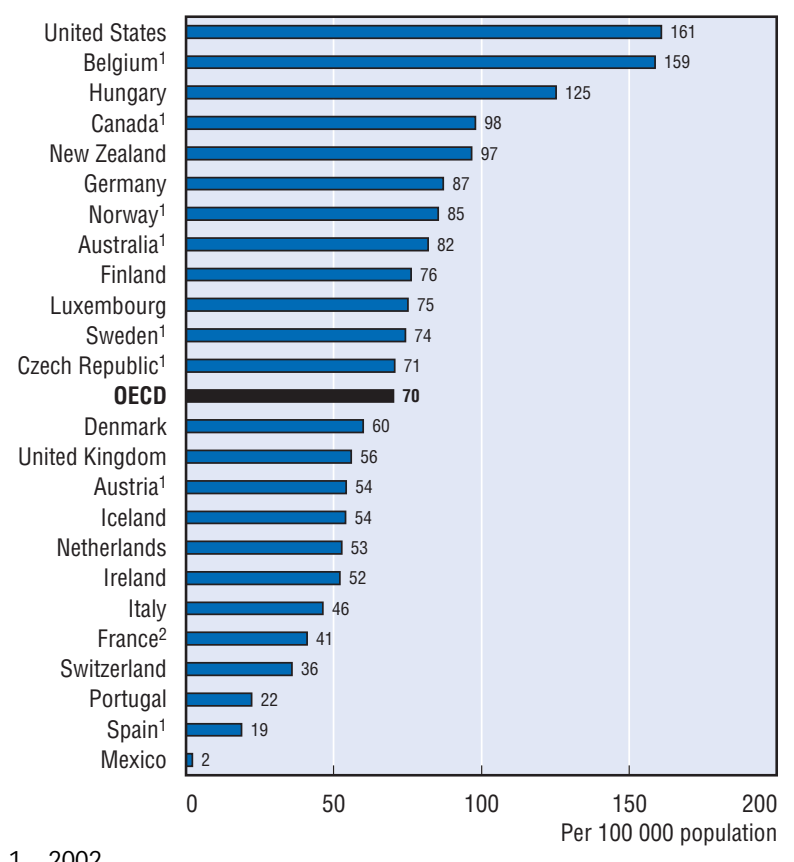

Chart 2.34. Coronary angioplasty procedures, per 100000 population, 2003

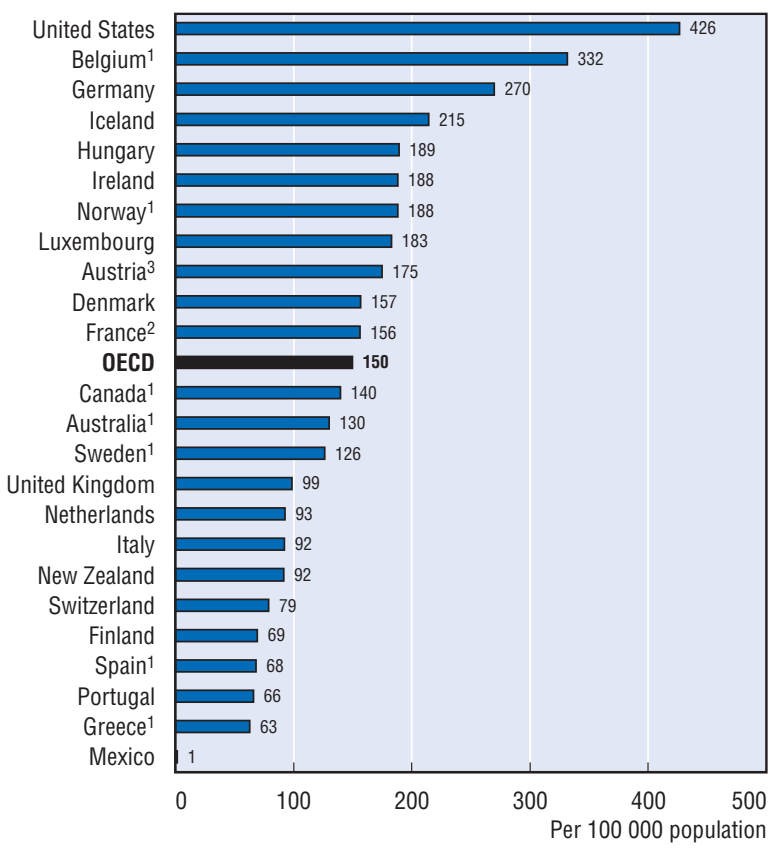

3. 2000

\section{Chart 2.35. Coronary re-vascularisation procedures ${ }^{1}$ and ischaemic heart disease mortality,} 2002

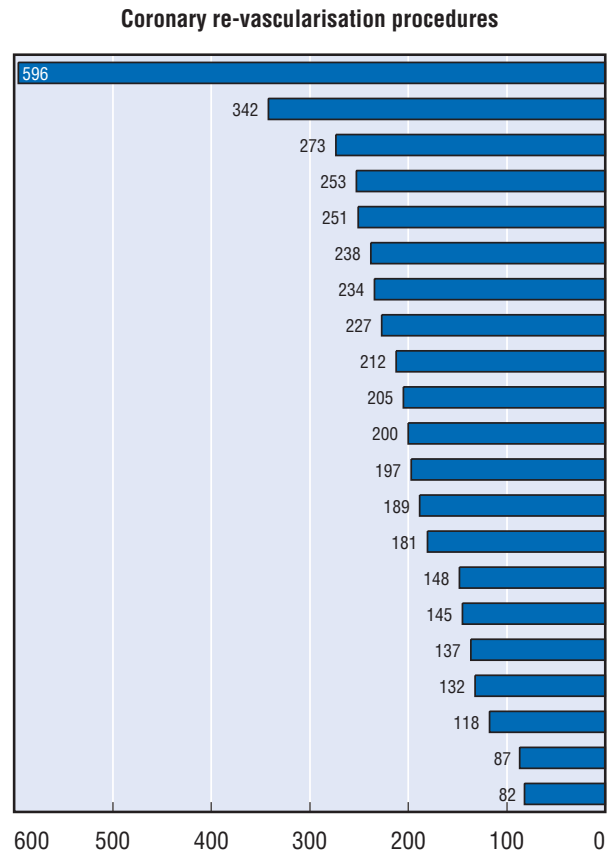

Per 100000 population

1. Coronary artery bypass grafts (CABG) and coronary angioplasty (PTCA)

2. 2001.

3. 2000.

Source: OECD Health Data 2005.

United States ${ }^{2}$
Germany
Norway
Iceland
Hungary
Canada ${ }^{2}$
Austria
Luxembourg
Australia
Denmark
Sweden
Srance
${ }^{2}$
New Zealand
Ireland

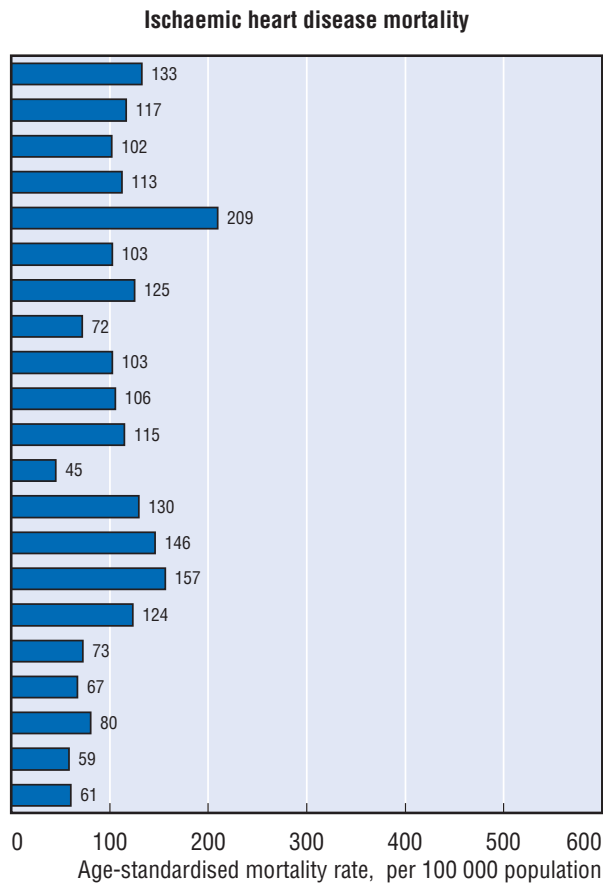

StatLink: http://dx.doi.org/10.1787/776428416831 
Caesarean rates (as a percentage of all births) have grown in all OECD countries over the past decade or so. This has raised questions of whether the costs of some of these caesareans might more than exceed the benefits to the mother or the infant, particularly if the intervention was not based on medical indication. There are a number of wellknown risk factors for caesarean sections, including the age of the mother, multiple births, having had a previous caesarean section and a gestation period lasting beyond the normal term. While some of these risk factors might be increasing over time, the rise in caesarean rates also seems to reflect changes in the practice of health professionals and changes in patients' preferences.

In 2002, the rate of caesarean sections as a percentage of all live births varied a lot in OECD countries (Chart 2.36). It ranged from a low of $14 \%-18 \%$ in the Netherlands, the Czech and Slovak Republics, Nordic Countries and France, to a high of over $33 \%$ of all births in Korea, Italy and Mexico. Caesarean section rates are also much higher-thanaverage in Portugal, Australia and the United States. In Korea, the high rate of caesarean sections has been explained at least partly by higher fees received for caesarean sections compared to normal deliveries (OECD, 2003b). In Italy, anecdotal evidence suggests that the high rates of caesarean sections might reflect changes in patients' choices (based partly on a false belief that caesareans are generally safer than normal deliveries) together with changes in the practice of doctors favouring caesarean sections (because they can be performed more quickly and can be planned in advance). In Mexico, there is also a widespread perception that caesarean sections are being performed excessively, often without any medical justification. The rate of caesarean sections in Mexico is higher in the private sector than in the public sector, which might reflect greater financial incentives to practice programmed caesareans in the private sector (Secretaria de Salud, 2003).

Caesarean section rates have increased over time in all OECD countries, and in some cases, the rise has been fairly rapid (Chart 2.37). On average across a common group of OECD countries, caesarean rates accounted for $13 \%$ of all births in 1990; by 2002, this share had increased to $21 \%$. The growth rate since 1990 has been particularly rapid in countries such as Italy, Australia, New Zealand, Ireland and the United Kingdom. On the other hand, in Nordic countries, the increase has been much slower, although there are signs that caesarean rates have also increased quite rapidly in Denmark, Sweden and Norway in recent years.

In the United States, a recent study by Declercq and colleagues (2005) analysed the rise in caesarean sections between 1996-2001, controlling for the most important risk factors, in order to focus on a category of "no indicated risk" caesareans (defined as mothers having a single baby at full term, who did not have any caesarean before and who were not reported to have any medical risk factors and for whom no complications of labour or delivery were listed on the birth certificate). The study found that the proportion of such "no indicated risk" primary caesareans increased to $5.5 \%$ of births in 2001, up from 3.7\% in 1996.

Although there continues to be some debate regarding the relative benefits of normal delivery compared with caesarean births when the latter may be unnecessary, the bulk of the evidence is that more health problems for the mother and infant tend to be associated with caesareans (Bewley and Cockburn, 2002). Unnecessary caesareans mean therefore that costly interventions are performed with higher risks.

\section{Definition and deviations}

Caesarean section rate is the number of caesareans per 100 live births. In Portugal, the denominator is only the number of live births which took place in National Health Service Hospitals in Mainland (resulting in an overestimation of caesarean rates). 


\section{Chart 2.36. Caesarean sections per 100 live births, 2002}

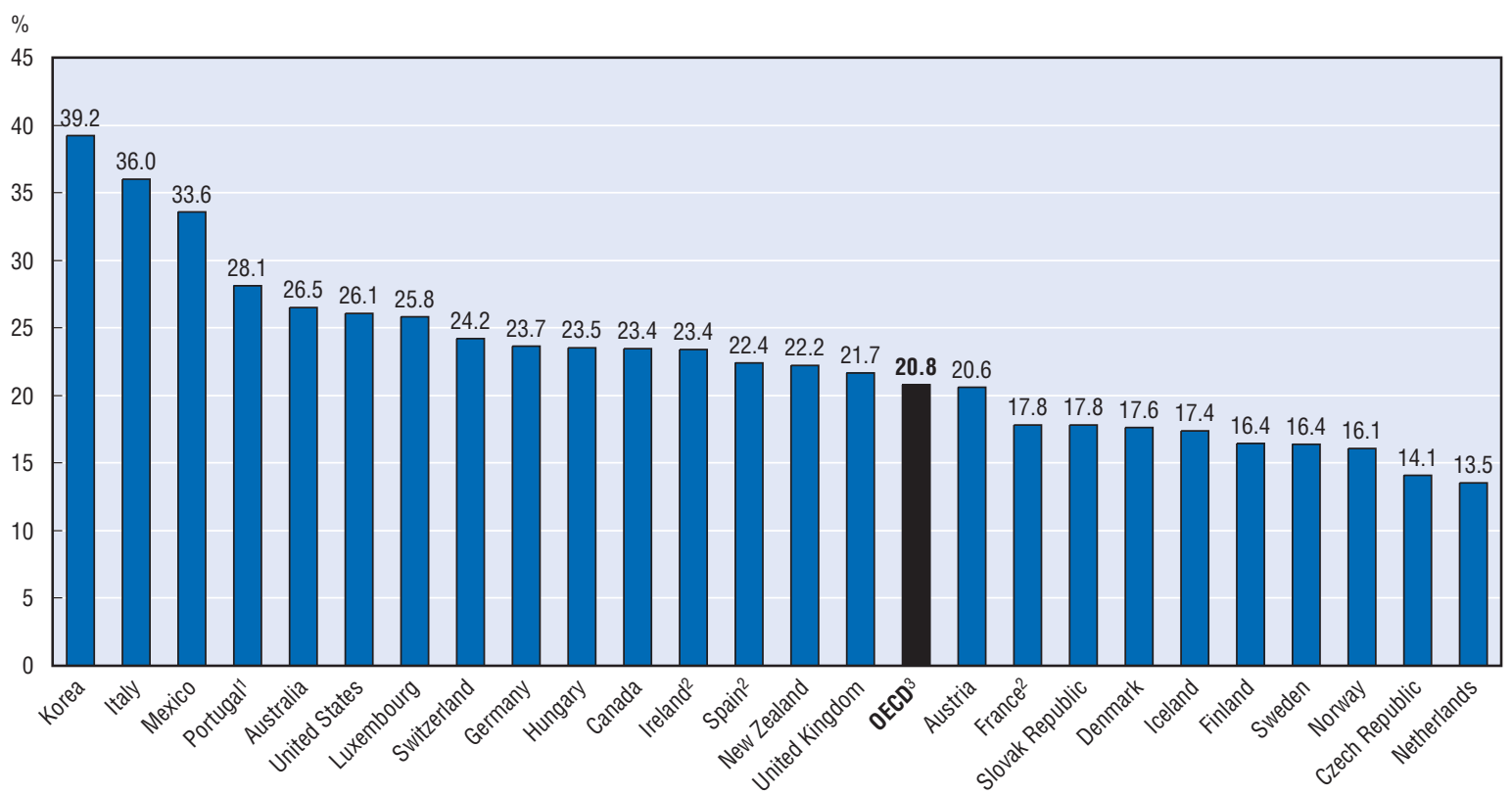

1. In Portugal, births only include those taking place in public hospitals (in Mainland), therefore resulting in an over-estimation of caesarean rates.

2. 2001.

3. The OECD average is the consistent average for a common group of countries (Table A.2.18).

Chart 2.37. Rise in caesarean sections per 100 births, 1990 to 2002

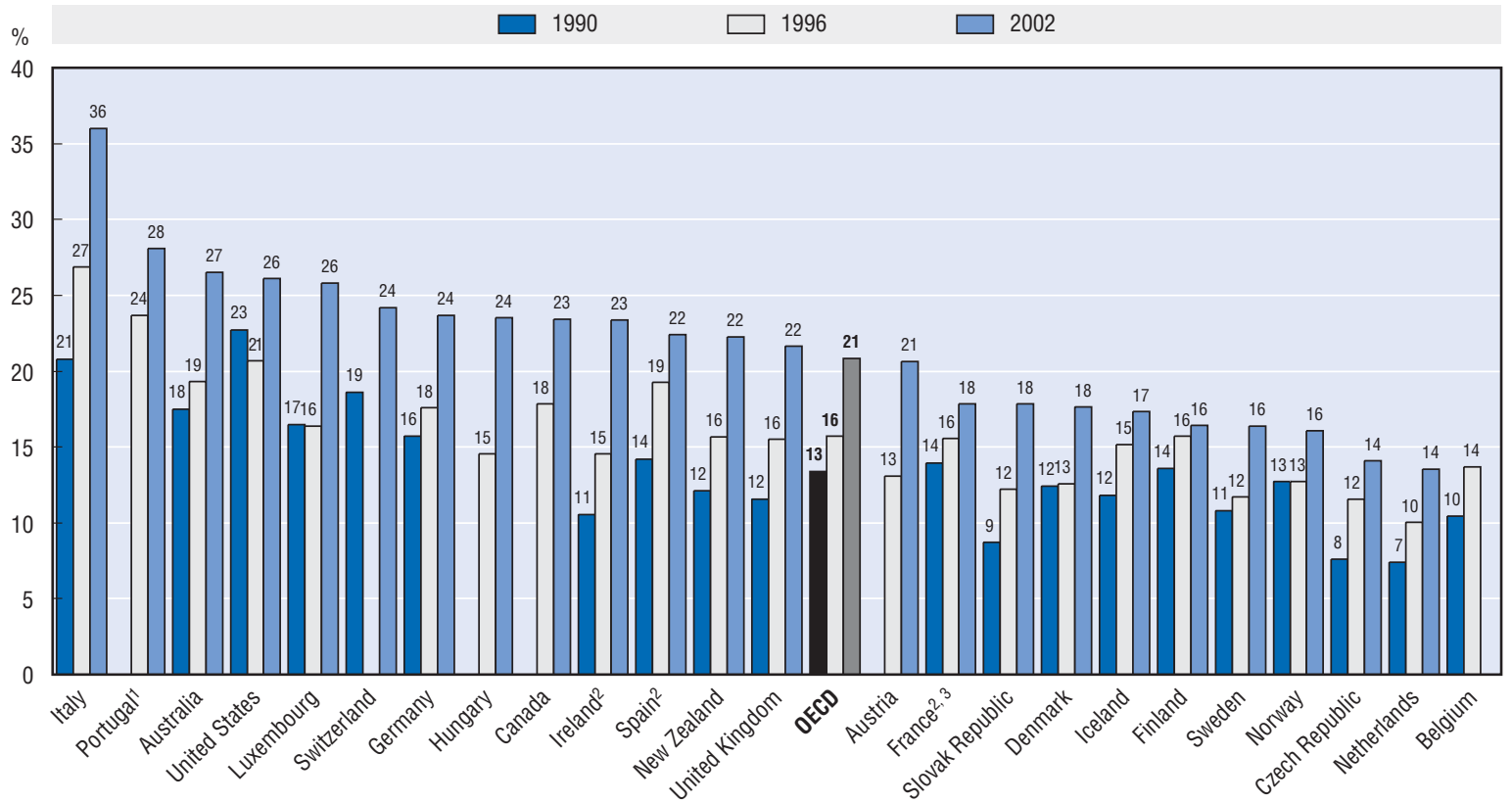

1. In Portugal, births only include those taking place in public hospitals (in Mainland), therefore resulting in an over-estimation of caesarean rates.

2. 2001.

3. 1997.

Source: OECD Health Data 2005. 


\section{II.13. CATARACT SURGERIES, AMBULATORY AND INPATIENT}

In the past twenty years, there has been a steady growth in the number of surgical procedures carried out on an ambulatory basis (also called day cases) in OECD countries. This rise has been made possible by advances in medical technologies, in particular the diffusion of less invasive surgical interventions and better anaesthetics. These innovations have not only brought benefits to patients, but may also help reduce the unit cost of such interventions (by shortening the length of stay). However, the development of ambulatory surgeries might also lead to an expansion in surgical activities, with the impact on overall health care costs depending on the relative magnitude of changes in unit cost and volume of procedures.

Cataract surgeries have now become the most frequent surgical procedure in several OECD countries (e.g., Canada, Belgium and France). They provide a good example of a high volume surgery which is now carried out predominantly on an ambulatory basis in many OECD countries.

In 2003 (or for the latest year available), there were huge variations in the number of cataract surgeries per capita among those countries which report complete data covering both inpatient and ambulatory procedures (Chart 2.38). The rate ranges from a low of 48 cataract surgeries per 100000 population in Mexico, to a high of over 1300 per 100000 population in Canada and Belgium. Some of the cross-country variations may be due however to different recording practices of cataract surgeries (see the box below on "Definition and deviations"). Other factors that might explain variations across countries include "demand" factors (e.g., an older population structure) and "supply" factors (e.g., more capacity to perform the intervention on an ambulatory or inpatient basis).

Looking at trends over time, the growing volume of cataract surgeries in recent years has been driven in most countries mainly by an increase in ambulatory surgeries. In many countries including Denmark, Finland, France, Ireland, Italy, the Netherlands and the United Kingdom, the growth in ambulatory surgeries over the past five years or so has exceeded the reduction in cataract surgeries requiring an overnight stay in hospital. This suggests that the development of ambulatory cataract surgeries in these countries has had both a "substitution" effect (replacing inpatient procedures) and an "expansion" effect (increasing the total volume).

In most countries, cataract surgeries performed on an ambulatory basis now represent the bulk of all cataract surgeries. It accounts for $90 \%$ or more of all cataract surgeries in Canada (99\%), Finland, Denmark, the Netherlands, the United Kingdom, New Zealand and Australia (Chart 2.39). On the other hand, the share of cataract surgeries carried out on an ambulatory basis remains lower in Luxembourg, France, Ireland and Portugal. In this latter group of countries, the proportion of cataract surgeries involving an hospital stay still accounts for over 50\% of all surgeries, suggesting the possibility of further efficiency gains. In France, the length of stay in hospitals following cataract surgery in 1999 was often very short (one or two days), indicating an important potential for development of ambulatory surgery. It has been estimated that an ambulatory surgery rate of between $77 \%$ and $90 \%$ might have been achieved if patients without medical counterindication had been treated on an ambulatory basis in France in 1999 (Sourty Le Gellec, 2001).

\section{Definition and deviations}

Cataract surgeries consist of removing the lens of the eye (because of the presence of cataracts which are partially or completely clouding the lens) and replacing it with an artificial lens.

Ambulatory (or day case) surgery is defined as those patients who are given surgical treatment (usually elective, non-emergency) which are carried out in a dedicated surgical unit (in a hospital or a clinic) and which lead to discharge on the day of the operation. Equivalent terms used in some countries include same-day (or day) surgery and outpatient surgery. Inpatient surgery refers to those patients who are given surgical treatment and who stay over at least one night in an institution.

Current health information systems in several countries remain incomplete in their coverage of day surgeries, especially those carried out in ambulatory settings outside hospitals (e.g., in private clinics). Also, there may be variations across countries in registration practices of cataract surgeries (for instance, whether they are counted as one intervention only involving at least two steps - removal or the lens and replacement with an artificial lens - or as two separate interventions). Therefore, caution is required in making cross-country comparisons of available data. 


\section{Chart 2.38. Number of cataract surgeries, inpatient and day cases, per 100000 population,} 2003 or latest year

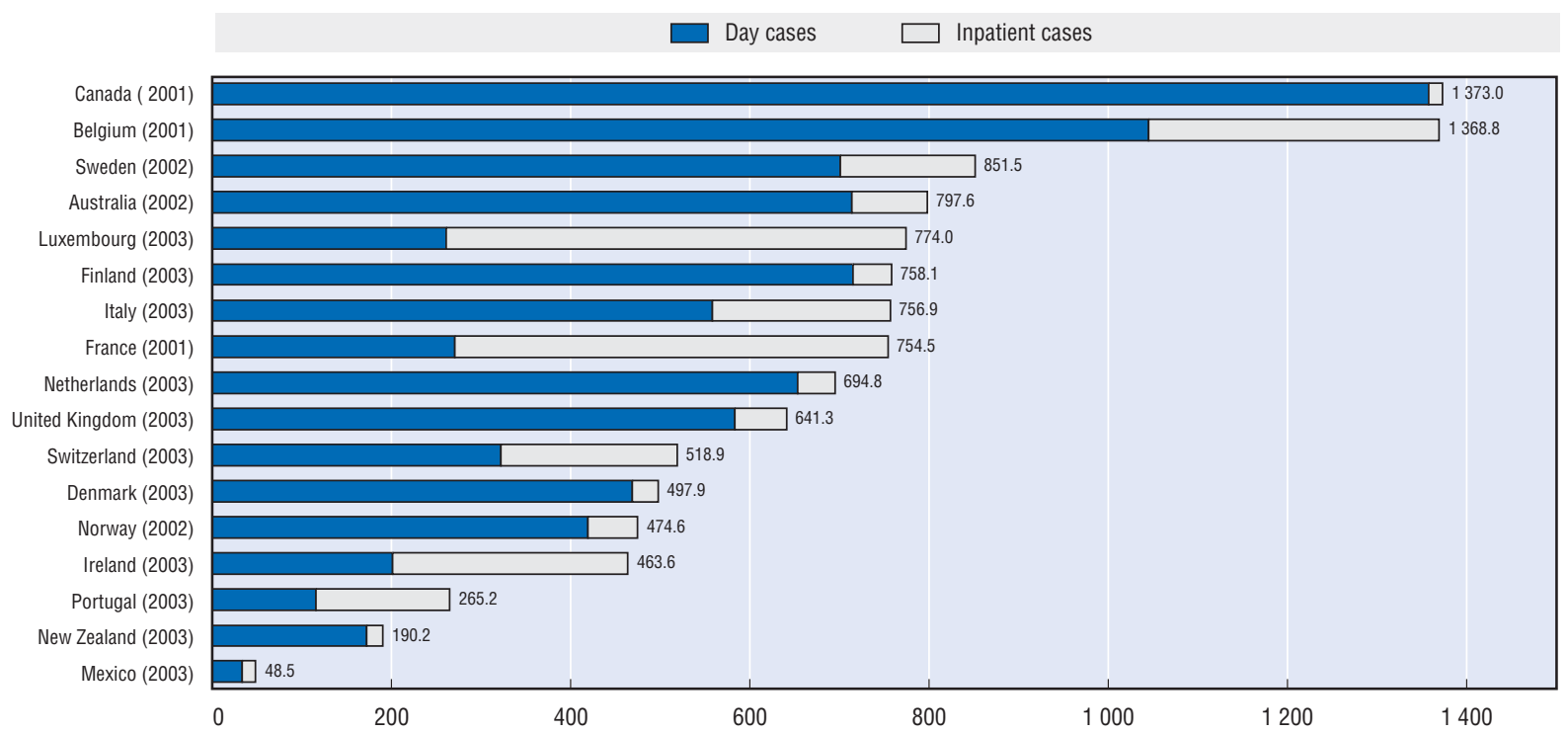

Note: Cross-country variations should be interpreted with caution due to differences in how countries register cataract surgeries and incomplete coverage of health care facilities.

\section{Chart 2.39. Share of cataract surgeries carried out as day cases, 1997 and 2003}

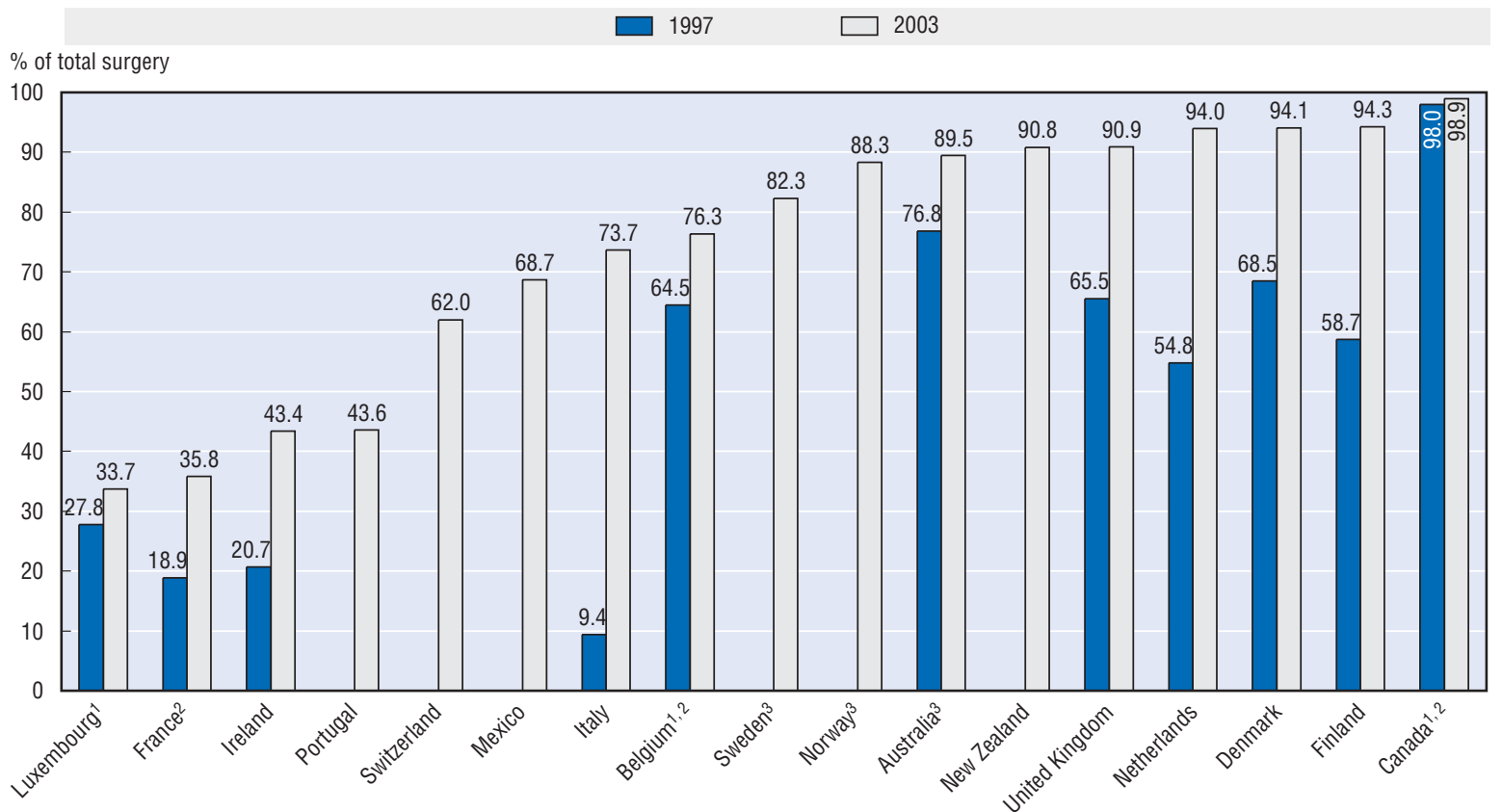

1. 1999.

2. 2001.

3. 2002.

Source: OECD Health Data 2005. 



\section{Health Expenditure and Financing}

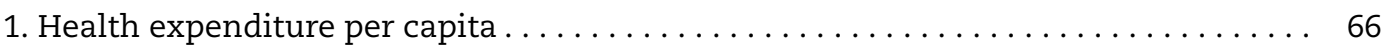

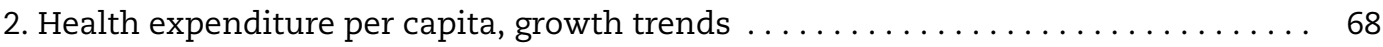

3. Health expenditure in relation to gross domestic product (GDP) $\ldots \ldots \ldots \ldots \ldots \ldots 70$

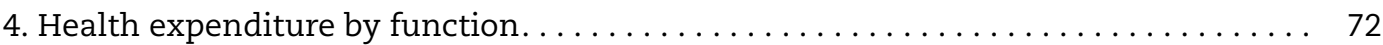

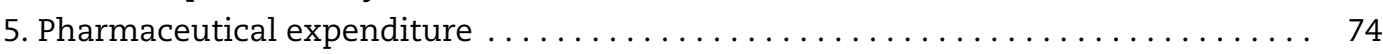

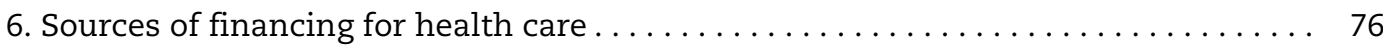


The level of health spending varies widely across OECD countries, reflecting different market and social factors as well as the different financing and organisational structures of the health system in each country. The United States spends far more per capita than other OECD countries 5635 USD PPP (purchasing power parities see "Definition and deviations" below) in 2003 (Chart 3.1 and Table A.3.1). This is almost 50\% more than the next highest-spending countries, Norway and Switzerland, and well over double the (unweighted) average across all OECD countries. At the other end of the scale, the Slovak Republic, Poland, Mexico and Turkey spend less than 1000 USD PPP on health, which is well below half the OECD average.

Concerning public expenditure on health, Luxembourg and Norway reported the highest per capita spending in 2003, with over 3000 USD PPP, which is around double the unweighted OECD average. Public expenditure on health per capita was lowest in Mexico, followed by Turkey, Poland and Korea (Table A.3.2). Although the health care system of the United States is primarily privately funded (see indicator "Sources of financing for health care"), public expenditure per capita, at 2503 USD PPP, was higher than both the OECD and EU-15 averages at 1714 USD PPP and 1906 USD PPP respectively.
Focusing on the period 1997 to 2003, which was characterised by significant growth in the OECD average, data show that differences between countries in terms of per capita spending decreased slightly. This was accompanied by a number of changes in the countries' position relative to the OECD average in both total and public health spending per capita. Chart 3.2 shows the level of total health expenditure in both 1997 and 2003, measured against the respective OECD average for each year. A ranking of the change in the relative level between 1997 and 2003 is then shown in Chart 3.3. (For further discussion on differences over time in health spending, see indicator "Health expenditure per capita, growth trends".)

Ireland was one of the countries reporting a rapid increase in health spending between 1997 and 2003. Total expenditure on health per capita increased by $63 \%$ in real terms, resulting in Ireland moving from a country spending almost $15 \%$ less than the OECD average for total health expenditure in 1997 to one which was spending above the average in 2003. Significant increases in the relative spending levels have also been reported in Norway and Hungary. On the other hand, a number of European countries, such as Germany, Switzerland and Italy, saw their positions relative to the OECD average fall in recent years. For instance, Germany moved from the third highest spender on health in 1997 to seventh place by 2003.

\section{Definition and deviations}

Total expenditure on health measures the final consumption of health care goods and services (i.e. current health expenditure) plus capital investment in health care infrastructure. This includes spending by both public and private sources (including households) on medical services and goods, public health and prevention programmes and administration. Excluded are health-related expenditure such as training, research and environmental health. The two major components of total current health expenditure are: expenditure on personal health care and expenditure on collective services. (For more detail on components of total health expenditure, see Annex B.)

To compare the overall level of consumption of health goods and services across countries at a given point in time, health expenditure per capita is converted to a common currency (US Dollar) and adjusted to take account of the different purchasing power of the national currencies in each country. Economy-wide (GDP) PPPs are used as the most available and reliable conversion rates. For further information about the definition of health expenditure and comparisons of health expenditure across countries, see Annex B. 


\section{Chart 3.1. Health expenditure, per capita, public and private expenditure, 2003}

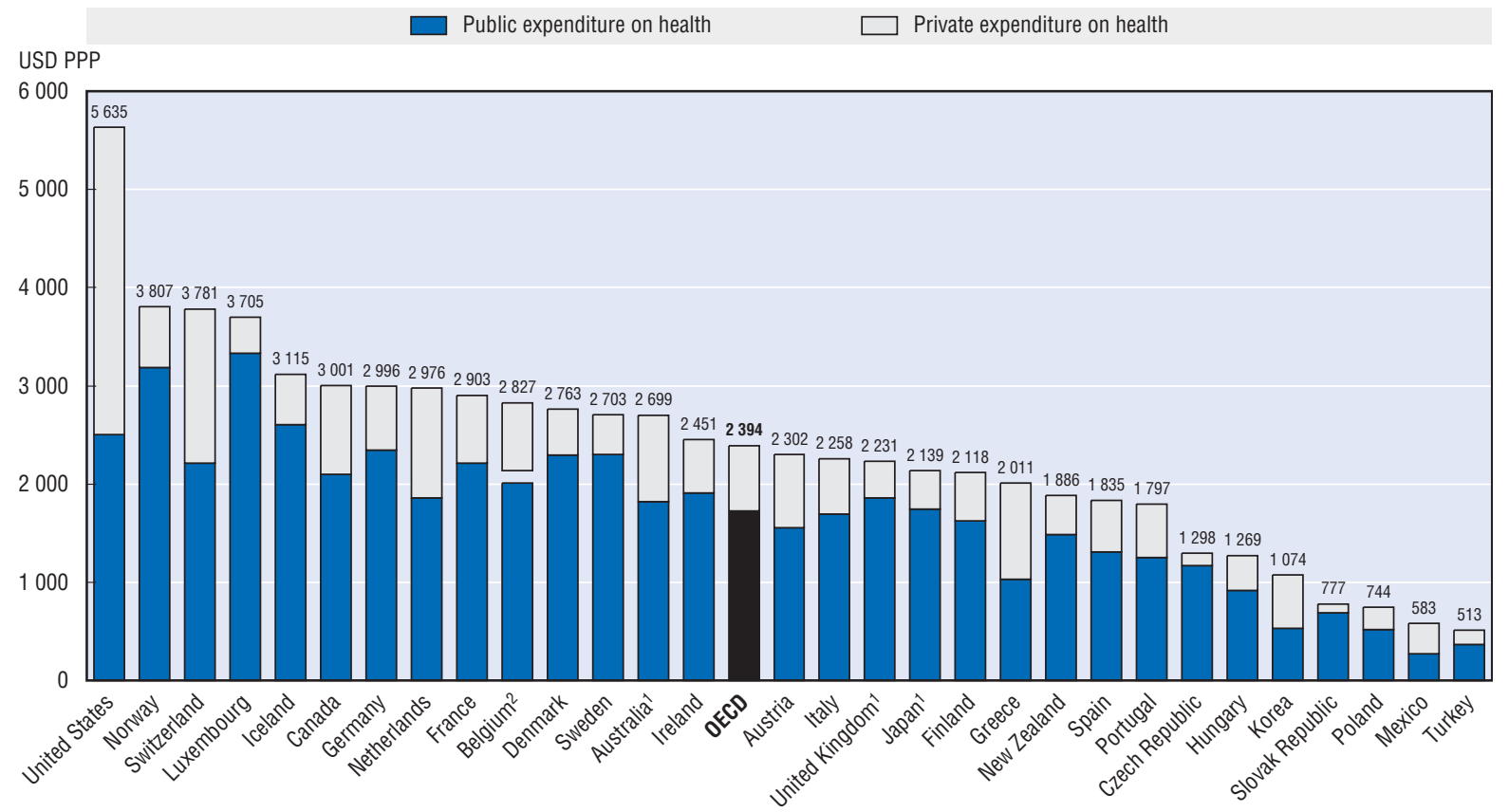

1. 2002.

2. For Belgium, current public and private expenditure on health are presented, although the figure is total expenditure on health i.e. including investment.

\section{Chart 3.2. Health expenditure, per capita,} 1997 and 2003

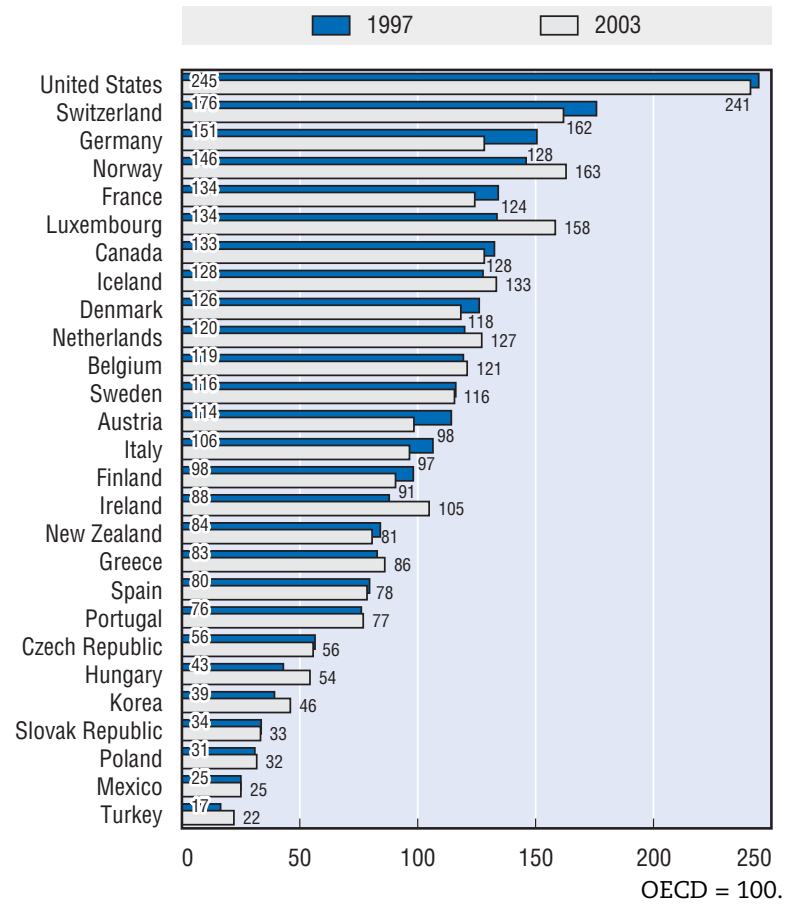

Chart 3.3. Health expenditure, change relative to OECD average, 1997 to 2003

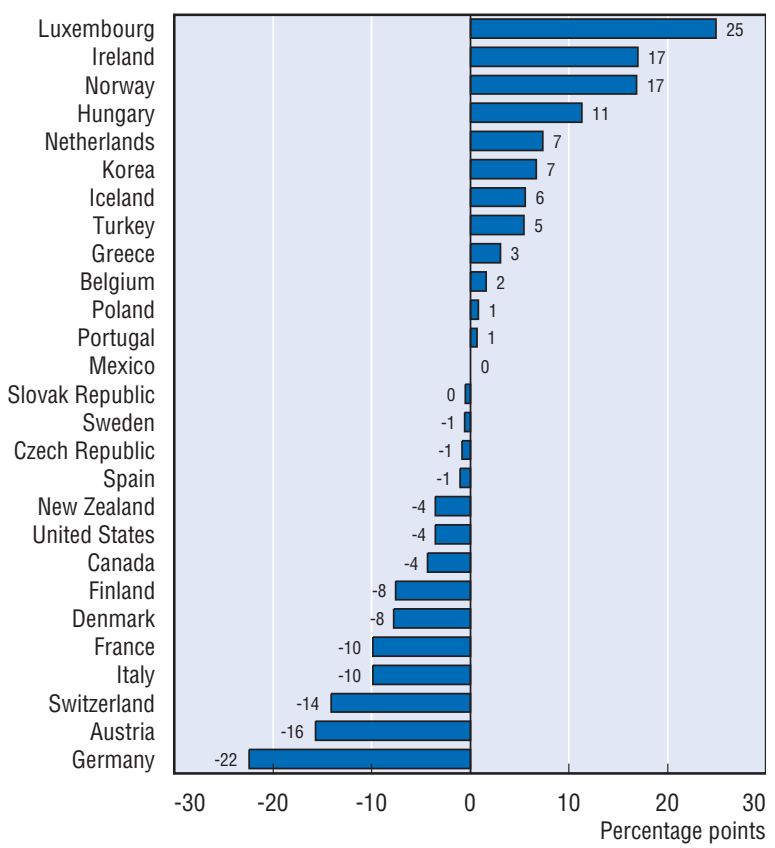

StatLink: http://dx.doi.org/10.1787/072446253457 
From 1980 to 2003, health expenditure grew in real terms by around 3\% per year, on average, across OECD countries, although with strikingly different growth rates when broken down over shorter time periods (Chart 3.4, Table A.3.3). Over the most recent period (1997-2003), health expenditure increased, on a yearly average, by $4.3 \%$, two times the overall economic growth rate. This is a large increase compared to the previous period (1992-1997), when the growth rate of health expenditure was only slightly above that of the overall economic growth (see indicator "Health expenditure in relation to GDP"). While growth rates in the European Union and the United States in the 1980s differed considerably, the last decade has seen a rather more similar growth pattern (Chart 3.5).

Behind the OECD averages, considerable variations across countries can be observed in health spending growth over time (Tables A.3.5 and A.3.6). Focusing on the 1992 to 2003 period, several countries (e.g., Czech Republic, Korea, Ireland and Turkey) with lower income and lower health expenditure per capita in the early $1990 \mathrm{~s}$ experienced exceptionally high growth in health expenditure, narrowing the gap with the OECD average. In 2003, health expenditure per capita in these countries was around, or more than, two times higher than in 1992. By contrast, some countries (e.g., Finland, Germany and Italy) experienced slow growth, both in total and public expenditure on health, following the introduction of costcontainment measures in the early 1990s. In 2003, expenditure on health per capita in these countries was only around 10-20\% higher than in 1992.

Governments are under continuous pressure to adjust public expenditure on health to economic growth (OECD, 2004a). Chart 3.6 shows that, concerning trends in public expenditure on health in OECD countries, the last decade can be roughly divided into two different periods. The period 1992-1997 saw stable economic growth matched by a similar or even slower growth in public expenditure on health in many countries, while in the early 2000s slow economic growth was accompanied by an upsurge in public expenditure on health, outpacing GDP growth in all countries. Trends in total expenditure show very similar pattern for most OECD countries (Table A.3.5). Considerable increases in public health spending have partly reflected deliberate policies in some countries, such as the United Kingdom and Canada, to relieve demand pressures arising from cost containment during the mid1990s (Coomber, 2002; Huber and Orosz, 2003; Wanless, 2002). However, recent data suggest that health expenditure growth slowed down again in 2003 in many OECD countries. For example, in Germany, New Zealand and Poland the growth rate remained below 1\%, and in Italy and Portugal it was negative.

Chart 3.5 compares the trends in yearly growth rates of public expenditure on health and GDP for EU-15 and the United States. The chart shows that fluctuations in public health expenditure growth in the EU member countries closely followed - with a one or two-year time-lag - fluctuations in GDP growth over the last two decades (similar patterns can be discerned for individual countries). The trend is less clear for the relationship between growth rates of public expenditure on health and that of the GDP in the United States.

\section{Definition and deviations}

See indicator "Health expenditure per capita" for definition of health expenditure. Growth rates are calculated in real terms (based on the 2000 GDP price index).

Note: The time periods shown in Chart 3.4 are defined according to the distinct periods observed in the overall trend of health expenditure, based on the OECD average: the first and third periods were characterised by low growth rate, while the second and fourth by higher growth rate. 
Chart 3.4. Average annual growth rate in real health expenditure, 1980 to 2003

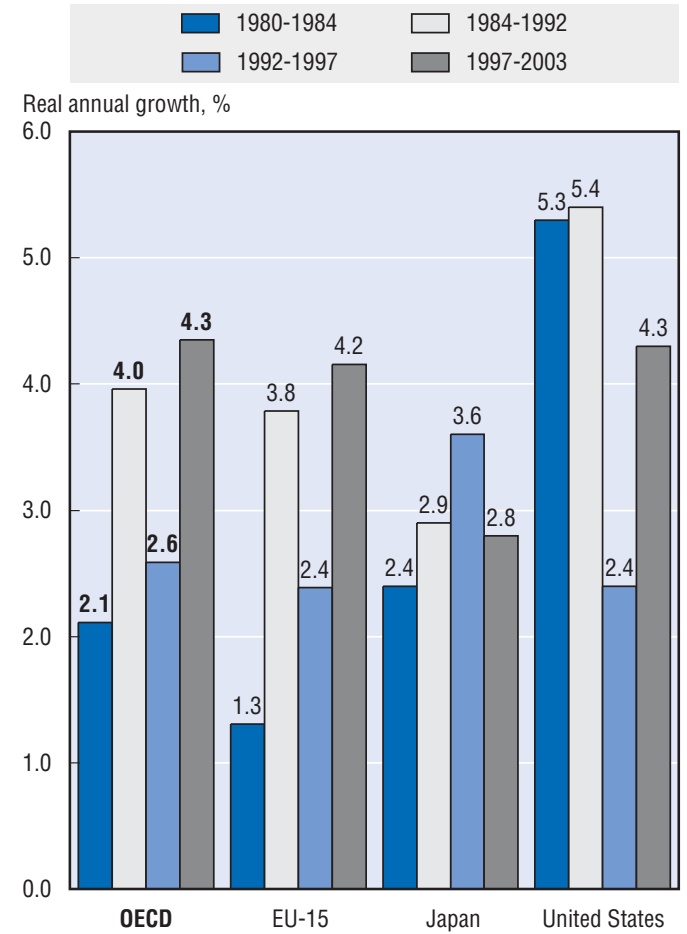

Chart 3.5. Public expenditure on health and GDP, EU-15 and United States, 1980 to 2003
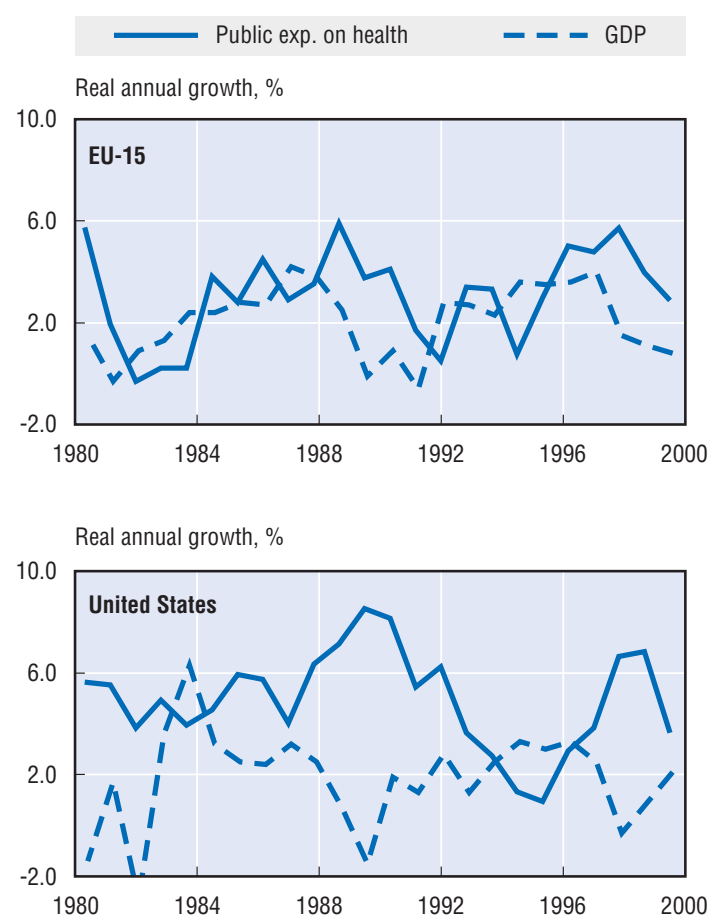

Chart 3.6. Increase in public expenditure on health and GDP, per capita

1992-1997

Real annual growth, public expenditure on health (\%)

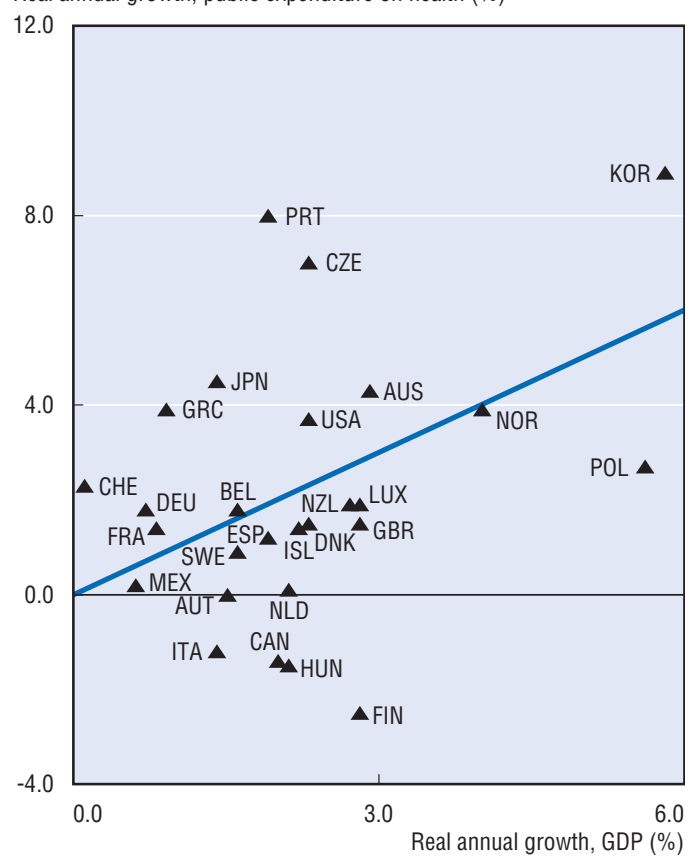

Source: OECD Health Data 2005.
1997-2003

Real annual growth, public expenditure on health (\%)

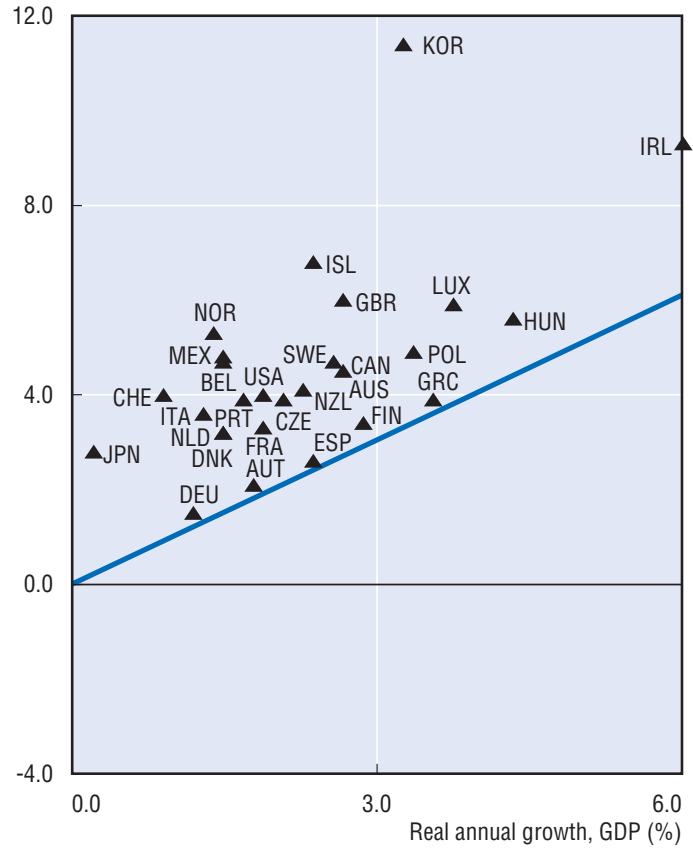

StatLink: http://dx.doi.org/10.1787/015885406552 
In 2003, OECD countries devoted, on average, $8.8 \%$ of their GDP to health spending. This proportion varies considerably across countries, ranging from $15 \%$ in the United States to less than $6 \%$ in the Slovak Republic and Korea (Chart 3.7). Following the United States, in terms of highest health spending as a percentage of GDP, were Switzerland and Germany which spent $11.5 \%$ and $11.1 \%$ of their GDP on health, respectively. In 2003, 14 countries devoted more than $9 \%$ of their GDP to health care, whereas in 1997 there were only 4 . Public spending on health accounted for more than $8 \%$ of GDP in Germany, Iceland and Norway, while only about $3 \%$ in Korea and Mexico.

To make a more comprehensive assessment of health spending in a country, the health spending to GDP ratio and the per capita health expenditure should be considered together. Countries having a relatively high health expenditure to GDP ratio might have relatively low per capita expenditure, and conversely, countries with a relatively low health expenditure to GDP ratio might have relatively high expenditure per capita. For example, Canada and Greece spent a similar share of GDP on health in 2003; however, per capita spending was about 50\% higher in Canada than in Greece (Charts 3.1 and 3.7).

Changes over time in the ratio of health expenditure to GDP (Chart 3.8) reflect the combined effect of the trends in GDP and health expenditure. OECD countries experienced a rise in the proportion of national income devoted to health over the 1997-2003 period due to an increasing rate of growth in health expenditure and an economic slowdown. On average across OECD countries, the health expenditure to GDP ratio increased from $7.8 \%$ to $8.8 \%$. In particular, Norway, Iceland and the United States experienced a high increase, as health expenditure grew more than two times faster than GDP in these countries. On the other hand, there were notable exceptions, for example, Finland and Spain, where the share of health expenditure to GDP only slightly increased, due to the growth rate of health expenditure only slightly surpassing economic growth (Chart 3.8).

Total health expenditure measures the consumption of health care goods and services plus capital investment in health care infrastructure. Due to the different nature of these two main components, it is important to examine them separately. Chart 3.9 shows that the share of consumption of health services and goods (that is, current health expenditure) in total final consumption expenditure is considerably higher than the health spending to GDP ratio in all OECD countries. Almost two thirds of OECD countries devote more than $10 \%$ of their final consumption expenditure to health care. This indicator reveals that countries with a high investment rate in their general economy rank differently according to this indicator than according to the ratio of total health expenditure to GDP (e.g., Ireland, Korea). For example, in 2003, Ireland spent a similar share of its final consumption expenditure on health care as Australia and Greece, while the ratio of total health expenditure to GDP in Ireland was considerably lower. (For the difference between the two indicators, see the box on "Definition and deviations" below.)

Chart 3.10 shows the well known positive association between GDP per capita and health expenditure per capita across OECD countries. While there is an overall tendency for countries with higher GDP to spend a greater proportion of their GDP on health, there is wide variation as GDP is not the sole factor influencing health expenditure levels. This association is stronger among lower-income OECD countries than among higher-income countries. Among countries with income levels of 25000 USD PPP and above, there are substantial differences in health expenditure at a given level of GDP (Huber, 1999). For instance, despite having similar levels of GDP per capita, France spent 35\% more on health than Japan in 2003, and Italy spent only $75 \%$ of the level of Germany.

\section{Definition and deviations}

By definition, Gross Domestic Product (GDP) = final consumption + gross capital formation - imports + exports. Final consumption includes goods and services which are used by households or the community to satisfy their individual wants and social needs. (Final consumption expenditure includes final consumption expenditure of households, general government and non-profit institutions serving households.) The differences in the relative positions of countries according to the ratio of total health expenditure to GDP and current health expenditure to final consumption expenditure are due to differences in the level of investments (in the economy as a whole, and in the health sector) and differences in the balance of foreign trade across countries.

Chart 3.8 shows the change in health expenditure to GDP ratio for two sub-periods of 1992-2003. The figures in the chart refer to the sum of the two periods. For those countries having a decrease in the first sub-period, the total change (that is, the balance of a negative and positive figure) is smaller than the increase in the second period. 


\section{Chart 3.7. Health expenditure as a share of GDP, 2003}

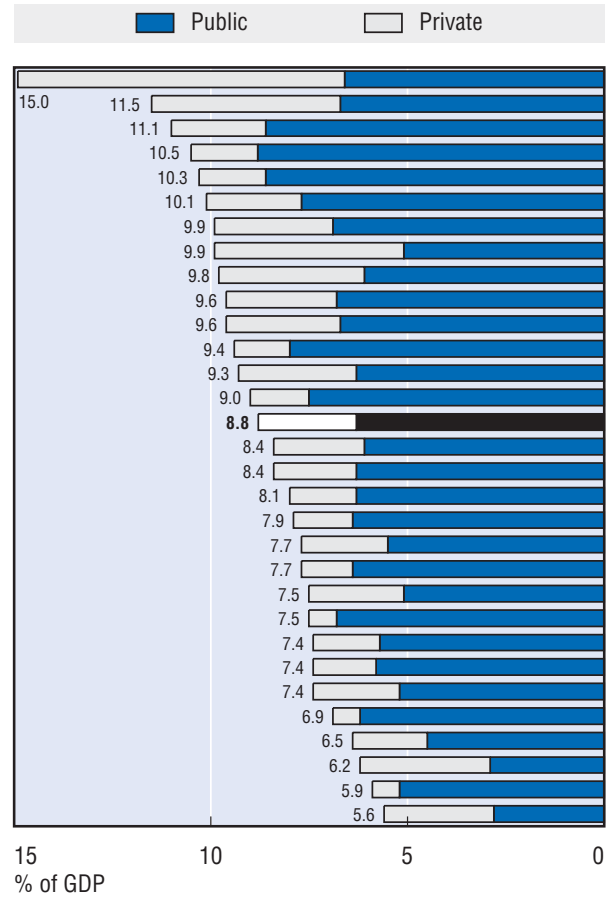

1. Public/private data refers to current health expenditure.

2. 2002.

Chart 3.9. Current health expenditure as a share of final consumption, 2003

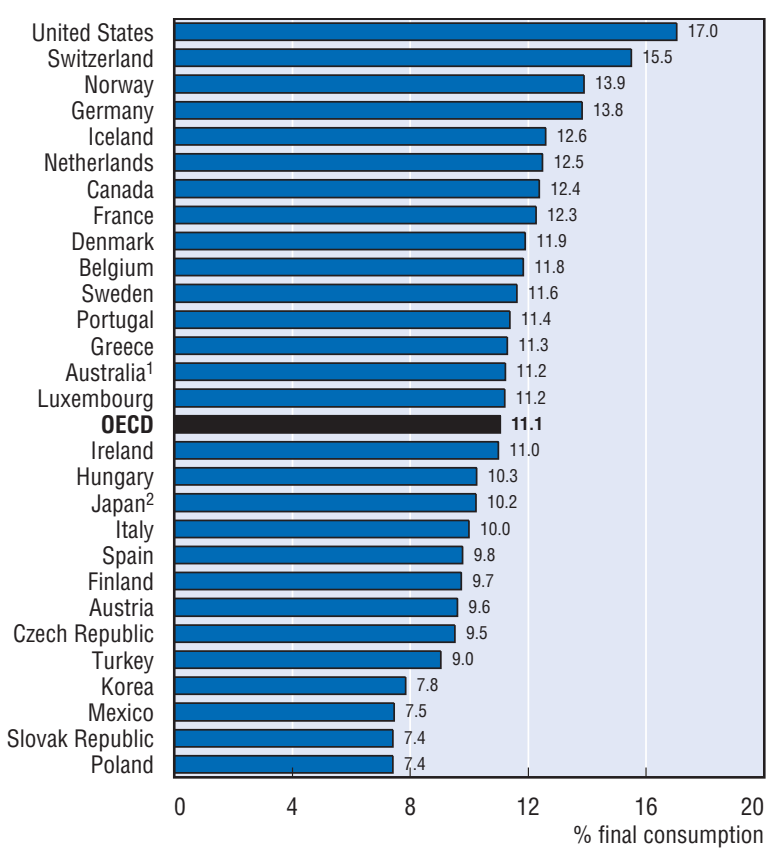

1. 2001.

2. 2002.

Source: OECD Health Data 2005.
Chart 3.8. Change in health expenditure as a share of GDP, 1992 to 2003
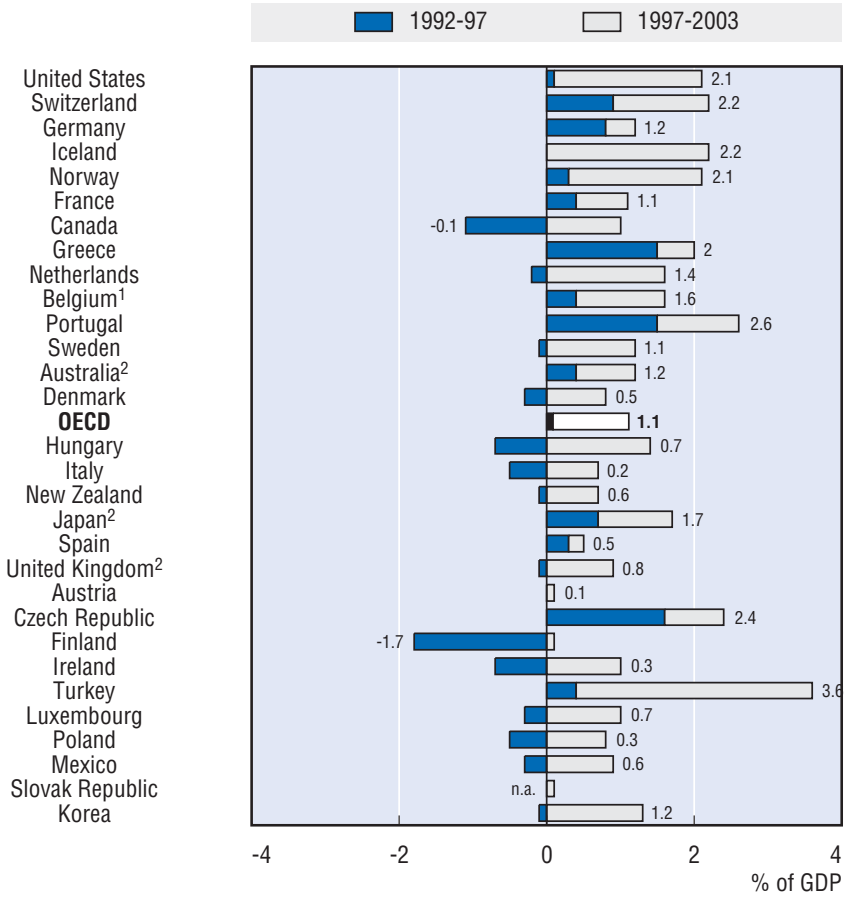

Chart 3.10. Health expenditure and GDP per capita, 2003

Health exp. per capita (USD PPP)

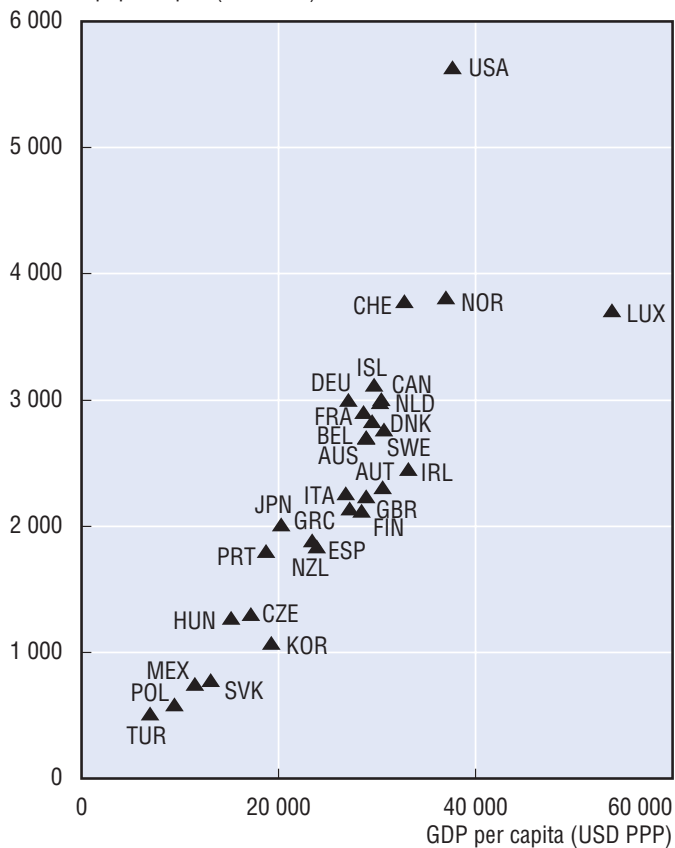


OECD countries differ in the ways health expenditure is allocated according to type of service provided and medical goods consumed (Chart 3.11 and Table A.3.9). Current total health expenditure comprises personal medical services and goods and collective services (see "Definition and deviations" and Annex B). Personal medical services cover curative, rehabilitative and long-term care as well as ancillary services. In addition, curative, rehabilitative and long-term care can also be classified by the mode of production (i.e. in-patient, out-patient and home care). In 2003, on average across OECD countries, $38 \%$ of current health expenditure was allocated to in-patient care, $34 \%$ for ambulatory services (including ancillary services and home care), $22 \%$ for medical goods (including pharmaceuticals and medical appliances) and the remaining $6 \%$ was spent on collective services. But there are significant differences among countries about how health spending is allocated, reflecting factors such as differences in capacities (availability of hospital beds and physicians), financial incentives for providers and differences in medical practice. For example, whereas Italy and France allocate more than $40 \%$ of current health expenditure to in-patient care, Canada and Spain spend $33 \%$ or less, with a correspondingly higher proportion of resources going to ambulatory care.

"Collective expenditure" includes spending on prevention and public health, which counts on average for around 3\% only of current health expenditure. This does not reflect the total amount spent on prevention, rather preventive services provided in the form of public and private programmes. For example, in those countries where there are obligatory occupational health checks and screening, such as Germany and Hungary, the expenditure on prevention can be around 5\% of current health expenditure (Chart 3.12). Preventive care is also provided through ambulatory care, but the magnitude is not known.

"Curative and rehabilitative care" accounts for more than half of current health expenditure on average across countries - ranging from $43 \%$ in Hungary to $67 \%$ in Spain and the United States. Where reported, the proportion of health expenditure spent on long-term care displays a striking range from less than $2 \%$ in the case of Spain and Hungary, up to more than $20 \%$ in Norway and Switzerland. The low share reported in some countries is partly due to the greater role of informal care by private households. However, currently the data also reflect methodological differences between countries in the extent to which long-term care services are reported as part of health expenditure.

Changes in practice norms and innovation in medical technology, reforms in payment mechanisms, and the search for more efficient allocation of health care resources all act together over time to modify the functional structure of health expenditure. There has been a trend to move some health services away from in-patient services to out-patient and home care. It is reflected in the decreasing share of in-patient care as a total of the curative-rehabilitative expenditure in 9 out of 12 countries between 1997 and 2003 (Chart 3.13). Furthermore, because expenditure on day-care, a growing area in many OECD countries, is currently included within in-patient services, this trend is likely to be even more pronounced than these data show. There has also been a trend to increase the share of health spending allocated to pharmaceuticals (see indicator "Pharmaceutical expenditure").

\section{Definition and deviations}

The System of Health Accounts applies a consistent functional approach in order to define the boundaries of the health system and examine the allocation of resources. Following the framework of the System of Health Accounts, total health expenditure consists of current health expenditure and gross capital formation. Current health expenditure comprises personal health services and goods provided directly to the individual and collective services, covering tasks of public health such as health promotion and disease prevention services and health administration, which are delivered to society at large. Personal health services comprise services of curative care, rehabilitative services, services of long-term care, ancillary services to health care, and medical goods dispensed to out-patients. The basic functions of care (curative, rehabilitative and long-term care) can also be classified by the mode of production (in-patient, out-patient and home care).

The most important factor limiting the comparability of functional structure across countries is the difference in estimating long-term care expenditure. Another important issue is that in some countries, in-patient expenditure is still linked to hospital expenditure (i.e. it includes other services, such as out-patient care, delivered in hospitals). For similar reasons, ancillary services may be included in either in-patient or out-patient expenditure. (For a more detailed discussion of methodological issues, see Orosz and Morgan, 2004.) 


\section{Chart 3.11. Current expenditure by medical services, medical goods and collective care, 2003}

Countries are ranked by total in-patient care as share of current expenditure on health

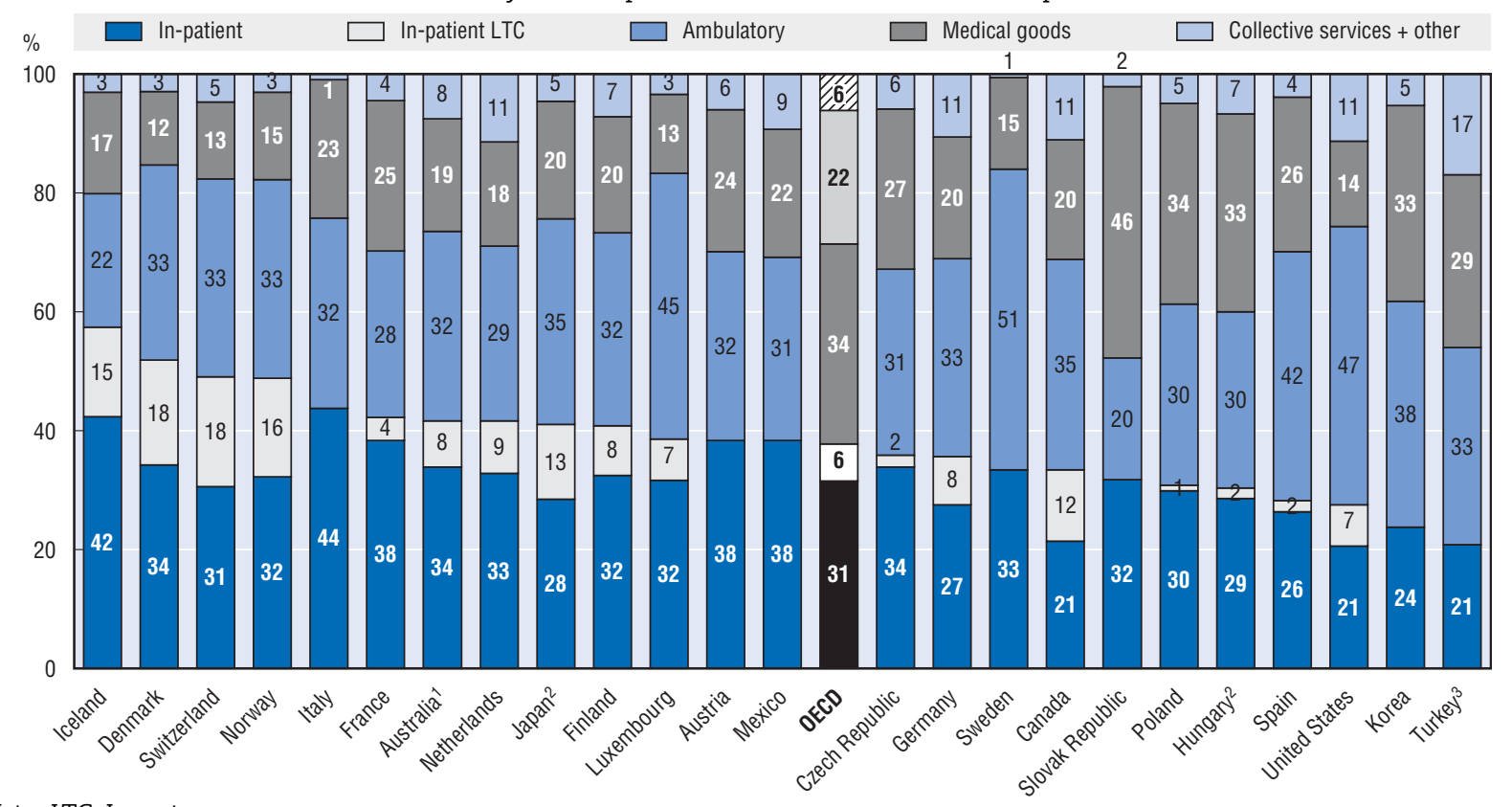

Note: LTC: Long-term care.

1. 2001.

3. 2000 .

\section{Chart 3.12. Expenditure on public health and prevention, 2003}

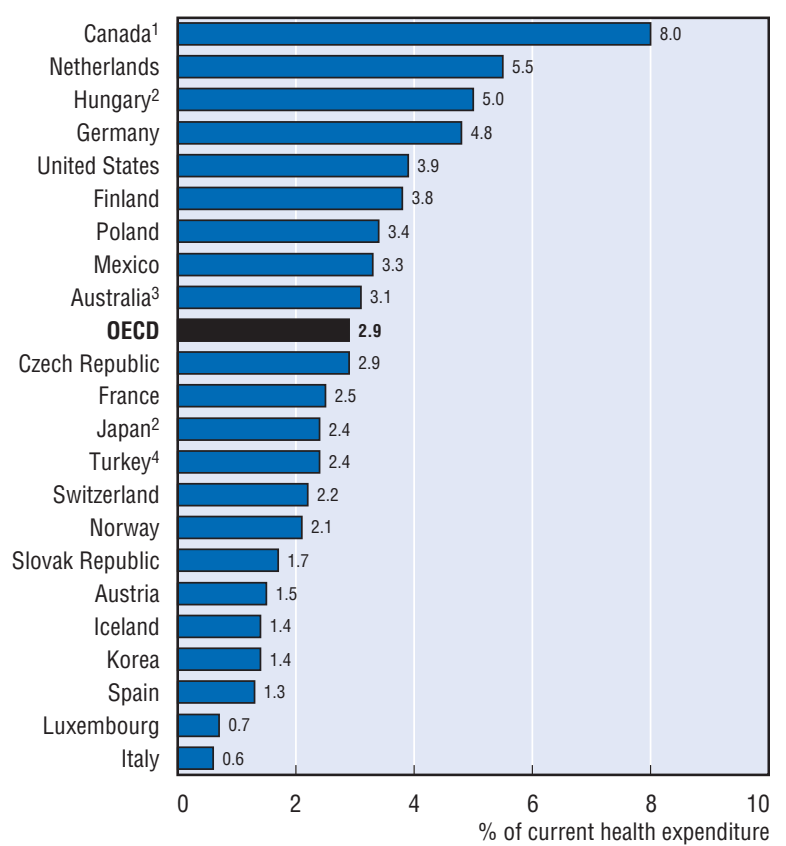

1. Includes administrative costs of provincial/territorial and federal health departments.

2. 2002.

3. 2001.

4. 2000

Source: OECD Health Data 2005.
Chart 3.13. In-patient share of curative-rehabilitative care, 1997 and 2003

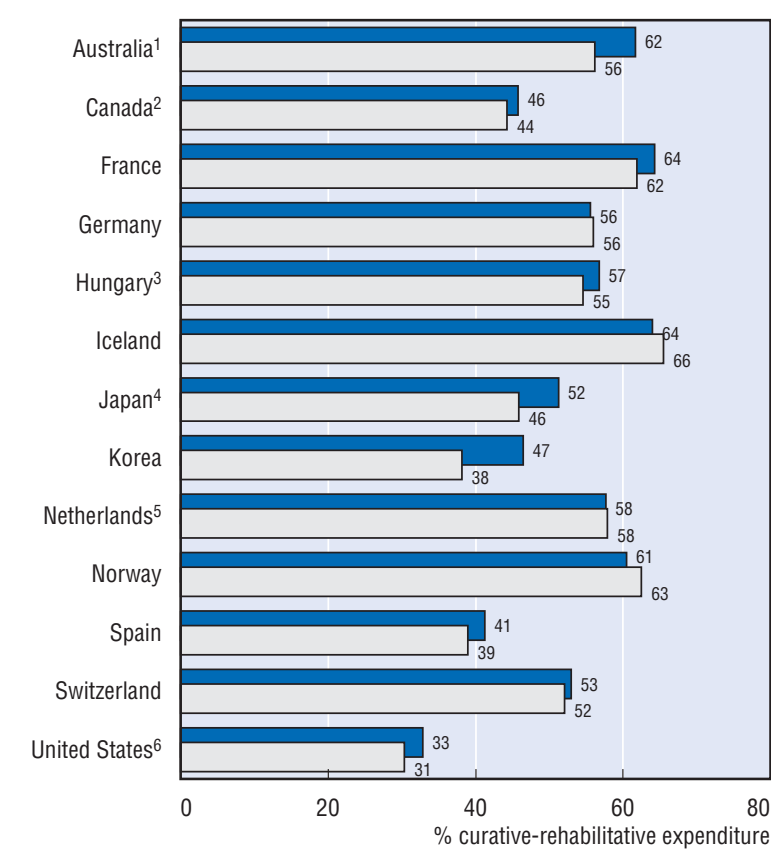

1. 1997-2001.

2. 1999-2003

3. $1998-2002$

4. 1997-2002

5. $1998-2003$

6. Does not include fees for independently billing physicians rendering care in hospitals. 
Expenditure on pharmaceuticals constitutes a growing share of health expenditure across OECD countries. The introduction and diffusion of new drugs has been one of the major factors pushing up overall heath expenditure over recent years. That said, the relationship is a complex one, in that increased expenditure on pharmaceuticals in the short term may lead to reduced expenditure on more costly and care-intensive treatments now or in the future.

Total OECD spending on pharmaceuticals in 2003 is estimated to be above USD 450 billion. On average, per capita spending on drugs has risen by more than a third in real terms since 1997. There are, however, considerable differences in pharmaceutical spending across countries, reflecting differences in volume, structure of consumption and price level (Chart 3.14 and Table A.3.10). Differences in income levels across countries is also a significant factor affecting spending on drugs. In 2003, the United States spent 728 USD PPP per capita on pharmaceuticals. This is almost double the OECD average of 380 USD PPP. However, this represents less than $13 \%$ of total health expenditure in the United States, somewhat lower than the average of $17.5 \%$ observed across the OECD (Chart 3.15). At the other end of the scale, both Mexico and Turkey only spent around a third of the OECD average. Pharmaceutical expenditure accounted for more than $20 \%$ of total health spending in France, Italy and Spain, and considerably more in some of the Eastern European member countries. So, although Hungary and Denmark both report similar per capita spending on pharmaceuticals in 2003, the share of drugs in total health spending represented $10 \%$ in Denmark and more than $25 \%$ in Hungary.

The rapid rise in drug spending in recent years more than $5 \%$ per year growth on average since 1997 - has been an important driver in the overall rise in total health spending. In fact, most OECD countries have seen growth in pharmaceutical spending outstrip growth in total health spending over this period (Chart 3.16). Both the United States and Australia have seen pharmaceutical spending growth at more than double the rate of growth in total spending over this period. Significant growth has also been observed in Ireland and Korea, albeit from a relatively low per capita base at the beginning of the period.

On average across OECD countries, $60 \%$ of the pharmaceutical bill is borne by public funds (Table A.3.11), the remainder being met by out-ofpocket payments and, to a lesser extent, private insurance. However, this average hides a very wide variation, ranging from $11 \%$ in Mexico to $84 \%$ in Ireland. One reason for this is how and even whether pharmaceuticals are covered by national health programmes and publicly financed insurance.

\section{Definition and deviations}

Pharmaceutical expenditure includes expenditure on prescription medicines and self-medication, often referred to as over-the-counter products. It also includes pharmacists' remuneration when the latter is separate from the price of medicines. Pharmaceuticals consumed in hospitals are excluded. Final expenditure on pharmaceuticals includes wholesale and retail margins and value-added tax. 
Chart 3.14. Expenditure on pharmaceuticals, per capita, 2003

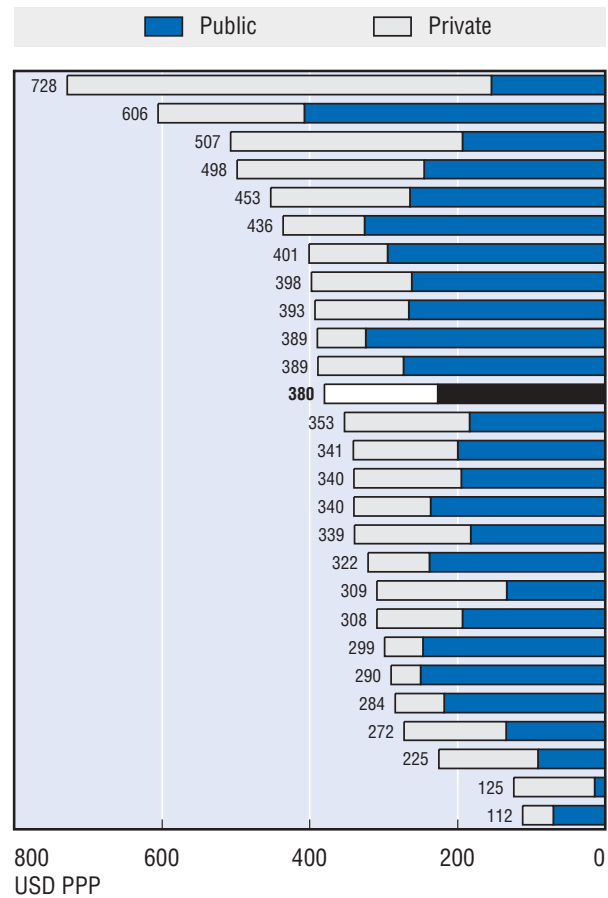

Chart 3.15. Pharmaceutical spending as a percentage of total health expenditure, 2003

1. 2002.

2. OECD average excludes Poland and Turkey because of the unavailability of consistent time series.

3. 2001.

4. 2000 .

Chart 3.16. Real annual growth in pharmaceutical spending and total health expenditure, 1997-2003

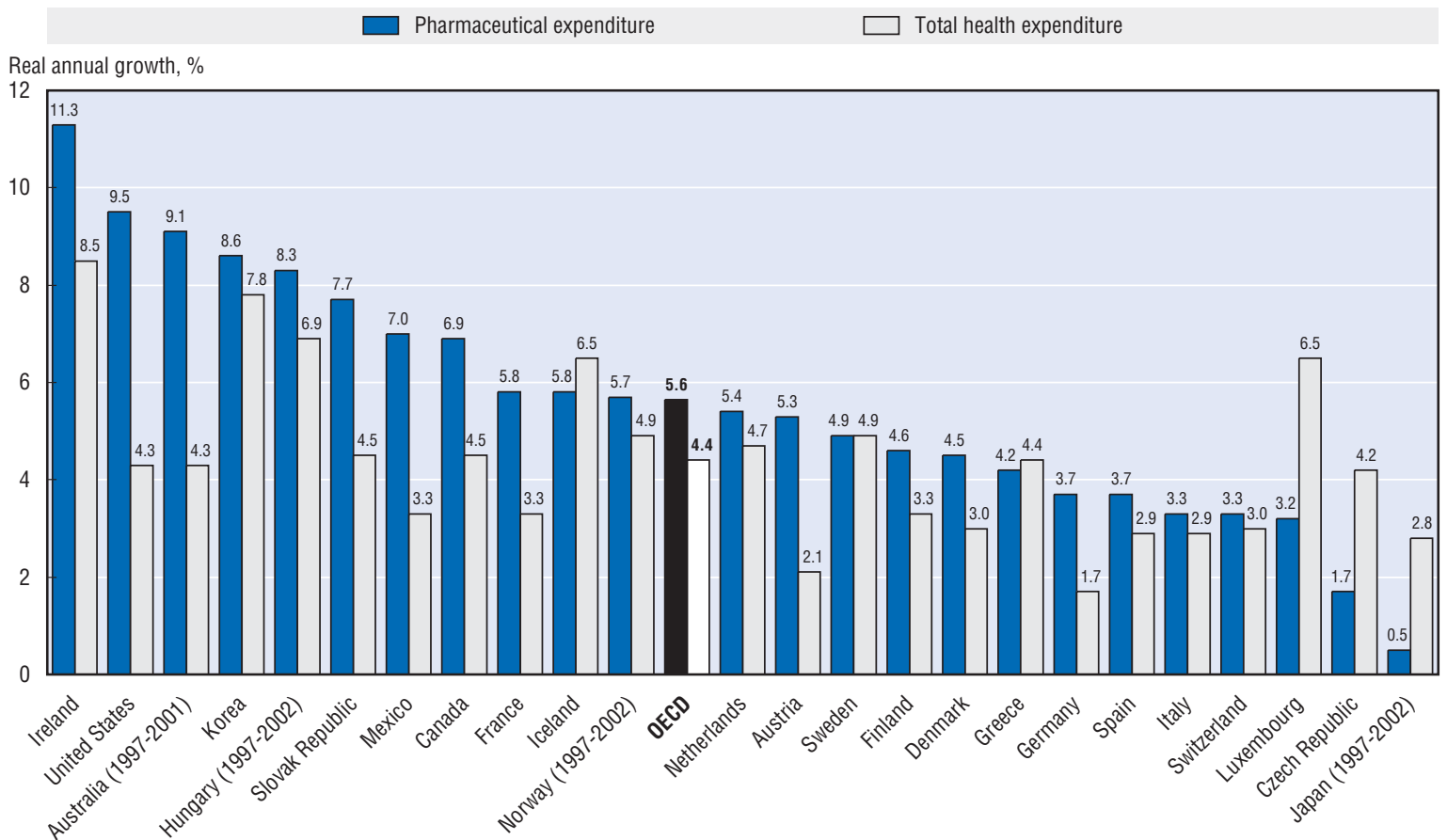

Source: OECD Health Data 2005. 


\section{III.6. SOURCES OF FINANCING FOR HEALTH CARE}

Different methods of financing health care can affect the level and distribution of health expenditure, and access to services across the population. OECD countries use a mix of public and private financing. Public financing can be a mix of general government revenues and social contributions in countries with social insurance based funding (e.g., France and Germany), or confined to government revenues in countries where central and/or local governments are responsible for financing health services (e.g., Finland and United Kingdom). Private financing, on the other hand, may consist of out-of-pocket payments of households, third-party payment arrangements effected through various forms of private health insurance (often funded by employers and subsidised by exemption from the calculation of taxable income by employees), employers' direct health benefits such as occupational health care, and other direct benefits provided by charities and the like.

Chart 3.17 shows the share of public financing across OECD countries. In 2003, the public sector continued to be the main source of health financing in all OECD countries apart from the United States, Mexico and Korea. On average the public share of health spending was $72 \%$. In a number of Central and Eastern European countries (the Czech and Slovak Republics), many of the Nordic states, Luxembourg, the United Kingdom and Japan, public financing accounts for over $80 \%$ of all health expenditure.

Many higher-income OECD countries have experienced a moderate decrease in the public share of health spending since the 1990s, following policies to shift some of the public burden towards the private sector (either directly to the patient or through private health insurance), particularly in the case of pharmaceuticals. In general, with a few exceptions, there has been a convergence of the public share of health spending among OECD countries since the early 1990s (Chart 3.18). Many of those countries with a relatively high public share in 1990 had seen this share decrease by 2003, particularly Poland and Hungary. On the other hand, several countries which show a low public share in 1990 have seen this share increase over time (e.g., the United States and Switzerland). In the United States, the increase in the public share of health spending during the 1990s reflects increases in the level and coverage of Medicare and Medicaid benefits to meet more of the health needs of the elderly and poor, combined with a growth in the proportion of the population eligible for benefits (Docteur et al., 2003).

Private sources of financing are split, for the most part, between private insurance and private households' out-of-pocket spending. The size and composition of private funding differs considerably however across countries. While private health insurance (PHI) represents only around $6 \%$ of total health expenditure on average across OECD countries (Chart 3.19), it can play an important financing role in some. It provides primary coverage for certain population groups in Germany and the Netherlands, and for a large proportion of the non-elderly population in the United States, where PHI accounted for almost $37 \%$ of health expenditure. In countries such as France and Canada, PHI can typically cover 10 to $15 \%$ of overall spending, but provides supplementary or complementary coverage in a public system with universal reach.

Countries with the highest shares of PHI tend to show a lower share of out-of-pocket spending, although the relationship between the importance of PHI and out-of-pocket spending in overall financing is weak (OECD, 2004c). In some of the Eastern European countries the practice of unofficial supplementary payments means that the level of out-of-pocket spending is probably underestimated.

The burden of out-of-pocket spending on households can also be measured by its share of final household consumption (Table A.3.13). In several countries, including the Netherlands, France and Germany, less than $2 \%$ of the total consumption of households was spent on out-of-pocket health services in 2003, while in Switzerland and Greece, such spending represented more than $6 \%$ of total household consumption. The United States, with 3\% of consumption being spent on out-of-pocket health services, is near the average.

\section{Definition and deviations}

"Source of financing" might be used in two senses: ultimate sources of funding (households, employers and the state) and financing schemes/arrangements (e.g., compulsory insurance or voluntary insurance, etc.). Here "Source of financing" is used in the sense of financing arrangements as defined in the System of Health Accounts. Public sources include general government revenues and social security funds. Private sources cover out-ofpocket payments of households, private health insurance and other private funds, such as from nongovernmental organisations and private companies funding occupational health care.

Out-of-pocket payments (OOP) are expenditures borne directly by a patient without the benefit of insurance. They include cost-sharing, OOP without cost-sharing and informal payments to health care providers. 
Chart 3.17. Public share of total health expenditure, 2003

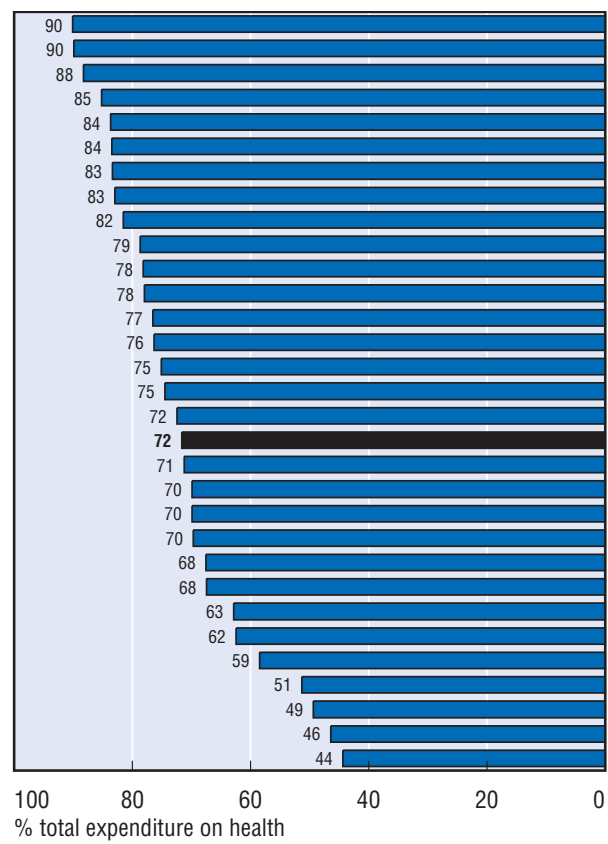

1. 2002.

2. 1992.

3. Current health expenditure.

4. 1991.

5. OECD average excludes Belgium and Slovak Republic.

6. 2000 .
Chart 3.19. Private health insurance share of total expenditure on health, 2003

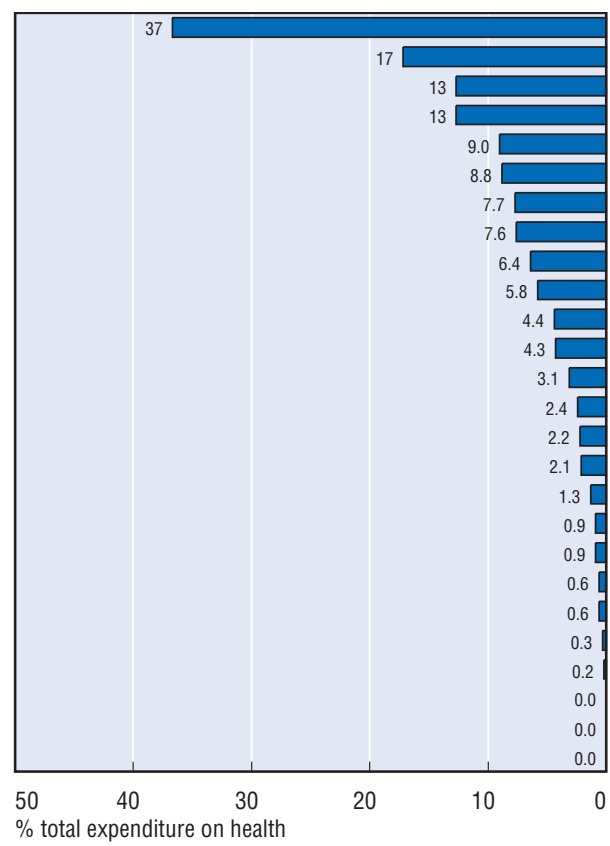

1. 2001.

2. 2000 .

3. 2002.

Source: OECD Health Data 2005.
Chart 3.18. Change in public share of total health expenditure, 1990 to 2003

$$
\begin{gathered}
\text { Czech Republic } \\
\text { Luxembourg } \\
\text { Slovak Republic } \\
\text { Sweden } \\
\text { Norway } \\
\text { Iceland } \\
\text { United Kingdom } \\
\text { Denmark } \\
\text { Japan }{ }^{1} \\
\text { New Zealand } \\
\text { Germany² } \\
\text { Ireland } \\
\text { Finland } \\
\text { France } \\
\text { Italy } \\
\text { Belgium } \\
\text { Hungary } \\
\text { Ho } \\
\text { OECD } \\
\text { Spain } \\
\text { Canada } \\
\text { Poland } \\
\text { Portugal } \\
\text { Austria } \\
\text { Australia }{ }^{1} \\
\text { Turkey } \\
\text { Netherlands } \\
\text { Switzerland } \\
\text { Greece } \\
\text { Korea } \\
\text { Mexico } \\
\text { United States }
\end{gathered}
$$

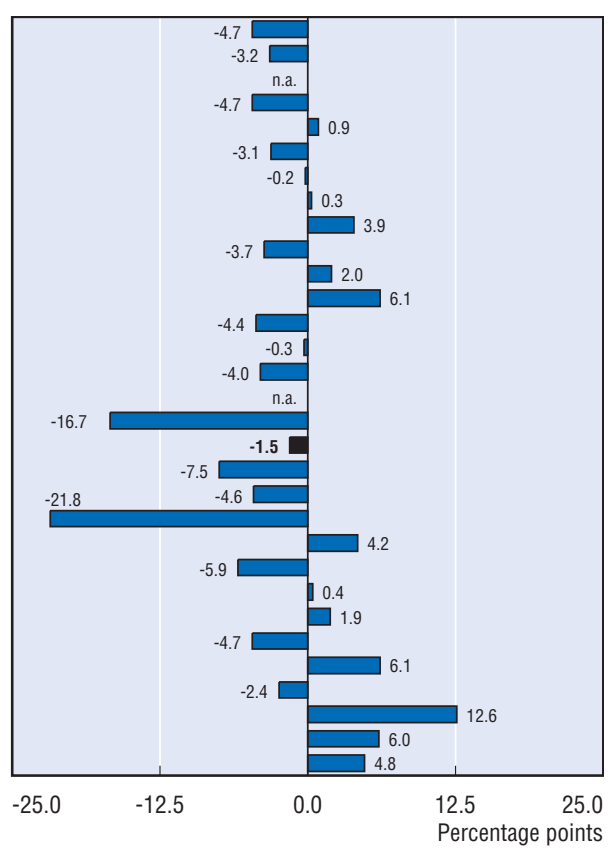

Chart 3.20. Out-of-pocket payments as a share of total expenditure on health, 2003

United States

Netherlands

Canada

France

Switzerland

Germany

Australia

Austria

Ireland

New Zealand

Turkey $^{2}$

Spain

Mexico

Finland

Greece

Korea

Denmark

Italy

Luxembourg

Hungary

Poland

Japan $^{3}$

Czech Republic

Iceland

Norway

Slovak Republic

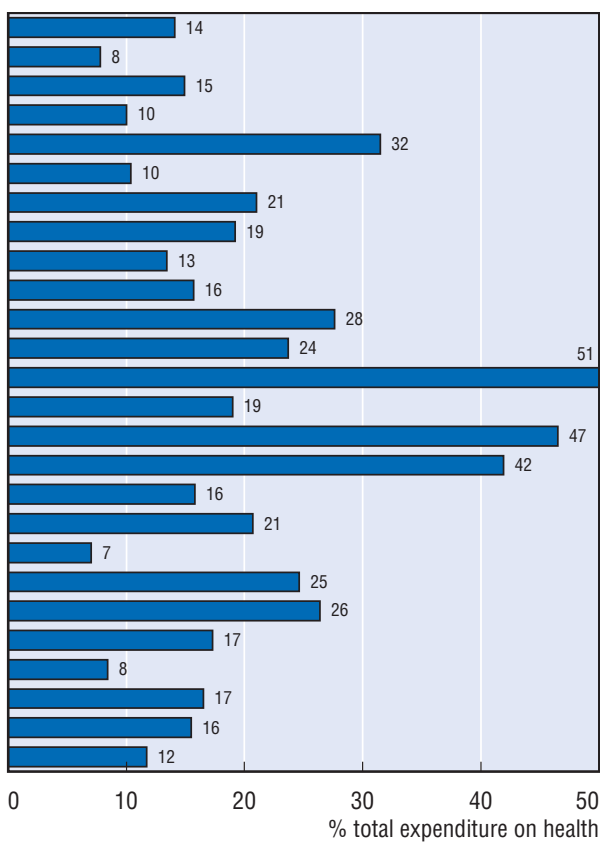

StatLink: $h t t p: / / d x . d o i . o r g / 10.1787 / 566216314520$ 



\section{Non-medical Determinants of Health}

1. Tobacco consumption.

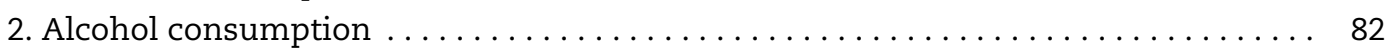

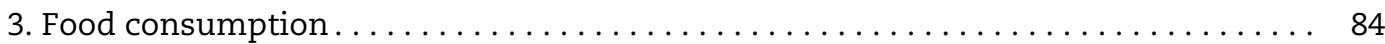

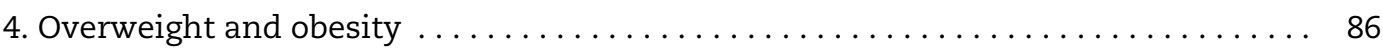




\section{IV.1. TOBACCO CONSUMPTION}

According to the World Health Organisation, tobacco is the second major cause of death in the world, and is directly responsible for about one in ten adult deaths worldwide, equating to about 5 million deaths each year (WHO, 2002). It is a major risk factor for at least two of the leading causes of premature mortality - circulatory diseases and a range of cancers. In addition, it is an important contributory factor for respiratory diseases, while smoking among pregnant women can lead to low birth weight and illnesses among infants. It remains the largest avoidable risk to health in OECD countries.

The proportion of daily smokers among the adult population varies greatly across OECD countries. Canada, the United States, Sweden and Australia have the lowest percentage of daily smokers, with $20 \%$ or less of adults reporting smoking each day in 2003 or the latest year available (Chart 4.1). Greece reported the highest rate of 35\% (in 2000), closely followed by Hungary and Luxembourg. Although large disparities remain, smoking rates across most OECD countries have shown a marked decline over recent decades (Chart 4.3).

Historically, in the post-war period, most OECD countries have tended to follow a general pattern marked at first by very high smoking rates among men (around $50 \%$ or above). This was the case for many OECD countries during the 1960s and 1970s, and remains so for Japan, Korea and Turkey today. This was generally followed, in the 1980 s and the 1990s, by a marked downturn in tobacco consumption, particularly among men. Much of this decline can be attributed to policies aimed at reducing tobacco consumption through public awareness campaigns, advertising bans and increased taxation, in response to rising rates of tobacco-related diseases (World Bank, 1999).

Smoking prevalence among men continues to be higher than among women in all OECD countries except Sweden. In 2003, the gender gap in smoking rates was particularly large in Korea, Japan and Turkey and, to a lesser extent, in Mexico, Poland and Greece (Chart 4.2). Nonetheless, the gender gap across a common group of countries has narrowed from $19 \%$ in 1980 , to $10 \%$ in 1990 , and $7 \%$ in 2003 , because smoking rates have declined more rapidly among men than among women in most countries over the past twenty years. In Japan, male smoking rates fell from $70 \%$ in 1980 to $48 \%$ in 2003 , while female smoking rates remained stable at $14 \%$. Smoking rates among males also declined sharply in Sweden (down from 36\% in 1980 to $17 \%$ in 2003), but less so among females (from 29\% in 1980 to $18 \%$ in 2003). In a number of countries, smoking rates among women have been stable or have even increased (in the case of Finland and France) between 1980 and 2003. In 2003, smoking rates among women were highest in the Netherlands, Hungary and Greece, with rates close to $30 \%$.

Chart 4.4 shows the correlation between tobacco consumption (as measured by grams per capita) and incidence of lung cancer across OECD countries, using a 22-year time lag. Higher tobacco consumption at the national level is also generally associated with higher mortality rates from lung cancer 15 or 25 years later across OECD countries.

\section{Definition and deviations}

The proportion of daily smokers is defined as the percentage of the population aged 15 years and over reporting to smoke every day.

International comparability is limited due to the lack of standardisation in the measurement of smoking habits in health interview surveys across OECD countries. There remain some variations in the wording of questions, response categories and survey methodologies. 


\section{Chart 4.1. Percentage of adult population smoking daily, 2003}

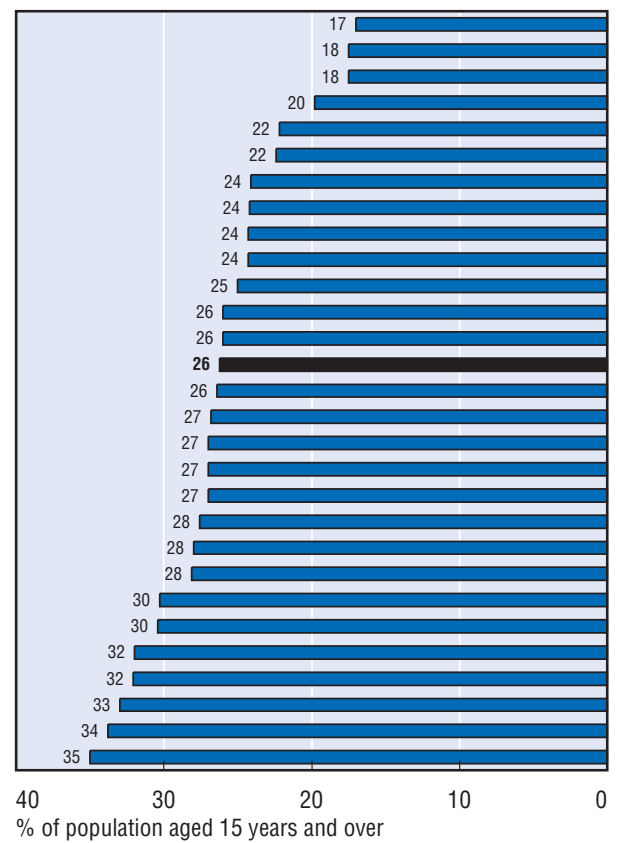

1. 2001.

2. 2002 .

3. 2000 .

Chart 4.3. Trends in daily smoking, percentage of adult population, selected OECD countries, 1980-2003

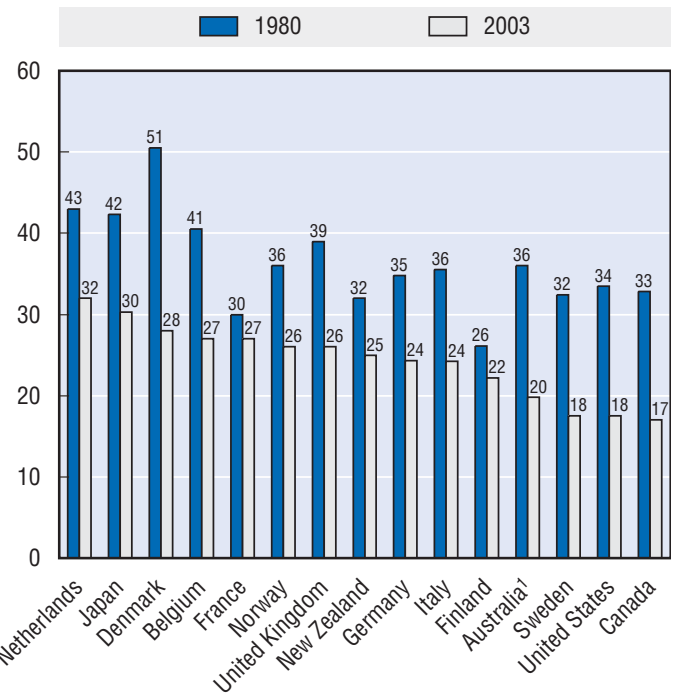

1. 2001.

Source: OECD Health Data 2005.

\section{Chart 4.2. Percentage of females} and males smoking daily, 2003

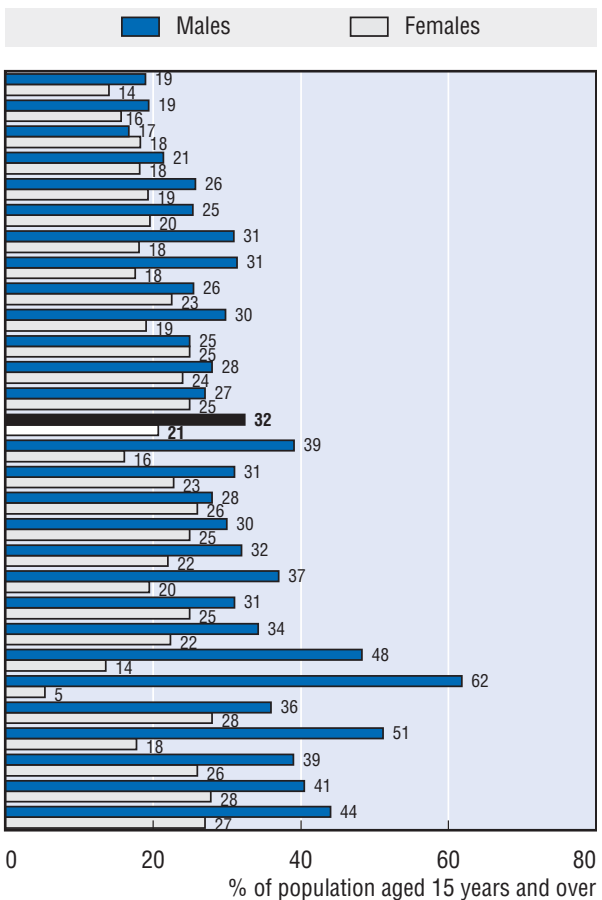

Canada

United States

Sweden

Australia

Finland

Iceland

Czech Republic ${ }^{2}$ Italy

Slovak Republic ${ }^{2}$

Germany

New Zealand

United Kingdom

Norway

OECD

Mexico ${ }^{2}$

Switzerland 2

Ireland²

Belgium

France

Poland ${ }^{1}$

Denmark

Spain

Japan

Korea ${ }^{1}$

Netherlands

Turkey

Luxembourg

Hungary

Greece $^{3}$
Chart 4.4. Tobacco consumption, 1980 and incidence of lung cancer, 2002

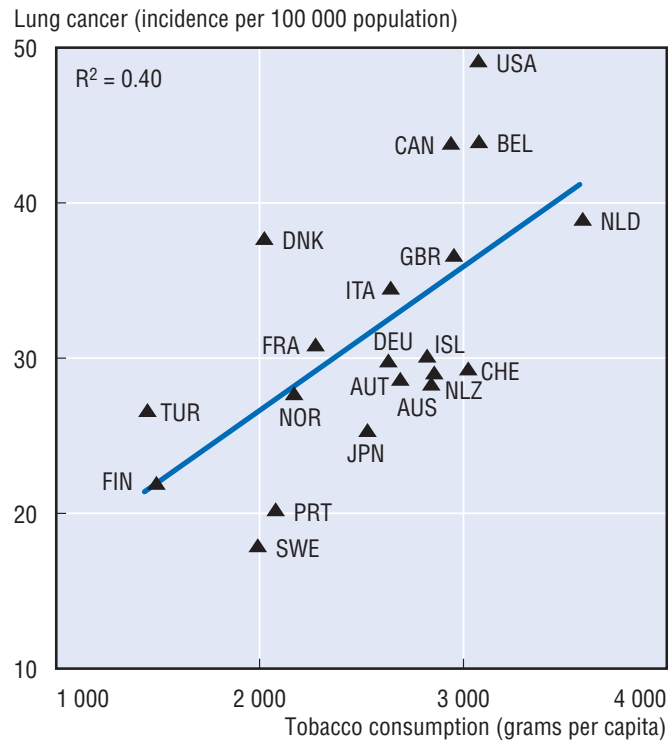

StatLink: http://dx.doi.org/10.1787/302004436182 
Whereas low to moderate alcohol consumption may have some protective health effects (WHO, 2004), excessive alcohol consumption is associated with numerous harmful health effects. High alcohol intake increases the risk for heart, stroke and vascular diseases, as well as liver cirrhosis and certain cancers. Foetal exposure to alcohol is a leading cause of congenital malformations and mental retardation. Alcohol also contributes to death and disability through accidents and injuries, assault, violence, homicide and suicide.

Alcohol consumption, as measured by annual sales, stood on average across OECD countries at 9.6 litres per adult in 2003. There is, however, much variation across countries. Leaving aside Luxembourg, given the high volume of purchases by non-residents in that country, France, Ireland and Hungary reported the highest consumption of alcohol, with more than 13 litres per adult per year in 2002-2003. At the other end of the scale, Turkey, Mexico and some of the Nordic countries (Norway, Iceland and Sweden) reported relatively low levels of alcohol consumption, ranging from 1.5 to 7 litres per adult (Chart 4.5).

Although average alcohol consumption has gradually fallen in many OECD countries over the past two decades, it has risen in some others (Chart 4.6). There has been a degree of convergence in drinking habits across the OECD, with wine consumption increasing in many traditional beerdrinking countries and vice versa. The traditional wine-producing countries of Italy and France have seen their alcohol consumption per capita drop substantially since 1980 (Chart 4.7). On the other hand, alcohol consumption per capita in Iceland and Ireland rose by more than $40 \%$ between 1980 and 2003 (although in the case of Iceland, it started from a very low level and therefore remains relatively low).

Variations in alcohol consumption across countries and over time reflect not only changing drinking habits but also the policy responses to control alcohol use. Curbs on advertising, sales restrictions and taxation have all proven to be effective measures to reduce alcohol consumption (Bennett, 2003). Strict controls on sales and high taxation are mirrored by overall lower consumption in most Nordic countries, while falls in consumption in France, Italy and Spain have been associated with stricter regulations with regard to advertising.

Although adult alcohol consumption per capita gives useful evidence of long-term trends, it does not identify sub-populations at risk from harmful drinking patterns. Often, the bulk of the drinking is done by a minority in a population, such as young males (WHO, 2004). This information can only be obtained from more detailed population surveys of drinking habits.

Chart 4.8 shows the relationship between alcohol consumption in 1990 and deaths from liver cirrhosis in 2002. In general, countries with high levels of alcohol consumption tend to experience higher death rates from liver cirrhosis 10 to 15 years later compared with countries with lower levels of consumption. In most OECD countries, death rates from liver cirrhosis have fallen over the past two decades, following quite closely the overall reduction in alcohol consumption.

\section{Definition and deviations}

Alcohol consumption is defined as annual sales of pure alcohol in litres per person aged 15 years and over. The methodology to convert alcohol drinks to pure alcohol may differ across countries.

Italy reports consumption for the population 14 years and over, Sweden for 16 years and over, and Japan 20 years and over. In some countries (e.g. Luxembourg), national sales do not accurately reflect actual consumption by residents, since purchases by non-residents may create a significant gap between national sales and consumption. 
Chart 4.5. Alcohol consumption in litres per capita, population 15 years and over, 2003

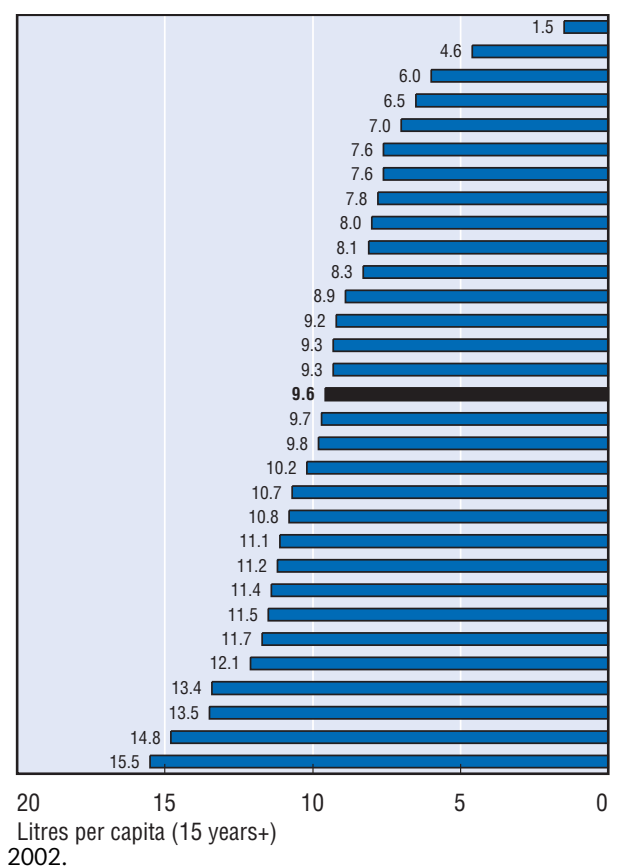

Chart 4.7. Trends in alcohol consumption, selected OECD countries, 1980 to 2003

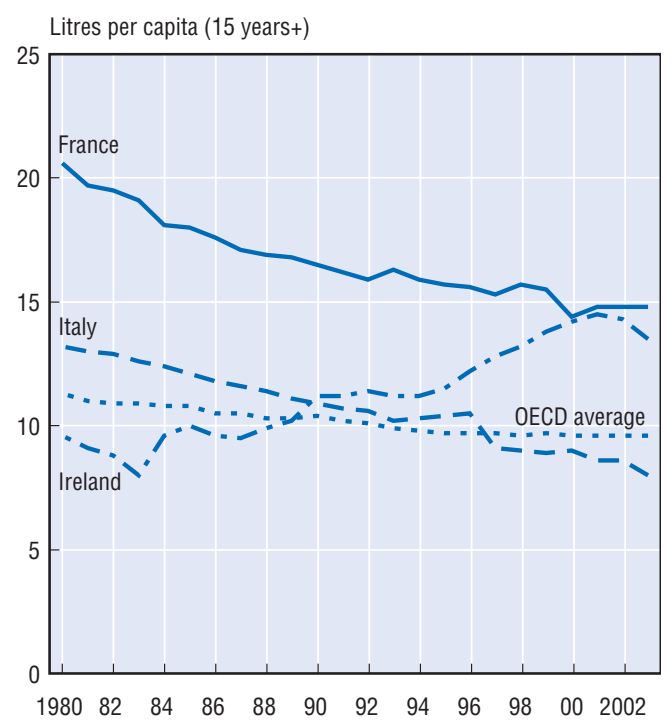

Source: OECD Health Data 2005.
Chart 4.6. Change in alcohol consumption per capita, population 15 years and over, 1980 to 2003

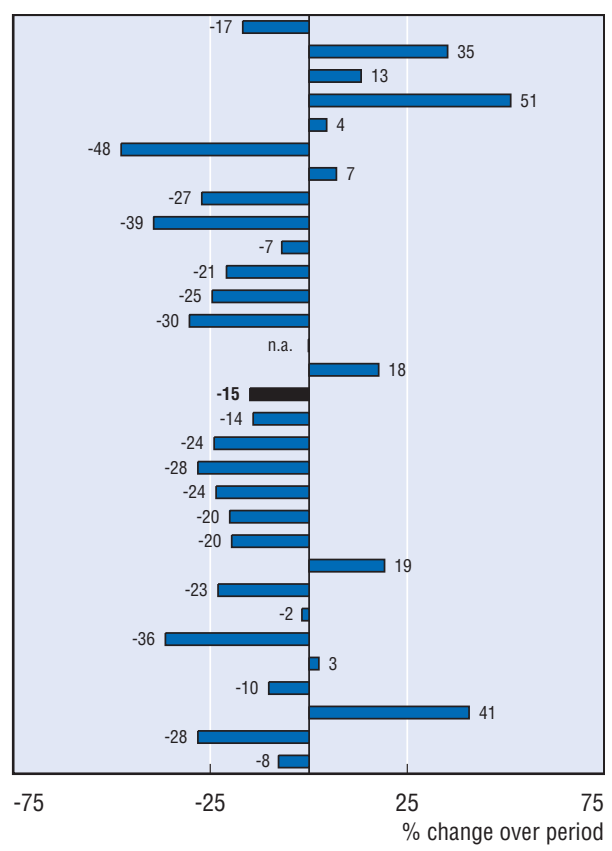

Chart 4.8. Liver cirrhosis deaths, 2002 and alcohol consumption, 1990

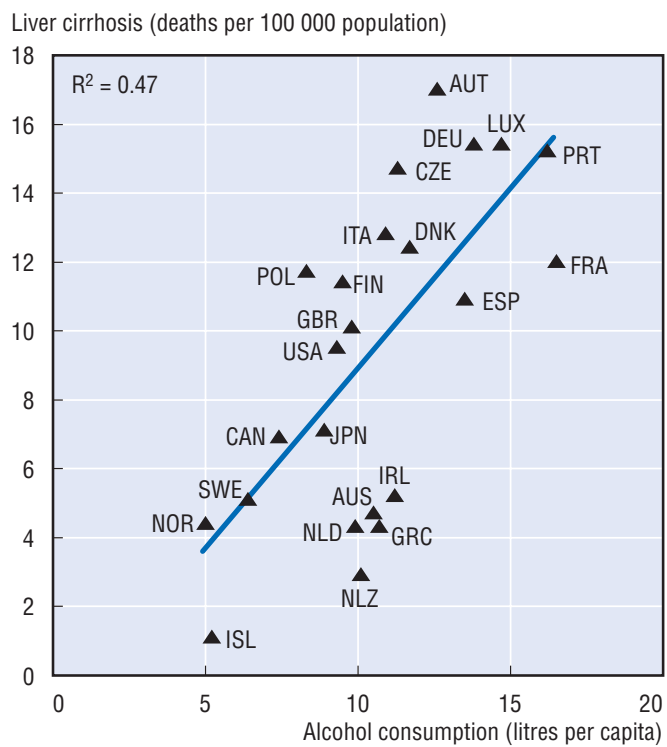

StatLink: http://dx.doi.org/10.1787/658408808217 
Health and nutrition are closely related. The "epidemic" of obesity, a growing public heath issue in many OECD countries (see indicator "Overweight and obesity"), is strongly linked to excessive consumption of food, together with physical inactivity. Moreover, an unhealthy diet, rich in saturated fat and in sugar consumption and poor in fruits and vegetables consumption, also increases the risks of many diseases, including coronary heart diseases, diabetes and some forms of cancer.

The following indicators present certain aspects of food consumption in OECD countries. However, it should be noted that these indicators refer to food available for consumption rather than food actually consumed (see the box on "Definition and deviations" below).

Rising rates of overweight and obesity observed in nearly all OECD countries are driven to a large extent by an imbalance between calorie consumption and calories expended (e.g., via physical activity). On average across OECD countries, estimated calorie consumption increased by some 450 calories per person per day between 1961 and 2002. In 2002, the United States was the country with the highest calories consumed per person, followed by Portugal and Greece (Chart 4.9). These are also the three countries where calorie consumption per capita increased the most since 1961 (Table A.4.3). At the other end of the scale, Japan had the lowest calorie consumption per person in 2002, followed by the Slovak Republic and Korea. In Japan and Korea, the relatively low calorie consumption per person is associated with the lowest rates of overweight and obesity among adults in all OECD countries. In the case of the Slovak Republic however, the relatively low calorie consumption per capita is associated with relatively high rates of overweight and obesity among adults, for reasons which are not clear.

The health effect of food consumption is not only related to overall calorie consumption, but also to the composition of food intake. Looking first at sugar consumption, high sugar intake increases the risk of many diseases (such as cardio-vascular diseases and diabetes), dental caries and obesity. Current recommendations from the $\mathrm{FAO} / \mathrm{WHO}$ are that added sugars in particular (contained notably in soft drinks, fruit drinks, cookies, ice cream, candy, etc.) should represent less than $10 \%$ of total daily calorie intake (FAO/WHO, 2003). Overall sugar consumption varies considerably across OECD countries. In 2002, it was particularly high in the United States, followed by Canada and New Zealand (Chart 4.10). Turkey and Japan were the countries with the lowest sugar consumption. Sugar consumption has increased in most OECD countries since 1961 (Table A.4.4).

Fruits and vegetables consumption, on the other hand, is highly recommended as a key component of a healthy diet. A recent WHO/FAO report recommends the intake of a minimum of 400 grams of fruits and vegetables per day for the prevention of chronic diseases such as heart diseases, cancer, diabetes and obesity (WHO/FAO, 2005). Consistent with this general guideline, governments in many countries have launched public education campaigns and programmes to promote the consumption of five servings of fruits and vegetables per day. In 2002, the estimated consumption of fruits and vegetables was the highest in Southern European countries (Greece, Turkey, Portugal, Italy, Spain) and Korea. It was the lowest in the Slovak and Czech Republics, and in Poland (Chart 4.11).

Data on the availability of food for consumption per capita provides only an aggregate measure of food consumption patterns across countries and trends over time. They do not identify which sub-groups in the population might have particularly unhealthy eating habits, nor the barriers which might need to be overcome to improve diets. This information can only be obtained from more detailed nutrition surveys or nutrition modules in general health surveys. For instance, in Switzerland, results from successive waves of the national health survey indicate a decline in fruit and vegetable consumption among younger age groups between 1992 and 2002, while consumption has increased among older age groups (Swiss Federal Statistical Office, 2005).

\section{Definition and deviations}

The food consumption data presented in this section come from the FAO Nutrition database. They refer to food available for consumption (i.e., reaching the consumers) rather than food actually consumed. In the United States, it has been estimated that food available for consumption may be $30 \%$ higher than food actually consumed because of waste (USDA, 1999), but this difference may be lower or higher depending on the country.

The consumption of fruits and vegetables excludes potatoes and other starchy tubers.

In Australia and New Zealand, total calorie consumption is under-estimated compared with other countries, because of the use of different conversion factors to calculate dietary energy supply. The difference with other OECD countries has been narrowing over time but still remains at a level of about $10 \%$. 


\section{Chart 4.9. Total calories consumption, 2002}

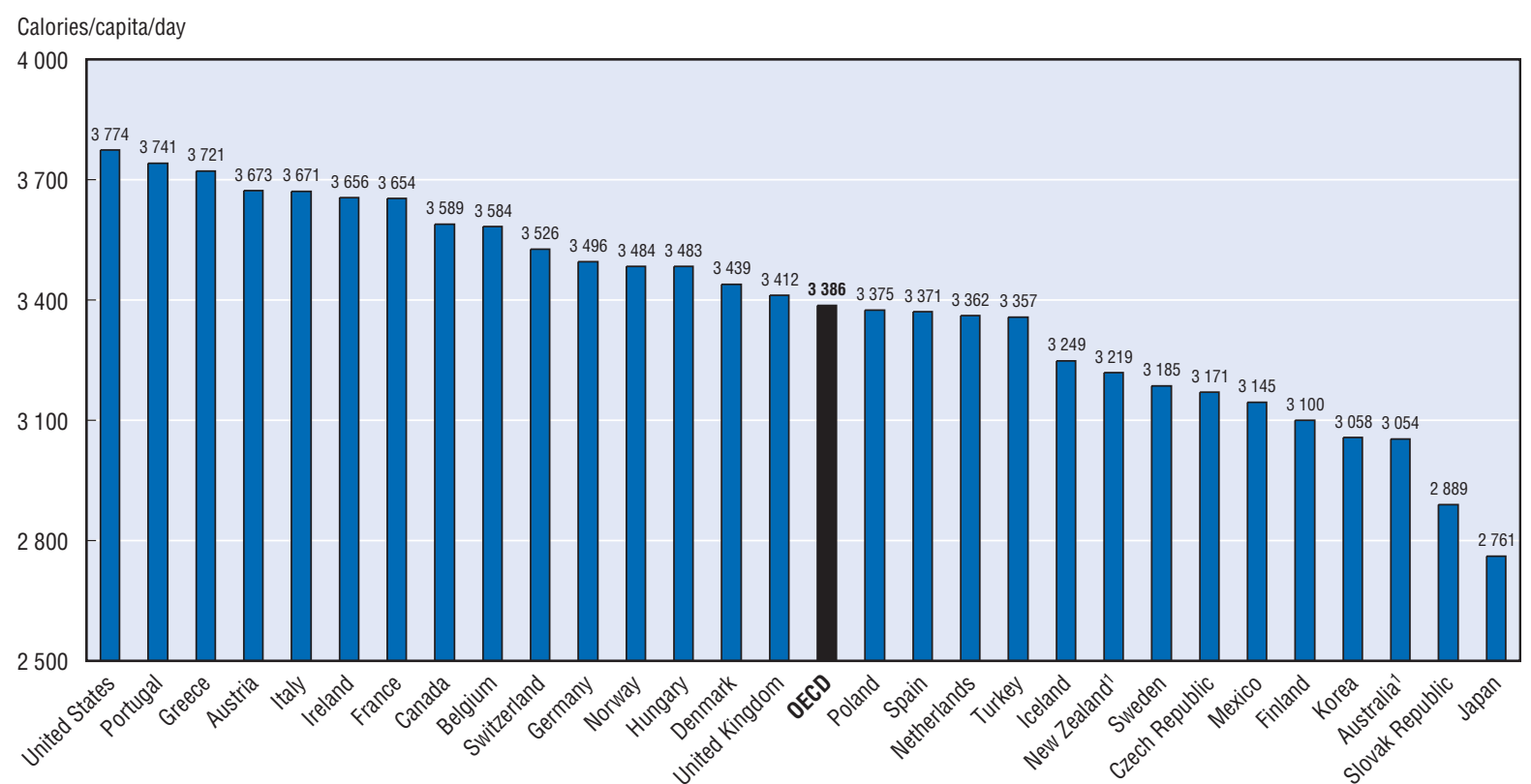

1. Data for Australia and New Zealand are not directly comparable with those from other countries because of the use of a different set of conversion factors, resulting in an under-estimation of about $10 \%$ in total calories consumption.

\section{Chart 4.10. Sugar consumption,}

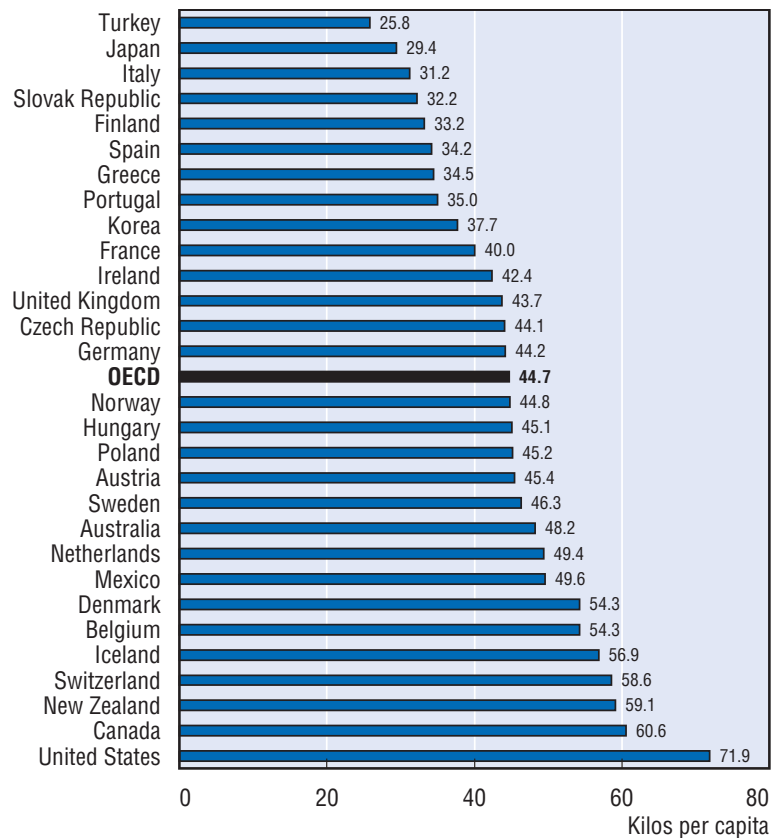

Chart 4.11. Fruits and vegetables consumption, 2002

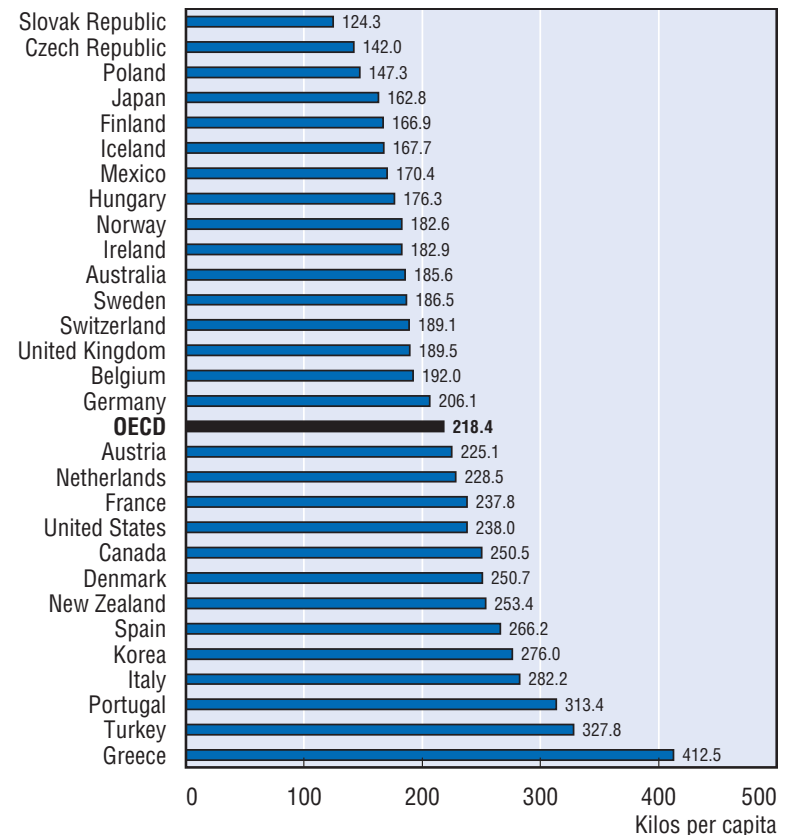

Source: OECD Health Data 2005. (The data come from the FAOSTAT Nutrition database. They refer to food available for consumption rather than food actually consumed.) 
In many OECD countries, the growth in overweight and obesity rates among children and adults is rapidly becoming a major public health concern. Obesity is a known risk factor for several health problems, including hypertension, high cholesterol, diabetes, cardiovascular diseases, respiratory problems (asthma), musculoskeletal diseases (arthritis) and some forms of cancer. In the United States, where more than 3 out of 10 adults are now obese, a recent study estimated that the cost related to obesity now exceeds the cost related to smoking and excessive drinking for a set of chronic health problems (Sturm, 2002).

More than $50 \%$ of adults are now defined as either being overweight or obese in no less than 10 OECD countries: the United States, Mexico, the United Kingdom, Australia, the Slovak Republic, Greece, New Zealand, Hungary, Luxembourg and the Czech Republic (Table A.4.6). By comparison, overweight and obesity rates are much lower in the OECD's two Asian countries (Japan and Korea) and in some European countries (France and Switzerland), although overweight and obesity rates are also increasing in these countries. Focussing only on obesity (which presents greater health risks than being only overweight), the prevalence of obesity among adults varies from a low of $3 \%$ in Japan and Korea, to a high of $31 \%$ in the United States (Charts 4.12 and 4.13 ).

It should be noted however that estimates of overweight and obesity rates in most countries are based on self-reported data, which is not the case for the United States, Australia, New Zealand and the United Kingdom where estimates are based on the actual measurement of people's height and weight. Evidence from many countries shows that selfreported data on height and weight are not as reliable as actual measures, usually because of an underestimation of weight. For instance, in the United States, the adult obesity rate based on face-to-face interviews was $22 \%$ in 1999 , compared with $31 \%$ in that same year based on actual measurements. Similarly, the obesity rate among adults in Australia was $18 \%$ in 2001 according to self-reported data, compared with $22 \%$ in 1999 based on the actual measurement of height and weight. This means that current estimates of obesity rates in many OECD countries under-estimate the true prevalence of obesity because of these reporting biases.

Using consistent measures of obesity over time, the rate of obesity has more than doubled over the past twenty years in the United States, while it has almost tripled in Australia and more than tripled in the United Kingdom (Chart 4.14). Some $21-24 \%$ of adults in Mexico, the United Kingdom, the Slovak Republic, Greece, Australia and New Zealand are now defined as obese, about the same rate as in the United States in the early 1990s. The obesity rate in many Western European countries has also increased substantially over the past decade.

In many countries, the rise in obesity has affected all population groups, regardless of sex, age, race, income or education level. Evidence from the United States and Canada indicates however that obesity tends to be more common among individuals in lower-income groups than in higherincome groups (Statistics Canada and CDC, 2004).

Because obesity is associated with higher risks of chronic illnesses, it is linked to significant additional health care costs. At a macro level, it has been estimated that health care costs which might be attributed to obesity accounted for about $5-7 \%$ of total health spending in the United States in the late 1990 s, and 2 to $3.5 \%$ of health spending in other countries like Canada, Australia and New Zealand (Thompson and Wolf, 2001). At a more micro level, estimates from the United States indicate that the cost of health care services is $36 \%$ higher, and the cost of medications $77 \%$ higher, for obese people than for people of normal weight (Sturm, 2002). There is a time lag of several years between the onset of obesity and related health problems, suggesting that the rise in obesity over the past two decades observed in most OECD countries will mean higher health care costs in the future.

A number of behavioural and environmental factors have contributed to the rise in overweight and obesity rates in industrialised countries, including falling real prices of food and more time spent being physically inactive. The relative importance of some of the factors driving obesity rates might vary across countries. In the United States, a study by Cutler and colleagues (2003) argued that the main factor explaining weight gains among American adults was an increase in calories consumed. This study found that $90 \%$ of the increase in calorie intake over the past twenty years in the United States was due to eating more "snacks" per day. In other countries like the United Kingdom, a reduction in physical activity might have played a larger role (Department of Health, 2005)

\section{Definition and deviations}

Overweight and obesity are defined as excessive weight presenting some health risks because of the high proportion of body fat. The most frequently used measure of overweight and obesity is based on the body mass index (BMI), which is a single number that evaluates an individual's weight status in relation to height (weight/height ${ }^{2}$, with weight in kilograms and height in metres). Based on the WHO current classification (WHO, 1997), individuals with a BMI between 25 and 30 are defined as overweight, and those with a BMI over 30 as obese. This classification may not be suitable however for all ethnic groups, who may have equivalent levels of risk at lower BMI (for example, Asians) or higher BMI (AIHW, 2004). It is not also suitable to measure overweight and obesity among children.

For most countries, estimates of overweight and obesity rates are self-reported through population-based health interview surveys. The exceptions are Australia, New Zealand, the United Kingdom and the United States, where estimates are derived from health examinations whereby actual measures are taken of people's height and weight. These differences in data collection methodologies seriously limit data comparability. Estimates from health examinations are generally higher and more reliable than those coming from health interviews, but health examination surveys are only conducted regularly in a few countries. 
Chart 4.12. Percentage of adult population with Body Mass Index over 30 (obese population), 2003 or latest year

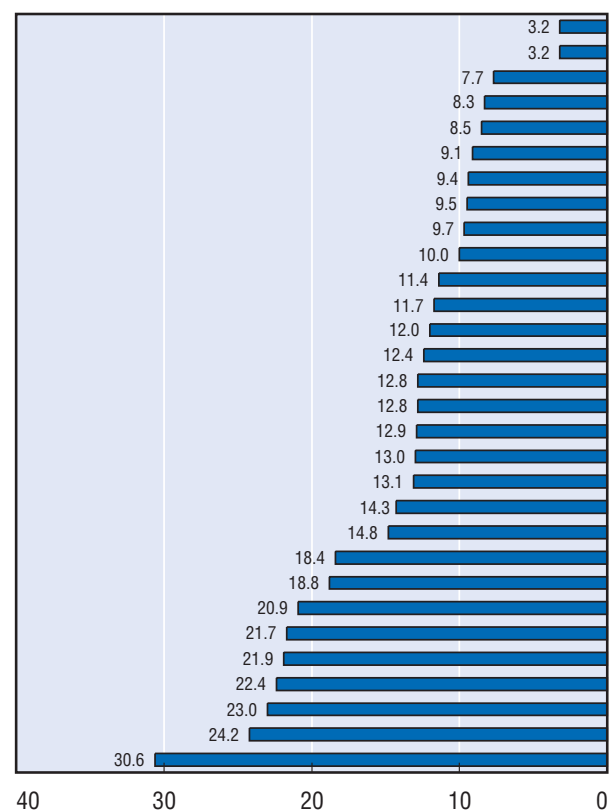

$\%$ of adult population

20

10

For Australia, New Zealand,

health interview surveys.

\section{Chart 4.14. Increasing obesity rates among the adult population in OECD countries}

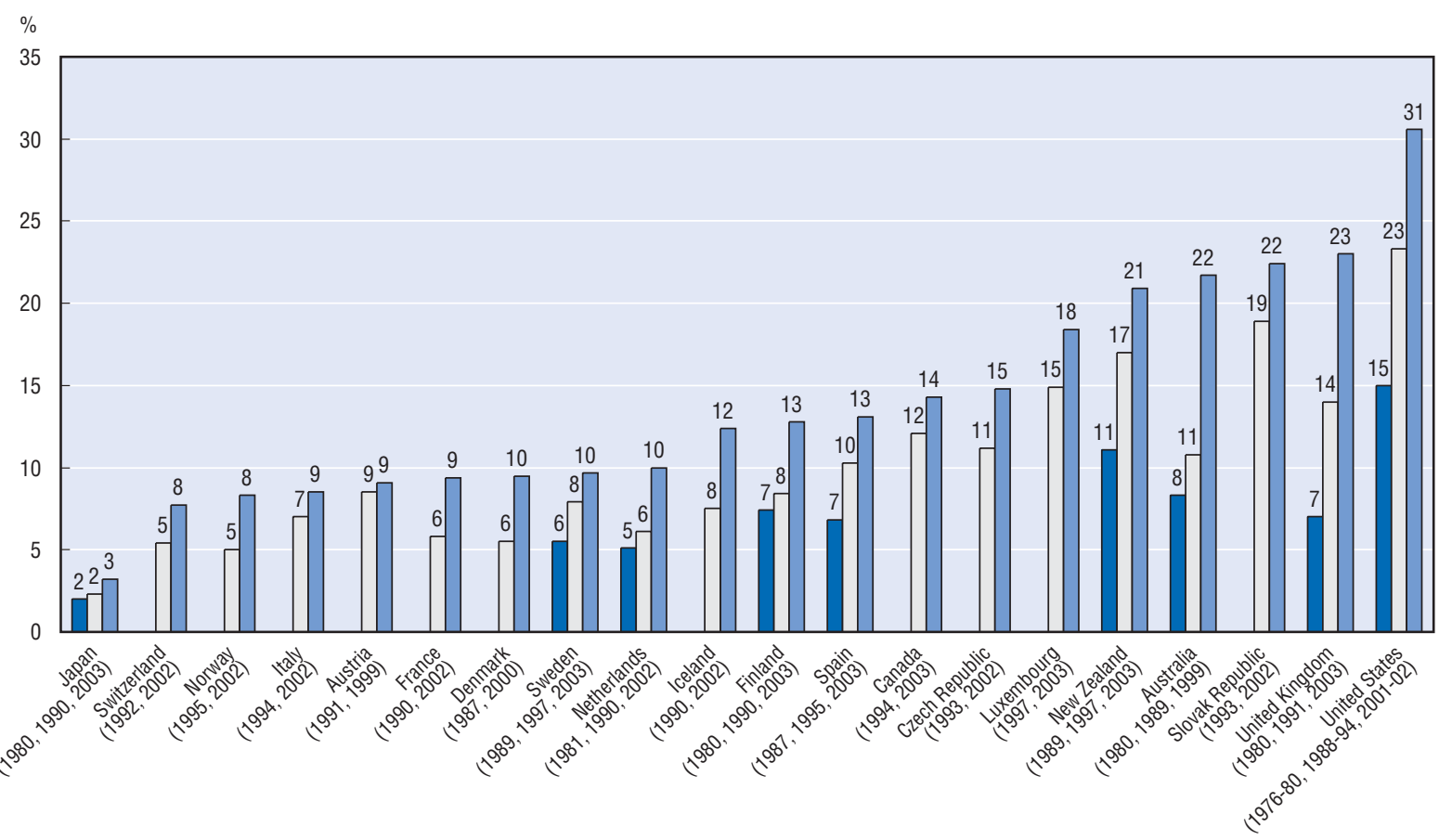

Note: See footnotes to Table A.4.6.

Source: OECD Health Data 2005. 



\section{Demographic and Economic Context}

1. Total population and population structure $\ldots \ldots \ldots \ldots \ldots \ldots \ldots \ldots \ldots \ldots \ldots$

2. Fertility rates. . . . . . . . . . . . . . . . . . . . . . . . . . 92

3. Gross domestic product (GDP) and income inequality................. 94 
The growth in populations through natural increase (births minus deaths) has slowed throughout the OECD, to varying extents, leading to ageing societies, which has implications for government and individual spending on health and welfare.

In 2003, OECD countries accounted for more than 1.15 billion people, around one-fifth of the World's population. The United States remains the most populous country in the OECD with 290 million people, more than a quarter of the total OECD population. Japan and Mexico follow with over 100 million people in each of these countries. At the other end of the scale, Iceland and Luxembourg are the least populated countries, each counting less than half a million people (Chart 5.1 and Table A.5.1).

Since 1960 the total population of the OECD countries has grown by more than $50 \%$ with the most pronounced growth occurring in the period between 1960 and 1980, due to relatively high fertility rates in some countries and falling mortality rates. Population growth has slowed significantly in the past two decades in many OECD countries, as fertility rates declined (see indicator "Fertility rates"). Between 1990 and 2003 population growth rates for all OECD countries averaged around $0.6 \%$ per year, only around half the rate observed in the 1960s and 1970s. Within this average, however, there are large variations. Whereas Mexico and Turkey have experienced the greatest population growth since 1960 - each experiencing a more than doubling of their populations over the period - some Eastern European countries have seen their populations little changed since 1960, including a contraction in recent decades due to external migration and low fertility rates (Chart 5.2). Population growth in most of the non-European countries, such as Australia, Canada, New Zealand and the United States, has also been relatively strong over the past four decades, in part through natural increase but also through net migration to these countries.

The demand for, and financing of, health and long-term care, as well as pensions and other social benefits, depend partly on how the demographic structure of a country changes. The percentage of the population that is 65 years or older has risen in all OECD countries and is expected to continue to do so. Both Italy and Japan can count almost a fifth of their population above the age of 65 , the latter seeing a three-fold increase in this proportion over the last forty years (Chart 5.3).

The old-age dependency ratio, which compares the number of persons aged 65 and over to the population of working age (age 15 to 64 ) is another useful way of assessing the effect of population ageing. In 2003, this ratio varied from less than one in ten in the case of Turkey and Mexico to more than one in four in Italy and Japan, as well as some other European countries including Germany and France. The OECD average of around one in five is expected to more than double by 2050 , leaving one elderly person to every two of working age. Since older populations tend to be in poorer health and thus in greater need of health and long-term care, population ageing can be expected to increase public expenditure in these areas. This could amount to an extra three percentage points of GDP by 2050 (Bains and Oxley, 2004).

\section{Definition and deviations}

Total population is defined as all nationals present in, or temporarily absent from, the country and foreigners permanently settled in the country, in the middle of the year.

The old-age dependency ratio is defined as the population age 65 and over compared to the population of working age, taken as age 15 to 64 . The inclusion of the 15-19 age group is based on a general assumption that the fraction of adolescents aged under age 20 in the labor force equals the fraction of the population aged 65 or more years still in the labor force.

Note that population figures for Germany represent West Germany prior to 1991. 
Chart 5.1. Total population of OECD countries, million, 2003

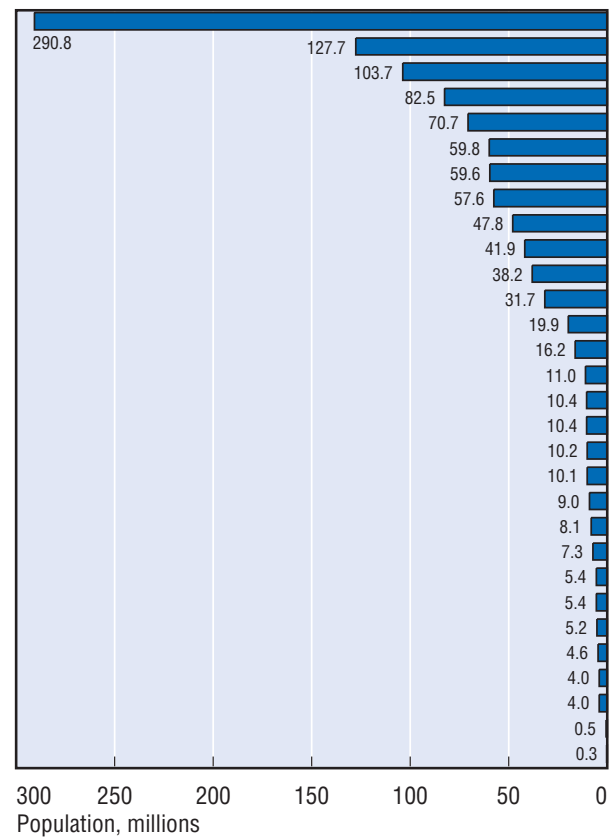

1. Population for 1960 refers to West Germany
Chart 5.2. Percentage change in population, 1960-2003
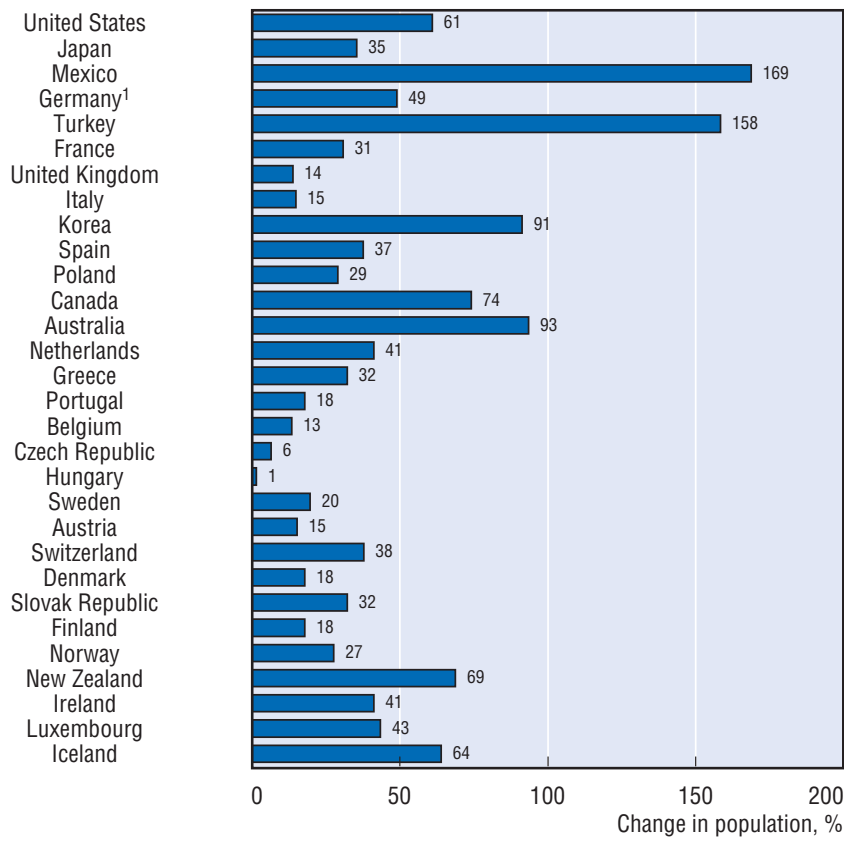

Chart 5.3. Share of population aged 65 and over, 1960 and 2003

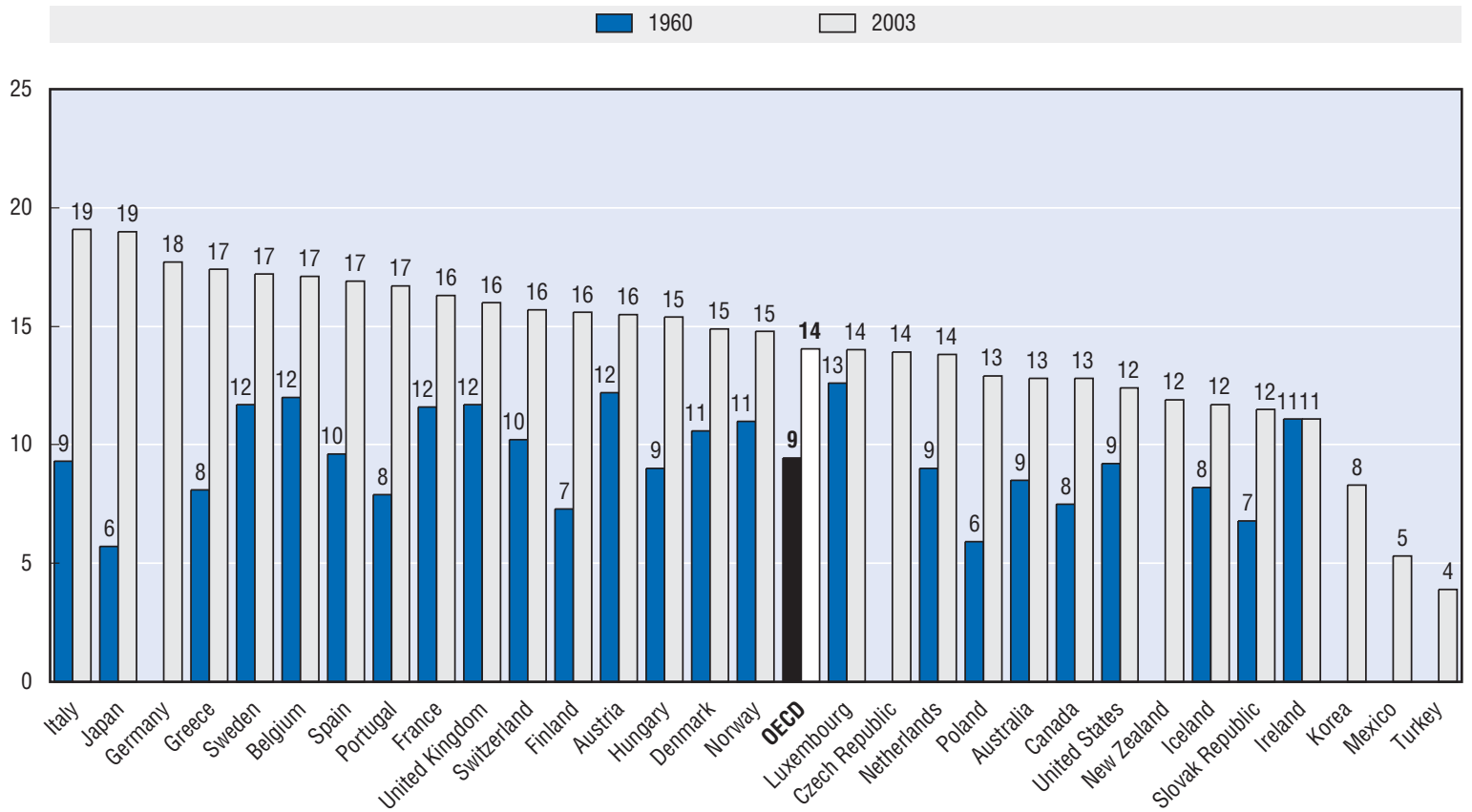

Source: OECD Health Data 2005. 
Along with declining mortality rates, the other main factor affecting the observed demographic change across OECD countries has been the dramatic decrease in fertility rates over recent decades. All countries have seen a fall in fertility since the 1960s, resulting in Mexico and Turkey now being the only OECD countries with a fertility rate above the "replacement level" of 2.1 children, the level required to ensure the broad stability of the population without net immigration and no change in mortality rates. Because of the impact on both the overall size of the population as well as the age structures, countries are looking at how their policies directly or indirectly affect birth rates.

The fertility rate for women aged 15-49 has declined steadily since the post war baby boom in all OECD countries. This rate has dropped from around three children per woman in 1960 to almost half this level in 2003 (Table A.5.4). The pace of decline has varied from country to country (Chart 5.4). However, even Turkey and Mexico, the only countries continuing to show fertility rates above 2.1 children, have seen dramatic reductions from the levels observed forty years earlier. Southern European countries, such as Greece, Italy and Spain, experienced a later fall in fertility rates but now report some of the lowest rates among the OECD, along with some Eastern European countries. Korea has also seen a dramatic reduction in fertility rates in recent decades (Chart 5.5). The introduction of the National Family Planning programme in the early 1960s, together with sustained economic growth over the following decades, saw the rate fall to the second-lowest of all OECD countries in 2003 (Choe and Park, 2005).

There are many inter-related factors affecting fertility rates, reflecting both individual behaviour and the social and historical influences within each country. The rapid increase in the availability of contraceptive methods in the second half of the twentieth century has been a major factor in the fall in fertility in many countries. Another prominent reason for the observed change in fertility has been the postponement of motherhood in many countries. This delay in childbearing can be related to a variety of individual and societal conditions such as the role of women within society in combining family-life and career, economic and financial security, and the changing importance of parenthood relative to other goals (D'Addio and Mira d'Ercole, 2005).

For a group of OECD countries, the average age at first childbirth has risen from under 24 in 1970 to over 27 by 2000 . The effect of successive cohorts of women delaying childbearing until later in life might result in a short-term overestimation of the decline in total fertility rates which could be reversed in the future, as age-specific fertility over a certain age (30, for example) increases.

Reversals of the downward trend in fertility rates have been observed, to varying extents in a number of countries since 1980, including in the United States the Netherlands and Nordic countries. The United States and Italy, for example, had similar fertility rates at the end of the 1970s. Since then, however, the fertility rate in the United States has risen and has hovered just below the "replacement level" since 1990, while Italy has continued to see a steady decline.

With past and future fertility rates impacting on the population structure, countries need to consider carefully policies which may impact on family size. Family friendly policies allowing women to combine education and career with childrearing (through affordable childcare and parental leave, for example), and the effect of tax and family benefits, can all have an effect on changing the fertility rate (OECD, 2005b).

\section{Definition and deviations}

The fertility rate in a specific year is the average number of children a woman can be expected to bear over the course of her childbearing years if she were to give birth to children at each age (between 15 and 49) in agreement with prevailing age-specific fertility rates.

A fertility rate of 2.1 children per woman ensures broad stability of the population (assuming no net migration flows and no change in mortality rates). 
Chart 5.4. Total fertility rates, children per woman aged 15-49, 1960, 1980 and 2003

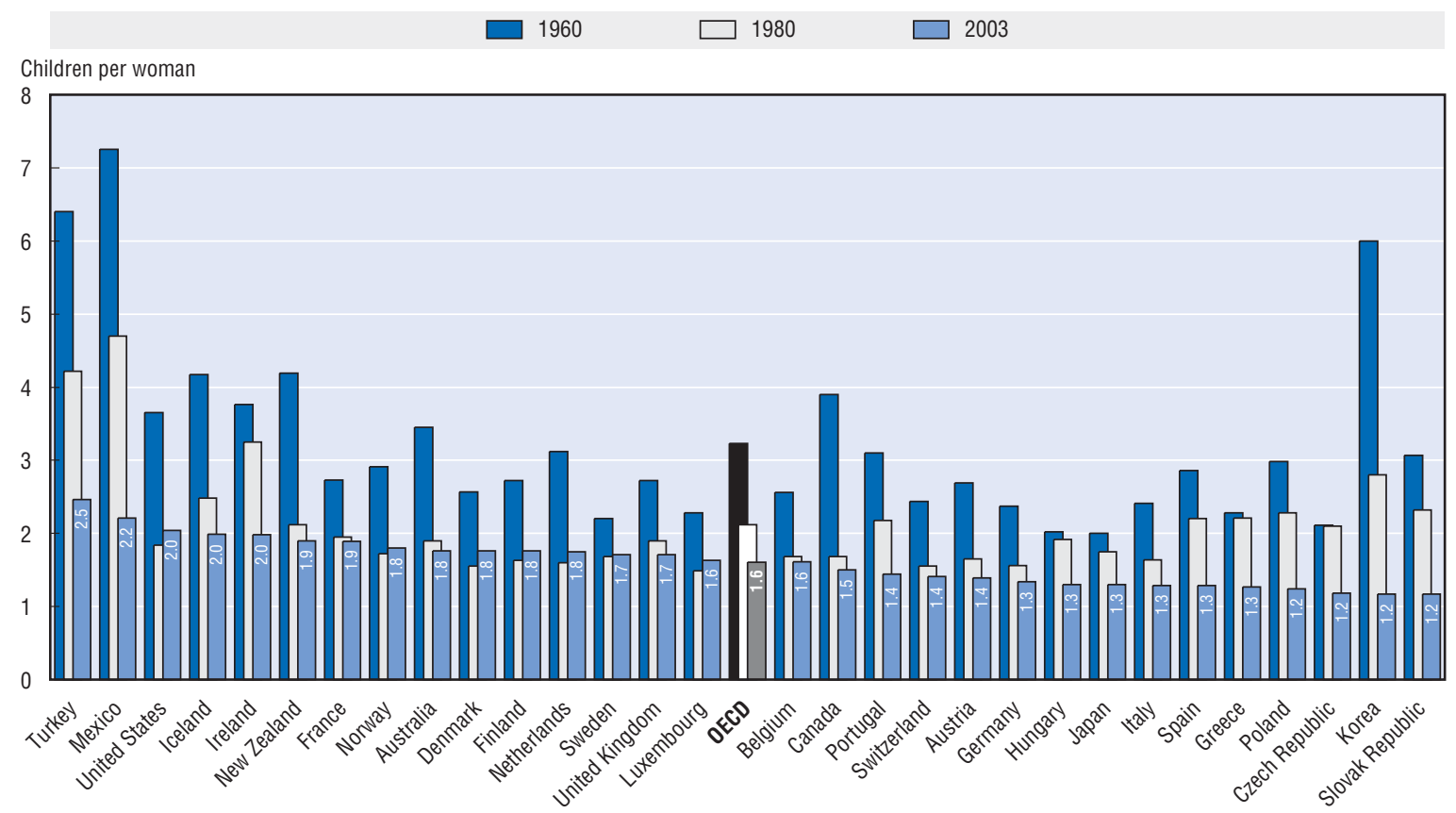

Chart 5.5. Total fertility rates, 1970 to 2003

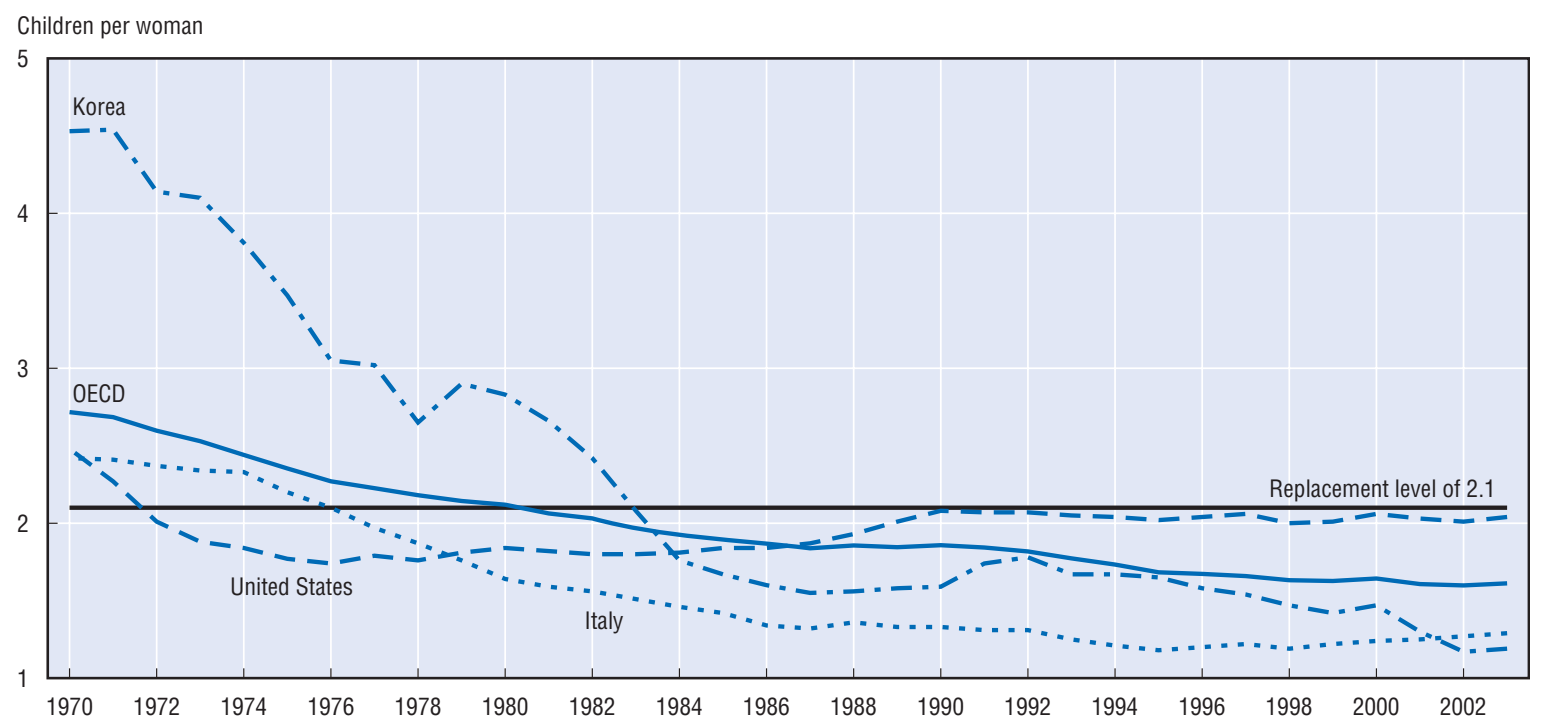

Source: OECD Health Data 2005.

StatLink: http://dx.doi.org/10.1787/383213044624 
GDP per capita provides an indication of the level of economic development in a country and the living standards of its population. However, in itself, GDP per capita provides only an average level of national monetary income and does not measure the distribution of income across the population.

In comparing levels of GDP per capita, expressed in USD PPPs (purchasing power parities), there is wide variation between the OECD countries. While Turkey and Mexico report GDP per capita of less than 10000 USD PPP in 2003, most OECD countries have GDP per capita falling between 20000 and 35000 USD PPP. The wealthiest countries in the OECD are Luxembourg, followed by the United States and Norway, both with GDP per capita over 35000 USD PPP in 2003 (Chart 5.6 and Table A.5.5). It should be noted though that measures of per capita income using GDP are somewhat overstated in a number of countries, notably Luxembourg and Ireland, either due to the number of foreign workers contributing to the country's domestic product, in the case of Luxembourg, or the influence of foreign companies operating in Ireland. The Gross National Income (GNI) is closer to a measure of the actual income that is domestically available in the country, although for most countries the use of GNI or GDP will make very little difference.

Since 1990, real GDP per capita has increased in all OECD countries to varying degrees. Ireland and
Korea has seen the fastest growth, with the former averaging an almost $6 \%$ increase in GDP per capita each year. This has taken Ireland from a country in the bottom half of OECD countries in terms of national income in 1990 to fourth overall by 2003. By contrast, Switzerland, Germany and the Czech Republic have seen per capita GDP growth average under 1\% since 1990 (Chart 5.7).

While higher GDP per capita is generally associated with better health status across countries, the relationship is less pronounced at higher levels of national income and there are significant differences in health status between OECD countries with similar per capita incomes (see indicator "Life expectancy at birth"). The distribution of national income may also have an effect on the health status of a country's population. Some analysts have reported evidence of a correlation between life expectancy across countries with income inequalities within countries, with life expectancy being higher in those countries with less income inequalities (Wilkinson, 1996, 2000). Chart 5.8 shows a measure of the income inequality, expressed as the Gini coefficient, across the OECD and the change observed since the mid-1980s. Income inequality is currently highest in Mexico and Turkey and lowest in Denmark and Sweden. In most countries, income inequality has risen since the mid-1980s, although it has decreased, at least slightly, in some (e.g. Ireland, Australia and France).

\section{Definition and deviations}

There are three different approaches to measuring GDP: 1) to sum up all the value added by resident producers; 2) to take the sum of income received by labour and capital; or 3) to add up all domestic expenditure plus exports, less imports of goods and services. The data presented here are based on the third approach (expenditure-based) (OECD, 2000b).

Comparisons of GDP across countries are best based on purchasing power parities (PPP), not simply on market exchange rates. Purchasing power parities reflect the amount of a national currency that will buy the same basket of goods and services in a given country as the US dollar in the United States. Because the cost of living is often lower in poorer countries, calculating income per capita using PPPs generally reduces the difference between the richest and the poorest countries in the OECD. Real GDP is measured by deflating the expenditure components by appropriate price indices, with prices in 2000 as the base.

Income distribution is measured by the Gini coefficient. The Gini coefficient is defined as the area between the Lorenz curve (which plots cumulative shares of population, from the poorest to the richest, against the cumulative share of incomes that they receive) and the $45^{\circ}$ line ("line of perfect equality"). The values range between 0 in the case of "perfect equality" and 100 in the case of "perfect inequality"). An increase in the Gini coefficient thus represents an increase in inequality. 


\section{V.3. GROSS DOMESTIC PRODUCT (GDP) AND INCOME INEQUALITY}

\section{Chart 5.6. GDP per capita,} 2003

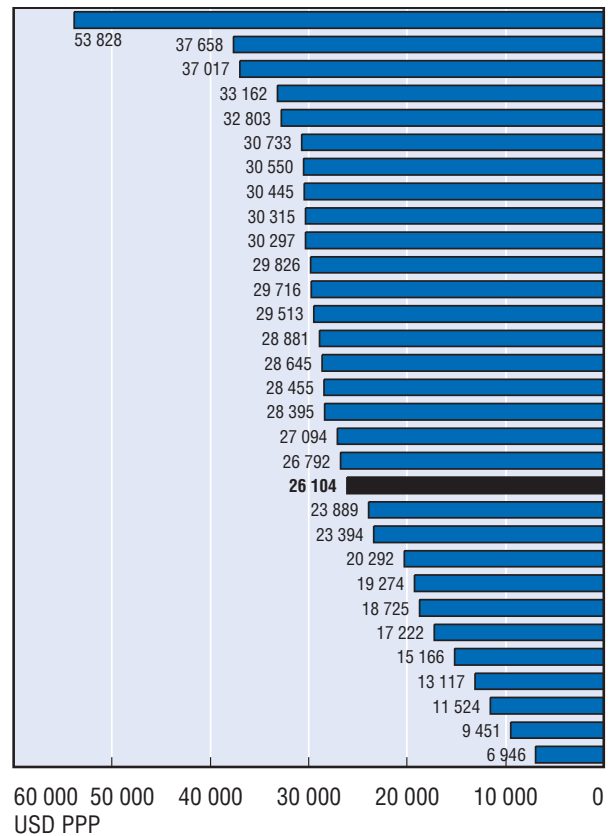

Source: OECD Health Data 2005.

\section{Chart 5.7. Annual growth rate in real GDP per capita, 1990 to 2003}

Luxembourg
United States
Norway
Ireland
Switzerland
Denmark
Austria
Canada
Netherlands
Australia
United Kingdom
Iceland
Belgium
Sweden
France
Finland
Japan
Germany
Italy
OECD
Spain
New Zealand
Greece
Korea
Portugal
Czech Republic
Hungary
Slovak Republic
Poland
Mexico
Turkey

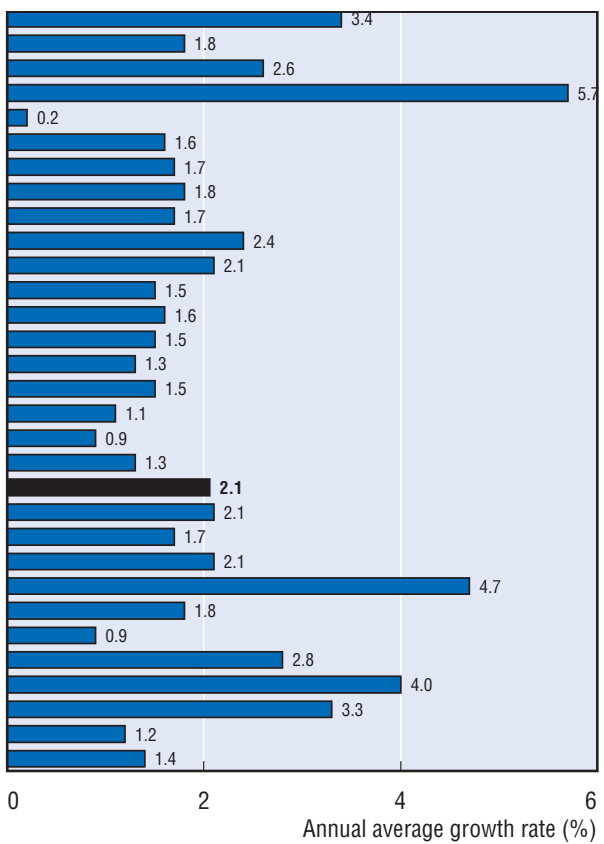

Chart 5.8. Income inequality, Gini coefficient, mid-1980s and 2000

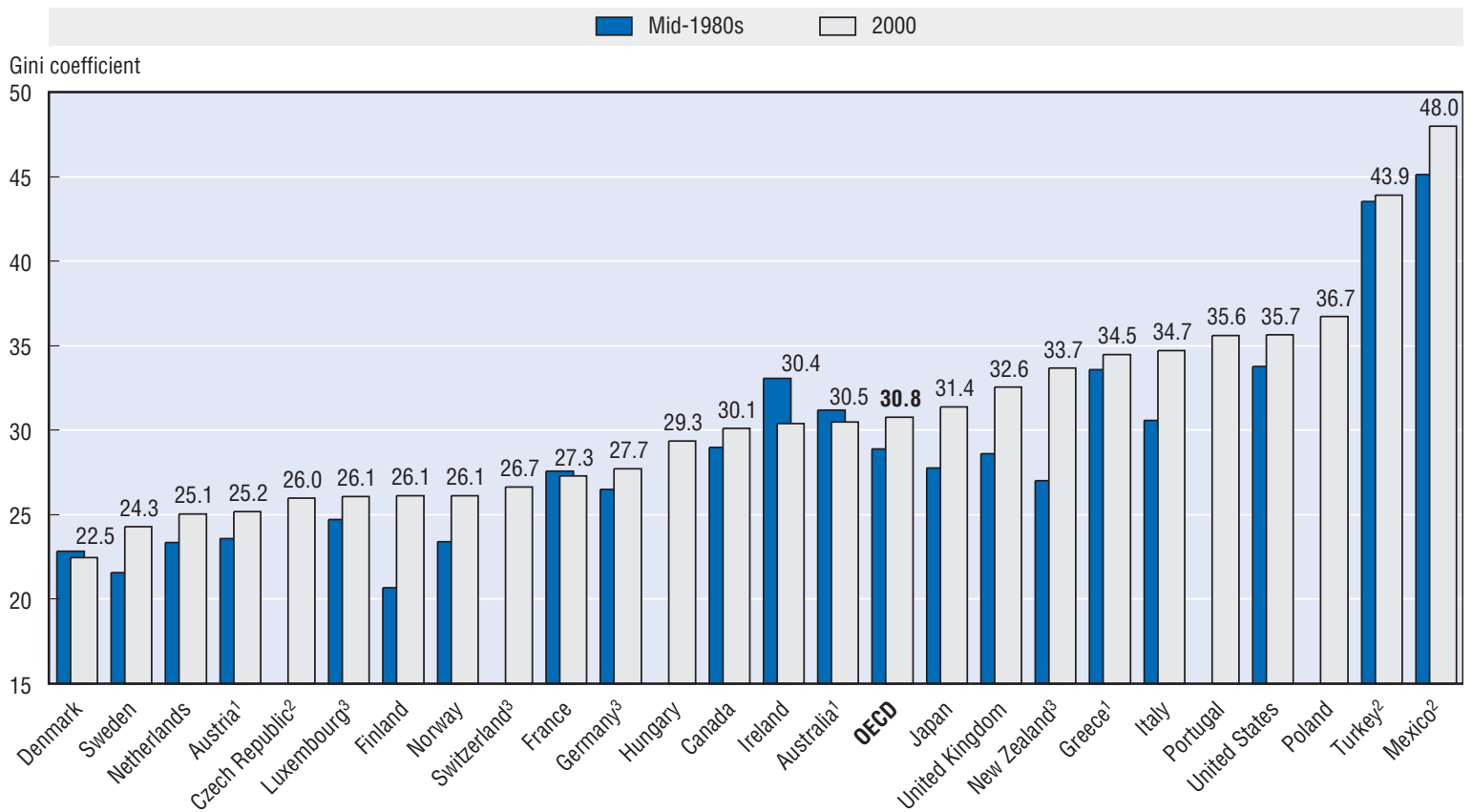

Note: A higher Gini coefficient means greater income inequality.

1. 1999

2. 2002 .

3. 2001.

Source: Förster and Mira d'Ercole (2005). 



\section{Bibliography}

AIHW - Australian Institute of Health and Welfare (2005), A Picture of Australia's Children, May 2005, Canberra, pp. 37-39.

AIHW - Australian Institute of Health and Welfare (2004), Australia's Health 2004, AIHW Cat. No. AUS 44, Canberra.

AMWAC - Australian Medical Workforce Advisory Committee and Australian Institute of Health Welfare (1996), Female Participation in the Australian Medical Workforce, AMWAC Report 1996.1, Sydney.

Babazano, A. and A.L. Hillman (1994), “A Comparison of International Health Outcomes and Health Care Spending”, International Journal of Technology Assess Health Care, Vol. 10(3), pp. 376-381.

Bains, M. and H. Oxley (2004), "Ageing-related Spending Projections on Health and Long-term Care", Chapter 7 in Towards High Performing Health Systems - Policy Studies, OECD, Paris, pp. 319-331.

Bennett, J. (2003), "Investment in Population Health in Five OECD Countries", OECD Health Working Papers, No. 2, OECD, Paris.

Bewley, S. and J. Cockburn (2002), “The Unfacts of "Request' Caesarean Section”, BJOG: An International Journal of Obstetrics and Gynaecology, Vol. 109, pp. 597-605.

Buchan, J. and L. Calman (2004), "Skill-mix and Policy Change in the Health Workforce: Nurses in Advanced Roles", OECD Health Working Papers, No. 17, Paris.

BVCV Callens, Pirenne and Co (2002), Bedrijfsrevisoren, vertegenwoordigd door B. Callens, Vlaamse Huisartseninkomens, vergelijkende studie met het ambtenaarswezen en de privésector, Antwerp.

Center for Disease Control (2000), Recommendations of the Advisory Committee on Immunisation Practices (ACIP), Morbidity and Mortality Weekly Report, Vol. 49 (RR-3), pp. 1-38.

Center for Disease Control (2003), National Vital Statistics Report, Vol. 52, No. 10, US National Center for Health Statistics, pp. 87-88.

Center for Disease Control (2004), "Influenza Vaccination and Self-reported Reasons for Not Receiving Influenza Vaccination Among Medicare Beneficiaries Aged 65 Years and Older - United States, 1991-2002", Morbidity and Mortality Weekly Report, Vol. 53(43), pp. 1012-1015.

Choe, M.K. and K.A. Park (2005), "Fertility Decline in South Korea: forty years of policy-behaviour dialogue", East West Center, International Union for the Scientific Study of Population, XXV International Population Conference, Tours, France.

Cutler, D. and R. Huckman (2003), “Technological Development and Medical Productivity: the diffusion of angioplasty in New York state”, Journal of Health Economics, Vol. 22 (2), March 2003, pp. 187-217.

Cutler, D. et al. (2003), "Why Have Americans Become More Obese?”, Discussion Paper No. 1994, Harvard Institute of Economic Research, January 2003.

D'Addio, A.C. and M. Mira d'Ercole (2005), “Trends and Determinants of Fertility Rates in OECD Countries: The role of policies", OECD Social, Employment and Migration Working Papers, No. 27, OECD, Paris.

Declercq E., F. Menacker and M. Macdorman (2005), “Rise in 'No Indicated Risk' Primary Caesareans in the United States, 1991-2001: cross sectional analysis”, British Medical Journal, Vol. 330, pp. 71-72.

Department of Health (2005), Choosing Health: Making Healthy Choices Easier, London.

Docteur, E. et al. (2003), “The US Health System: An Assessment and Prospective Directions for Reform", Economics Department Working Papers, No. 350, OECD, Paris. 
DREES (2005), Études et Résultats, No. 387, Ministère de la Solidarité, de la Santé et de la Famille, Paris, March 2005.

Eun-Hwan Oh, Y. Imanaka and E. Evans (2005), "Determinants of the Diffusion of Computed Tomography and Magnetic Resonance Imaging", International Society for Technology Assessment in Health Care, Vol. 21 (1).

FAO/WHO (2003), "Diet, Nutrition and the Prevention of Chronic Diseases; Report of the joint WHO/FAO expert consultation”, WHO Technical Report Series, No. 916.

Förster, M. and M. Mira d'Ercole (2005), "Income Distribution and Poverty in OECD Countries in the Second Half of the 1990s", OECD Social, Employment and Migration Working Papers, No. 22, OECD, Paris.

Häkkinen, U. et al. (2004), "Regional Differences in Outcome of the Treatment of AMI Patients: does an increase in the use of evidence based technology matter?", paper presented at NHESG meeting, Reykjavik, August 2004.

Hisashige, A. (1992), "The Introduction and Evaluation of MRI in Japan”, International Society for Technology Assessment in Health Care, Vol. 3, No. 126.

Institute of Cancer Research (2003), Prostate Cancer, Fact Sheet, Web site accessed on 10/05/2005 (www.icr.ac.uk/everyman/about/prostate.html).

International Agency for Research on Cancer (IARC) (2004), GLOBOCAN 2002: Cancer Incidence, Mortality and Prevalence Worldwide, IARC CancerBase No. 5, Version 2.0, IARC Press, Lyon.

Jeong, H.S. and A. Gunji (1994), “The Influence of System Factors upon the Macro-economic Efficiency of Health Ccare: implications for the health policies of developing and developed countries", Health Policy, Vol. 27.

Jeong, H.S. and J. Hurst (2001), “An Assessment of the Performance of the Japanese Health Care System”, OECD Labour Market and Social Policy Occasional Papers, No. 56, Paris.

Kane, C.K. and H. Loeblich (2003), "Physician Income: The Decade in Review", Physicians Socioeconomic Statistics, 2003 Edition, AMA Press, Chicago, pp. 5-11.

Kiely, J., K. Brett, S. Yu and D. Rowley (1995), "Low Birth Weight and Intrauterine Growth Retardation", in L. Wilcox and J. Marks (eds.), From Data to Action: CDC's Public Health Surveillance for Women, Infants, and Children, USDHHS, CDC, Atlanta, pp. 185-202.

Kroneman, M. and J. Siegers (2004), "The Effect of Hospital Bed Reduction on the Use of Beds: A comparative study of 10 European countries", Social Science and Medicine, Vol. 59, pp. 1731-1740.

Marshall, M. et al. (2002), Quality Indicators for General Practice: A practical guide to clinical quality indicators for primary health professionals and managers, Royal Society of Medicine Press, London.

Mathers, C. et al. (2005), "Counting the Dead and What They Died From: an assessment of the global status of cause of death data", Bulletin of the World Health Organisation, Vol. 83 (3), March 2005, pp. 171-177.

Max Planck Institute for Demographic Research (1999), "Male-female Differences in Mortality in the Developed World”, MPIDR Working Paper 1999-2000, by A. Gjonça, C. Tomassini and J.W. Vaupel, Germany.

Moïse, P. (2003), “The Heart of the Health Care System: Summary of the Ischaemic Heart Disease Part of the OECD Ageing-Related Diseases Study", A Disease-based Comparison of Health Systems: What is Best and at What Cost?, OECD, Paris.

Moïse, P., S. Jacobzone et al. (2003), “OECD Study of Cross-national Differences in the Treatment, Costs and Outcomes for Ischaemic Heart Disease", OECD Health Working Papers, No. 3, OECD, Paris.

Moon, L., P. Moïse and S. Jacobzone (2003), "Stroke Care in OECD Countries: A Comparison of Treatment, Costs and Outcomes in 17 OECD Countries", OECD Health Working Papers, No. 5, OECD, Paris.

National Cancer Institute (2004), “Radiation Therapy for Cancer: Questions and Answers”, Cancer Facts, Vol. 7.1.

National Center for Health Statistics (2004), Health, United States, 2004, with Chart on Trends in the Health of Americans, Hyattsville, Maryland.

OECD (2000a), A System of Health Accounts, OECD, Paris.

OECD (2000b), National Accounts, OECD, Paris. 
OECD (2003a), A Disease-based Comparison of Health Systems: What is Best and at What Cost?, OECD, Paris.

OECD (2003b), OECD Reviews of Health Care Systems - Korea, OECD, Paris.

OECD (2004a), Towards High-Performing Health Systems, OECD, Paris.

OECD (2004b), Towards High-Performing Health Systems - Policy Studies, OECD, Paris.

OECD (2004c), Private Health Insurance in OECD Countries, OECD, Paris.

OECD (2005a), Pensions at a Glance, OECD, Paris.

OECD (2005b), Extending Opportunities: How Active Social Policy Can Benefit Us All, OECD, Paris.

OECD (2005c), OECD Reviews of Health Systems - Mexico, OECD, Paris.

OECD (2005d), OECD Health Data 2005 - Statistics and Indicators for 30 Countries, CD-Rom, Paris.

Ohmi, H., K. Hirooka, A. Hata and Y. Mochizuki (2001), "Recent Trend of Increase in Proportion of Low Birth Weight Infants in Japan", International Journal of Epidemiology, Vol. 30, pp. 1269-1271.

Orosz, E. and D. Morgan (2004), "SHA-Based National Health Accounts in Thirteen OECD Countries: A Comparative Analysis", OECD Health Working Papers, No. 16, OECD, Paris.

Retzlaff-Roberts, D., C. Chang and R. Rubin (2004), "Technical Efficiency in the Use of Health Care Resources: a comparison of OECD countries", Health Policy, Vol. 69, pp. 55-72.

Secretaria de Salud (2003), Nacimientos por cesarean en Mexico, Sintesis Ejecutiva, Mexico.

Simoens, S. and J. Hurst (2004), "Matching Supply with Demand for the Services of Physicians and Nurses", Chapter 4 in Towards High-Performing Health Systems: Policy Studies, OECD, Paris.

Simoens, S., M. Villeneuve and J. Hurst (2005), “Tackling Nurse Shortages in OECD Countries", OECD Health Working Papers, No. 19, OECD, Paris.

Singleton, J.A. et al. (2000), "Influenza, Pneumococcal, and Tetanus Toxoid Vaccination of Adults United States, 1993-1997", in CDC Surveillance Summaries, Morbidity and Mortality Weekly Report, Vol. 49(SS-9), pp. 39-63, cited in National Center for Health Statistics (2004), Health, United States, 2004, Hyattsville, Maryland.

Sourty Le-Guellec, M. (2001), Le potentiel de développement de la chirurgie ambulatoire de la cataracte en France, en 1999, Rapport No. 1357, CREDES, septembre 2001 (Perspectives of Development for Ambulatory Surgical Procedures of Cataract in France, in 1999).

Statistics Canada and Centers for Disease Control and Prevention (2004), Joint Canada/United States Survey of Health, 2002-2003, Statistics Canada Cat. 82M0022-XIE, Ottawa.

Statistics Netherlands (2004), The Netherlands on the European Scale, August 2004, second edition.

Stegmayr, B. et al. (1997), "Stroke Incidence and Mortality Correlated to Stroke Risk Factors in the WHO MONICA Project”, Stroke, Vol. 28 (7), pp. 1367-1374.

Sturm, R. (2002), “The Effects of Obesity, Smoking and Drinking on Medical Problems and Costs”, Health Affairs, Vol. 21, No. 2, March/April 2002, pp. 245-253.

Swiss Federal Statistical Office (2005), Development of Daily Fruit and Vegetable Consumption as a Function of Age Groups, tables accessed in June 2005 at www.bfs.admin.ch.

Thompson, D. and A.M. Wolf (2001), "The Medical-care Burden of Obesity”, Obesity Reviews 2, International Association for the Study of Obesity, pp. 189-197.

Tunstall-Pedoe, H. et al. (2000), "Estimation of Contribution of Changes in Coronary Care to Improving Survival, Event Rates, and Coronary Heart Disease Mortality across the WHO MONICA Project Populations", The Lancet, Vol. 355, pp. 688-700.

Tyrrell, L. and D. Dauphinee (1999), Task Force on Physician Supply in Canada, prepared for the Canadian Medical Forum Task Force, November 1999, Ottawa.

UNICEF and WHO (2004), Low Birthweight: Country, Regional and Global Estimates, UNICEF, New York.

US Preventive Services Task Force (1996), Guide to Clinical Preventive Services, 2nd ed., US Department of Health and Human Services, Washington, DC.

USDA (1999), "US Food Supply Providing More Food and Calories", article by Judy Putnam in Food Review, Vol. 22, No. 3, September-December 1999.

Van der Heyden, J. et al. (2003), "Measurement of the Use of Curative Health Services: Health Interview Survey versus National Registers", Archives of Public Health, Vol. 61, No. 4, Brussels, pp. 177-190. 
Van Doorslaer, E., C. Masseria et al. (2004), "Income-related Inequality in the Use of Medical Care in 21 OECD Countries", Chapter 3 in Towards High-Performing Health Systems: Policy Studies, OECD, Paris.

WHO (2003), The World Oral Health Report 2003: continuous improvement of oral health in the 21st century the approach of the WHO Global Oral Health Programme, P.E. Petersen, Geneva.

WHO (2002), The Tobacco Atlas, Judith Mackay, WHO, Geneva.

WHO (2004), Global Status Report on Alcohol 2004, WHO, Geneva.

WHO (2005), Measles, Fact Sheet No. 286, March 2005, WHO, Geneva.

WHO/EURO (2005), Press Release EURO 09/05, Copenhagen, 27 April 2005.

WHO/FAO (2005), Fruits and Vegetables for Health, Report of a Joint FAO/WHO Workshop, 1-3 September 2004, Kobe, Japan.

Wilkinson, R.G. (1996), Unhealthy Societies: The Afflictions of Inequality, Routledge, London.

Wilkinson, R.G. (2000), "Putting the Picture Together: prosperity, redistribution, health and welfare", in M. Marmot and R. Wilkinson (eds.), Social Determinants of Health, Oxford University Press.

World Bank (1999), Curbing the Epidemic: Governments and the Economics of Tobacco Control, Prabhat Jha, editor. 


\section{ANNEX A}

\section{Statistical Annex}

\section{Health Status}

A.1.1. Life expectancy at birth, total population, 1960 to 2003 . . . . . . . . . . . . . . 104

A.1.2. Life expectancy at birth, females, 1960 to 2003 . . . . . . . . . . . . . . . . 105

A.1.3. Life expectancy at birth, males, 1960 to $2003 \ldots \ldots \ldots \ldots \ldots \ldots \ldots \ldots \ldots$. . . . . . . . 106

A.1.4. Life expectancy at 65, females, 1960 to 2003 . . . . . . . . . . . . . . . . . . . . . . 107

A.1.5. Life expectancy at 65, males, 1960 to $2003 \ldots \ldots \ldots \ldots \ldots \ldots \ldots \ldots \ldots \ldots . \ldots \ldots$

A.1.6. Mortality, all causes, age-standardised death rates per 100000 population, 1960 to 2002 . . . . . . . . . . . . . . . . . . . . . . . 109

A.1.7. Percentage of mortality attributable to leading causes of deaths, 1980 and 2002 . . . . . . . . . . . . . . . . . . . . . . . . . . . . . . . . . . 110

A.1.8. Cardio-vascular diseases, age-standardised mortality rate,

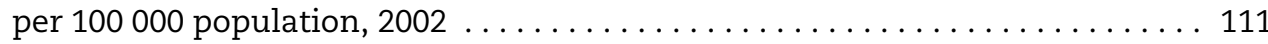

A.1.9. Ischaemic heart disease, age-standardised mortality rate, per 100000 females, males and total population, 1960, 1980 and 2002 . . . . 112

A.1.10. Cerebro-vascular disease, age-standardised mortality rate, per 100000 females, males and total population, 1960, 1980 and 2002 . . . . . 113

A.1.11. All cancers, age-standardised mortality rate, per 100000 females, males and total population, 1960, 1980 and $2002 \ldots \ldots \ldots \ldots \ldots \ldots \ldots \ldots$

A.1.12. Lung cancers, age-standardised mortality rate, per 100000 females, males and total population, 1960, 1980 and $2002 \ldots \ldots \ldots \ldots \ldots \ldots \ldots$

A.1.13. Breast and prostate cancers, age-standardised mortality rate,

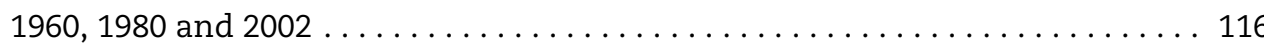

A.1.14. Mortality, external causes, age-standardised death rates per 100000 population, $2002 \ldots \ldots \ldots \ldots \ldots \ldots$. . . . . . . . . . . . 117

A.1.15. Mortality, road accidents, age-standardised death rates per 100000 population, 1960 to $2002 \ldots \ldots \ldots \ldots \ldots \ldots \ldots \ldots \ldots \ldots \ldots \ldots \ldots \ldots$

A.1.16. Mortality, accidental falls, age-standardised death rates per 100000 population, 1960 to 2002 . . . . . . . . . . . . . . . . . . . . . . . . 119

A.1.17. Mortality, suicides, age-standardised death rates per 100000 population, 1960 to 2002 .......................... 120

A.1.18. Mortality, homicides, age-standardised death rates per 100000 population, 1960 to 2002 
A.1.19. Infant mortality rate, deaths per 1000 live births, 1970 to $2003 \ldots \ldots \ldots \ldots$. . 122

A.1.20. Low birthweight, percentage of total live births, 1980 to 2003 . . . . . . . . 123

A.1.21. Decayed, missing and filled teeth, average number at age 12, 1980 to 2000 . . . 124

\section{Health Care Resources and Utilisation}

A.2.1. Practising physicians, density per 1000 population, 1970 to $2003 \ldots \ldots \ldots \ldots$. . . 125

A.2.2. Practising nurses, density per 1000 population, 1970 to 2003 ............ 126

A.2.3. Remuneration of specialists, salaried and self-employed, USD PPP, latest year(s) available . . . . . . . . . . . . . . . . . . . . . . . . . . . . 127

A.2.4. Remuneration of general practitioners, salaried and self-employed, USD PPP, latest year(s) available . . . . . . . . . . . . . . . . . . . . . . 128

A.2.5. Remuneration of salaried hospital nurses, USD PPP, latest year(s) available . . . . 129

A.2.6. Acute care beds, density per 1000 population, 1980 to 2002 . . . . . . . . . . . 130

A.2.7. Occupancy rate of acute care hospital beds, in percentage, 1980 to 2002 . . . . 131

A.2.8. Medical technologies: CT scanners and MRI units, per million population, 1990 to 2002 . . . . . . . . . . . . . . . . . . . . . . . . 132

A.2.9. Medical technologies: Mammographs and radiation therapy equipment, per million population, 1990, 1995 and $2002 \ldots \ldots \ldots \ldots \ldots \ldots \ldots \ldots \ldots$

A.2.10. Consultations with doctors, per capita, 1980 to 2003 . . . . . . . . . . . . . . 134

A.2.11. Immunisation, percentage of children immunised against DTP and measles, 1980 to 2003 . . . . . . . . . . . . . . . . . . . . . . . . . . . . . . . 135

A.2.12. Influenza vaccination among people aged 65 years and over, 1993 to 2003 . . . . 136

A.2.13. Hospital discharge rates for all causes, per 100000 population, 1990 to 2003 . . . . 137

A.2.14. Hospital discharge rates for selected causes, per 100000 population, 1990 to 2002 . . . . . . . . . . . . . . . . . . . . . . . . . . . . . . . . . . . . . . . . . . . 138

A.2.15. Average length of stay for acute care, all conditions, days, 1990 to 2003 . . . . 139

A.2.16. Average length of stay, specific conditions, days, 1990 to 2002 . . . . . . . . . . 140

A.2.17. Cardiovascular surgeries, per 100000 population, 1990 to 2003 ........... 141

A.2.18. Caesarean sections per 100 live births, 1990 to 2002 . . . . . . . . . . . . . . . . . . 142

A.2.19. Number of cataract surgeries, inpatient and day cases, per 100000 population, 1997, 2000 and $2003 \ldots \ldots \ldots \ldots \ldots \ldots \ldots \ldots$

\section{Health Expenditure and Financing}

A.3.1. Total expenditure on health per capita, USD PPP, 1970 to 2003 . . . . . . . . . . 144

A.3.2. Public expenditure on health, per capita, USD PPP, 1970 to 2003 . . . . . . . . . 145

A.3.3. Growth of total expenditure on health compared to GDP growth,

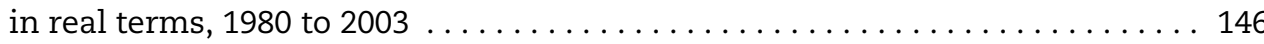

A.3.4. Growth of public expenditure on health compared to GDP growth, in real terms, 1980 to 2003

A.3.5. Annual growth rate of total per capita expenditure on health,

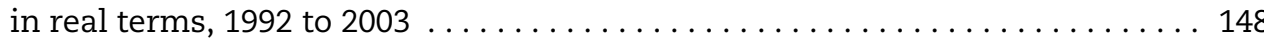

A.3.6. Annual growth rate of public per capita expenditure on health, in real terms, 1992 to 2003 . . . . . . . . . . . . . . . . . . . . . . . . . . . . . 149

A.3.7. Total expenditure on health, share of Gross Domestic Product, 1970 to $2003 \ldots 150$

A.3.8. Public expenditure on health, share of Gross Domestic Product, 1970 to 2003 . . . 151

A.3.9. Current expenditure on health by function of care, 2003

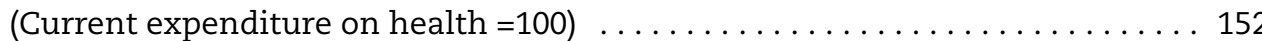


A.3.10. Pharmaceutical expenditure, per capita, 2003, and annual average growth rate, in real terms, 1970 to $2003 \ldots \ldots \ldots \ldots \ldots \ldots \ldots \ldots \ldots \ldots \ldots$

A.3.11. Public share of total expenditure on pharmaceuticals, 1970 to 2003 . . . . . 154

A.3.12. Health expenditure by source of funding, 2003

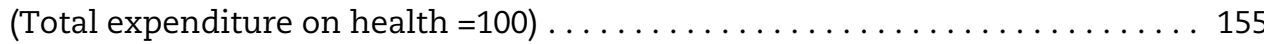

A.3.13. Out-of pocket spending as share of total health expenditure, private expenditure and final household consumption, 1990 and 2003 . . . . . 156

\section{Non-medical Determinants of Health}

A.4.1. Tobacco consumption, daily smokers, female, male and total population,

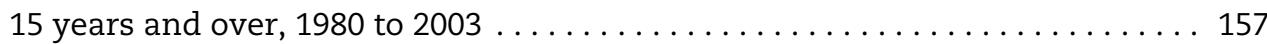

A.4.2. Alcohol consumption, litres per population aged 15 and over, 1960 to 2003 . . . . 158

A.4.3. Total calories consumption per capita, per day, 1961 to 2002 . . . . . . . . . . . 159

A.4.4. Sugar consumption per capita, kilos per year, 1961 to 2002 . . . . . . . . . . . 160

A.4.5. Fruits and vegetables consumption per capita, kilos per year, 1961 to 2002 . . . . 161

A.4.6. Overweight or obesity rate, population aged 15+, latest year available. . . . . . 162

5. Demographic and Economic Context

A.5.1. Total population, mid-year, thousands, 1960 to $2003 \ldots \ldots \ldots$. . . . . . . . . . . 163

A.5.2. Share of the population aged 65 and over, 1960 to $2003 . \ldots \ldots \ldots \ldots \ldots \ldots . \ldots 164$

A.5.3. Share of the population aged 80 and over, 1960 to $2003 \ldots \ldots \ldots \ldots \ldots \ldots 165$

A.5.4. Total fertility rate, number of children per woman aged 15-49, 1960 to 2003 . . . . 166

A.5.5. GDP per capita, 2003 in USD PPP and annual average growth rates 1970 to 2003 
Table A.1.1. Life expectancy at birth, total population, 1960 to 2003

\begin{tabular}{|c|c|c|c|c|c|c|}
\hline & 1960 & 1970 & 1980 & 1990 & 2000 & 2003 \\
\hline Australia & 70.9 & 70.8 & 74.6 & 77.0 & 79.3 & 80.3 \\
\hline Austria & 68.7 & 70.0 & 72.6 & 75.5 & 78.1 & 78.6 \\
\hline Belgium & 70.6 & 71.0 & 73.4 & 76.1 & 77.7 & 78.1 (2002) \\
\hline Canada & 71.3 (1961) & 72.9 (1971) & 75.3 & 77.6 & 79.3 & 79.7 (2002) \\
\hline Czech Republic & 70.7 & 69.6 & 70.3 & 71.5 & 75.1 & 75.3 \\
\hline Denmark & 72.4 & 73.3 & 74.3 & 74.9 & 76.9 & 77.2 \\
\hline Finland & 69.0 & 70.8 & 73.4 & 74.9 & 77.6 & 78.5 \\
\hline France & 70.3 & 72.2 & 74.3 & 76.9 & 79.0 & 79.4 \\
\hline Germany & 69.6 & 70.4 & 72.9 & 75.2 & 78.0 & 78.4 \\
\hline Greece & 69.9 & 72.0 & 74.5 & 77.1 & 78.1 & 78.1 \\
\hline Hungary & 68.0 & 69.2 & 69.1 & 69.4 & 71.7 & 72.4 \\
\hline Iceland & 72.9 & 74.3 & 76.7 & 78.0 & 79.7 & 80.7 \\
\hline Ireland & 70.0 & 71.2 & 72.9 & 74.9 & 76.5 & 77.8 (2002) \\
\hline Italy & 69.8 (1961) & 72.0 & 74.0 & 76.9 & 79.6 & 79.9 \\
\hline Japan & 67.8 & 72.0 & 76.1 & 78.9 & 81.2 & 81.8 \\
\hline Korea & 52.4 & $62.6(1971)$ & 65.4 (1979) & 71.0 (1989) & 75.5 (1999) & 76.9 (2002) \\
\hline Luxembourg & 69.4 & 70.3 & 72.5 & 75.4 & 78.0 & 78.2 (2002) \\
\hline Mexico & 57.5 & 60.9 & 67.2 & 71.2 & 74.1 & 74.9 \\
\hline Netherlands & 73.5 & 73.7 & 75.9 & 77.0 & 78.0 & 78.6 \\
\hline New Zealand & 71.3 & 71.5 & 73.2 & 75.4 & 78.7 & 78.7 (2002) \\
\hline Norway & 73.6 & 74.2 & 75.8 & 76.6 & 78.7 & 79.5 \\
\hline Poland & 67.8 & 70.0 & 70.2 & 71.5 & 73.8 & 74.7 \\
\hline Portugal & 64.0 & 67.5 & 71.5 & 73.9 & 76.6 & 77.3 \\
\hline Slovak Republic & 70.6 & 69.8 & 70.6 & 71.0 & 73.3 & 73.9 (2002) \\
\hline Spain & 69.8 & 72.0 & 75.6 & 76.8 & 79.1 & 80.5 \\
\hline Sweden & 73.1 & 74.7 & 75.8 & 77.6 & 79.7 & 80.2 \\
\hline Switzerland & 71.6 & 73.8 & 76.2 & 77.4 & 79.8 & $80.4 \quad(2002)$ \\
\hline Turkey & 48.3 & 54.2 & 58.1 & 66.5 & 68.1 & 68.7 \\
\hline United Kingdom & 70.8 & 71.9 & 73.2 & 75.7 & 77.9 & 78.5 \\
\hline United States & 69.9 & 70.9 & 73.7 & 75.3 & 76.8 & 77.2 (2002) \\
\hline Average (30) & 68.5 & 70.3 & 72.6 & 74.9 & 77.2 & 77.8 \\
\hline Median & 70.0 & 71.1 & 73.4 & 75.5 & 78.0 & 78.5 \\
\hline
\end{tabular}

Note: Each country calculates its life expectancy according to methodologies that can vary somewhat. These differences in methodology can affect the comparability of reported life expectancy estimates, as different methods can change a country's life expectancy estimates by a fraction of a year.

Life expectancy at birth for the total population is calculated by the OECD Secretariat for all countries, using the unweighted average of life expectancy of men and women.

Source: OECD Health Data 2005. (For the 22 European countries, the Eurostat NewCronos database is the main data source for 1985 onwards.) 
Table A.1.2. Life expectancy at birth, females, 1960 to 2003

\begin{tabular}{|c|c|c|c|c|c|c|}
\hline & 1960 & 1970 & 1980 & 1990 & 2000 & 2003 \\
\hline Australia & 73.9 & 74.2 & 78.1 & 80.1 & 82.0 & 82.8 \\
\hline Austria & 71.9 & 73.4 & 76.1 & 78.8 & 81.1 & 81.6 \\
\hline Belgium & 73.5 & 74.2 & 76.8 & 79.4 & 80.8 & 81.1 (2002) \\
\hline Canada & 74.2 (1961) & 76.4 (1971) & 78.9 & 80.8 & 81.9 & $82.1 \quad$ (2002) \\
\hline Czech Republic & 73.4 & 73.0 & 73.9 & 75.4 & 78.4 & 78.5 \\
\hline Denmark & 74.4 & 75.9 & 77.3 & 77.7 & 79.3 & 79.5 \\
\hline Finland & 72.5 & 75.0 & 77.6 & 78.9 & 81.0 & 81.8 \\
\hline France & 73.6 & 75.9 & 78.4 & 80.9 & 82.7 & 82.9 \\
\hline Germany & 72.4 & 73.6 & 76.1 & 78.4 & 81.0 & 81.3 \\
\hline Greece & 72.4 & 73.8 & 76.8 & 79.5 & 80.6 & 80.7 \\
\hline Hungary & 70.1 & 72.1 & 72.7 & 73.7 & 75.9 & 76.5 \\
\hline Iceland & 75.0 & 77.3 & 79.7 & 80.5 & 81.4 & 82.4 \\
\hline Ireland & 71.9 & 73.5 & 75.6 & 77.6 & 79.1 & 80.3 (2002) \\
\hline Italy & 72.3 (1961) & 74.9 (1971) & 77.4 & 80.1 & 82.5 & 82.9 \\
\hline Japan & 70.2 & 74.7 & 78.8 & 81.9 & 84.6 & 85.3 \\
\hline Korea & 53.7 & 66.1 (1971) & 69.5 (1979) & 75.1 (1989) & 79.2 (1999) & $80.4 \quad(2002)$ \\
\hline Luxembourg & 72.2 & 73.4 & 75.9 & 78.5 & 81.1 & $81.5 \quad(2002)$ \\
\hline Mexico & 59.2 & 63.2 & 70.2 & 74.1 & 76.5 & 77.4 \\
\hline Netherlands & 75.4 & 76.5 & 79.2 & 80.1 & 80.5 & 80.9 \\
\hline New Zealand & 73.9 & 74.6 & 76.3 & 78.3 & 81.1 & 81.1 (2002) \\
\hline Norway & 75.8 & 77.3 & 79.2 & 79.8 & 81.4 & 81.9 \\
\hline Poland & 70.6 & 73.3 & 74.4 & 76.3 & 77.9 & 78.9 \\
\hline Portugal & 66.8 & 70.8 & 75.2 & 77.4 & 80.0 & 80.6 \\
\hline Slovak Republic & 72.7 & 72.9 & 74.3 & 75.4 & 77.4 & 77.8 (2002) \\
\hline Spain & 72.2 & 74.8 & 78.6 & 80.3 & 82.5 & 83.7 \\
\hline Sweden & 74.9 & 77.1 & 78.8 & 80.4 & 82.0 & 82.4 \\
\hline Switzerland & 74.5 & 76.9 & 79.6 & 80.7 & 82.6 & $83.0 \quad(2002)$ \\
\hline Turkey & 50.3 & 56.3 & 60.3 & 68.7 & 70.4 & 71.0 \\
\hline United Kingdom & 73.7 & 75.0 & 76.2 & 78.5 & 80.2 & 80.7 \\
\hline United States & 73.1 & 74.7 & 77.4 & 78.8 & 79.5 & 79.9 (2002) \\
\hline Average (30) & 71.0 & 73.4 & 76.0 & 78.2 & 80.2 & 80.7 \\
\hline Median & 72.6 & 74.4 & 76.8 & 78.8 & 80.9 & 81.1 \\
\hline
\end{tabular}

Note: Each country calculates its life expectancy according to methodologies that can vary somewhat. These differences in methodology can affect the comparability of reported life expectancy estimates, as different methods can change a country's life expectancy estimates by a fraction of a year.

Source: OECD Health Data 2005. (For the 22 European countries, the Eurostat NewCronos database is the main data source for 1985 onwards.) 
Table A.1.3. Life expectancy at birth, males, 1960 to 2003

\begin{tabular}{|c|c|c|c|c|c|c|c|}
\hline & 1960 & 1970 & 1980 & 1990 & 2000 & 200 & 03 \\
\hline Australia & 67.9 & 67.4 & 71 & 73.9 & 76.6 & 77.8 & \\
\hline Austria & 65.4 & 66.5 & 69 & 72.2 & 75.1 & 75.6 & \\
\hline Belgium & 67.7 & 67.8 & 70 & 72.7 & 74.6 & 75.1 & (2002) \\
\hline Canada & 68.4 (1961) & 69.3 (1971) & 71.7 & 74.4 & 76.7 & 77.2 & (2002) \\
\hline Czech Republic & 67.9 & 66.1 & 66.8 & 67.6 & 71.7 & 72 & \\
\hline Denmark & 70.4 & 70.7 & 71.2 & 72 & 74.5 & 74.9 & \\
\hline Finland & 65.5 & 66.5 & 69.2 & 70.9 & 74.2 & 75.1 & \\
\hline France & 67 & 68.4 & 70.2 & 72.8 & 75.3 & 75.8 & \\
\hline Germany & 66.9 & 67.2 & 69.6 & 72 & 75 & 75.5 & \\
\hline Greece & 67.3 & 70.1 & 72.2 & 74.6 & 75.5 & 75.4 & \\
\hline Hungary & 65.9 & 66.3 & 65.5 & 65.1 & 67.4 & 68.3 & \\
\hline Iceland & 70.7 & 71.2 & 73.7 & 75.4 & 78 & 79 & \\
\hline Ireland & 68.1 & 68.8 & 70.1 & 72.1 & 73.9 & 75.2 & (2002) \\
\hline Italy & 67.2 (1961) & 69 (1971) & 70.6 & 73.6 & 76.6 & 76.9 & \\
\hline Japan & 65.3 & 69.3 & 73.4 & 75.9 & 77.7 & 78.4 & \\
\hline Korea & 51.1 & 59 (1971) & 61.3 (1979) & 66.8 (1989) & 71.7 (1999) & 73.4 & (2002) \\
\hline Luxembourg & 66.5 & 67.1 & 69.1 & 72.3 & 74.8 & 74.9 & (2002) \\
\hline Mexico & 55.8 & 58.5 & 64.1 & 68.3 & 71.6 & 72.4 & \\
\hline Netherlands & 71.5 & 70.8 & 72.5 & 73.8 & 75.5 & 76.2 & \\
\hline New Zealand & 68.7 & 68.3 & 70 & 72.4 & 76.3 & 76.3 & (2002) \\
\hline Norway & 71.3 & 71 & 72.3 & 73.4 & 76 & 77 & \\
\hline Poland & 64.9 & 66.6 & 66 & 66.7 & 69.7 & 70.5 & \\
\hline Portugal & 61.2 & 64.2 & 67.7 & 70.4 & 73.2 & 74 & \\
\hline Slovak Republic & 68.4 & 66.7 & 66.8 & 66.6 & 69.2 & 69.9 & (2002) \\
\hline Spain & 67.4 & 69.2 & 72.5 & 73.3 & 75.7 & 77.2 & \\
\hline Sweden & 71.2 & 72.2 & 72.8 & 74.8 & 77.4 & 77.9 & \\
\hline Switzerland & 68.7 & 70.7 & 72.8 & 74 & 76.9 & 77.8 & (2002) \\
\hline Turkey & 46.3 & 52 & 55.8 & 64.2 & 65.8 & 66.4 & \\
\hline United Kingdom & 67.9 & 68.7 & 70.2 & 72.9 & 75.5 & 76.2 & \\
\hline United States & 66.6 & 67.1 & 70 & 71.8 & 74.1 & 74.5 & (2002) \\
\hline Average (30) & 66.0 & 67.2 & 69.3 & 71.6 & 74.2 & 74.9 & \\
\hline Median & 67.4 & 68.1 & 70.1 & 72.4 & 75.1 & 75.5 & \\
\hline
\end{tabular}

Note: Each country calculates its life expectancy according to methodologies that can vary somewhat. These differences in methodology can affect the comparability of reported life expectancy estimates, as different methods can change a country's life expectancy estimates by a fraction of a year.

Source: OECD Health Data 2005. (For the 22 European countries, the Eurostat NewCronos database is the main data source for 1985 onwards.) 
Table A.1.4. Life expectancy at 65, females, 1960 to 2003

\begin{tabular}{|c|c|c|c|c|c|c|c|}
\hline & 1960 & 1970 & 1980 & 1990 & 2000 & 20 & 03 \\
\hline Australia & 15.6 & 15.6 & 17.9 & 19.0 & 20.4 & 21.0 & \\
\hline Austria & 14.7 & 14.9 & 16.3 & 17.8 & 19.4 & 19.9 & \\
\hline Belgium & 14.8 & 15.3 & 16.9 & 18.5 & 19.5 & 19.7 & (2002) \\
\hline Canada & 16.1 (1961) & 17.5 (1971) & 18.9 & 19.9 & 20.4 & 20.6 & (2002) \\
\hline Czech Republic & 14.5 & 14.2 & 14.3 & 15.2 & 17.1 & 17.4 & (2002) \\
\hline Denmark & 15.3 & 16.7 & 17.6 & 17.8 & 18.3 & 18.3 & (2002) \\
\hline Finland & 13.7 & 14.4 (1971) & 16.5 & 17.7 & 19.3 & 19.6 & (2002) \\
\hline France & 15.6 & 16.8 & 18.2 & 19.8 & 21.2 & 21.3 & (2001) \\
\hline Germany & 14.6 & 15.0 & 16.7 & 17.6 & 19.4 & 19.6 & (2001) \\
\hline Greece & 14.6 & 15.2 & 16.8 & 18.0 & 18.3 & 18.8 & (2002) \\
\hline Hungary & 13.8 & 14.3 & 14.6 & 15.3 & 16.4 & 16.7 & \\
\hline Iceland & . & 17.8 (1973) & 19.1 & 19.5 & 19.6 & 20.4 & \\
\hline Ireland & 14.4 & 15.0 & 15.7 & 16.9 & 17.8 & 18.6 & (2002) \\
\hline Italy & 15.3 (1961) & 16.2 (1971) & 17.1 & 18.8 & 20.4 & 20.7 & (2001) \\
\hline Japan & 14.1 & 15.3 & 17.7 & 20.0 & 22.4 & 23.0 & \\
\hline Korea & $\ldots$ & 14.6 (1971) & 15.1 (1979) & 16.2 (1989) & 18.0 (1999) & 18.7 & (2002) \\
\hline Luxembourg & 14.5 & 14.9 & 16.0 & 18.2 & 19.7 & 19.9 & (2002) \\
\hline Mexico & 14.6 & 15.6 & 17.0 & 18.0 & 18.3 & 18.6 & \\
\hline Netherlands & 15.3 & 16.1 & 18.0 & 18.9 & 19.2 & 19.5 & \\
\hline New Zealand & 15.6 & 16.0 & 17.0 & 18.3 & 20.0 & 20.0 & (2002) \\
\hline Norway & 16.0 & 16.7 & 18.0 & 18.5 & 19.7 & 19.7 & (2002) \\
\hline Poland & 14.9 & 15.3 & 15.5 & 16.9 & 17.3 & 18.1 & \\
\hline Portugal & 15.3 & 15.0 & 16.5 & 17.0 & 18.7 & 19.1 & \\
\hline Slovak Republic & 14.6 & 14.5 & 15.4 & 15.7 & 16.5 & 17.0 & (2002) \\
\hline Spain & 15.3 & 16.0 & 17.9 & 19.0 & 20.4 & .. & \\
\hline Sweden & 15.3 & 16.8 & 17.9 & 19.0 & 20.0 & 20.3 & \\
\hline Switzerland & .. & .. & $18.3(1982)$ & 19.4 & 20.7 & 21.0 & (2002) \\
\hline Turkey & 12.1 & 12.6 & 12.8 & 13.9 & 14.2 & 14.3 & \\
\hline United Kingdom & 15.1 & 16.0 & 16.6 & 17.9 & 18.9 & 19.1 & (2002) \\
\hline United States & 15.8 & 17.0 & 18.3 & 18.9 & 19.2 & 19.5 & (2002) \\
\hline Latest average $^{a}$ & $\ldots$ & $\ldots$ & $\ldots$ & $\ldots$ & . & 19.4 & \\
\hline Consistent average $(29)^{b}$ & . & 15.6 & 16.8 & 17.9 & 19.0 & 19.3 & \\
\hline Median & 14.9 & 15.3 & 17.0 & 18.1 & 19.4 & 19.6 & \\
\hline
\end{tabular}

Note: Each country calculates its life expectancy according to methodologies that can vary somewhat. These differences in methodology can affect the comparability of reported life expectancy estimates, as different methods can change a country's life expectancy estimates by a fraction of a year.

a) Average consists of the latest available data for all OECD countries.

b) Excludes Switzerland.

Source: OECD Health Data 2005. (For the 22 European countries, the Eurostat NewCronos database is the main data source for 1985 onwards.) 
Table A.1.5. Life expectancy at 65, males, 1960 to 2003

\begin{tabular}{|c|c|c|c|c|c|c|}
\hline & 1960 & 1970 & 1980 & 1990 & 2000 & 2003 \\
\hline Australia & 12.5 & 11.9 & 13.7 & 15.2 & 16.9 & 17.6 \\
\hline Austria & 12.0 & 11.7 & 12.9 & 14.3 & 16.0 & 16.4 \\
\hline Belgium & 12.4 & 12.1 & 13.0 & 14.3 & 15.5 & 15.8 (2002) \\
\hline Canada & 13.5 (1961) & 13.7 (1971) & 14.5 & 15.7 & 16.8 & 17.2 (2002) \\
\hline Czech Republic & 12.5 & 11.1 & 11.2 & 11.6 & 13.7 & 14.0 (2002) \\
\hline Denmark & 13.7 & 13.7 & 13.6 & 14.0 & 15.2 & 15.4 (2002) \\
\hline Finland & 11.5 & 11.4 (1971) & 12.5 & 13.7 & 15.5 & 15.8 (2002) \\
\hline France & 12.5 & 13.0 & 13.6 & 15.5 & 16.7 & 16.9 (2001) \\
\hline Germany & 12.4 & 12.0 & 13.0 & 14.0 & 15.7 & 16.0 (2001) \\
\hline Greece & 13.4 & 13.9 & 14.6 & 15.7 & 16.2 & $16.7 \quad(2002)$ \\
\hline Hungary & 12.3 & 12.0 & 11.6 & 12.0 & 12.7 & 12.9 \\
\hline Iceland & .. & 15.0 & 15.8 & 16.2 & 18.1 & 17.8 \\
\hline Ireland & 12.6 & 12.4 & 12.6 & 13.3 & 14.6 & 15.3 (2002) \\
\hline Italy & 13.4 (1961) & 13.3 (1971) & 13.3 & 15.1 & 16.5 & 16.7 (2001) \\
\hline Japan & 11.6 & 12.5 & 14.6 & 16.2 & 17.5 & 18.0 \\
\hline Korea & . & 10.2 (1971) & 10.4 (1979) & 12.2 (1989) & 14.1 (1999) & 14.9 (2002) \\
\hline Luxembourg & 12.5 & 12.1 & 12.3 & 14.2 & 15.5 & 15.9 (2002) \\
\hline Mexico & 14.2 & 14.8 & 15.4 & 16.2 & 16.8 & 17.1 \\
\hline Netherlands & 13.9 & 13.3 & 13.7 & 14.4 & 15.3 & 15.8 \\
\hline New Zealand & 13.0 & 12.4 & 13.2 & 14.7 & 16.7 & 16.7 (2002) \\
\hline Norway & 14.5 & 13.8 & 14.3 & 14.6 & 16.0 & $16.2(2002)$ \\
\hline Poland & 12.7 & 12.5 & 12.0 & 12.7 & 13.6 & 14.0 \\
\hline Portugal & 13.0 & 12.2 & 12.9 & 13.9 & 15.3 & 15.7 \\
\hline Slovak Republic & 13.2 & 12.3 & 12.3 & 12.2 & 12.9 & $13.3 \quad(2002)$ \\
\hline Spain & 13.1 & 13.3 & 14.8 & 15.4 & 16.5 & . \\
\hline Sweden & 13.7 & 14.2 & 14.3 & 15.3 & 16.7 & 17.0 \\
\hline Switzerland & .. & & $14.6(1982)$ & 15.3 & 16.9 & 17.4 (2002) \\
\hline Turkey & 11.2 & 11.5 & 11.7 & 12.4 & 12.6 & 12.7 \\
\hline United Kingdom & 11.9 & 12.0 & 12.6 & 14.0 & 15.7 & 16.1 (2002) \\
\hline United States & 12.8 & 13.1 & 14.1 & 15.1 & 16.3 & 16.6 (2002) \\
\hline Latest average $^{a}$ & . & . & $\ldots$ & . & . & 15.9 \\
\hline Consistent average $(29)^{b}$ & . & 12.7 & 13.3 & 14.3 & 15.6 & 15.9 \\
\hline Median & 12.7 & 12.4 & 13.3 & 14.4 & 15.9 & 16.1 \\
\hline
\end{tabular}

Note: Each country calculates its life expectancy according to methodologies that can vary somewhat. These differences in methodology can affect the comparability of reported life expectancy estimates, as different methods can change a country's life expectancy estimates by a fraction of a year.

a) Average consists of the latest available data for all OECD countries.

b) Excludes Switzerland.

Source: OECD Health Data 2005. (For the 22 European countries, the Eurostat NewCronos database is the main data source for 1985 onwards.) 
Table A.1.6. Mortality, all causes, age-standardised death rates per 100000 population, 1960 to 2002

\begin{tabular}{|c|c|c|c|c|c|c|c|}
\hline & 1960 & 1970 & 1980 & 1990 & 2000 & 20 & 02 \\
\hline Australia & 1092.3 & 1120.8 & 847.5 & 689.9 & 546.0 & 526.2 & (2001) \\
\hline Austria & 1203.6 & 1161.0 & 975.5 & 771.7 & 621.6 & 610.9 & \\
\hline Belgium & 1185.1 & 1104.8 & 954.7 & 754.3 & .. & .. & \\
\hline Canada & 1053.3 & 933.5 & 794.4 & 679.0 & 574.8 & 564.5 & (2001) \\
\hline Czech Republic & & . & & 1117.8 & 847.3 & 834.4 & \\
\hline Denmark & 1022.7 & 916.3 & 876.7 & 829.4 & 715.9 & .. & \\
\hline Finland & 1279.4 & 1192.6 & 928.2 & 825.9 & 665.7 & 638.0 & \\
\hline France & 1089.5 & 924.7 & 804.0 & 650.4 & 574.9 & 568.9 & (2001) \\
\hline Germany & 1220.9 & 1128.6 & 924.1 & 807.0 & 639.5 & 620.9 & (2001) \\
\hline Greece & 948.1 & 844.0 & 801.2 & 710.9 & 668.2 & 635.8 & \\
\hline Hungary & 1255.7 & 1206.9 & 1243.7 & 1190.8 & 1009.2 & 968.9 & \\
\hline Iceland & 873.4 & 878.5 & 704.5 & 645.0 & 569.2 & 534.3 & \\
\hline Ireland & 1149.7 & 1149.6 & 1059.3 & 890.2 & 758.8 & 719.1 & (2001) \\
\hline Italy & 1121.2 & 1006.3 & 866.2 & 704.2 & 562.7 & 546.4 & (2001) \\
\hline Japan & 1280.6 & 1046.9 & 759.9 & 586.1 & 474.1 & 449.3 & \\
\hline Korea & . & . & . & 799.8 & 755.4 & 711.6 & \\
\hline Luxembourg & 1061.3 & 1172.1 & 1023.5 & 794.2 & 628.6 & 629.1 & \\
\hline Mexico & . & 1268.9 & 1116.2 (1981) & 950.2 & $\ldots$ & . & \\
\hline Netherlands & 934.7 & 921.9 & 777.3 & 714.9 & 659.3 & 644.9 & \\
\hline New Zealand & 1060.5 & 1084.1 & 981.9 & 775.9 & 598.7 & . & \\
\hline Norway & 914.9 & 888.6 & 786.0 & 739.9 & 621.0 & 609.0 & \\
\hline Poland & 1150.6 & 1141.1 & 1115.8 & 1067.5 & 888.2 & 840.0 & \\
\hline Portugal & 1262.2 & 1225.4 & 1079.8 & 884.5 & 719.5 & 690.7 & \\
\hline Slovak Republic & $\ldots$ & $\ldots$ & . & 993.9 (1992) & 942.1 & 915.6 & \\
\hline Spain & 1098.6 & 1036.9 (1969) & 784.2 & 700.7 & 578.2 & 560.0 & \\
\hline Sweden & 983.5 & 849.0 & 793.5 & 682.0 & 573.3 & 567.3 & (2001) \\
\hline Switzerland & 1064.4 & 948.9 & 782.3 & 671.1 & 549.9 & 529.2 & (2001) \\
\hline Turkey & $\ldots$ & .. & .. & .. & $\ldots$ & .. & \\
\hline United Kingdom & 1093.7 & 1050.3 & 939.6 & 786.0 & 694.6 (1999) & 644.7 & \\
\hline United States & 1099.6 & 1020.7 & 842.3 & 756.8 & 685.5 & 674.1 & (2001) \\
\hline Latest average $^{a}$ & . & . & $\cdots$ & . & . & 649.9 & \\
\hline Consistent average $(24)^{b}$ & 1096.4 & 1035.4 & 895.5 & 773.1 & 649.1 & 628.6 & \\
\hline Median & 1093.7 & 1048.6 & 871.5 & 771.7 & 639.5 & 629.1 & \\
\hline
\end{tabular}

Note: All mortality rates are standardised to the OECD standard population (1980).

a) Average comprises all countries for which recent data is available (2000+).

b) Excludes Belgium, Czech Republic, Korea, Mexico, Slovak Republic and Turkey. The 2000 figures of Denmark and New Zealand have been used for the calculation of the 2002 OECD average.

Source: OECD Health Data 2005. The raw mortality data is extracted from the WHO Mortality Database (March 2005). 
Table A.1.7. Percentage of mortality attributable to leading causes of deaths, 1980 and 2002

\begin{tabular}{|c|c|c|c|c|c|c|c|c|}
\hline & \multicolumn{2}{|c|}{ Circulatory disease } & \multicolumn{2}{|c|}{ Cancer } & \multicolumn{2}{|c|}{ Respiratory disease } & \multicolumn{2}{|c|}{ External causes } \\
\hline & 1980 & 2002 & 1980 & 2002 & 1980 & 2002 & 1980 & 2002 \\
\hline Australia & 52.4 & 35.9 (2001) & 21.1 & 30.6 (2001) & 7.0 & $8.0(2001)$ & 6.8 & $7.0(2001)$ \\
\hline Austria & 50.9 & 44.2 & 20.8 & 26.5 & 5.0 & 5.1 & 8.5 & 7.2 \\
\hline Belgium & 41.8 & . & 23.1 & .. & 6.6 & .. & 8.1 & .. \\
\hline Canada & 47.7 & 32.3 (2001) & 23.4 & 30.9 (2001) & 6.6 & 7.6 (2001) & 8.2 & 6.7 (2001) \\
\hline Czech Republic & .. & 51.8 & .. & 26.5 & .. & 4.3 & . & 6.8 \\
\hline Denmark & 45.9 & $33.0(2000)$ & 25.1 & $29.7(2000)$ & 7.2 & $9.0(2000)$ & 7.8 & $6.6(2000)$ \\
\hline Finland & 52.6 & 40.7 & 19.4 & 21.9 & 8.9 & 7.3 & 8.0 & 10.0 \\
\hline France & 35.1 & 26.9 (2001) & 23.9 & 30.5 (2001) & 5.7 & $5.3(2001)$ & 10.3 & $9.3(2001)$ \\
\hline Germany & 48.7 & 43.4 (2001) & 21.6 & 26.9 (2001) & 5.4 & $5.6(2001)$ & 6.8 & $5.3(2001)$ \\
\hline Greece & 43.7 & 47.8 & 18.5 & 24.1 & 7.4 & 7.1 & 5.8 & 5.0 \\
\hline Hungary & 53.0 & 49.2 & 18.3 & 25.1 & 6.9 & 3.5 & 8.7 & 7.8 \\
\hline Iceland & 47.9 & 38.6 & 23.1 & 30.3 & 9.8 & 7.4 & 9.2 & 7.1 \\
\hline Ireland & 51.3 & 38.6 (2001) & 18.8 & $26.5(2001)$ & 13.2 & 14.1 (2001) & 5.0 & $5.7(2001)$ \\
\hline Italy & 47.2 & $38.0(2001)$ & 21.6 & 31.1 (2001) & 7.1 & $5.5(2001)$ & 6.1 & $6.1(2001)$ \\
\hline Japan & 44.6 & 28.9 & 20.7 & 32.6 & 8.4 & 12.3 & 6.3 & 9.5 \\
\hline Korea & .. & 26.3 & .. & 24.0 & .. & 7.6 & . & 9.4 \\
\hline Luxembourg & 47.8 & 36.9 & 22.0 & 25.9 & 4.0 & 9.4 & 8.1 & 9.4 \\
\hline Mexico & .. & .. & .. & . & . & .. & . & . \\
\hline Netherlands & 44.4 & 32.6 & 27.1 & 28.7 & 6.0 & 8.9 & 5.4 & 4.2 \\
\hline New Zealand & 49.6 & $38.8(2000)$ & 20.2 & $30.2(2000)$ & 11.6 & $7.5(2000)$ & 7.1 & $6.8(2000)$ \\
\hline Norway & 47.5 & 36.2 & 21.1 & 27.4 & 8.2 & 9.3 & 7.5 & 6.4 \\
\hline Poland & 50.1 & 46.7 & 16.3 & 24.2 & 5.5 & 4.3 & 6.7 & 7.2 \\
\hline Portugal & 43.6 & 36.0 & 14.1 & 22.1 & 7.4 & 8.1 & 6.8 & 6.8 \\
\hline Slovak Republic & .. & 54.6 & .. & 21.8 & .. & 5.7 & . & 5.7 \\
\hline Spain & 46.3 & 31.5 & 19.6 & 28.3 & 9.3 & 10.2 & 5.3 & 5.7 \\
\hline Sweden & 52.4 & 41.4 (2001) & 22.1 & 26.7 (2001) & 5.4 & $5.9(2001)$ & 7.5 & 6.7 (2001) \\
\hline Switzerland & 46.8 & 35.1 (2001) & 23.7 & $28.3(2001)$ & 5.5 & 5.7 (2001) & 9.0 & $7.5(2001)$ \\
\hline Turkey & .. & $\ldots$ & .. & $\ldots$ & .. & $\ldots$ & . & $\ldots$ \\
\hline United Kingdom & 49.1 & 37.2 & 22.1 & 28.2 & 13.7 & 11.8 & 4.3 & 4.1 \\
\hline United States & 49.1 & $35.8(2001)$ & 21.5 & $25.0(2001)$ & 6.4 & $9.2(2001)$ & 8.1 & 7.7 (2001) \\
\hline Latest average $^{a}$ & . & 38.5 & $\ldots$ & 27.2 & . & 7.6 & . & 7.0 \\
\hline Consistent average $(24)^{b}$ & 47.8 & 37.7 & 21.1 & 27.6 & 7.6 & 7.8 & 7.2 & 6.9 \\
\hline Median & 47.8 & 37.2 & 21.5 & 26.9 & 7.0 & 7.5 & 7.5 & 6.8 \\
\hline
\end{tabular}

Note: All mortality rates are standardised to the OECD standard population (1980).

a) Average comprises all countries for which recent data is available (2000+).

b) Excludes Belgium, Czech Republic, Korea, Mexico, Slovak Republic and Turkey.

Source: OECD Health Data 2005. The raw mortality data is extracted from the WHO Mortality Database (March 2005). 
Table A.1.8. Cardio-vascular diseases, age-standardised mortality rate, per 100000 population, 2002

\begin{tabular}{|c|c|c|c|c|c|}
\hline & & Ischaemic heart disease & Cerebro-vascular disease & Other circulatory diseases & Total \\
\hline Australia & (2001) & 102.5 & 44.9 & 41.4 & 188.8 \\
\hline Austria & & 123.0 & 58.6 & 88.3 & 269.9 \\
\hline Belgium & & . & $\ldots$ & $\ldots$ & . \\
\hline Canada & (2001) & 102.6 & 36.5 & 43.0 & 182.1 \\
\hline Czech Republic & & 170.6 & 124.6 & 137.1 & 432.3 \\
\hline Denmark & (2000) & 106.0 & 57.0 & 73.6 & 236.6 \\
\hline Finland & & 156.5 & 58.7 & 44.5 & 259.7 \\
\hline France & (2001) & 45.1 & 35.9 & 72.3 & 153.3 \\
\hline Germany & (2001) & 116.6 & 53.5 & 99.1 & 269.2 \\
\hline Greece & & 81.3 & 108.0 & 114.7 & 304.0 \\
\hline Hungary & & 209.3 & 130.0 & 137.7 & 477.0 \\
\hline Iceland & & 112.7 & 44.1 & 49.6 & 206.4 \\
\hline Ireland & (2001) & 146.1 & 58.9 & 72.3 & 277.3 \\
\hline Italy & (2001) & 67.2 & 55.8 & 84.6 & 207.6 \\
\hline Japan & & 31.6 & 55.2 & 43.0 & 129.8 \\
\hline Korea & & 35.6 & 113.9 & 38.0 & 187.5 \\
\hline Luxembourg & & 72.4 & 66.1 & 93.4 & 231.9 \\
\hline Mexico & & $\ldots$ & $\ldots$ & . & . \\
\hline Netherlands & & 72.6 & 52.1 & 85.5 & 210.2 \\
\hline New Zealand & (2000) & 129.7 & 54.9 & 47.9 & 232.5 \\
\hline Norway & & 102.2 & 51.9 & 66.1 & 220.2 \\
\hline Poland & & 119.0 & 95.1 & 178.0 & 392.1 \\
\hline Portugal & & 60.6 & 116.8 & 71.1 & 248.5 \\
\hline Slovak Republic & & 266.8 & 84.9 & 147.8 & 499.5 \\
\hline Spain & & 58.7 & 49.2 & 68.3 & 176.2 \\
\hline Sweden & (2001) & 114.6 & 53.1 & 67.2 & 234.9 \\
\hline Switzerland & (2001) & 80.4 & 33.1 & 72.3 & 185.8 \\
\hline Turkey & & . & $\ldots$ & . & . \\
\hline United Kingdom & & 123.7 & 63.3 & 52.6 & 239.6 \\
\hline United States & (2001) & 132.8 & 41.1 & 67.7 & 241.6 \\
\hline Average $(27)^{a}$ & & 108.9 & 66.6 & 79.9 & 255.4 \\
\hline Median & & 106.0 & 55.8 & 72.3 & 234.9 \\
\hline
\end{tabular}

Note: All mortality rates are standardised to the OECD standard population (1980).

a) Excludes Belgium, Mexico and Turkey.

Source: OECD Health Data 2005. The raw mortality data is extracted from the WHO Mortality Database (March 2005). 
Table A.1.9. Ischaemic heart disease, age-standardised mortality rate, per 100000 females, males and total population, 1960, 1980 and 2002

\begin{tabular}{|c|c|c|c|c|c|c|c|c|c|c|}
\hline & \multicolumn{3}{|c|}{1960} & \multicolumn{3}{|c|}{1980} & \multicolumn{4}{|c|}{2002} \\
\hline & Female & Male & Total & Female & Male & Total & Female & Male & & tal \\
\hline Australia & 242.9 & 451.8 & 338.0 & 164.9 & 341.5 & 242.5 & 73.8 & 136.8 & 102.5 & (2001) \\
\hline Austria & 188.4 & 296.8 & 232.8 & 100.5 & 219.3 & 147.1 & 93.0 & 166.8 & 123.0 & \\
\hline Belgium & 95.5 & 172.6 & 130.5 & 80.4 & 186.7 & 126.0 & . & . & .. & \\
\hline Canada & 254.8 & 451.1 & 351.8 & 159.1 & 322.0 & 231.8 & 71.3 & 142.6 & 102.6 & (2001) \\
\hline Czech Republic & .. & .. & .. & .. & .. & .. & 128.4 & 230.9 & 170.6 & \\
\hline Denmark & 216.2 & 329.4 & 269.4 & 179.6 & 366.1 & 261.2 & 74.5 & 148.0 & 106.0 & (2000) \\
\hline Finland & 244.9 & 457.0 & 330.8 & 168.9 & 411.4 & 265.2 & 108.9 & 223.9 & 156.5 & \\
\hline France & 53.6 & 104.4 & 74.4 & 47.3 & 108.0 & 73.5 & 27.8 & 68.6 & 45.1 & (2001) \\
\hline Germany & 165.1 & 257.2 & 204.3 & 107.6 & 249.7 & 162.2 & 84.6 & 163.0 & 116.6 & (2001) \\
\hline Greece & 99.6 & 105.7 & 102.3 & 44.2 & 114.5 & 76.3 & 53.2 & 113.5 & 81.3 & \\
\hline Hungary & 234.9 & 291.2 & 259.5 & 156.1 & 298.0 & 217.0 & 162.9 & 276.3 & 209.3 & \\
\hline Iceland & 163.4 & 246.9 & 201.3 & 136.7 & 325.1 & 224.5 & 71.5 & 163.1 & 112.7 & \\
\hline Ireland & 258.5 & 385.1 & 319.4 & 177.2 & 367.3 & 264.9 & 98.6 & 204.6 & 146.1 & (2001) \\
\hline Italy & 205.9 & 265.5 & 232.7 & 86.9 & 169.6 & 123.2 & 46.2 & 95.4 & 67.2 & (2001) \\
\hline Japan & 78.0 & 109.0 & 91.0 & 40.0 & 68.1 & 52.0 & 21.3 & 44.8 & 31.6 & \\
\hline Korea & . & . & .. & .. & . & . & 27.4 & 47.3 & 35.6 & \\
\hline Luxembourg & 122.5 & 207.8 & 163.0 & 96.5 & 191.0 & 137.7 & 48.0 & 105.1 & 72.4 & \\
\hline Mexico & . & . & . & .. & . & . & . & . & .. & \\
\hline Netherlands & 176.6 & 259.6 & 215.9 & 106.1 & 246.2 & 167.2 & 48.7 & 105.5 & 72.6 & \\
\hline New Zealand & 224.8 & 403.7 & 308.2 & 193.3 & 386.3 & 277.2 & 91.2 & 178.1 & 129.7 & (2000) \\
\hline Norway & 157.8 & 273.0 & 211.1 & 125.2 & 293.4 & 200.6 & 67.6 & 148.0 & 102.2 & \\
\hline Poland & 63.2 & 106.9 & 81.0 & 57.5 & 160.7 & 101.5 & 81.5 & 171.9 & 119.0 & \\
\hline Portugal & 121.1 & 158.4 & 136.9 & 64.2 & 124.3 & 89.6 & 42.2 & 83.8 & 60.6 & \\
\hline Slovak Republic & $\ldots$ & .. & . & . & . & . & 215.9 & 341.3 & 266.8 & \\
\hline Spain & 80.7 & 108.6 & 93.0 & 49.1 & 108.7 & 75.1 & 37.5 & 85.4 & 58.7 & \\
\hline Sweden & 224.7 & 336.2 & 276.9 & 187.7 & 388.5 & 276.8 & 77.6 & 162.6 & 114.6 & (2001) \\
\hline Switzerland & 229.2 & 310.3 & 265.1 & 71.5 & 175.7 & 115.6 & 56.2 & 113.5 & 80.4 & (2001) \\
\hline Turkey & . & . & . & . & . & . & . & . & .. & \\
\hline United Kingdom & 231.5 & 403.1 & 302.9 & 162.0 & 366.6 & 247.7 & 84.1 & 174.7 & 123.7 & \\
\hline United States & 272.6 & 490.1 & 374.0 & 168.5 & 330.2 & 237.1 & 98.9 & 176.6 & 132.8 & (2001) \\
\hline Latest average $^{a}$ & . & . & . & . & . & . & 77.5 & 150.8 & 108.9 & \\
\hline Consistent average $(24)^{b}$ & 179.6 & 283.7 & 226.5 & 118.8 & 255.5 & 177.8 & 71.7 & 143.9 & 102.8 & \\
\hline Median & 188.4 & 273.0 & 232.7 & 107.6 & 249.7 & 167.2 & 73.8 & 148.0 & 106.0 & \\
\hline
\end{tabular}

Note: All mortality rates are standardised to the OECD standard population (1980).

a) Average comprises all countries for which recent data is available (2000+).

b) Excludes Belgium, Czech Republic, Korea, Mexico, Slovak Republic and Turkey.

Source: OECD Health Data 2005. The raw mortality data is extracted from the WHO Mortality Database (March 2005). 
Table A.1.10. Cerebro-vascular disease, age-standardised mortality rate, per 100000 females, males and total population, 1960, 1980 and 2002

\begin{tabular}{|c|c|c|c|c|c|c|c|c|c|c|}
\hline & & 1960 & & & 1980 & & & & & \\
\hline & Female & Male & Total & Female & Male & Total & Female & Male & Tot & tal \\
\hline Australia & 156.3 & 156.3 & 157.0 & 104.5 & 116.0 & 110.7 & 42.2 & 47.5 & 44.9 & (2001) \\
\hline Austria & 161.5 & 194.2 & 174.5 & 133.1 & 168.7 & 146.7 & 53.1 & 67.1 & 58.6 & \\
\hline Belgium & 67.6 & 82.9 & 74.4 & 89.8 & 111.5 & 98.7 & .. & .. & .. & \\
\hline Canada & 131.1 & 135.9 & 133.7 & 64.1 & 78.1 & 70.2 & 33.3 & 40.4 & 36.5 & (2001) \\
\hline Czech Republic & . & . & . & . & . & . & 113.9 & 139.0 & 124.6 & \\
\hline Denmark & 131.9 & 129.3 & 130.7 & 68.6 & 88.7 & 77.0 & 51.9 & 63.2 & 57.0 & (2000) \\
\hline Finland & 189.8 & 190.5 & 190.9 & 100.4 & 122.1 & 108.9 & 53.6 & 64.4 & 58.7 & \\
\hline France & 116.2 & 157.4 & 131.7 & 78.2 & 111.7 & 91.8 & 30.6 & 43.0 & 35.9 & (2001) \\
\hline Germany & 189.8 & 210.1 & 198.3 & 115.3 & 145.9 & 126.8 & 47.9 & 61.3 & 53.5 & (2001) \\
\hline Greece & 107.6 & 98.7 & 103.7 & 151.8 & 143.9 & 148.9 & 108.1 & 106.3 & 108.0 & \\
\hline Hungary & 180.1 & 190.4 & 184.4 & 189.1 & 243.0 & 211.7 & 108.6 & 162.1 & 130.0 & \\
\hline Iceland & 147.2 & 108.8 & 130.9 & 67.7 & 67.2 & 66.3 & 40.5 & 46.1 & 44.1 & \\
\hline Ireland & 141.8 & 130.4 & 136.3 & 127.3 & 132.0 & 129.7 & 53.9 & 64.8 & 58.9 & (2001) \\
\hline Italy & 146.6 & 185.3 & 163.4 & 104.0 & 133.9 & 116.7 & 49.8 & 64.1 & 55.8 & (2001) \\
\hline Japan & 252.0 & 351.2 & 295.2 & 150.2 & 212.3 & 176.5 & 43.5 & 71.3 & 55.2 & \\
\hline Korea & .. & .. & .. & .. & .. & .. & 97.4 & 139.7 & 113.9 & \\
\hline Luxembourg & 71.5 & 90.5 & 80.6 & 159.5 & 203.8 & 177.0 & 63.5 & 72.9 & 66.1 & \\
\hline Mexico & .. & .. & .. & .. & .. & .. & .. & .. & .. & \\
\hline Netherlands & 124.9 & 119.2 & 122.3 & 73.6 & 89.5 & 80.4 & 47.5 & 57.9 & 52.1 & \\
\hline New Zealand & 144.0 & 129.5 & 137.7 & 116.0 & 126.0 & 120.2 & 52.7 & 57.3 & 54.9 & (2000) \\
\hline Norway & 155.6 & 154.9 & 155.4 & 86.7 & 106.6 & 95.4 & 46.8 & 58.5 & 51.9 & \\
\hline Poland & 57.1 & 58.9 & 58.0 & 69.3 & 82.1 & 75.1 & 84.4 & 109.5 & 95.1 & \\
\hline Portugal & 181.0 & 217.7 & 196.0 & 250.1 & 306.2 & 273.9 & 104.2 & 132.7 & 116.8 & \\
\hline Slovak Republic & .. & .. & .. & .. & .. & .. & 70.9 & 105.6 & 84.9 & \\
\hline Spain & 136.8 & 157.9 & 145.6 & 121.2 & 142.4 & 130.3 & 43.7 & 55.6 & 49.2 & \\
\hline Sweden & 133.2 & 133.1 & 133.2 & 69.6 & 83.4 & 75.9 & 48.1 & 59.0 & 53.1 & (2001) \\
\hline Switzerland & 120.9 & 136.5 & 127.5 & 80.3 & 98.1 & 87.4 & 29.3 & 38.5 & 33.1 & (2001) \\
\hline Turkey & . & . & .. & .. & .. & .. & .. & .. & . & \\
\hline United Kingdom & 156.4 & 173.3 & 163.2 & 107.4 & 122.8 & 114.1 & 59.6 & 67.2 & 63.3 & \\
\hline United States & 128.3 & 144.5 & 135.8 & 65.1 & 76.7 & 70.0 & 39.1 & 43.2 & 41.1 & (2001) \\
\hline Latest average $^{a}$ & . & .. & . & .. & .. & . & 59.9 & 75.5 & 66.6 & \\
\hline Consistent average $(24)^{b}$ & 144.2 & 156.4 & 149.4 & 110.5 & 133.4 & 120.1 & 55.7 & 68.9 & 61.4 & \\
\hline Median & 141.8 & 144.5 & 136.3 & 104.0 & 122.1 & 110.7 & 51.9 & 64.1 & 55.8 & \\
\hline
\end{tabular}

Note: All mortality rates are standardised to the OECD standard population (1980).

a) Average comprises all countries for which recent data is available (2000+)

b) Excludes Belgium, Czech Republic, Korea, Mexico, Slovak Republic and Turkey.

Source: OECD Health Data 2005. The raw mortality data is extracted from the WHO Mortality Database (March 2005). 
Table A.1.11. All cancers, age-standardised mortality rate, per 100000 females, males and total population, 1960, 1980 and 2002

\begin{tabular}{|c|c|c|c|c|c|c|c|c|c|c|}
\hline & & 1960 & & & 1980 & & & & & \\
\hline & Female & Male & Total & Female & Male & Total & Female & Male & Tot & tal \\
\hline Australia & 132.9 & 192.5 & 158.5 & 136.4 & 239.1 & 179.1 & 126.7 & 205.6 & 161.0 & (2001) \\
\hline Austria & 182.6 & 277.0 & 220.0 & 162.9 & 274.0 & 203.0 & 126.6 & 216.6 & 161.9 & \\
\hline Belgium & 174.3 & 242.8 & 204.4 & 158.5 & 310.0 & 220.4 & .. & .. & .. & \\
\hline Canada & 156.4 & 200.1 & 177.3 & 146.5 & 238.5 & 185.8 & 144.1 & 216.7 & 174.4 & (2001) \\
\hline Czech Republic & . & . & .. & .. & . & .. & 164.9 & 305.6 & 221.4 & \\
\hline Denmark & 198.6 & 230.2 & 213.0 & 187.2 & 267.0 & 219.7 & 186.8 & 251.4 & 212.5 & (2000) \\
\hline Finland & 159.0 & 268.1 & 202.2 & 132.8 & 264.2 & 180.2 & 111.4 & 187.3 & 140.0 & \\
\hline France & 147.6 & 234.9 & 182.0 & 128.4 & 281.1 & 192.0 & 115.9 & 251.6 & 173.7 & (2001) \\
\hline Germany & 179.3 & 236.3 & 203.1 & 162.2 & 266.9 & 200.0 & 132.3 & 220.9 & 167.3 & (2001) \\
\hline Greece & 96.1 & 151.4 & 120.5 & 109.8 & 195.5 & 148.3 & 110.1 & 205.6 & 153.1 & \\
\hline Hungary & 165.1 & 210.2 & 184.1 & 176.9 & 299.1 & 227.0 & 175.3 & 345.0 & 243.1 & \\
\hline Iceland & 217.8 & 211.1 & 213.2 & 140.3 & 191.8 & 162.6 & 142.7 & 187.3 & 161.8 & \\
\hline Ireland & 150.1 & 182.6 & 165.5 & 169.1 & 237.9 & 199.3 & 161.0 & 233.9 & 190.5 & (2001) \\
\hline Italy & 137.6 & 191.2 & 161.2 & 135.2 & 256.0 & 187.0 & 122.9 & 234.3 & 169.7 & (2001) \\
\hline Japan & 127.6 & 185.6 & 153.5 & 117.3 & 211.3 & 157.1 & 99.9 & 210.5 & 146.5 & \\
\hline Korea & .. & .. & .. & .. & .. & .. & 105.5 & 271.4 & 170.5 & \\
\hline Luxembourg & 152.2 & 199.4 & 174.6 & 182.0 & 289.2 & 225.1 & 125.1 & 217.2 & 162.8 & \\
\hline Mexico & .. & .. & .. & .. & .. & .. & .. & . & .. & \\
\hline Netherlands & 170.5 & 228.0 & 197.5 & 149.9 & 297.0 & 210.8 & 147.2 & 242.4 & 185.0 & \\
\hline New Zealand & 147.3 & 191.3 & 166.6 & 165.8 & 247.9 & 198.6 & 148.3 & 225.4 & 180.7 & (2000) \\
\hline Norway & 143.9 & 180.0 & 159.7 & 137.4 & 207.5 & 166.1 & 138.9 & 209.1 & 166.9 & \\
\hline Poland & 110.4 & 148.0 & 125.1 & 139.8 & 244.7 & 182.3 & 146.4 & 291.5 & 203.6 & \\
\hline Portugal & 104.8 & 140.0 & 119.0 & 119.7 & 200.0 & 152.5 & 108.5 & 212.0 & 152.4 & \\
\hline Slovak Republic & .. & .. & .. & .. & .. & .. & 139.1 & 291.8 & 200.0 & \\
\hline Spain & 120.8 & 173.3 & 142.7 & 112.6 & 211.2 & 153.9 & 101.8 & 232.8 & 158.5 & \\
\hline Sweden & 155.6 & 189.5 & 170.5 & 150.1 & 212.7 & 175.5 & 133.3 & 179.5 & 151.6 & (2001) \\
\hline Switzerland & 161.7 & 238.4 & 193.9 & 142.0 & 250.7 & 185.7 & 112.9 & 203.3 & 149.8 & (2001) \\
\hline Turkey & .. & .. & .. & .. & .. & .. & .. & .. & .. & \\
\hline United Kingdom & 156.4 & 248.3 & 193.3 & 168.7 & 273.0 & 208.1 & 153.2 & 223.0 & 181.8 & \\
\hline United States & 145.9 & 197.5 & 169.3 & 144.4 & 234.2 & 180.7 & 141.6 & 206.7 & 168.5 & (2001) \\
\hline Latest average $^{a}$ & . & .. & .. & .. & .. & . & 134.2 & 232.5 & 174.4 & \\
\hline Consistent average (24) ${ }^{b}$ & 150.8 & 204.4 & 173.6 & 146.6 & 245.4 & 186.7 & 133.9 & 225.4 & 171.5 & \\
\hline Median & 152.2 & 199.4 & 174.6 & 144.4 & 247.9 & 185.8 & 133.3 & 220.9 & 168.5 & \\
\hline
\end{tabular}

Note: All mortality rates are standardised to the OECD standard population (1980).

a) Average comprises all countries for which recent data is available (2000+).

b) Excludes Belgium, Czech Republic, Korea, Mexico, Slovak Republic and Turkey.

Source: OECD Health Data 2005. The raw mortality data is extracted from the WHO Mortality Database (March 2005). 
Table A.1.12. Lung cancers, age-standardised mortality rate, per 100000 females, males and total population, 1960, 1980 and 2002

\begin{tabular}{|c|c|c|c|c|c|c|c|c|c|c|}
\hline & & 1960 & & & 1980 & & & & & \\
\hline & Female & Male & Total & Female & Male & Total & Female & Male & Tot & tal \\
\hline Australia & 4.6 & 35.9 & 19.0 & 13.0 & 70.8 & 38.2 & 20.0 & 46.8 & 32.1 & (2001) \\
\hline Austria & 7.3 & 65.5 & 31.2 & 10.4 & 72.5 & 34.0 & 16.2 & 52.8 & 31.3 & \\
\hline Belgium & 5.1 & 48.5 & 24.8 & 8.4 & 110.6 & 51.7 & .. & . & . & \\
\hline Canada & 4.8 & 33.9 & 19.2 & 17.2 & 75.0 & 42.9 & 34.2 & 63.7 & 47.0 & (2001) \\
\hline Czech Republic & $\ldots$ & . & . & . & . & . & 17.0 & 79.2 & 43.0 & \\
\hline Denmark & 8.1 & 38.2 & 22.3 & 18.8 & 75.2 & 43.5 & 37.9 & 65.2 & 49.6 & (2000) \\
\hline Finland & 3.8 & 76.1 & 33.0 & 8.7 & 94.2 & 41.1 & 11.3 & 48.0 & 26.0 & \\
\hline France & 4.5 & 28.2 & 14.6 & 5.2 & 57.1 & 27.6 & 10.0 & 60.5 & 32.5 & (2001) \\
\hline Germany & 6.0 & 45.2 & 22.7 & 8.1 & 70.8 & 31.9 & 14.7 & 57.2 & 32.4 & (2001) \\
\hline Greece & 6.1 & 32.6 & 18.1 & 8.3 & 59.7 & 31.7 & 10.4 & 66.4 & 35.9 & \\
\hline Hungary & 8.5 & 35.6 & 20.5 & 14.0 & 79.5 & 41.7 & 28.9 & 102.6 & 59.0 & \\
\hline Iceland & 16.5 & 12.6 & 15.1 & 29.7 & 24.5 & 27.0 & 30.8 & 36.4 & 33.2 & \\
\hline Ireland & 7.3 & 32.0 & 19.5 & 19.8 & 62.9 & 39.7 & 25.1 & 54.3 & 37.8 & (2001) \\
\hline Italy & 5.2 & 26.4 & 14.9 & 8.2 & 71.8 & 36.3 & 12.0 & 67.2 & 35.8 & (2001) \\
\hline Japan & 4.6 & 13.4 & 8.6 & 10.2 & 36.1 & 21.2 & 12.1 & 47.1 & 26.8 & \\
\hline Korea & .. & .. & .. & .. & .. & .. & 16.0 & 67.8 & 36.1 & \\
\hline Luxembourg & .. & .. & .. & 10.6 & 96.5 & 46.8 & 10.9 & 64.3 & 33.6 & \\
\hline Mexico & .. & .. & .. & . & . & .. & . & . & .. & \\
\hline Netherlands & 4.6 & 53.9 & 28.0 & 8.1 & 113.0 & 52.9 & 23.8 & 74.6 & 45.0 & \\
\hline New Zealand & 6.1 & 37.6 & 20.7 & 17.6 & 71.6 & 41.1 & 24.4 & 47.2 & 34.4 & (2000) \\
\hline Norway & 3.6 & 16.2 & 9.5 & 7.6 & 33.8 & 19.3 & 22.1 & 47.4 & 33.1 & \\
\hline Poland & 4.2 & 22.5 & 11.8 & 9.5 & 72.6 & 36.0 & 18.0 & 94.7 & 49.4 & \\
\hline Portugal & 2.9 & 11.4 & 6.4 & 5.0 & 28.7 & 15.0 & 7.2 & 39.5 & 21.4 & \\
\hline Slovak Republic & .. & .. & .. & .. & .. & .. & 9.8 & 73.0 & 35.5 & \\
\hline Spain & 5.1 & 22.5 & 12.7 & 5.4 & 46.1 & 22.9 & 6.7 & 63.6 & 32.0 & \\
\hline Sweden & 4.9 & 19.1 & 11.6 & 9.9 & 35.8 & 21.4 & 19.6 & 30.5 & 24.2 & (2001) \\
\hline Switzerland & 4.2 & 41.5 & 20.6 & 7.4 & 66.3 & 32.6 & 13.7 & 49.1 & 28.9 & (2001) \\
\hline Turkey & .. & .. & . & .. & .. & .. & .. & .. & .. & \\
\hline United Kingdom & 10.4 & 82.0 & 40.9 & 23.8 & 103.7 & 56.1 & 28.8 & 56.3 & 40.6 & \\
\hline United States & 6.0 & 40.7 & 22.4 & 22.1 & 77.2 & 45.5 & 36.9 & 66.6 & 49.7 & (2001) \\
\hline Latest average $^{a}$ & . & . & . & . & $\ldots$ & .. & 19.2 & 60.1 & 36.5 & \\
\hline Consistent average $(24)^{b}$ & 6.1 & 35.8 & 19.3 & 12.4 & 66.5 & 35.3 & 19.8 & 58.4 & 36.3 & \\
\hline Median & 5.1 & 34.8 & 19.4 & 9.9 & 71.6 & 36.3 & 17.0 & 60.5 & 34.4 & \\
\hline
\end{tabular}

Note: All mortality rates are standardised to the OECD standard population (1980).

a) Average comprises all countries for which recent data is available (2000+).

b) Excludes Belgium, Czech Republic, Korea, Mexico, Slovak Republic and Turkey.

Source: OECD Health Data 2005. The raw mortality data is extracted from the WHO Mortality Database (March 2005). 
Table A.1.13. Breast and prostate cancers, age-standardised mortality rate, 1960, 1980 and 2002

\begin{tabular}{|c|c|c|c|c|c|c|c|}
\hline & \multicolumn{3}{|c|}{$\begin{array}{c}\text { Breast } \\
\text { Per } 100000 \text { females }\end{array}$} & \multicolumn{4}{|c|}{$\begin{array}{c}\text { Prostate } \\
\text { Per } 100000 \text { males }\end{array}$} \\
\hline & 1960 & 1980 & 2002 & 1960 & 1980 & 20 & 02 \\
\hline Australia & 24.4 & 24.9 & $21.3(2001)$ & 25.9 & 26.3 & 26.9 & (2001) \\
\hline Austria & 20.3 & 26.5 & 23.8 & 23.2 & 27.1 & 25.9 & \\
\hline Belgium & 26.7 & 33.0 & . & 23.8 & 29.7 & . & \\
\hline Canada & 30.4 & 29.5 & 24.2 (2001) & 22.1 & 24.2 & 24.5 & (2001) \\
\hline Czech Republic & .. & .. & 25.5 & .. & .. & 30.0 & \\
\hline Denmark & 31.9 & 34.6 & $33.4 \quad(2000)$ & 23.2 & 28.9 & 34.3 & (2000) \\
\hline Finland & 17.3 & 20.4 & 19.2 & 20.5 & 30.2 & 29.7 & \\
\hline France & 20.7 & 23.5 & $24.1 \quad$ (2001) & 26.2 & 26.5 & 24.8 & (2001) \\
\hline Germany & 21.4 & 27.0 & 25.1 (2001) & 19.9 & 27.1 & 23.8 & (2001) \\
\hline Greece & 6.0 (1961) & 18.3 & 21.1 & 7.3 (1961) & 12.8 & 17.9 & \\
\hline Hungary & 15.3 & 26.2 & 27.7 & 17.9 & 26.8 & 25.7 & \\
\hline Iceland & 26.6 & 15.9 & 22.4 & 14.1 & 13.0 & 43.5 & \\
\hline Ireland & 24.7 & 35.7 & 31.1 (2001) & 15.2 & 25.3 & 32.5 & (2001) \\
\hline Italy & 18.7 & 24.2 & 23.2 (2001) & 13.3 & 18.1 & 17.4 & (2001) \\
\hline Japan & 4.7 & 6.6 & 9.8 & 2.3 & 4.7 & 9.2 & \\
\hline Korea & . & . & 5.5 & . & . & 7.3 & \\
\hline Luxembourg & . & 30.2 & 23.7 & . & 31.2 & 18.8 & \\
\hline Mexico & . & .. & . & . & . & . & \\
\hline Netherlands & 32.0 & 33.3 & 30.1 & 23.1 & 28.3 & 28.6 & \\
\hline New Zealand & 25.8 & 34.0 & $27 \quad(2000)$ & 21.9 & 30.2 & 33.0 & (2000) \\
\hline Norway & 22.0 & 23.0 & 21.3 & 27.7 & 37.3 & 36.7 & \\
\hline Poland & 7.2 & 18.3 & 19.2 & 6.0 & 14.5 & 23.0 & \\
\hline Portugal & 15.2 & 18.8 & 19.8 & 15.6 & 24.5 & 26.6 & \\
\hline Slovak Republic & . & . & 22.1 & .. & . & 23.5 & \\
\hline Spain & 10.6 & 17.2 & 18.2 & 16.5 & 22.0 & 21.0 & \\
\hline Sweden & 25.7 & 25.2 & $20.0 \quad(2001)$ & 28.7 & 35.0 & 36.6 & (2001) \\
\hline Switzerland & 29.8 & 31.1 & $23.7 \quad(2001)$ & 26.9 & 32.2 & 29.9 & (2001) \\
\hline Turkey & . & . & . & .. & . & . & \\
\hline United Kingdom & 30.4 & 35.9 & 27.4 & 20.4 & 21.6 & 26.4 & \\
\hline United States & 27.5 & 27.9 & 22.4 (2001) & 22.9 & 25.3 & 21.3 & (2001) \\
\hline Latest average $^{a}$ & . & . & 22.7 & . & . & 25.9 & \\
\hline Consistent average $(24)^{b}$ & 21.2 & 25.3 & 23.3 & 19.2 & 24.7 & 26.6 & \\
\hline Median & 23.2 & 26.2 & 23.2 & 21.2 & 26.5 & 25.9 & \\
\hline
\end{tabular}

Note: All mortality rates are standardised to the OECD standard population (1980).

a) Average comprises all countries for which recent data is available (2000+).

b) Excludes Belgium, Czech Republic, Korea, Mexico, Slovak Republic and Turkey.

Source: OECD Health Data 2005. The raw mortality data is extracted from the WHO Mortality Database (March 2005). 
Table A.1.14. Mortality, external causes, age-standardised death rates per 100000 population, 2002

\begin{tabular}{|c|c|c|c|c|c|c|c|}
\hline & & Road accidents & Accidental falls & Suicides & Homicides & $\begin{array}{l}\text { Other external } \\
\text { causes }\end{array}$ & Total \\
\hline Australia & (2001) & 9.7 & 2.5 & 11.9 & 1.5 & 11.1 & 36.7 \\
\hline Austria & & 11.1 & 8.0 & 16.1 & 0.9 & 8.1 & 44.2 \\
\hline Belgium & & .. & .. & . & .. & .. & \\
\hline Canada & (2001) & 9.2 & 4.1 & 10.8 & 1.5 & 12.1 & 37.7 \\
\hline Czech Republic & & 13.3 & 13.8 & 12.8 & 1.2 & 16.0 & 57.1 \\
\hline Denmark & $(2000)$ & 9.1 & 6.2 & 11.4 & 1.2 & 19.1 & 47.0 \\
\hline Finland & & 8.3 & 13.9 & 18.8 & 2.5 & 20.3 & 63.8 \\
\hline France & (2001) & 12.7 & 5.4 & 15.0 & 0.8 & 18.9 & 52.8 \\
\hline Germany & (2001) & 8.7 & 5.0 & 11.0 & 0.7 & 7.5 & 32.9 \\
\hline Greece & & 15.2 & 3.6 & 2.4 & 0.7 & 9.9 & 31.8 \\
\hline Hungary & & 15.4 & 22.3 & 23.2 & 2.2 & 12.6 & 75.7 \\
\hline Iceland & & 10.3 & 5.5 & 9.7 & 1.8 & 10.7 & 38.0 \\
\hline Ireland & (2001) & 9.8 & 8.6 & 12.2 & 1.0 & 9.1 & 40.7 \\
\hline Italy & (2001) & 12.3 & 8.8 & 5.6 & 0.9 & 5.7 & 33.3 \\
\hline Japan & & 7.7 & 3.0 & 18.7 & 0.5 & 12.6 & 42.5 \\
\hline Korea & & 20.1 & 8.6 & 18.7 & 1.6 & 18.2 & 67.2 \\
\hline Luxembourg & & 14.6 & 7.8 & 17.2 & 1.9 & 17.8 & 59.3 \\
\hline Mexico & & .. & . & .. & .. & .. & \\
\hline Netherlands & & 6.4 & 3.8 & 8.4 & 1.2 & 7.3 & 27.1 \\
\hline New Zealand & $(2000)$ & 13.4 & 5.1 & 12.0 & 1.4 & 8.8 & 40.7 \\
\hline Norway & & 7.7 & 10.1 & 10.2 & 0.9 & 9.8 & 38.7 \\
\hline Poland & & 15.3 & 8.6 & 13.9 & 1.6 & 20.9 & 60.3 \\
\hline Portugal & & 19.8 & 4.4 & 9.5 & 1.6 & 11.5 & 46.8 \\
\hline Slovak Republic & & 13.0 & 6.4 & 11.9 & 2.1 & 18.4 & 51.8 \\
\hline Spain & & 12.9 & 2.6 & 6.6 & 1.0 & 8.9 & 32.0 \\
\hline Sweden & (2001) & 6.3 & 3.4 & 11.3 & 0.9 & 16.3 & 38.2 \\
\hline Switzerland & (2001) & . & 8.5 & 15.4 & 1.1 & .. & 39.5 \\
\hline Turkey & & .. & .. & .. & .. & .. & \\
\hline United Kingdom & & 5.7 & 3.4 & 6.3 & 0.9 & 10.1 & 26.4 \\
\hline United States & (2001) & 15.7 & 3.9 & 10.0 & 7.1 & 15.1 & 51.8 \\
\hline Average $(27)^{a}$ & & 11.7 & 6.9 & 12.3 & 1.5 & 13.0 & 45.0 \\
\hline Median & & 11.7 & 5.5 & 11.9 & 1.2 & 11.8 & 40.7 \\
\hline
\end{tabular}

Note: All mortality rates are standardised to the OECD standard population (1980).

a) Excludes Belgium, Mexico and Turkey. In addition, the average for road accidents and other external causes excludes Switzerland. Source: OECD Health Data 2005. The raw mortality data is extracted from the WHO Mortality Database (March 2005). 
Table A.1.15. Mortality, road accidents, age-standardised death rates per 100000 population, 1960 to 2002

\begin{tabular}{|c|c|c|c|c|c|c|c|}
\hline & 1960 & 1970 & 1980 & 1990 & 2000 & 200 & 02 \\
\hline Australia & 28.1 & 32.8 & 24.6 & 14.4 & 10.2 & 9.7 & (2001) \\
\hline Austria & 27.6 & 33.3 & 25.5 & 18.3 & 11.2 & 11.1 & \\
\hline Belgium & 19.2 & 29.8 & 24.9 & 18.1 & .. & .. & \\
\hline Canada & 21.8 & 25.0 & 22.1 & 13.9 & 9.6 & 9.2 & (2001) \\
\hline Czech Republic & . & .. & .. & 14.5 & 14.1 & 13.3 & \\
\hline Denmark & 17.1 & 24.2 & 13.5 & 11.2 & 9.1 & $\ldots$ & \\
\hline Finland & 18.1 & 23.7 & 11.4 & 13.8 & 7.5 & 8.3 & \\
\hline France & 18.1 & 23.2 & 20.4 & 17.5 & 12.5 & 12.7 & (2001) \\
\hline Germany & 25.6 & 32.2 & 20.3 & 13.6 & 9.5 & 8.7 & (2001) \\
\hline Greece & 4.8 & 11.6 & 17.1 & 21.2 & 18.2 & 15.2 & \\
\hline Hungary & 6.7 & 16.3 & 19.1 & 26.9 & 13.3 & 15.4 & \\
\hline Iceland & 5.3 & 16.6 & 10.1 & 11.1 & 11.7 & 10.3 & \\
\hline Ireland & 9.0 & 16.6 & 17.9 & 13.9 & 10.4 & 9.8 & (2001) \\
\hline Italy & 17.8 & 24.3 & 19.2 & 14.9 & 12.1 & 12.3 & (2001) \\
\hline Japan & 15.9 & 22.5 & 11.4 & 11.9 & 8.5 & 7.7 & \\
\hline Korea & . & . & . & 36.1 & 27.0 & 20.1 & \\
\hline Luxembourg & 23.8 & 41.6 & 29.6 & 18.7 & 18.7 & 14.6 & \\
\hline Mexico & .. & 9.3 & . & 21.7 & . & . & \\
\hline Netherlands & 17.6 & 24.8 & 13.7 & 8.8 & 7.0 & 6.4 & \\
\hline New Zealand & 16.5 & 24.2 & 19.8 & 22.3 & 13.4 & . & \\
\hline Norway & 8.6 & 15.0 & 9.1 & 8.1 & 8.6 & 7.7 & \\
\hline Poland & 4.7 & 12.1 & .. & 24.8 & 16.7 & 15.3 & \\
\hline Portugal & 9.1 & 22.5 & 29.4 & 28.0 & 13.0 & 19.8 & \\
\hline Slovak Republic & .. & $\ldots$ & . & 20.6 (1992) & 14.4 & 13.0 & \\
\hline Spain & 8.5 & 13.6 (1969) & 17.1 & 19.9 & 14.6 & 12.9 & \\
\hline Sweden & 14.4 & 16.5 & 10.5 & 8.8 & 6.3 & 6.3 & (2001) \\
\hline Switzerland & 22.0 & 26.1 & 18.5 & 13.1 & . & . & \\
\hline Turkey & . & . & . & . & $\ldots$ & . & \\
\hline United Kingdom & 14.3 & 14.2 & 12.1 & 9.8 & 5.8 (1999) & 5.7 & \\
\hline United States & 22.6 & 27.0 & 22.4 & 18.5 & 15.8 & 15.7 & (2001) \\
\hline Latest average $^{a}$ & . & . & . & . & . & 11.7 & \\
\hline Consistent average $(24)^{b}$ & 15.5 & 22.3 & 18.0 & 16.1 & 11.5 & 11.2 & \\
\hline Median & 17.1 & 23.5 & 18.8 & 14.9 & 11.9 & 11.7 & \\
\hline
\end{tabular}

Note: All mortality rates are standardised to the OECD standard population (1980).

a) Average comprises all countries for which recent data is available (2000+).

b) Excludes Belgium, Czech Republic, Korea, Mexico, Slovak Republic, Switzerland and Turkey. The 2000 figures of Denmark and New Zealand have been used for the calculation of the 2002 OECD average.

Source: OECD Health Data 2005. The raw mortality data is extracted from the WHO Mortality Database (March 2005). 
Table A.1.16. Mortality, accidental falls, age-standardised death rates per 100000 population, 1960 to 2002

\begin{tabular}{|c|c|c|c|c|c|c|c|}
\hline & 1960 & 1970 & 1980 & 1990 & 2000 & 20 & 02 \\
\hline Australia & 12.7 & 12.4 & 7.6 & 5.6 & 2.4 & 2.5 & (2001) \\
\hline Austria & 20.7 & 25.1 & 18.9 & 12.2 & 7.9 & 8.0 & \\
\hline Belgium & 9.5 & 17.3 & 16.0 & 8.1 & .. & . & \\
\hline Canada & 13.5 & 9.7 & 8.3 & 6.8 & 3.8 & 4.1 & (2001) \\
\hline Czech Republic & . & .. & .. & 26.5 & 14.8 & 13.8 & \\
\hline Denmark & 20.5 & 13.0 & 11.2 & 13.9 & 6.2 & .. & \\
\hline Finland & 21.2 & 15.2 & 12.1 & 13.6 & 13.5 & 13.9 & \\
\hline France & 14.0 & 19.2 & 16.0 & 11.8 & 5.4 & 5.4 & (2001) \\
\hline Germany & 20.8 & 21.5 & 12.5 & 9.9 & 5.3 & 5.0 & (2001) \\
\hline Greece & $13.1 \quad(1961)$ & 14.2 & 12.5 & 5.5 & 3.5 & 3.6 & \\
\hline Hungary & 13.9 & 22.7 & 28.0 & 33.0 & 21.9 & 22.3 & \\
\hline Iceland & 18.6 & 16.5 & 10.1 & 8.3 & 5.8 & 5.5 & \\
\hline Ireland & 9.4 & 13.1 & 10.7 & 7.7 & 7.9 & 8.6 & (2001) \\
\hline Italy & 14.0 & 14.0 & 13.6 & 11.7 & 8.5 & 8.8 & (2001) \\
\hline Japan & 6.3 & 6.3 & 4.4 & 3.0 & 3.2 & 3.0 & \\
\hline Korea & .. & . & .. & 3.7 & 7.4 & 8.6 & \\
\hline Luxembourg & . & 24.9 & 20.0 & 5.1 & 7.8 & 7.8 & \\
\hline Mexico & .. & 3.8 & .. & 10.4 & . & . & \\
\hline Netherlands & 13.3 & 19.6 & 10.9 & 7.7 & 3.3 & 3.8 & \\
\hline New Zealand & 16.5 & 20.3 & 15.7 & 7.1 & 5.1 & . & \\
\hline Norway & 17.5 & 15.4 & 16.3 & 13.0 & 10.5 & 10.1 & \\
\hline Poland & 1.5 & 7.4 & .. & 11.8 & 9.8 & 8.6 & \\
\hline Portugal & 10.0 & 9.3 & 13.2 & 7.1 & 3.6 & 4.4 & \\
\hline Slovak Republic & .. & .. & .. & 17.5 (1992) & 8.3 & 6.4 & \\
\hline Spain & 5.2 & 7.1 (1969) & 6.3 & 2.4 & 2.6 & 2.6 & \\
\hline Sweden & 18.0 & 11.1 & 14.0 & 7.9 & 3.0 & 3.4 & (2001) \\
\hline Switzerland & 20.6 & 20.8 & 15.3 & 16.0 & 8.7 & 8.5 & \\
\hline Turkey & .. & .. & .. & .. & $\ldots$ & . & \\
\hline United Kingdom & 12.2 & 10.8 & 7.6 & 5.0 & 4.8 (1999) & 3.4 & \\
\hline United States & 13.2 & 9.0 & 5.4 & 4.1 & 3.6 & 3.9 & (2001) \\
\hline Latest average $^{a}$ & . & . & . & . & . & 6.9 & \\
\hline Consistent average $(24)^{b}$ & 14.2 & 14.9 & 12.6 & 9.6 & 6.6 & 6.6 & \\
\hline Median & 13.7 & 14.1 & 12.5 & 8.1 & 5.8 & 5.5 & \\
\hline
\end{tabular}

Note: All mortality rates are standardised to the OECD standard population (1980).

a) Average comprises all countries for which recent data is available (2000+).

b) Excludes Belgium, Czech Republic, Korea, Mexico, Slovak Republic and Turkey. The 2000 figures of Denmark and New Zealand have been used for the calculation of the 2002 OECD average.

Source: OECD Health Data 2005. The raw mortality data is extracted from the WHO Mortality Database (March 2005). 
Table A.1.17. Mortality, suicides, age-standardised death rates per 100000 population, 1960 to 2002

\begin{tabular}{|c|c|c|c|c|c|c|c|}
\hline & 1960 & 1970 & 1980 & 1990 & 2000 & 20 & 02 \\
\hline Australia & 11.3 & 13.3 & 11.2 & 12.5 & 11.8 & 11.9 & (2001) \\
\hline Austria & 21.2 & 23.0 & 23.7 & 20.5 & 16.5 & 16.1 & \\
\hline Belgium & 13.3 & 15.1 & 20.2 & 16.6 & .. & . & \\
\hline Canada & 8.8 & 12.4 & 13.9 & 12.0 & 10.8 & 10.8 & (2001) \\
\hline Czech Republic & .. & . & .. & 17.8 & 13.8 & 12.8 & \\
\hline Denmark & 19.7 & 20.4 & 29.2 & 20.5 & 11.4 & .. & \\
\hline Finland & 21.6 & 21.4 & 24.1 & 27.8 & 20.4 & 18.8 & \\
\hline France & 15.0 & 14.7 & 17.9 & 17.7 & 15.6 & 15.0 & (2001) \\
\hline Germany & 17.5 & 20.2 & 18.5 & 14.5 & 11.0 & 11.0 & (2001) \\
\hline Greece & 4.1 & 3.1 & 3.1 & 3.1 & 3.0 & 2.4 & \\
\hline Hungary & 25.6 & 32.9 & 41.4 & 35.3 & 26.8 & 23.2 & \\
\hline Iceland & 9.5 & 14.9 & 11.4 & 15.9 & 18.0 & 9.7 & \\
\hline Ireland & 3.0 & 1.9 & 7.1 & 10.1 & 11.7 & 12.2 & (2001) \\
\hline Italy & 6.2 & 5.6 & 6.7 & 6.5 & 5.7 & 5.6 & (2001) \\
\hline Japan & 25.1 & 17.4 & 18.0 & 14.5 & 19.1 & 18.7 & \\
\hline Korea & . & . & . & 7.9 & 14.1 & 18.7 & \\
\hline Luxembourg & 8.7 & 13.6 & 11.6 & 16.0 & 12.8 & 17.2 & \\
\hline Mexico & .. & 1.7 & . & 3.0 & . & . & \\
\hline Netherlands & 7.3 & 8.5 & 9.9 & 8.7 & 8.2 & 8.4 & \\
\hline New Zealand & 10.7 & 10.7 & 11.3 & 13.4 & 12.0 & . & \\
\hline Norway & 6.2 & 8.1 & 11.9 & 14.4 & 11.6 & 10.2 & \\
\hline Poland & 8.9 & 11.7 & 12.6 (1979) & 12.9 & 13.8 & 13.9 & \\
\hline Portugal & 9.8 & 8.9 & 7.6 & 8.0 & 4.1 & 9.5 & \\
\hline Slovak Republic & $\ldots$ & .. & .. & 14.6 (1992) & 12.4 & 11.9 & \\
\hline Spain & 6.0 & 4.6 (1969) & 4.4 & 6.8 & 6.9 & 6.6 & \\
\hline Sweden & 15.9 & 20.4 & 17.7 & 15.0 & 10.9 & 11.3 & (2001) \\
\hline Switzerland & 18.6 & 18.2 & 23.8 & 19.1 & 16.2 & 15.4 & \\
\hline Turkey & .. & . & . & . & $\ldots$ & . & \\
\hline United Kingdom & 9.7 & 7.3 & 8.1 & 7.4 & 6.9 (1999) & 6.3 & \\
\hline United States & 11.4 & 12.3 & 11.6 & 11.9 & 9.8 & 10.0 & (2001) \\
\hline Latest average $^{a}$ & . & . & . & . & . & 12.3 & \\
\hline Consistent average (24) ${ }^{b}$ & 12.6 & 13.6 & 14.9 & 14.4 & 12.3 & 12.0 & \\
\hline Median & 10.7 & 12.9 & 11.9 & 14.4 & 11.8 & 11.9 & \\
\hline
\end{tabular}

Note: All mortality rates are standardised to the OECD standard population (1980).

a) Average comprises all countries for which recent data is available (2000+).

b) Excludes Belgium, Czech Republic, Korea, Mexico, Slovak Republic and Turkey. The 2000 figures of Denmark and New Zealand have been used for the calculation of the 2002 OECD average.

Source: OECD Health Data 2005. The raw mortality data is extracted from the WHO Mortality Database (March 2005). 
Table A.1.18. Mortality, homicides, age-standardised death rates per 100000 population, 1960 to 2002

\begin{tabular}{|c|c|c|c|c|c|c|c|}
\hline & 1960 & 1970 & 1980 & 1990 & 2000 & 20 & 002 \\
\hline Australia & 1.5 & 1.5 & 1.9 & 2.1 & 1.6 & 1.5 & (2001) \\
\hline Austria & 1.2 & 1.5 & 1.2 & 1.6 & 0.9 & 0.9 & \\
\hline Belgium & 0.6 & 1.1 & 1.5 & 1.3 & .. & . & \\
\hline Canada & 1.4 & 2.1 & 2.0 & 2.0 & 1.5 & 1.5 & (2001) \\
\hline Czech Republic & . & . & .. & 1.8 & 1.4 & 1.2 & \\
\hline Denmark & 0.5 & 0.7 & 1.3 & 1.0 & 1.2 & . & \\
\hline Finland & 3.0 & 2.1 & 3.0 & 3.0 & 2.5 & 2.5 & \\
\hline France & 1.6 & 0.7 & 1.0 & 1.0 & 0.8 & 0.8 & (2001) \\
\hline Germany & 0.9 & 1.4 & 1.2 & 1.0 & 0.7 & 0.7 & (2001) \\
\hline Greece & 1.5 & 0.6 & 0.7 & 1.0 & 1.0 & 0.7 & \\
\hline Hungary & 1.6 & 1.9 & 2.5 & 2.9 & 2.3 & 2.2 & \\
\hline Iceland & 0.0 & 0.0 & 0.8 & 0.4 & 2.1 & 1.8 & \\
\hline Ireland & 0.1 & 0.4 & 0.8 & 0.7 & 1.0 & 1.0 & (2001) \\
\hline Italy & 1.3 & 0.8 & 1.9 & 2.5 & 1.0 & 0.9 & (2001) \\
\hline Japan & 1.9 & 1.3 & 0.9 & 0.6 & 0.6 & 0.5 & \\
\hline Korea & .. & . & .. & 1.5 & 1.7 & 1.6 & \\
\hline Luxembourg & 0.6 & 0.6 & 1.8 & 2.6 & 1.6 & 1.9 & \\
\hline Mexico & .. & 23.3 & . & 21.5 & . & .. & \\
\hline Netherlands & 0.3 & 0.5 & 0.8 & 0.9 & 1.1 & 1.2 & \\
\hline New Zealand & 1.0 & 1.2 & 1.3 & 2.3 & 1.4 & .. & \\
\hline Norway & 0.4 & 0.7 & 1.1 & 1.1 & 1.2 & 0.9 & \\
\hline Poland & 1.1 & 1.2 & 1.0 (1979) & 2.9 & 2.0 & 1.6 & \\
\hline Portugal & 1.0 & 0.8 & 1.3 & 1.6 & 0.9 & 1.6 & \\
\hline Slovak Republic & .. & $\ldots$ & . & 2.3 (1992) & 2.1 & 2.1 & \\
\hline Spain & 0.3 & 0.3 (1969) & 1.0 & 0.9 & 0.9 & 1.0 & \\
\hline Sweden & 0.6 & 0.9 & 1.2 & 1.2 & 1.0 & 0.9 & (2001) \\
\hline Switzerland & 0.6 & 0.7 & 1.0 & 1.3 & 0.8 & 1.1 & \\
\hline Turkey & .. & .. & .. & .. & $\ldots$ & .. & \\
\hline United Kingdom & 0.5 & 0.8 & 1.0 & 0.7 & 0.8 (1999) & 0.9 & \\
\hline United States & 5.0 & 8.7 & 10.2 & 9.7 & 6.1 & 7.1 & (2001) \\
\hline Latest average $^{a}$ & . & . & . & . & . & 1.5 & \\
\hline Consistent average (24) ${ }^{b}$ & 1.2 & 1.3 & 1.7 & 1.9 & 1.5 & 1.5 & \\
\hline Median & 1.0 & 0.9 & 1.2 & 1.5 & 1.2 & 1.2 & \\
\hline
\end{tabular}

Note: All mortality rates are standardised to the OECD standard population (1980).

a) Average comprises all countries for which recent data is available (2000+).

b) Excludes Belgium, Czech Republic, Korea, Mexico, Slovak Republic and Turkey. The 2000 figures of Denmark and New Zealand have been used for the calculation of the 2002 OECD average.

Source: OECD Health Data 2005. The raw mortality data is extracted from the WHO Mortality Database (March 2005). 
Table A.1.19. Infant mortality rate, deaths per 1000 live births, 1970 to 2003

\begin{tabular}{|c|c|c|c|c|c|}
\hline & 1970 & 1980 & 1990 & 2000 & 2003 \\
\hline Australia & 17.9 & 10.7 & 8.2 & 5.2 & 4.8 \\
\hline Austria & 25.9 & 14.3 & 7.8 & 4.8 & 4.5 \\
\hline Belgium & 21.1 & 12.1 & 8.0 & 4.8 & 4.3 \\
\hline Canada & 18.8 & 10.4 & 6.8 & 5.3 & 5.4 (2002) \\
\hline Czech Republic & 20.2 & 16.9 & 10.8 & 4.1 & 3.9 \\
\hline Denmark & 14.2 & 8.4 & 7.5 & 5.3 & 4.4 \\
\hline Finland & 13.2 & 7.6 & 5.6 & 3.8 & 3.1 \\
\hline France & 18.2 & 10.0 & 7.3 & 4.4 & 3.9 \\
\hline Germany & 22.5 & 12.4 & 7.0 & 4.4 & 4.2 \\
\hline Greece & 29.6 & 17.9 & 9.7 & 5.9 & 4.8 \\
\hline Hungary & 35.9 & 23.2 & 14.8 & 9.2 & 7.3 \\
\hline Iceland & 13.2 & 7.7 & 5.9 & 3.0 & 2.4 \\
\hline Ireland & 19.5 & 11.1 & 8.2 & 6.2 & 5.1 \\
\hline Italy & 29.6 & 14.6 & 8.2 & 4.5 & 4.3 \\
\hline Japan & 13.1 & 7.5 & 4.6 & 3.2 & 3.0 \\
\hline Korea & 45.0 & 17.0 (1981) & 12.0 (1989) & 6.2 (1999) & .. \\
\hline Luxembourg & 24.9 & 11.4 & 7.3 & 5.1 & 4.9 \\
\hline Mexico & 79.3 & 50.9 & 36.1 & 23.3 & 20.1 \\
\hline Netherlands & 12.7 & 8.6 & 7.1 & 5.1 & 4.8 \\
\hline New Zealand & 16.7 & 13.0 & 8.4 & 6.3 & $5.6(2001)$ \\
\hline Norway & 12.7 & 8.1 & 7.0 & 3.8 & 3.4 \\
\hline Poland & 36.7 & 25.5 & 19.3 & 8.1 & 7.0 \\
\hline Portugal & 55.5 & 24.3 & 11.0 & 5.5 & 4.1 \\
\hline Slovak Republic & 25.7 & 20.9 & 12.0 & 8.6 & 7.9 \\
\hline Spain & 28.1 & 12.3 & 7.6 & 3.9 & 4.1 \\
\hline Sweden & 11.0 & 6.9 & 6.0 & 3.4 & 3.1 \\
\hline Switzerland & 15.1 & 9.1 & 6.8 & 4.9 & 4.3 \\
\hline Turkey & 145.0 & 117.5 & 57.6 & 41.9 & 29.0 \\
\hline United Kingdom & 18.5 & 13.9 & 7.9 & 5.6 & 5.3 \\
\hline United States & 20.0 & 12.6 & 9.2 & 6.9 & 7.0 \\
\hline Latest average $^{a}$ & . & . & . & . & 6.1 \\
\hline Consistent average $(29)^{b}$ & 28.1 & 17.9 & 11.2 & 7.1 & 6.1 \\
\hline Median & 20.1 & 12.4 & 8.0 & 5.2 & 4.5 \\
\hline
\end{tabular}

Note: In the United States, Canada and some Nordic countries, very premature babies with a low chance of survival are registered as live births which may not be the case in other countries.

a) Consists of the latest available data for all 30 OECD countries.

b) Excludes Korea.

Source: OECD Health Data 2005. 
Table A.1.20. Low birthweight, percentage of total live births, 1980 to 2003

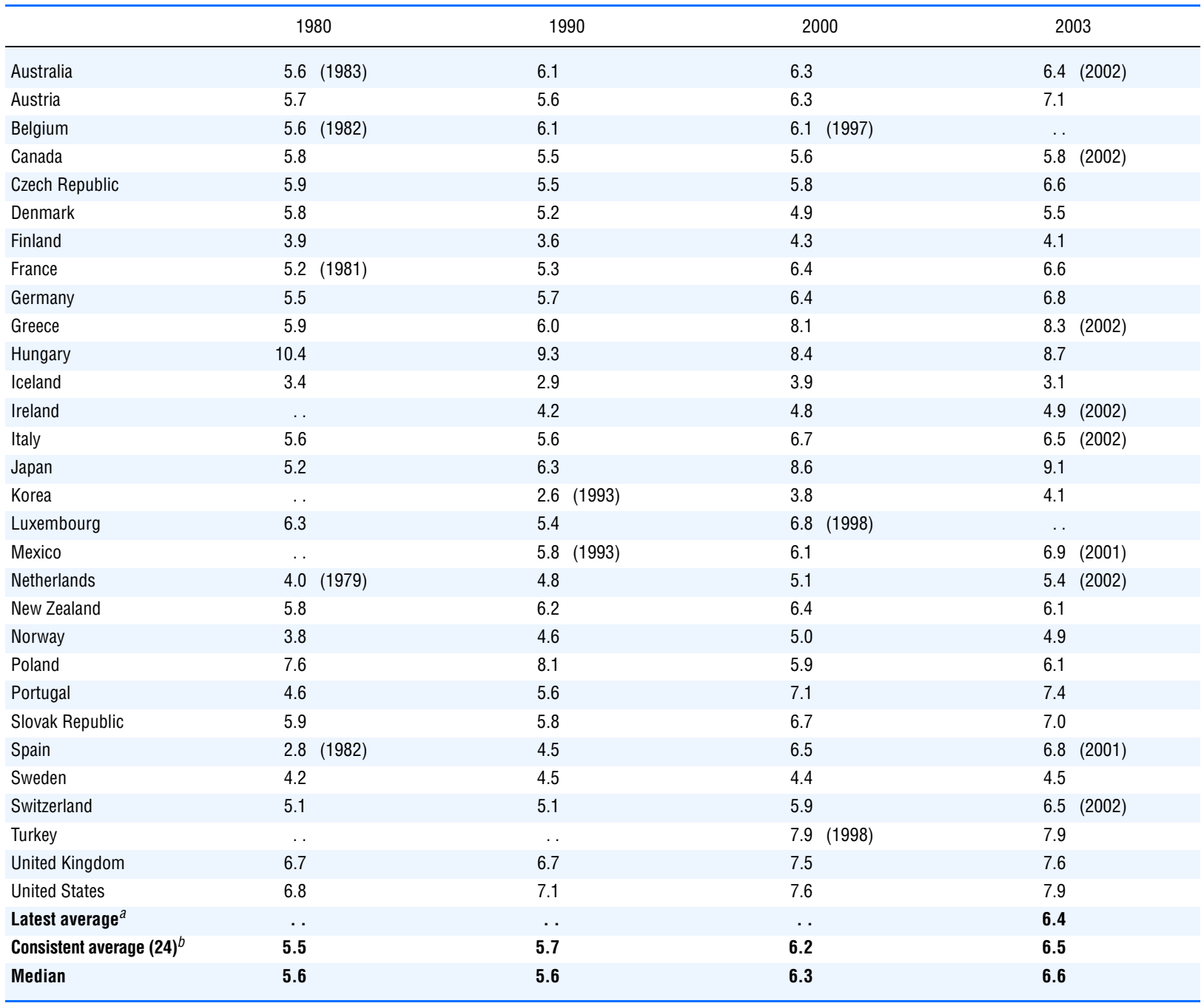

a) Average comprises all countries for which recent data is available (2001+).

b) Excludes Belgium, Ireland, Korea, Luxembourg, Mexico and Turkey.

Source: OECD Health Data 2005. 
Table A.1.21. Decayed, missing and filled teeth, average number at age 12, 1980 to 2000

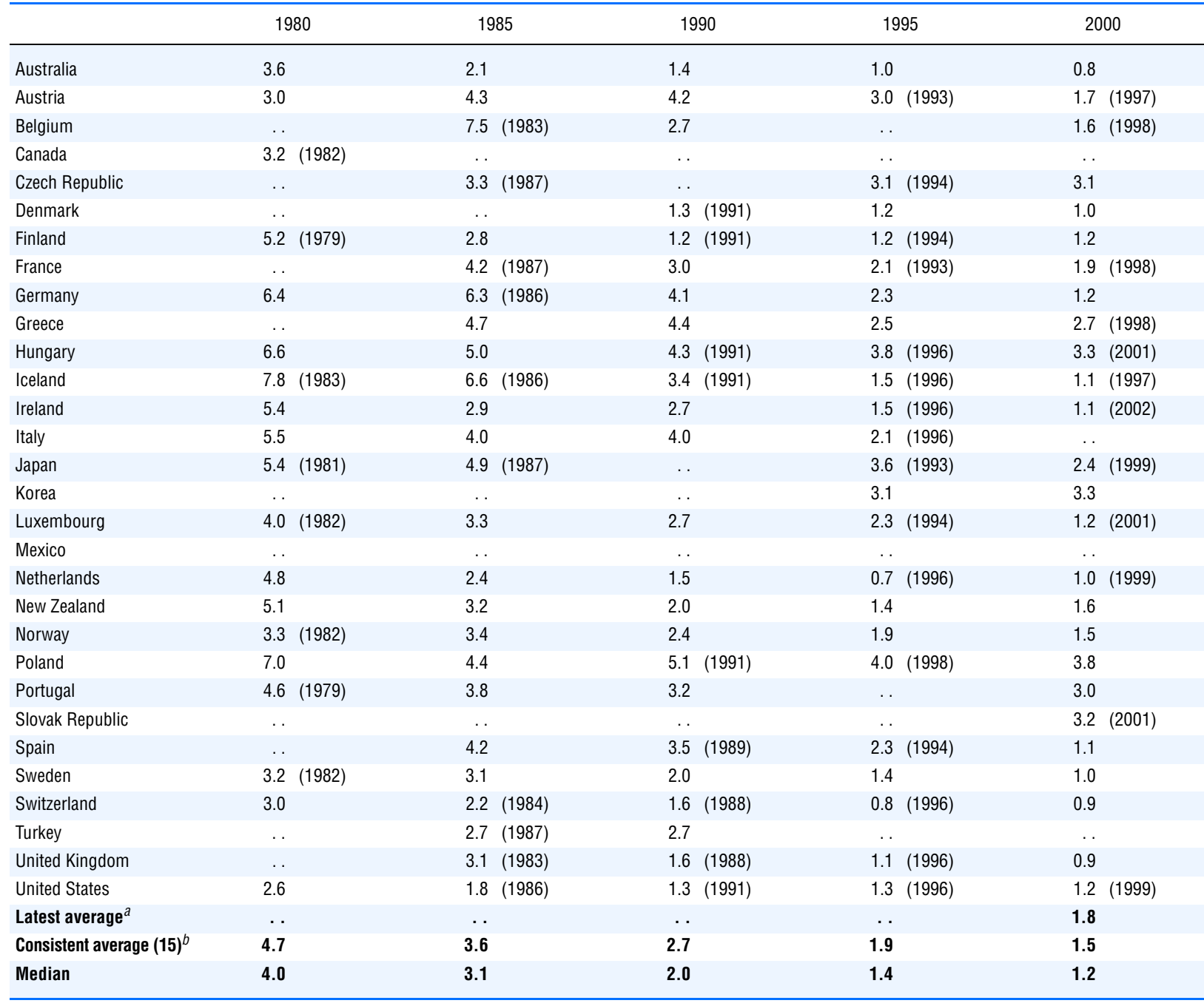

a) Average comprises all countries for which recent data is available (1997+).

b) Includes Australia, Austria, Finland, Germany, Hungary, Iceland, Ireland, Luxembourg, Netherlands, New Zealand, Norway, Poland, Sweden, Switzerland and the United States.

Source: OECD Health Data 2005. 
Table A.2.1. Practising physicians, density per 1000 population, 1970 to 2003

\begin{tabular}{|c|c|c|c|c|c|c|}
\hline & 1970 & 1980 & 1990 & 2000 & 20 & 03 \\
\hline Australia & 1.2 (1971) & 1.8 (1981) & 2.2 & 2.5 & 2.5 & (2002) \\
\hline Austria & 1.4 & 1.6 & 2.2 & 3.2 & 3.4 & \\
\hline Belgium $^{a}$ & $1.6 \quad(1971)$ & 2.3 & 3.3 & 3.9 & 3.9 & (2002) \\
\hline Canada & 1.4 & 1.8 & 2.1 & 2.1 & 2.1 & \\
\hline Czech Republic $^{b}$ & 1.8 & 2.3 & 2.7 & 3.4 & 3.5 & \\
\hline Denmark $^{a}$ & . & 1.8 & 2.5 & 2.8 & 2.9 & (2002) \\
\hline Finland & . & $\ldots$ & 2.0 & 2.6 & 2.6 & \\
\hline France $^{a}$ & 1.2 & 1.9 & 3.1 & 3.3 & 3.4 & \\
\hline Germany & $\ldots$ & $\ldots$ & 2.8 (1991) & 3.3 & 3.4 & \\
\hline Greece & 1.6 & 2.4 & 3.4 & 4.3 & 4.4 & (2001) \\
\hline Hungary & 2.0 & 2.3 & 2.8 & 3.1 (1999) & 3.2 & \\
\hline Iceland ${ }^{a}$ & 1.4 & 2.1 & 2.8 & 3.4 & 3.6 & \\
\hline Ireland ${ }^{\mathrm{C}}$ & . & . & 2.0 (1992) & 2.2 & 2.6 & \\
\hline Italy & $\ldots$ & $\ldots$ & . & 4.2 & 4.1 & \\
\hline Japan & 1.1 & 1.3 & 1.7 & 1.9 & 2.0 & (2002) \\
\hline Korea & $\ldots$ & $0.5 \quad(1981)$ & 0.8 & 1.3 & 1.6 & \\
\hline Luxembourg $^{a}$ & 1.1 & 1.7 & 2.0 & 2.5 & 2.7 & \\
\hline Mexico $^{b}$ & . & $\ldots$ & 1.0 & 1.6 & 1.5 & \\
\hline Netherlands ${ }^{c}$ & 1.2 & 1.9 & 2.5 & 3.2 & 3.1 & \\
\hline New Zealand & 1.1 (1971) & 1.6 & 1.9 & 2.2 & 2.2 & \\
\hline Norway $^{b}$ & 1.4 & 2.0 & 2.6 (1991) & 2.9 & 3.1 & \\
\hline Poland & 1.4 & 1.8 & 2.1 & 2.2 & 2.5 & \\
\hline Portugal & 0.9 & 2.0 & 2.8 & 3.2 & 3.3 & \\
\hline Slovak Republic & . & . & . & 3.2 & 3.1 & \\
\hline Spain & . & . & $\ldots$ & 3.2 & 3.2 & \\
\hline Sweden & 1.3 & 2.2 & 2.9 & 3.1 & 3.3 & (2002) \\
\hline Switzerland & 1.5 & 2.5 & 3.0 & 3.5 & 3.6 & (2002) \\
\hline Turkey & 0.4 & 0.6 & 0.9 & 1.3 & 1.4 & \\
\hline United Kingdom & 0.9 & 1.3 & 1.6 & 1.9 & 2.2 & \\
\hline United States $^{a}$ & 1.2 & 1.5 & 1.8 & 2.2 & 2.3 & (2002) \\
\hline Latest average $^{d}$ & $\ldots$ & . & . & $\ldots$ & 2.9 & \\
\hline Consistent average $(21)^{e}$ & 1.3 & 1.9 & 2.4 & 2.8 & 2.9 & \\
\hline Median & 1.3 & 1.8 & 2.2 & 3.0 & 3.1 & \\
\hline
\end{tabular}

a) Includes physicians working in industry, administration and research.

b) The Czech Republic, Mexico and Norway report full time equivalents (FTE) rather than head counts.

c) Ireland and Netherlands provide the number of physicians entitled to practise rather than practising physicians.

d) Average consists of the latest available data for all OECD countries.

e) Excludes Denmark, Finland, Germany, Ireland, Italy, Korea, Mexico, Slovak Republic and Spain.

Source: OECD Health Data 2005. 
Table A.2.2. Practising nurses, density per 1000 population, 1970 to 2003

\begin{tabular}{|c|c|c|c|c|c|c|c|}
\hline & 1970 & 1980 & 1990 & 2000 & 2001 & 2002 & 2003 \\
\hline Australia & 6.7 & 10.3 & 11.6 & 10.5 & 10.4 & 10.6 & 10.2 \\
\hline Austria $^{a}$ & 3.4 & 5.4 & 7.3 & 9.3 & 9.3 & 9.3 & 9.4 \\
\hline Belgium & $\ldots$ & .. & . & 5.4 & 5.5 & 5.6 & 5.8 \\
\hline Canada & 6.9 & 9.6 & 11.1 & 10.1 & 10.0 & 9.4 & 9.8 \\
\hline Czech Republic & . & 6.8 & 8.4 & 8.9 & 9.2 & 9.4 & 9.4 \\
\hline Denmark & . & 6.9 & 9.3 & 10.0 & 10.2 & 10.3 & . \\
\hline Finland & $\ldots$ & $\ldots$ & 6.0 & 8.2 & 8.6 & 9.0 & 9.3 \\
\hline France $^{b}$ & $3.1 \quad(1971)$ & 4.7 & 5.6 & 6.7 & 7.0 & 7.2 & 7.3 \\
\hline Germany & . & . & . & 9.4 & 9.5 & 9.6 & 9.7 \\
\hline Greece & 1.4 & 1.9 & 3.4 & 3.9 & . & . & . \\
\hline Hungary ${ }^{c}$ & 2.7 & 3.7 & 4.5 & 4.9 & 4.9 & 5.0 & 5.1 \\
\hline Iceland & 4.2 & 8.9 & 12.5 & 13.3 & 13.1 & 13.3 & 13.7 \\
\hline Ireland & $\ldots$ & . & 11.3 & 13.9 & 14.8 & 15.3 & 14.8 \\
\hline Italy ${ }^{a}$ & . & . & . & 5.3 & 5.4 & 5.5 & 5.4 \\
\hline Japan & 2.5 & 4.0 & 5.8 & 7.6 & . & 7.8 & . \\
\hline Korea & . & . & . & 1.4 & 1.5 & 1.7 & 1.7 \\
\hline Luxembourg & . & . & . & 9.9 & 10.2 & 10.6 & . \\
\hline Mexico $^{c}$ & . & . & 1.7 & 2.2 & 2.2 & 2.2 & 2.1 \\
\hline Netherlands & . & . & . & 13.4 & 12.8 & $\ldots$ & . \\
\hline New Zealand & . & 6.1 & 9.3 & 9.6 & 9.6 & 9.4 & 9.1 \\
\hline Norway $b, c$ & . & . & . & 10.3 & 10.4 & . & . \\
\hline Poland & 3.0 & 4.4 & 5.5 & 4.9 & 4.9 & 4.9 & 4.9 \\
\hline Portugal & 1.8 (1971) & 2.3 & 2.8 & 3.7 & 3.8 & 4.0 & 4.2 \\
\hline Slovak Republic & $\ldots$ & $\ldots$ & $\ldots$ & 7.4 & 7.3 & 6.9 & 6.5 \\
\hline Spain $^{d}$ & . & . & . & 6.4 & 6.6 & 7.3 & 7.5 \\
\hline Sweden & 4.3 & 7.0 & 9.2 & 9.8 & 9.9 & 10.2 & . \\
\hline Switzerland & . & . & .. & 10.7 & . & .. & . \\
\hline Turkey & . & 1.0 & 1.3 & 1.7 & 1.7 & 1.7 & 1.7 \\
\hline United Kingdom & . & . & 7.8 & 8.3 & 8.6 & 8.9 & 9.1 \\
\hline United States & 3.7 & 5.6 & 7.2 & 8.0 & 7.9 & 7.9 & . \\
\hline Average $(15)^{e}$ & . & 5.8 & 7.4 & 7.9 & 8.0 & 8.0 & 8.1 \\
\hline Median & . & 5.5 & 7.3 & 8.3 & 8.6 & 8.4 & 7.5 \\
\hline
\end{tabular}

a) Austria and Italy report only nurses employed in hospitals; they do not include nurses working in other health facilities.

b) In France and Norway, auxiliary/practical nurses are not included.

c) In Hungary, Mexico and Norway, data refer to full time equivalent nurses (not head counts)

d) Spain includes only publicly employed nurses (nurses employed in the National Health Service).

e) The average excludes: Belgium, Finland, Germany, Greece, Ireland, Italy, Korea, Luxembourg, Mexico, Netherlands, Norway, Slovak Republic, Spain, Switzerland and United Kingdom. For 2003, the average includes 2002 data for Denmark, Japan, Sweden and United States.

Source: OECD Health Data 2005. 


\section{Table A.2.3. Remuneration of specialists, salaried and self-employed, USD PPP, latest year(s) available}

\begin{tabular}{|c|c|c|c|c|c|c|c|c|c|c|c|c|}
\hline & \multicolumn{6}{|c|}{ Salaried } & \multicolumn{6}{|c|}{ Self-employed } \\
\hline & 1999 & 2000 & 2001 & 2002 & 2003 & 2004 & 1999 & 2000 & 2001 & 2002 & 2003 & 2004 \\
\hline Belgium $^{a}$ & & & & & & & & & & 175554 & & \\
\hline Canada $^{b}$ & & & & & & & 150239 & & 150869 & 152559 & & \\
\hline Czech Republic ${ }^{c}$ & & 20560 & 23053 & 27130 & 28696 & & & 27122 & 33889 & 35177 & 35515 & \\
\hline Denmark & & 77276 & 81670 & 84768 & 88788 & & & & & & & \\
\hline Finland $^{d}$ & & & & & 75435 & & & & & & & \\
\hline France ${ }^{e}$ & & & & & & & & & 126923 & & & \\
\hline Germany $^{f}$ & & & & & & 76153 & & & & & & \\
\hline Greece $^{g}$ & & & & & & & & & & & 69124 & \\
\hline Hungary ${ }^{h}$ & & & & & 26865 & & & & & & & \\
\hline Ireland $^{i}$ & & & & & & 142931 & & & & & & \\
\hline Mexico $^{j}$ & 23570 & 23882 & 24721 & 25115 & 25099 & & & & & & & \\
\hline Netherlands ${ }^{k}$ & & & & & 130904 & & & & & & 252713 & \\
\hline New Zealand ${ }^{\prime}$ & 77874 & 80527 & 81817 & 85471 & 88313 & 88345 & & & & & & \\
\hline Norway ${ }^{m}$ & & & 63002 & 65220 & 75295 & 74745 & & & & & & \\
\hline Portugal $^{n}$ & 60733 & 64600 & 66222 & 68987 & 68034 & 68816 & & & & & & \\
\hline Sweden $^{0}$ & & & & 71011 & & & & & & & & \\
\hline Switzerland ${ }^{p}$ & & & & & & & & & 115783 & & & \\
\hline United Kingdom $q$ & 108236 & 113846 & & 137192 & & & & & & & & \\
\hline United States $^{r}$ & & & & & & & 219000 & & & & & \\
\hline
\end{tabular}

Note: Remuneration of salaried specialists does not include any additional income derived from private practice (in those countries where this might be applicable).

a) The part of the fees kept by the hospital to cover the costs of personnel, machines and facilities, is a rough estimate.

b) Average fee-for-service payments for specialists who billed the provincial medical care plans at least CAD 50000 annually in 1999 and CAD 60000 in 2001 and 2002, adjusted for practice expenses. Estimates of practice expenses are rough.

c) Salaried specialists also include general practitioners working as employees (about $15 \%$ of all GPs). Self-employed specialists: data do not include social (e.g. pension) and health contributions.

d) Figures also include doctors specialized in General Practice who are not working in health care centres. Also, 39\% of all specialists report part-time work in the private sector (these payments are not included).

e) Physicians who are working all days in a hospital (with a private practice in this hospital) are excluded. Social security contributions have been estimated.

f) Data is based on a salary table for employees in the public sector (federal and state level) in the Western states, but can be used as a guideline for all German hospitals.The average income does not include overtime payments. According to the collective agreement overtime has to be compensated by free time. Only where this is not possible, employees have the right to be reimbursed financially.

g) Data is based on declared income, resulting in an underestimation because of tax evasion. Physicians who are primarily non-salaried might also receive a salary. The figure excludes salaries (for working in the NHS or public University Clinics).

h) Data applies to specialists employed in the public service (approx. $90 \%$ of all specialists). Income does not include informal payments, which can substantially increase the income.

i) The figure refers to consultants working in publicly funded hospitals (52\% of all consultants in 2004). It does not include emergency call-out payments and on-call payments (except for the minimum flat annual payment of EUR 3 500). It is estimated that these payments vary from EUR 3500 to EUR 30000 per annum.

j) Figures do not include overtime payments. Data for 1999 to 2002 have been estimated, based on the growth rate of the minimum wage.

k) Salaried specialists: average income for salaried specialists working in general and academic hospitals. Figures for specialists working in general hospitals are based on a salary scale; they do not include overtime payments and bonuses.

Self-employed specialists: data is for full-time equivalents. Practice expenses have been estimated.

l) Figures only show base salary; extra pay received for overtime or other reasons are not included.

m) Data do not only apply to specialists, but also to newly qualified doctors (assistant doctors).

n) The figures are for specialists working in the National Health Service. Additional income, such as payments for working nights and weekends and overtime compensation, is not included.

o) Overtime payments are not included.

p) The figure relates to gross income subject to the contribution for "old age and survivors insurance", which is the 1st pillar of the Swiss social security system. However, this "gross' income excludes deduction for voluntary payments to the 2nd and 3rd pillar of the social security system, of which the legal ceiling is set at about CHF 30000.

q) Data cover NHS-consultants in England.

r) The data applies not only to self-employed but to salaried specialists as well. In $2001,61.5 \%$ of all physicians were self-employed, $34.5 \%$ worked as employees and $4.0 \%$ as independent contractors (Kane and Loeblich, 2003).

Source: OECD Health Data 2005. 


\section{Table A.2.4. Remuneration of general practitioners, salaried and self-employed, USD PPP,} latest year(s) available

\begin{tabular}{|c|c|c|c|c|c|c|c|c|c|c|c|c|}
\hline & \multicolumn{6}{|c|}{ Salaried } & \multicolumn{6}{|c|}{ Self-employed } \\
\hline & 1999 & 2000 & 2001 & 2002 & 2003 & 2004 & 1999 & 2000 & 2001 & 2002 & 2003 & 2004 \\
\hline Belgium $^{a}$ & & & & & & & & 52099 & & & & \\
\hline Canada $^{b}$ & & & & & & & 100664 & & 101882 & 102045 & & \\
\hline Czech Republic ${ }^{c}$ & & & & & & & & 23816 & 27272 & 28413 & 32219 & \\
\hline Denmark & & & & & & & & 92666 & & 101901 & & \\
\hline Finland $^{d}$ & 48571 & 51654 & 57223 & 61527 & 64957 & & & & & & & \\
\hline France ${ }^{e}$ & & & & & & & & & 76889 & & & \\
\hline Germany $^{f}$ & & & & & & & 86719 & & & & & \\
\hline Hungary $g$ & & & & & 26389 & & & & & & & \\
\hline Mexico ${ }^{h}$ & 20248 & 20515 & 21236 & 21575 & 21561 & & & & & & & \\
\hline Netherlands ${ }^{i}$ & & & & & & & & & & & 113147 & \\
\hline Portugal $^{j}$ & 60733 & 64600 & 66222 & 68987 & 68034 & 68816 & & & & & & \\
\hline Sweden ${ }^{k}$ & & & & 62468 & & & & & & & & \\
\hline Switzerland ${ }^{\prime}$ & & & & & & & & & 104439 & & & \\
\hline United Kingdom $^{m}$ & & & & & & & 81691 & 85731 & 90602 & 100998 & & \\
\hline United States $^{n}$ & & & & & & & 138000 & & & & & \\
\hline
\end{tabular}

Note: Remuneration of salaried general practitioners does not include any additional income derived from private practice (in those countries where this might be applicable).

a) OECD calculation, based on raw data contained in a report for the Flemish association of GPs (BVCV Callens, Pirenne and Co, 2002). Estimates on practice expenses are based on a very small sample.

b) Average fee-for-service payments for GPs who billed the provincial medical care plans at least CAD 50000 annually in 1999 and CAD 60000 in 2001 and 2002, adjusted for practice expenses. Estimates of practice expenses are rough.

c) Data do not include social (e.g. pension) and health contributions.

d) GPs refer to doctors working in health care centres. $21 \%$ of the physicians working in health care centres reported additional part-time work, mainly in private practices (these payments are not included).

e) The figure refers to both GPs and physicians who do not have a recognized specialty. Social security contributions have been estimated.

f) The figure refers to the category "medium practice size" (average annual working hours per GP: 2 748)

g) Data refers to approximately 400 GPs employed in the public service; the percentage of GPs employed in the public service is about $10 \%$. Income does not include informal payments, which can substantially increase the income.

h) Figures do not include overtime payments. Data for 1999 to 2002 have been estimated, based on the growth rate of the minimum wage.

i) Average annual income based on a norm practice (2 350 patients).

j) The figures are for GPs working in the National Health Service. Additional income, such as payments for working nights and weekends and overtime compensation, is not included.

k) Payments for being on call and overtime payments are not included.

l) The figure relates to gross income subject to the contribution for "old age and survivors insurance", which is the 1st pillar of the Swiss social security system. However, this "gross' income excludes deduction for voluntary payments to the 2nd and 3rd pillar of the social security system, of which the legal ceiling is set at about CHF 30000.

m) Data refers to Great Britain. Figures are for GPs on a "GMS (General Medical Services) contract" and show estimates of gross annual income minus indirectly reimbursed practice expenses.

n) Data applies not only to self-employed but also to salaried primary care physicians. In 2001, $61.5 \%$ of all physicians were selfemployed, $34.5 \%$ worked as employees and $4.0 \%$ as independent contractors (Kane and Loeblich, 2003).

Source: OECD Health Data 2005. 


\section{Table A.2.5. Remuneration of salaried hospital nurses, USD PPP, latest year(s) available}

\begin{tabular}{|c|c|c|c|c|c|c|}
\hline & 1999 & 2000 & 2001 & 2002 & 2003 & 2004 \\
\hline Australia $^{a}$ & 39170 & 40047 & 42202 & 45077 & & \\
\hline Czech Republic ${ }^{b}$ & & 10086 & 11600 & 13559 & 14436 & \\
\hline Denmark $^{c}$ & & 37074 & 38747 & 39814 & 41129 & \\
\hline Finland $^{d}$ & 25088 & 26395 & 26255 & 27712 & 28405 & \\
\hline Hungary ${ }^{e}$ & & & & & 13574 & \\
\hline Ireland ${ }^{f}$ & & & & & & 40739 \\
\hline Mexico $^{g}$ & 12600 & 12767 & 13215 & 13426 & 13417 & \\
\hline New Zealand ${ }^{h}$ & & & & 32012 & & \\
\hline Norway ${ }^{i}$ & & & 31005 & 33718 & 33729 & 34292 \\
\hline Portugal $^{j}$ & 27778 & 31622 & 32430 & 36982 & 36471 & 36890 \\
\hline United Kingdom ${ }^{k}$ & 33232 & 35735 & & 40158 & & \\
\hline United States ${ }^{\prime}$ & & 47554 & & & & \\
\hline
\end{tabular}

a) Data are for all levels of registered nurses, employed in public acute and psychiatric hospitals, but exclude New South Wales, the largest State.

b) Included are wages of all paramedical personnel. Nurses earn less than other professional paramedical personnel (a rough estimate is about $10 \%$ difference in income).

c) Data are for all levels of registered nurses working in hospitals. To the extent that there is overtime payment, it is included.

d) Figures are for nurses who work in health care centres and hospitals. Public health nurses, specialist nurses and chief nurses are not included.

e) Data is for hospital nurses working in the public service (over $99 \%$ of all nurses). Gratuity payments are not included.

f) Figures are for nurses working in publicly funded hospitals. Overtime payments are not included.

g) Figures do not include overtime payments. Data for 1999 to 2002 have been estimated, based on the growth rate of the minimum wage.

h) Data is for nurses working in publicly funded hospitals and other health care settings.

i) Figures apply to professional nurses (nurses with a three-year education at university level, but no specialist training) working in central government maintained hospitals.

j) Figures are an average of all the categories (except for nurse managers) and scales of hospital nurses working in the National Health Service. Any additional income, such as payments for working nights and weekends and overtime compensation, is not included.

k) The figures apply to NHS-nurses in England.

l) The figure relates to registered nurses only.

Source: OECD Health Data 2005. 
Table A.2.6. Acute care beds, density per 1000 population, 1980 to 2002

\begin{tabular}{|c|c|c|c|c|c|c|}
\hline & 1980 & 1985 & 1990 & 1995 & 2000 & 2002 \\
\hline Australia & 6.4 & 5.3 & 4.8 (1989) & 4.2 & 3.8 & 3.6 \\
\hline Austria & .. & 7.5 & 7.1 & 6.6 & 6.3 & 6.1 \\
\hline Belgium & 5.5 & 5.9 & 4.9 & 4.7 & 4.1 & 4.0 \\
\hline Canada & 4.6 & 4.4 & 4.0 & 4.2 & 3.2 & 3.2 \\
\hline Czech Republic & 8.6 & 8.6 & 8.5 & 7.2 & 6.6 & 6.5 \\
\hline Denmark & 5.3 & 4.7 & 4.1 & 3.9 & 3.5 & 3.4 (2001) \\
\hline Finland & 4.9 & 4.8 & 4.3 & 4.0 & 2.4 & 2.3 \\
\hline France & 6.2 & 5.7 & 5.2 & 4.6 & 4.1 & 3.9 \\
\hline Germany & .. & .. & 8.3 (1991) & 7.5 & 6.8 & 6.6 \\
\hline Greece & .. & .. & $\ldots$ & .. & .. & .. \\
\hline Hungary & 6.6 & 6.8 & 7.1 & 7.0 & 6.3 & 5.9 \\
\hline Iceland & .. & .. & 4.3 & 3.7 & .. & .. \\
\hline Ireland & 4.3 & 4.2 & 3.3 & 3.2 & 3.0 & 3.0 \\
\hline Italy & 7.9 & 7.0 & 6.2 & 5.6 & 4.2 & 3.9 \\
\hline Japan & $\ldots$ & $\ldots$ & 12.3 (1993) & 12.0 & 9.6 & 8.9 \\
\hline Korea & .. & $\ldots$ & 2.7 & 3.8 & 5.2 & 5.7 \\
\hline Luxembourg & 7.4 & 7.1 (1986) & 6.8 & 6.2 & 5.9 & 5.7 \\
\hline Mexico & .. & $\ldots$ & .. & 1.1 (1997) & 1.0 & 1.0 \\
\hline Netherlands & 5.2 & 4.7 & 4.3 & 3.8 & 3.5 & 3.2 \\
\hline New Zealand & .. & .. & .. & .. & .. & .. \\
\hline Norway & 5.2 & 4.7 & 3.8 & 3.3 & 3.1 & 3.1 \\
\hline Poland & 5.6 & 5.7 & 6.3 & 5.8 & 5.1 & 4.7 \\
\hline Portugal & 4.2 & 3.5 & 3.4 & 3.3 & 3.3 & 3.1 \\
\hline Slovak Republic & .. & .. & .. & 7.0 (1996) & 6.5 & 6.2 \\
\hline Spain & 3.8 & 3.7 & 3.6 & 3.5 & 3.3 & 3.1 \\
\hline Sweden & 5.1 & 4.6 & 4.1 & 3.0 & 2.4 & .. \\
\hline Switzerland & 7.2 & 6.8 & 6.5 & 5.5 & 4.1 & 3.9 \\
\hline Turkey & 1.5 & 1.6 & 2.0 & 2.1 & 2.2 & 2.1 \\
\hline United Kingdom & .. & . & $\ldots$ & 4.0 & 3.7 & 3.7 \\
\hline United States & 4.4 & 4.2 & 3.7 & 3.3 & 2.9 & 2.9 \\
\hline Latest average $^{a}$ & .. & $\ldots$ & . & . & . & 4.2 \\
\hline Consistent average (24) ${ }^{b}$ & . & . & 5.3 & 4.9 & 4.4 & 4.2 \\
\hline Median & 5.3 & 4.8 & 4.3 & 4.1 & 3.8 & 3.8 \\
\hline
\end{tabular}

Note: The definition of "acute care" beds may vary from one country to the other. In Japan, many "acute care" beds are devoted to long-term care. Cross-country variations should therefore be interpreted with caution.

a) Average comprises all countries for which recent data is available (2000+)

b) Excludes Greece, Iceland, Mexico, New Zealand, Slovak Republic and the United Kingdom. The 2002 average includes the most recent figure for Sweden.

Source: OECD Health Data 2005. 
Table A.2.7. Occupancy rate of acute care hospital beds, in percentage, 1980 to 2002

\begin{tabular}{|c|c|c|c|c|c|c|}
\hline & 1980 & 1985 & 1990 & 1995 & 2000 & 2002 \\
\hline Australia & 66.3 & 69.0 & 68.8 (1989) & 69.5 & 70.4 & 73.9 \\
\hline Austria & $80.8 \quad(1982)$ & 79.0 & 78.2 & 75.8 & 75.5 & 76.3 \\
\hline Belgium & 77.7 & 83.3 (1986) & 81.9 & 79.7 & 79.9 (1998) & $\ldots$ \\
\hline Canada & 80.4 & 83.4 & 78.6 & 84.7 & 90.9 & 86.6 \\
\hline Czech Republic & 81.8 & 80.8 & 69.6 & 72.6 & 70.5 & 72.1 \\
\hline Denmark & 75.3 & 78.9 & 78.5 & 78.6 & 85.0 & 84.0 (2001) \\
\hline Finland & 76.2 & 76.9 & 74.2 & 74.0 & . & $\ldots$ \\
\hline France & 79.0 & 79.1 & 77.3 & 76.0 & 75.0 & 74.9 \\
\hline Germany & $\ldots$ & . & 84.1 (1991) & 82.1 & 81.9 & 80.1 \\
\hline Greece & 66.0 & 66.0 & 63.2 & 62.1 & 68.0 (1999) & . \\
\hline Hungary & 83.3 & 80.6 & 74.9 & 72.6 & 73.2 & 77.8 \\
\hline Iceland & $\ldots$ & $\ldots$ & $\ldots$ & $\ldots$ & $\ldots$ & . \\
\hline Ireland & 82.2 & 75.9 & 84.5 & 82.5 & 83.2 & 84.4 \\
\hline Italy & 69.0 & 67.9 & 69.3 & 70.7 & 75.6 & 76.9 \\
\hline Japan & . & . & . & 81.6 & 81.8 & 80.0 \\
\hline Korea & 60.8 (1981) & 61.0 & 83.9 & 66.3 & 67.2 & 65.2 \\
\hline Luxembourg & 76.2 & 78.4 & 79.4 & 74.3 (1994) & 70.1 & 68.6 \\
\hline Mexico & $\ldots$ & . & 68.1 (1993) & 68.7 & 69.5 & 70.6 \\
\hline Netherlands & 83.5 & 79.1 & 73.3 & 73.3 & 65.7 & 66.0 (2001) \\
\hline New Zealand & . & . & . & . & . & . \\
\hline Norway & 79.3 & 82.0 & 77.0 & 79.4 & 85.2 & 87.6 \\
\hline Poland & 85.0 & 77.0 & 66.0 & 67.3 & 74.0 & 77.0 \\
\hline Portugal & . & 67.7 & 66.7 & 72.6 & 71.3 & 70.8 \\
\hline Slovak Republic & $\ldots$ & $\ldots$ & $\ldots$ & 80.3 (1996) & 71.2 & 66.8 \\
\hline Spain & . & 72.2 & 73.5 & 76.4 & 77.1 & 77.2 (2001) \\
\hline Sweden & 72.1 & 75.3 & 72.2 & 75.9 & $\cdots$ & . \\
\hline Switzerland & 77.9 & 80.0 & 79.0 & 77.7 (1994) & 84.8 & 84.6 \\
\hline Turkey & 44.0 (1979) & 52.1 & 57.2 & 55.4 & 58.7 & 57.1 \\
\hline United Kingdom & 74.8 & 75.8 & 74.0 & 78.7 & 82.7 & 84.3 \\
\hline United States & 75.4 & 64.8 & 66.8 & 62.8 & 63.9 & 65.7 \\
\hline Latest average $^{a}$ & $\cdots$ & $\cdots$ & $\cdots$ & $\cdots$ & $\cdots$ & 75.1 \\
\hline Consistent average $(23)^{b}$ & . & . & 73.6 & 73.0 & 74.8 & 75.2 \\
\hline Median & 77.0 & 77.0 & 74.1 & 75.1 & 74.5 & 76.6 \\
\hline
\end{tabular}

a) Average comprises all countries for which recent data is available (1999+).

b) Excludes Belgium, Finland, Iceland, Japan, New Zealand, Slovak Republic and Sweden. The 2002 average includes the most recent figure for Greece.

Source: OECD Health Data 2005. 
Table A.2.8. Medical technologies: CT scanners and MRI units, per million population, 1990 to 2002

\begin{tabular}{|c|c|c|c|c|c|c|c|}
\hline & & CT scanners & & & MRI units & & \\
\hline & 1990 & 1995 & 2002 & 1990 & 1995 & 200 & 02 \\
\hline Australia $^{a}$ & 13.8 & 20.8 & .. & 0.6 & 2.9 & 3.7 & \\
\hline Austria & 11.7 & 24.2 (1996) & 27.2 & 1.2 (1989) & 7.5 (1996) & 13.4 & \\
\hline Belgium & 16.1 & 16.7 (1994) & 28.8 & 2.0 & 3.3 & 6.6 & \\
\hline Canada & 7.1 & 8.0 & 10.3 & 0.7 & 1.4 & 4.5 & (2003) \\
\hline Czech Republic & 2.1 (1991) & 6.7 & 12.1 & 0.2 (1991) & 1.0 & 2.2 & \\
\hline Denmark & 4.3 & 7.3 & 13.8 & 2.5 & .. & 8.6 & \\
\hline Finland & 9.8 & 11.7 & 13.3 & 1.8 & 4.3 & 12.5 & \\
\hline France & 6.7 & 9.2 & 9.7 & 0.8 & 2.1 & 2.7 & \\
\hline Germany & 6.4 (1991) & 9.0 & 14.2 & 1.1 (1991) & 2.3 & 6.0 & \\
\hline Greece & 6.5 & 13.5 (1997) & 17.1 & 0.4 & 1.9 (1997) & 2.3 & \\
\hline Hungary & 1.9 & 4.6 & 6.8 & 0.1 & 1.0 & 2.5 & \\
\hline Iceland & 11.8 & 18.7 & 20.9 & 3.9 & 7.5 & 17.4 & \\
\hline Ireland & 4.3 & $\ldots$ & . & . & $\ldots$ & .. & \\
\hline Italy & 6.0 & 12.0 & 23.4 & 1.3 & 2.6 (1994) & 10.6 & \\
\hline $\operatorname{Japan}^{b}$ & 55.2 & 74.7 (1996) & 92.6 & 6.1 & 18.8 (1996) & 35.3 & \\
\hline Korea & 12.2 (1993) & 15.5 & 30.9 & 1.4 (1992) & 3.9 & 7.9 & \\
\hline Luxembourg & 15.7 & 24.5 & 24.7 & 2.6 & 2.4 & 4.5 & \\
\hline Mexico & .. & 0.4 (1997) & 1.5 & . & . & 0.2 & \\
\hline Netherlands & 7.3 & 9.0 (1993) & .. & 0.9 & 3.9 & .. & \\
\hline New Zealand & 3.6 & 7.5 (1996) & 11.2 & .. & 2.7 (1996) & 3.7 & (2003) \\
\hline Norway & . & $\ldots$ & $\ldots$ & . & $\ldots$ & .. & \\
\hline Poland & .. & $\ldots$ & 5.8 & .. & . & 0.9 & \\
\hline Portugal & 4.5 & 12.1 (1997) & 12.8 & 0.8 & 2.8 (1997) & 3.9 & (2003) \\
\hline Slovak Republic & $\ldots$ & .. & 8.7 (2003) & $\ldots$ & $\ldots$ & 2.0 & (2003) \\
\hline Spain & 4.4 (1988) & 8.3 & 12.9 & $0.7 \quad(1988)$ & 2.7 & 6.2 & \\
\hline Sweden & 10.5 & 13.8 (1993) & 14.2 (1999) & 1.5 & 6.8 & 7.9 & (1999) \\
\hline Switzerland & $\ldots$ & 18.3 (1997) & 18.0 & .. & 12.4 (1997) & 14.1 & \\
\hline Turkey & 1.6 & 2.9 (1994) & 7.5 & . & 0.6 (1996) & 3.0 & \\
\hline United Kingdom ${ }^{c}$ & .. & .. & 5.8 (2001) & .. & . & 5.2 & (2001) \\
\hline United States $^{d}$ & 14.6 & 14.1 & 13.1 & 3.7 & 7.2 & 8.6 & \\
\hline Latest average $^{e}$ & . & $\ldots$ & 17.6 & . & $\ldots$ & 7.3 & \\
\hline Consistent average $(21,19)^{f}$ & 10.1 & 15.0 & 19.9 & 1.6 & 4.3 & 8.4 & \\
\hline Median & 6.9 & 12.0 & 13.2 & 1.2 & 2.8 & 5.2 & \\
\hline
\end{tabular}

a) In Australia, the data on the number of MRI relate only to those eligible for public insurance (60\% of the total in 1999).

b) In Japan, data on MRI units include only those in hospitals before 2002. Since 2002, they include those in hospitals and general clinics.

c) Raw numbers for England and Wales have been increased pro-rata to provide estimates for the UK. The private sector is not included.

d) The figures for the US under-estimate considerably the real number of devices in that country, because they refer to the number of hospitals reporting to have at least one of these equipment rather than the total number of equipment in hospitals and in other locations (e.g., specialised clinics).

e) Average comprises all countries for which recent data is available (1999+).

f) The average for CT scanners excludes Australia, Ireland, Mexico, Netherlands, Norway, Poland, Slovak Republic, Switzerland and United Kingdom. The average for MRI units excludes Denmark, Ireland, Mexico, Netherlands, New Zealand, Norway, Poland, Slovak Republic, Switzerland, Turkey and United Kingdom.

Source: OECD Health Data 2005. 
Table A.2.9. Medical technologies: Mammographs and radiation therapy equipment, per million population, 1990, 1995 and 2002

\begin{tabular}{|c|c|c|c|c|c|c|}
\hline & \multicolumn{3}{|c|}{ Mammographs } & \multicolumn{3}{|c|}{ Radiation therapy equipment } \\
\hline & 1990 & 1995 & 2002 & 1990 & 1995 & 2002 \\
\hline Australia & 15.9 (1989) & . & .. & 2.9 & 4.4 & 5.4 \\
\hline Austria & $\ldots$ & . & . & . & 3.3 (1996) & 4.5 \\
\hline Belgium & . & . & 20.5 & 6.1 (1991) & 6.1 & . \\
\hline Canada & $\ldots$ & .. & $19.3(2001)$ & $5.6(1993)$ & 6.9 & . \\
\hline Czech Republic & 3.8 (1991) & 8.4 & 13.2 & 5.4 (1991) & 4.9 & 6.7 \\
\hline Denmark & . & .. & $\ldots$ & . & . & 6.0 \\
\hline Finland & 29.3 & 37.6 & 39.6 & 10.0 & 8.6 & 8.8 \\
\hline France & 23.8 & 42.0 & 42.4 & 6.0 & 6.2 & 6.0 \\
\hline Germany & $\ldots$ & .. & .. & 4.2 (1991) & 4.5 & 4.6 \\
\hline Greece & . & $\ldots$ & 27.9 & 5.3 & 5.7 & 4.0 (1999) \\
\hline Hungary & $\ldots$ & $6.8(1997)$ & 11.4 & 1.5 & 1.7 (1992) & 2.5 \\
\hline Iceland & 15.7 & 18.7 & 17.4 & 23.5 & 15.0 & 13.9 \\
\hline Ireland & .. & .. & $\ldots$ & . & . & $\ldots$ \\
\hline Italy & . & . & . & 1.3 & 2.1 (1994) & 4.3 \\
\hline Japan & $\ldots$ & . & .. & $\ldots$ & $\ldots$ & 6.6 \\
\hline Korea & $\ldots$ & . & 19.4 & 4.5 (1992) & 4.1 & 4.5 \\
\hline Luxembourg & 25.5 (1992) & 24.5 & 22.4 & $\ldots$ & .. & 4.5 \\
\hline Mexico & $\ldots$ & $\ldots$ & 1.2 & $\ldots$ & .. & 0.6 \\
\hline Netherlands & $\ldots$ & $\ldots$ & $\ldots$ & 6.5 (1992) & 7.1 & .. \\
\hline New Zealand & .. & 17.2 (1997) & 25.1 & $\ldots$ & 7.2 (1996) & 8.1 \\
\hline Norway & .. & $\ldots$ & $\ldots$ & . & $\ldots$ & .. \\
\hline Poland & . & $\ldots$ & 13.6 & . & $\ldots$ & . \\
\hline Portugal & . & 3.6 (1997) & 11.6 (2003) & . & 2.9 (1997) & 3.4 (2003) \\
\hline Slovak Republic & $\ldots$ & $\ldots$ & 13.0 & $\ldots$ & $\ldots$ & 7.1 (2003) \\
\hline Spain & .. & . & .. & 2.9 (1988) & 3.3 & 3.7 \\
\hline Sweden & . & . & .. & $\ldots$ & $\ldots$ & .. \\
\hline Switzerland & $\ldots$ & .. & . & $\ldots$ & 11.1 (1997) & 10.6 \\
\hline Turkey & . & 1.9 (1996) & 6.6 & $0.3(1988)$ & 0.6 (1996) & 1.8 (2001) \\
\hline United Kingdom ${ }^{a}$ & . & 4.9 & 7.3 & $\ldots$ & .. & 3.9 \\
\hline United States $^{b}$ & 14.7 (1992) & 13.7 & 12.0 & 4.1 & 4.4 & 4.0 \\
\hline Latest average $^{c}$ & .. & $\ldots$ & 18.0 & . & $\ldots$ & 5.5 \\
\hline Consistent average $(11,17)^{d}$ & . & 16.3 & 19.0 & . & 5.3 & 5.7 \\
\hline Median & 15.9 & 13.7 & 15.5 & 4.9 & 4.7 & 4.5 \\
\hline
\end{tabular}

a) Raw numbers for England and Wales have been increased pro-rata to provide estimates for the United Kingdom. The private sector is not included.

b) The figures for the United States under-estimate considerably the real number of devices in that country, because they refer to the number of hospitals reporting to have at least one of these equipment rather than the total number of equipment in hospitals and in other locations (e.g., specialised clinics).

c) Average comprises all countries for which recent data is available (1999+).

d) The average for mammographs excludes Australia, Austria, Belgium, Canada, Denmark, Germany, Greece, Ireland, Italy, Japan, Korea, Mexico, Netherlands, Norway, Poland, Slovak Republic, Spain, Sweden and Switzerland. The average for radiation therapy equipment excludes Belgium, Canada, Denmark, Ireland, Japan, Luxembourg, Mexico, Netherlands, Norway, Poland, Slovak Republic, Sweden and United Kingdom.

Source: OECD Health Data 2005. 
Table A.2.10. Consultations with doctors, per capita, 1980 to 2003

\begin{tabular}{|c|c|c|c|c|}
\hline & 1980 & 1990 & 2000 & 2003 \\
\hline Australia & 4.0 & 6.1 & 6.4 & 6.0 \\
\hline Austria & 5.4 & 5.9 & 6.7 & 6.7 \\
\hline Belgium & 7.1 & 7.7 & 7.9 & $7.8 \quad(2002)$ \\
\hline Canada & 5.6 & 6.7 & 6.3 & $6.2(2001)$ \\
\hline Czech Republic & 12.4 & 11.8 & 12.6 & 13.0 \\
\hline Denmark $^{a}$ & 5.0 & 5.7 & 6.9 & 7.3 \\
\hline Finland & 3.2 & 3.9 & 4.3 & 4.2 \\
\hline France & 4.2 & 5.9 & 6.9 & 6.9 (2002) \\
\hline Germany & . & 5.3 (1991) & 7.3 & . \\
\hline Greece & 2.6 & 2.5 & . & $\ldots$ \\
\hline Hungary & $\ldots$ & . & 11.1 & 12.2 \\
\hline Iceland & $\ldots$ & 5.1 & 5.5 & 5.6 (2001) \\
\hline Ireland & . & $\ldots$ & . & $\ldots$ \\
\hline Italy ${ }^{b}$ & . & 6.8 (1991) & 6.1 & $\ldots$ \\
\hline Japan & . & 13.8 & 14.4 & 14.1 (2002) \\
\hline Korea & . & . & . & 10.6 (2002) \\
\hline Luxembourg & . & . & 6.1 & 6.3 \\
\hline Mexico & 1.3 & 1.7 & 2.5 & 2.5 \\
\hline Netherlands ${ }^{b, c}$ & 4.9 & 5.5 & 5.9 & 5.6 (2002) \\
\hline New Zealand ${ }^{b}$ & 3.7 & & $\ldots$ & 3.2 \\
\hline Norway & . & . & . & . \\
\hline Poland & 6.5 & 5.8 & 5.4 & 6.1 \\
\hline Portugal $^{d}$ & 3.7 & 3.0 & 3.5 & 3.7 \\
\hline Slovak Republic & $\ldots$ & . & 15.0 & 12.4 \\
\hline Spain $^{b}$ & $\ldots$ & $\ldots$ & . & 9.5 \\
\hline Sweden & 2.6 & 2.8 & 2.8 & $2.9(2001)$ \\
\hline Switzerland ${ }^{b}$ & $\ldots$ & $\ldots$ & $\ldots$ & 3.4 (2002) \\
\hline Turkey ${ }^{d}$ & 1.2 & . & 2.5 & $2.6(2001)$ \\
\hline United Kingdom ${ }^{e}$ & 5.2 & 6.1 & 5.4 & 5.2 \\
\hline United States $^{a}$ & $\ldots$ & $\ldots$ & 8.9 & 8.9 \\
\hline Latest average $^{f}$ & . & $\ldots$ & $\cdots$ & 6.9 \\
\hline Consistent average (14) ${ }^{g}$ & 5.1 & 5.6 & 6.0 & 6.0 \\
\hline Median & 4.2 & 5.8 & 6.3 & 6.2 \\
\hline
\end{tabular}

a) Denmark and the United States include consultations by telephone; they are therefore not limited to physician visits.

b) For Italy, Netherlands, New Zealand (2003 estimate), Spain and Switzerland, data come from health interview surveys.

c) The Netherlands do not include contacts for maternal and childcare.

d) Portugal and Turkey exclude visits to private practitioners.

e) The United Kingdom does not include consultations with specialists in the independent sector or consultations with specialists outside hospital outpatient departments.

f) Average comprises all countries for which recent data is available (2000+).

g) The average includes: Australia, Austria, Belgium, Canada, Czech Republic, Denmark, Finland, France, Mexico, Netherlands, Poland, Portugal, Sweden and United Kingdom.

Source: OECD Health Data 2005. 
Table A.2.11. Immunisation, percentage of children immunised against DTP and measles, 1980 to 2003

\begin{tabular}{|c|c|c|c|c|c|c|c|c|}
\hline & & & & & & & & \\
\hline & 1980 & 1990 & 2000 & 2003 & 1980 & 1990 & 2000 & 2003 \\
\hline Australia & 75 (1983) & 71 (1989) & 90 & 92 & 68 (1983) & 84 (1989) & 91 & 94 \\
\hline Austria & 90 (1981) & 90 & 81 & 84 & .. & 60 & 75 & 79 \\
\hline Belgium & 95 (1981) & 94 (1989) & 97 (1999) & .. & $\ldots$ & 85 & 82 & 75 \\
\hline Canada & .. & 85 (1993) & 84 (1998) & .. & .. & 85 (1988) & 96 (1998) & 95 (2002) \\
\hline Czech Republic & 97 & 99 & 98 & 97 & 98 & 98 & 97 & 99 \\
\hline Denmark & 85 & 95 & 97 & 96 & .. & 84 & 99 & 96 \\
\hline Finland & 92 (1981) & 94 & 95 & 96 (2002) & 70 (1981) & 87 & 96 & 97 (2002) \\
\hline France & 79 (1981) & 95 & 98 & 97 & $\ldots$ & 71 & 84 & 87 \\
\hline Germany & . & $\ldots$ & 98 & 98 & $\ldots$ & & 91 & 93 \\
\hline Greece & . & 85 (1991) & 88 & 88 & $\ldots$ & 76 & 88 & 88 \\
\hline Hungary & 99 & 100 & 100 & 100 & 99 & 99 & 100 & 100 \\
\hline Iceland & 99 & 99 & 98 & 97 & $\ldots$ & 95 & 91 & 93 \\
\hline Ireland & . & 65 & 86 & 85 & $\ldots$ & 78 & 77 & 78 \\
\hline Italy & .. & 83 & 87 & 96 & .. & 43 & 73 & 83 \\
\hline Japan & 63 & 87 & 95 & 100 & 54 & 66 & 98 & 100 \\
\hline Korea & $\ldots$ & 91 (1988) & 97 & 97 & $\ldots$ & 85 (1988) & 90 (1999) & . \\
\hline Luxembourg & 75 (1983) & 90 & 98 (1996) & $100(2002)$ & $\ldots$ & 80 & 91 (1996) & 95 (2002) \\
\hline Mexico & 44 & 53 & 97 & 98 & .. & 75 & 96 & 96 \\
\hline Netherlands & 95 & 97 & 97 & 98 (2002) & 91 & 94 & 96 & 96 \\
\hline New Zealand & . & 81 (1992) & 89 & . & .. & 82 (1992) & 85 & .. \\
\hline Norway & 90 (1983) & 86 & 95 & 90 & 80 (1983) & 87 & 92 & 84 \\
\hline Poland & 96 & 96 & 98 & 99 & 93 (1981) & 95 & 97 & 97 \\
\hline Portugal & 73 & 89 & 96 & 99 & 54 & 85 & 87 & 96 \\
\hline Slovak Republic & 99 & 99 & 98 & 99 & 99 & 99 & 99 & 99 \\
\hline Spain & $\ldots$ & 93 & 95 & 98 (2002) & . & 97 & 94 & 97 \\
\hline Sweden & 99 & 99 & 98 & 98 & 93 (1983) & 96 & 94 & 94 \\
\hline Switzerland & .. & 95 & 94 & 95 & .. & 80 & 82 & 82 \\
\hline Turkey & 42 & 74 & 80 & 68 & $\ldots$ & 68 & 86 & 75 \\
\hline United Kingdom & 57 & 81 & 92 & 91 & 53 & 87 & 88 & 82 \\
\hline United States & $66(1983)$ & 72 (1993) & 82 & 85 & . & 82 (1991) & 91 & 93 \\
\hline Latest average $^{a}$ & $\ldots$ & . & . & 94 & .. & .. & . & 91 \\
\hline Consistent average $(25)^{b}$ & . & 87 & 93 & 94 & $\ldots$ & 83 & 90 & 91 \\
\hline Median & 90 & 90 & 96 & 97 & 86 & 85 & 91 & 94 \\
\hline
\end{tabular}

a) Average of the latest available data for all 30 OECD countries.

b) Excludes Belgium, Canada, Germany, Korea and New Zealand.

Source: OECD Health Data 2005. 
Table A.2.12. Influenza vaccination among people aged 65 years and over, 1993 to 2003

\begin{tabular}{|c|c|c|c|c|c|c|c|c|c|c|c|}
\hline & 1993 & 1994 & 1995 & 1996 & 1997 & 1998 & 1999 & 2000 & 2001 & 2002 & 2003 \\
\hline Australia & . & . & .. & .. & . & . & 69.0 & 74.0 & 78.0 & 76.9 & 76.9 \\
\hline Austria & . & . & . & . & .. & . & 23.7 & . & . & .. & . \\
\hline Belgium & . & $\ldots$ & . & .. & 48.2 & .. & .. & .. & 58.0 & .. & . \\
\hline Canada & . & . & . & 47.9 & .. & . & . & 63.0 & . & . & 62.4 \\
\hline Czech Republic & . & . & . . & .. & . & .. & .. & .. & . & 16.5 & . \\
\hline Denmark & . & . & . & . & . & . & .. & . & . & 29.8 & 44.9 \\
\hline Finland & . & .. & . & .. & .. & .. & . & .. & 25.0 & 43.0 & 46.0 \\
\hline France & 65.0 & 60.0 & 59.0 & 56.0 & 55.0 & 61.0 & 58.0 & 65.0 & 65.0 & 67.0 & . \\
\hline Germany & .. & .. & .. & .. & .. & 36.0 & 44.6 & .. & 55.8 & .. & 48.0 \\
\hline Greece & . & . & .. & .. & . & .. & .. & .. & . & . & . \\
\hline Hungary & . & . & .. & . & .. & . & . & .. & .. & 36.8 & 38.9 \\
\hline Iceland & . & .. & .. & .. & . & .. & . & .. & .. & .. & . \\
\hline Ireland & . & $\ldots$ & .. & . & . & . & . & .. & . & .. & . \\
\hline Italy & . & .. & .. & .. & . & .. & 40.7 & 50.7 & 55.2 & 60.3 & 63.4 \\
\hline Japan & . & $\ldots$ & .. & . & . & . & . & .. & 28.0 & 35.0 & 43.0 \\
\hline Korea & . & . & . & .. & . & .. & . & .. & .. & .. & . \\
\hline Luxembourg & . & . & .. & .. & . & .. & .. & .. & 42.8 & 46.0 & 49.1 \\
\hline Mexico & .. & .. & . & .. & .. & . & .. & .. & . & .. & . \\
\hline Netherlands & 37.0 & 39.0 & 42.0 & 54.0 & 67.0 & 72.0 & 72.0 & 76.0 & 77.0 & . & 79.2 \\
\hline New Zealand & .. & .. & .. & .. & .. & .. & .. & . & .. & 62.0 & 51.0 \\
\hline Norway & .. & . & . & . & . & . & .. & . & .. & .. & . \\
\hline Poland & . & $\ldots$ & . & . & . & . & . & . & .. & . & . \\
\hline Portugal & . & . & .. & . & . & . & .. & .. & . & . & . \\
\hline Slovak Republic & .. & . & .. & . & .. & . & . & 20.5 & 31.5 & . & 37.5 \\
\hline Spain & 51.3 & . & 51.1 & .. & 51.3 & . & . & .. & 56.1 & . & . \\
\hline Sweden & .. & .. & .. & .. & .. & .. & .. & . & .. & .. & . \\
\hline Switzerland & . & . & .. & . & . & 41.0 & 46.0 & 51.0 & 54.0 & 55.0 & 58.0 \\
\hline Turkey & . & $\ldots$ & .. & .. & . & .. & . & .. & & .. & . \\
\hline United Kingdom & .. & . & .. & .. & .. & .. & .. & 65.0 & 68.0 & 69.0 & 71.0 \\
\hline United States & 52.3 & 55.6 & 58.8 & . & 63.2 & 63.3 & 65.7 & 64.4 & 63.1 & 65.7 & 65.5 \\
\hline
\end{tabular}

Note: In most countries, the data come from population-based surveys, which may suffer from incorrect recall. Survey data may also exclude the institutionalised population in certain countries. In some countries (e.g., Denmark, Hungary, Italy, New Zealand and the United Kingdom), the data come from administration sources, which may only capture vaccination delivered under the payment system covered by the data. It is unknown to what extent the use of administrative data in certain countries may bias downward (or upward) the reported immunisation rates compared with those countries using survey data.

Source: OECD Health Data 2005. 
Table A.2.13. Hospital discharge rates for all causes, per 100000 population, 1990 to 2003

\begin{tabular}{|c|c|c|c|c|c|c|}
\hline & 1990 & 1995 & 2000 & 2001 & 2002 & 2003 \\
\hline Australia & .. & 16482 & 15812 & 15707 & 15663 & .. \\
\hline Austria $^{a}$ & 22823 & 24253 & 28798 & 29165 & 30204 & . \\
\hline Belgium & . & 15884 & 15431 & 16202 & 15994 & .. \\
\hline Canada & 12898 & 11028 & 9411 & 9083 & 8828 & .. \\
\hline Czech Republic ${ }^{a}$ & 17367 (1992) & 20740 & 21203 & 21218 & 21861 & 22759 \\
\hline Denmark & $\ldots$ & 18093 & 18812 & 18942 & 19578 & 19741 \\
\hline Finland $^{b}$ & 21743 & 24567 & 25659 & 25129 & 25165 & 24981 \\
\hline France $^{a}$ & $\ldots$ & 23370 (1993) & 25130 & 25192 & 25110 & . \\
\hline Germany & $\ldots$ & 18159 & 19961 & 20060 & 20164 & . \\
\hline Greece & 12603 & 14078 & 16095 & $\ldots$ & . & . \\
\hline Hungary ${ }^{a}$ & .. & . & 24071 & 23553 & 25297 & 25745 \\
\hline Iceland & 17639 & 18111 & 18163 & 17798 & 18125 & . \\
\hline Ireland & $\ldots$ & 11460 & 12717 & 12916 & 12310 & 12405 \\
\hline Italy & . & 15352 (1996) & 15698 & 15423 & 14892 & 14053 \\
\hline Japan & .. & 10010 (1996) & 10435 (1999) & $\ldots$ & 10199 & . \\
\hline Korea & 6536 & 7710 (1994) & 9596 (1999) & $\ldots$ & 11067 & . \\
\hline Luxembourg & .. & . & 18293 & 17949 & 17627 & 17517 \\
\hline Mexico $^{C}$ & 3681 (1991) & 3897 & 4056 & 4076 & 4126 & 4197 \\
\hline Netherlands & 10212 & 10230 & 9266 & 9125 & 9388 & 9706 \\
\hline New Zealand ${ }^{a}$ & 14716 & 17362 & 20065 & 21115 & 20761 & 20387 \\
\hline Norway & .. & 14544 & 15408 & 15984 & 16263 & 17092 \\
\hline Poland & 12597 & 13887 & 13138 (1999) & $\ldots$ & $\ldots$ & . \\
\hline Portugal & $\ldots$ & 8598 & 7365 & 7398 & 7797 & 7818 \\
\hline Slovak Republic & 15279 & 19188 & 19738 & 20231 & 19337 & 18790 \\
\hline Spain & 9502 & 10664 & 11210 & 10883 & 10893 & . \\
\hline Sweden & 17884 & 17458 & 16458 & 16255 & 16009 & . \\
\hline Switzerland & $\ldots$ & .. & . & $\ldots$ & 15421 & 15487 \\
\hline Turkey & 5677 & 6094 & 7416 & 7669 & 7908 & 8100 \\
\hline United Kingdom & 17237 & 20765 & 22946 & 22962 & 23215 & 23659 \\
\hline United States ${ }^{a}$ & 12334 & 11538 & 11236 & 11452 & 11712 & . \\
\hline Latest average $^{d}$ & . & $\ldots$ & $\ldots$ & $\ldots$ & 16138 & . \\
\hline Consistent average (23) ${ }^{e}$ & . & 15558 & 16172 & 16260 & 16318 & . \\
\hline Median & $\ldots$ & 15352 & 15812 & 16255 & 16002 & . \\
\hline
\end{tabular}

a) Austria, Czech Republic, France, Hungary, New Zealand and the United States include same-day separations whereas other countries exclude them.

b) Finland includes transfers from one hospital unit to another while these are excluded in other countries.

c) Data for Mexico are restricted to public hospitals only.

d) Average comprises all countries for which recent data is available (2000+).

e) Excludes Greece, Hungary, Japan, Korea, Luxembourg, Poland, and Switzerland.

Source: OECD Health Data 2005. 
Table A.2.14. Hospital discharge rates for selected causes, per 100000 population, 1990 to 2002

\begin{tabular}{|c|c|c|c|c|c|c|}
\hline & \multicolumn{2}{|c|}{ Circulatory } & \multicolumn{2}{|c|}{ Respiratory } & \multicolumn{2}{|c|}{ Digestive } \\
\hline & 1990 & 2002 & 1990 & 2002 & 1990 & 2002 \\
\hline Australia & .. & 1714 & .. & 1409 & .. & 1487 \\
\hline Austria $^{a}$ & 3220 & 3985 & 1696 & 1895 & 2164 & 2653 \\
\hline Belgium & .. & 2296 & . & 1354 & . & 1738 \\
\hline Canada & 1544 & 1331 & 1288 & 760 & 1479 & 961 \\
\hline Czech Republic ${ }^{a}$ & 2474 (1992) & 3494 & 1515 & 1424 & 1794 (1992) & 2115 \\
\hline Denmark & . & 2573 & .. & 1607 & . & 1590 \\
\hline Finland $^{b}$ & 3293 & 3645 & 2094 & 2156 & 1553 & 1810 \\
\hline France $^{a}$ & .. & 2264 & .. & 1262 & . & 2979 \\
\hline Germany & . & 3300 & . & 1258 & . & 2079 \\
\hline Greece & 1594 & $2316 \quad(2000)$ & 1052 & $1363 \quad(2000)$ & 1444 & $1739(2000)$ \\
\hline Hungary $^{a}$ & . & 4590 & .. & 1872 & .. & 1875 \\
\hline Iceland & . & 1867 & . & 1395 & .. & 1428 \\
\hline Ireland & . & 1432 & .. & 1348 & .. & 1283 \\
\hline Italy & .. & 2529 & .. & 1177 & .. & 1633 \\
\hline Japan & .. & 1280 & .. & 932 & .. & 1044 \\
\hline Korea & 330 & 902 & 525 & 870 & 872 & 1040 \\
\hline Luxembourg & . & 2450 & .. & 1514 & . & 1688 \\
\hline Mexico $^{c}$ & 131 (1991) & 205 & 208 (1991) & 259 & 294 (1991) & 433 \\
\hline Netherlands & 1420 & 1416 & 686 & 627 & 854 & 846 \\
\hline New Zealand ${ }^{a}$ & 1383 & 1810 & 1182 & 1546 & 1071 & 1674 \\
\hline Norway & 1924 & 2379 & 924 & 1370 & 962 & 1156 \\
\hline Poland & 1816 & .. & 1169 & .. & 1286 & .. \\
\hline Portugal & . & 1165 & .. & 815 & .. & 1005 \\
\hline Slovak Republic & 1953 & 2882 & 1589 & 1429 & 1844 & 2081 \\
\hline Spain & 783 & 1410 & 701 & 1065 & 971 & 1278 \\
\hline Sweden & 2796 & 2692 & 1274 & 1011 & 1359 & 1240 \\
\hline Switzerland & . & 1709 & .. & 835 & .. & 1230 \\
\hline Turkey & 573 & 1101 & 558 & 967 & 604 & 768 \\
\hline United Kingdom & 1444 & 1978 & 1066 & 1367 & 1504 & 2345 \\
\hline United States $^{a}$ & 2067 & 2213 & 1188 & 1230 & 1298 & 1153 \\
\hline Latest average $^{d}$ & . & 2170 & . & 1245 & . & 1529 \\
\hline Consistent average (16) & 1683 & 2110 & 1097 & 1209 & 1254 & 1456 \\
\hline Median & 1594 & 2213 & 1169 & 1348 & 1298 & 1487 \\
\hline
\end{tabular}

a) Austria, Czech Republic, France, Hungary, New Zealand and the United States include same-day separations whereas other countries exclude them.

b) Finland includes transfers from one hospital unit to another while these are excluded in other countries.

c) Data for Mexico are restricted to public hospitals only.

d) Average comprises all countries for which recent data is available (2000+).

e) Excludes Australia, Belgium, Denmark, France, Germany, Hungary, Iceland, Ireland, Italy, Japan, Luxembourg, Poland, Portugal and Switzerland.

Source: OECD Health Data 2005. 
Table A.2.15. Average length of stay for acute care, all conditions, days, 1990 to 2003

\begin{tabular}{|c|c|c|c|c|c|c|}
\hline & 1990 & 1995 & 2000 & 2001 & 2002 & 2003 \\
\hline Australia & 7.2 (1989) & 6.5 & 6.1 & 6.2 & 6.2 & .. \\
\hline Austria $^{a}$ & 9.3 & 7.9 & 6.3 & 6.1 & 5.9 & 5.8 \\
\hline Belgium & 9.8 (1993) & 9.4 & 7.9 & 7.8 & 7.7 & .. \\
\hline Canada $^{b}$ & 7.4 (1994) & 7.2 & 7.2 & 7.3 & 7.4 & . \\
\hline Czech Republic ${ }^{a}$ & 12.0 & 10.2 & 8.7 & 8.5 & 8.3 & 8.3 \\
\hline Denmark & 4.1 (1994) & 4.1 & 3.8 & 3.8 & 3.7 & 3.6 \\
\hline Finland & 7.0 & 5.5 & 4.4 & 4.4 & 4.3 & 4.3 \\
\hline France $^{a}$ & 7.0 & 6.2 & 5.6 & 5.7 & 5.7 & 5.6 \\
\hline Germany & $13.2(1992)$ & 11.4 & 9.7 & 9.4 & 9.2 & 8.9 \\
\hline Greece & 7.5 & 6.4 & 6.2 & .. & .. & .. \\
\hline Hungary $^{a}$ & 9.9 & 9.2 & 7.1 & 7.0 & 6.9 & 6.7 \\
\hline Iceland & 7.0 & 5.9 & 6.1 & 5.7 & 5.2 & .. \\
\hline Ireland & 6.7 & 6.6 & 6.4 & 6.4 & 6.5 & 6.5 \\
\hline Italy & 9.5 (1991) & 8.4 & 7.0 & 6.9 & 6.8 & . \\
\hline Japan & . & 33.2 & 24.8 & 23.5 & 22.2 & 20.7 \\
\hline Korea & 12.0 & 11.0 & 11.0 & 11.0 & 11.0 & 10.6 \\
\hline Luxembourg & 11.0 & 9.8 & 7.7 & 7.6 & 7.6 & 7.4 \\
\hline Mexico $^{C}$ & $4.2(1993)$ & 4.0 & 4.0 & 4.0 & 4.0 & 3.9 \\
\hline Netherlands & 11.2 & 9.9 & 9.0 & 8.6 & .. & .. \\
\hline Norway & 7.8 & 6.5 & 6.0 & 5.8 & 5.7 & 5.4 \\
\hline Poland & 12.5 & 10.8 & 8.9 & 8.4 & 7.9 & .. \\
\hline Portugal & 8.4 & 7.9 & 7.7 & 7.3 & .. & . \\
\hline Slovak Republic & .. & $10.8(1998)$ & 8.8 & 8.5 & 8.1 & 7.9 \\
\hline Spain & 9.6 & 8.8 & 7.1 & 7.0 & .. & .. \\
\hline Sweden & 6.5 & 5.2 & 5.0 & 5.0 & 4.8 & . \\
\hline Switzerland & 13.4 & 12.0 & 9.3 & 9.2 & 9.1 & 9.0 \\
\hline Turkey & 6.0 & 5.7 & 5.4 & 5.4 & 5.2 & .. \\
\hline United Kingdom & 9.2 & 7.0 & 6.9 & 6.9 & 6.9 & 6.7 \\
\hline United States $^{a}$ & 7.3 & 6.5 & 5.8 & 5.8 & 5.7 & 5.7 \\
\hline Latest average $^{d}$ & . & . & .. & . & 6.7 & . \\
\hline Consistent average (27) ${ }^{e}$ & 8.8 & 7.8 & 6.9 & 6.8 & 6.7 & . \\
\hline Median & 8.4 & 7.9 & 7.0 & 7.0 & 6.8 & . \\
\hline
\end{tabular}

a) Austria, Czech Republic, France, Hungary, and the United States include same-day separations whereas other countries exclude them.

b) Break in time series in Canada in 1994. Before 1994, the Canadian figures represent ALOS in short-term units of all hospitals. Starting in 1994, they represent ALOS in short-stay hospitals; many of the short-stay hospitals also have long-term care beds.

c) Data for Mexico are restricted to public hospitals only.

d) Average comprises all countries for which recent data is available (2000+).

e) Excludes Greece, Japan and Slovak Republic. The 2001 figures for the Netherlands, Portugal and Spain have been used for the calculation of the 2002 OECD average.

Source: OECD Health Data 2005. 
Table A.2.16. Average length of stay, specific conditions, days, 1990 to 2002

\begin{tabular}{|c|c|c|c|c|c|c|c|c|}
\hline & \multicolumn{2}{|c|}{ AMI } & \multicolumn{2}{|c|}{ Cerebrovascular } & \multicolumn{2}{|c|}{ Pneumonia/Influenza } & \multicolumn{2}{|c|}{ Normal delivery } \\
\hline & 1990 & 2002 & 1990 & 2002 & 1990 & 2002 & 1990 & 2002 \\
\hline Australia & .. & 6.5 & $\cdots$ & 11.7 & .. & 6.8 & $\ldots$ & 2.8 \\
\hline Austria & 18.9 & 12.5 & 21.9 & 17.2 & 14.7 & 14.9 & 7.2 & 5.5 \\
\hline Belgium & .. & 9.2 & .. & 14.3 & .. & 11.7 & .. & 5.1 \\
\hline Canada & 12.0 & 8.1 & 43.0 & 14.6 & 11.7 & 7.7 & 3.5 & 2.0 \\
\hline Czech Republic & 16.8 (1992) & 7.8 & 18.0 (1992) & 14.1 & 14.3 (1992) & 10.9 & 7.4 (1992) & 5.6 \\
\hline Denmark & 8.0 & 5.7 & $\ldots$ & 12.0 & 9.3 & 6.8 & 3.8 & 3.0 \\
\hline Finland & 22.3 & 12.6 & 51.2 & 37.2 & 58.6 & 30.9 & 5.4 & 3.6 \\
\hline France & .. & 7.2 & .. & 12.1 & .. & 9.7 & .. & 4.8 \\
\hline Germany & .. & 10.3 & .. & 14.3 & .. & 11.8 & .. & 4.4 \\
\hline Greece & 11.0 & $7.0(2000)$ & 14.0 & $12.0(2000)$ & 8.0 & $7.0(2000)$ & 5.0 & $4.0 \quad(2000)$ \\
\hline Hungary & 15.4 (1992) & 9.3 & .. & 11.5 & 18.2 (1992) & 9.7 & 7.3 (1992) & 6.4 \\
\hline Iceland & 12.5 & 6.9 & .. & 13.9 & 11.5 & 6.6 & 5.3 & 2.2 \\
\hline Ireland & 10.7 & 10.8 & .. & 17.9 & 16.2 & 10.7 & 5.8 & 3.5 (2001) \\
\hline Italy & 15.6 & 8.6 & 16.5 (1991) & 9.6 & 15.9 & 10.1 & 5.8 & 3.7 \\
\hline Japan & .. & .. & .. & .. & .. & .. & .. & .. \\
\hline Korea & .. & .. & .. & 29.0 & .. & 8.4 & .. & 2.5 \\
\hline Luxembourg & .. & 8.1 & .. & 14.8 & .. & 10.6 & .. & 4.2 \\
\hline Mexico $^{a}$ & 9.0 (1992) & 7.5 & .. & 7.5 & 6.9 (1991) & 5.9 & 1.0 (1991) & 1.3 \\
\hline Netherlands & 12.7 & 9.5 & 25.5 (1988) & 17.2 & 15.4 (1988) & 12.1 & 3.7 & 2.5 \\
\hline New Zealand & 8.7 & 7.5 & 48.8 & 45.3 & 15.8 & 12.1 & 4.2 & 2.0 \\
\hline Norway & 8.6 & 6.7 & 21.4 & 9.4 & 12.4 & 7.9 & 5.3 & 3.9 \\
\hline Poland & 19.1 & .. & 19.3 & .. & 18.1 & .. & .. & .. \\
\hline Portugal & 11.9 & 9.2 & & 10.2 & 10.9 (1991) & 10.3 & 3.5 & 3.7 \\
\hline Slovak Republic & 18.5 & 10.0 & 18.3 & 11.2 & 17.8 & 9.9 & 8.3 & 6.5 \\
\hline Spain & 12.9 & 10.0 & 19.7 & 12.0 & 12.7 & 10.0 & 4.1 & 3.0 \\
\hline Sweden & 9.2 (1992) & 6.1 & 25.6 (1992) & 12.3 & 12.6 (1992) & 6.6 & 4.4 & 2.6 \\
\hline Switzerland & 15.1 & 9.6 & .. & 22.7 & 15.5 (1991) & 12.5 & 7.6 & 5.9 \\
\hline Turkey & .. & .. & 8.7 & 7.4 & 5.6 & 6.2 & 1.9 & 1.8 \\
\hline United Kingdom & 11.9 & 9.1 & 41.5 & 27.0 & 46.5 & 13.4 & 3.5 & 1.9 \\
\hline United States & 8.4 & 5.6 & 9.5 & 5.3 & 8.2 & 5.7 & 2.0 & 1.9 \\
\hline Latest average $^{b}$ & .. & 8.5 & .. & 15.8 & .. & 10.2 & .. & 3.6 \\
\hline Consistent average ${ }^{C}$ & 12.9 & 8.6 & 25.6 & 16.8 & 16.3 & 10.4 & 4.8 & 3.5 \\
\hline Median & 12.3 & 8.4 & 20.6 & 13.1 & 14.3 & 10.0 & 4.7 & 3.6 \\
\hline
\end{tabular}

a) Data for Mexico are restricted to public hospitals only.

b) Average comprises all countries for which recent data is available (2000+).

c) Includes those countries for which data is available for both 1990 and 2002.

Source: OECD Health Data 2005. 
Table A.2.17. Cardio-vascular surgeries, per 100000 population, 1990 to 2003

\begin{tabular}{|c|c|c|c|c|c|c|c|c|c|c|c|}
\hline & \multicolumn{5}{|c|}{ Coronary artery bypass grafts (CABG) } & \multicolumn{6}{|c|}{ Coronary angioplasties } \\
\hline & 1990 & 19 & 95 & 2000 & 2003 & 1990 & 19 & 95 & 2000 & & 003 \\
\hline Australia & 61.1 & 94.9 & & 89.4 & $82.0(2002)$ & 28.7 & 62.8 & & 113.7 & 130.2 & $(2002)$ \\
\hline Austria & $\ldots$ & 56.0 & (1997) & 57.4 & $54.2(2002)$ & .. & 122.7 & (1997) & 177.0 & .. & \\
\hline Belgium & . & & & 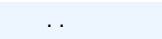 & 158.9 & . & 97.8 & & 262.1 & 331.8 & $(2002)$ \\
\hline Canada & . & 111.6 & & 142.0 & $97.9(2002)$ & . & 73.8 & & 172.0 & 139.9 & $(2002)$ \\
\hline Czech Republic & $6.2(1991)$ & 23.0 & & 57.8 & 70.7 (2002) & $5.8(1992)$ & .. & & .. & .. & \\
\hline Denmark & 20.1 & 41.5 & & 66.2 & 60.0 & $17.5(1992)$ & 29.8 & & 96.2 & 156.8 & \\
\hline Finland & 38.4 & 84.9 & & 80.0 & 76.3 & 13.1 & 35.3 & & 51.7 & 69.3 & \\
\hline France & . & 36.0 & (1993) & 40.6 & 40.9 (2001) & .. & 34.8 & (1993) & 146.5 & 156.3 & (2001) \\
\hline Germany & 41.3 & 71.9 & & 93.5 & 87.1 & 53.4 & 133.3 & & 219.4 & 269.8 & \\
\hline Greece & 18.8 & 59.6 & & .. & . & 6.6 & 30.3 & & 49.7 & 62.7 & (2002) \\
\hline Hungary & .. & & & 91.4 & 125.3 & 1.6 (1992) & 6.4 & (1993) & 46.5 & 189.3 & \\
\hline Iceland & 54.2 & 72.9 & & 60.8 & 53.9 & 51.4 & 127.1 & & 160.7 & 214.5 & \\
\hline Ireland & $\ldots$ & 25.8 & & 44.0 (2001) & 52.1 & .. & 18.0 & & 100.9 & 188.1 & \\
\hline Italy & .. & 33.8 & (1996) & 48.7 & 46.4 & . & 29.3 & (1996) & 88.1 & 92.2 & \\
\hline Japan & .. & . & & .. & .. & .. & .. & & .. & .. & \\
\hline Korea & . & $\ldots$ & & $\ldots$ & .. & .. & $\ldots$ & & . & .. & \\
\hline Luxembourg & .. & .. & & 40.8 & 75.1 & .. & .. & & 125.6 & 182.7 & \\
\hline Mexico & .. & 0.4 & & 1.3 & 2.1 & . & 0.3 & & 0.9 & 1.4 & \\
\hline Netherlands & 61.5 & 62.7 & & 59.5 & 52.8 & 42.2 (1992) & 64.6 & & 69.1 & 92.6 & \\
\hline New Zealand & .. & 68.3 & (1996) & 103.3 & 96.7 & $\ldots$ & 54.2 & (1996) & 73.9 & 91.8 & \\
\hline Norway & .. & 72.7 & (1996) & 76.1 & 85.3 (2002) & $\ldots$ & 49.4 & (1993) & 117.2 & 187.9 & (2002) \\
\hline Poland & .. & 8.0 & (1993) & .. & $\ldots$ & 4.4 (1992) & 4.8 & (1993) & . & . & \\
\hline Portugal & .. & 19.3 & & 22.9 & 22.3 & $\ldots$ & 14.4 & & 45.5 & 66.1 & \\
\hline Slovak Republic & . & . & & . & . & $\ldots$ & . & & . & . & \\
\hline Spain & 11.2 & 18.0 & & 16.9 & 18.7 (2002) & 12.7 (1991) & 31.4 & & 50.5 & 68.0 & (2002) \\
\hline Sweden & 50.6 & 71.7 & & 72.8 & 74.2 (2002) & 12.8 & 54.7 & & 94.1 & 126.1 & (2002) \\
\hline Switzerland & $\ldots$ & .. & & . & 35.9 & 45.7 (1992) & 65.1 & (1993) & .. & 78.8 & \\
\hline Turkey & .. & .. & & . & . & $\ldots$ & .. & & .. & . & \\
\hline United Kingdom & 31.1 & 44.5 & & 57.3 & 55.9 & 11.5 & 30.0 & & 70.6 & 98.6 & \\
\hline United States & 157.1 & 215.2 & & 183.8 & 160.7 & 114.2 & 162.7 & & 363.2 & 426.3 & \\
\hline Latest average $^{a}$ & $\ldots$ & . & & $\ldots$ & 70.2 & $\ldots$ & . & & . & 149.9 & \\
\hline Consistent average $(\mathbf{1 0})^{b}$ & 52.7 & 77.8 & & 78.0 & 72.2 & 35.8 & 73.2 & & 128.9 & 165.2 & \\
\hline Median & 39.9 & 57.8 & & 60.2 & 65.4 & 13.1 & 42.4 & & 96.2 & 130.2 & \\
\hline
\end{tabular}

Note: The data relate to the number of inpatient procedures only. They do not include coronary angioplasties performed on an ambulatory basis (a growing share of overall activity rates in many countries).

a) Average comprises all countries for which recent data is available (2000+).

b) Includes Australia, Denmark, Finland, Germany, Iceland, Netherlands, Spain, Sweden, United Kingdom and United States.

Source: OECD Health Data 2005. 
Table A.2.18. Caesarean sections per 100 live births, 1990 to 2002

\begin{tabular}{|c|c|c|c|c|c|}
\hline & 1990 & 1995 & 2000 & 2001 & 2002 \\
\hline Australia & 17.5 & 19.2 & 23.1 & 25.1 & 26.5 \\
\hline Austria & . & 12.4 & 17.2 & 18.9 & 20.6 \\
\hline Belgium & 10.5 & 13.5 & 15.9 (1999) & .. & . \\
\hline Canada & . & 17.5 & 20.9 & 22.2 & 23.4 \\
\hline Czech Republic & 7.6 & 11.2 & 12.9 & 13.3 & 14.1 \\
\hline Denmark & 12.4 & 12.5 & 14.5 & 16.1 & 17.6 \\
\hline Finland & 13.6 & 15.7 & 15.8 & 16.5 & 16.4 \\
\hline France & 13.9 & 15.2 (1993) & 17.1 & 17.8 & .. \\
\hline Germany & 15.7 & 17.2 & 20.9 & 22.0 & 23.7 \\
\hline Greece & .. & .. & .. & $\ldots$ & . \\
\hline Hungary & . & 13.6 & 20.1 & 21.9 & 23.5 \\
\hline Iceland & 11.8 & 14.1 & 17.7 & 16.8 & 17.4 \\
\hline Ireland & 10.5 & 13.4 & 21.4 & 23.4 & . \\
\hline Italy & 20.8 & 26.1 & 33.3 & 34.8 & 36.0 \\
\hline Japan & .. & $\ldots$ & .. & $\ldots$ & . . \\
\hline Korea & . & .. & . & 39.6 & 39.2 \\
\hline Luxembourg & 16.5 & 16.4 & 21.8 & 24.2 & 25.8 \\
\hline Mexico & .. & $\ldots$ & .. & 32.3 & 33.6 \\
\hline Netherlands & 7.4 & 9.7 & 11.9 & 13.6 & 13.5 \\
\hline New Zealand & 12.1 & 15.1 & 20.2 & 21.2 & 22.2 \\
\hline Norway & 12.8 & 12.6 & 13.7 & 15.6 & 16.1 \\
\hline Poland & .. & 15.2 & .. & .. & . \\
\hline Portugal $^{a}$ & . & 23.3 & 26.3 & 28.2 & 28.1 \\
\hline Slovak Republic & 8.7 & 11.5 & 14.7 & 16.6 & 17.8 \\
\hline Spain & 14.2 & 18.8 & 21.5 & 22.4 & .. \\
\hline Sweden & 10.8 & 12.0 & 15.2 & 16.5 & 16.4 \\
\hline Switzerland & 18.6 & .. & .. & .. & 24.2 \\
\hline Turkey & .. & .. & .. & & . \\
\hline United Kingdom & 11.6 & 15.9 & 22.3 & 22.6 & 21.7 \\
\hline United States & 22.7 & 20.8 & 22.9 & 24.4 & 26.1 \\
\hline Latest average $^{b}$ & . & . & . & . & 22.7 \\
\hline Consistent average (18) ${ }^{c}$ & 13.4 & 15.4 & 18.9 & 20.2 & 20.8 \\
\hline Median & 12.6 & 15.2 & 20.1 & 22.0 & 22.8 \\
\hline
\end{tabular}

a) In Portugal, births only include those taking place in public hospitals (in Mainland), therefore resulting in an over-estimation of caesarean rates.

b) Average comprises all countries for which recent data is available (2001+)

c) Excludes Austria, Belgium, Canada, Greece, Hungary, Japan, Korea, Mexico, Poland, Portugal, Switzerland and Turkey. The 2001 figures of France, Ireland and Spain have been used for the calculation of the 2002 OECD average.

Source: OECD Health Data 2005. 
Table A.2.19. Number of cataract surgeries, inpatient and day cases, per 100000 population, 1997, 2000 and 2003

\begin{tabular}{|c|c|c|c|c|c|c|c|c|c|}
\hline & \multicolumn{3}{|c|}{1997} & \multicolumn{3}{|c|}{2000} & \multicolumn{3}{|c|}{2003} \\
\hline & Inpatients & Day cases & Total & Inpatients & Day cases & Total & Inpatients & Day cases & Total \\
\hline Australia & 131.7 & 536.2 & 667.9 (1999) & 113.4 & 598.9 & 712.3 & 83.9 & 713.7 & 797.6 (2002) \\
\hline Austria & 471.5 & .. & .. & 578.8 & . & . & 659.9 & .. & .. (2002) \\
\hline Belgium & 408.7 & 742.6 & 1151.3 (1999) & 359.4 & 888.4 & 1247.8 & 324.0 & 1044.8 & 1368.9 \\
\hline Canada & 26.7 & 1339.8 & 1366.5 (1999) & 22.3 & 1414.4 & 1436.6 & 15.6 & 1357.4 & 1373.0 \\
\hline Czech Republic & .. & $\ldots$ & .. & .. & $\ldots$ & $\ldots$ & 386.3 & .. & .. \\
\hline Denmark & 114.7 & 248.8 & 363.5 & 84.3 & 342.5 & 426.8 & 29.3 & 468.6 & 497.9 \\
\hline Finland & 243.5 & 346.0 & 589.5 & 117.7 & 521.3 & 638.9 & 43.1 & 715.0 & 758.1 \\
\hline France & 507.0 & 118.4 & 625.3 & 498.5 & 231.1 & 729.6 & 484.0 & 270.5 & 754.5 (2001) \\
\hline Germany & . & .. & .. & . & .. & .. & .. & .. & .. \\
\hline Greece & $\ldots$ & . & 346.4 & .. & . & 560.5 & . & . & .. \\
\hline Hungary & $\ldots$ & .. & 669.5 (1999) & .. & . & 698.7 & . & . & 768.9 \\
\hline Iceland & 54.4 & 204.7 & 259.1 (1998) & . & . & . & .. & . & 566.6 (2002) \\
\hline Ireland & 286.5 & 74.7 & 361.2 & 317.8 & 128.4 & 446.2 & 262.4 & 201.2 & 463.6 \\
\hline Italy & 394.5 & 41.1 & 435.7 & 417.7 & 251.6 & 669.3 & 198.8 & 558.1 & 756.9 \\
\hline Japan & . & . & . & . & . & .. & . & . & .. \\
\hline Korea & . & .. & . & $\ldots$ & . & $\ldots$ & . & . & 315.8 (2002) \\
\hline Luxembourg & 483.4 & 185.8 & 669.3 (1999) & 505.8 & 209.9 & 715.8 & 512.9 & 261.1 & 774.1 \\
\hline Mexico & 5.7 & 28.1 & 33.8 & 7.1 & 30.3 & 37.3 & 15.2 & 33.3 & 48.4 \\
\hline Netherlands & 210.1 & 254.4 & 464.5 & 95.4 & 457.9 & 553.3 & 41.4 & 653.4 & 694.8 \\
\hline New Zealand & .. & .. & .. & 25.6 & 218.3 & 243.9 & 17.6 & 172.6 & 190.2 \\
\hline Norway & .. & . & . & 65.4 & 448.8 & 514.2 & 55.4 & 419.2 & 474.5 (2002) \\
\hline Poland & . & $\ldots$ & $\ldots$ & .. & .. & .. & .. & .. & .. \\
\hline Portugal & . & . & 114.5 & 132.4 & 13.2 & 145.6 & 149.5 & 115.7 & 265.2 \\
\hline Slovak Republic & . & . & .. & .. & $\ldots$ & . & .. & .. & .. \\
\hline Spain & 199.7 & . & $\ldots$ & 228.8 & $\ldots$ & . . & 129.3 & $\ldots$ & .. (2002) \\
\hline Sweden & . & $\ldots$ & $\ldots$ & .. & $\ldots$ & . & 150.4 & 701.1 & 851.5 (2002) \\
\hline Switzerland & .. & $\ldots$ & .. & . . & . & .. & 197.0 & 321.9 & 518.9 \\
\hline Turkey & .. & $\ldots$ & $\ldots$ & . . & . & .. & . & .. & .. \\
\hline United Kingdom & 138.7 & 263.3 & 401.9 & 94.9 & 445.0 & 540.0 & 58.2 & 583.1 & 641.3 \\
\hline United States & 4.5 & .. & .. & 2.7 & .. & .. & 2.0 & .. & .. \\
\hline
\end{tabular}

Note: Cross-country variations should be interpreted with caution due to differences in how countries register cataract surgeries and incomplete coverage of health care facilities.

Source: OECD Health Data 2005. 
Table A.3.1. Total expenditure on health per capita, USD PPP, 1970 to 2003

\begin{tabular}{|c|c|c|c|c|c|c|c|}
\hline & 1970 & 1980 & 1990 & 2000 & 2001 & 2002 & 2003 \\
\hline Australia & 188 (1969) & 691 & 1307 & 2403 & 2521 & 2699 & .. \\
\hline Austria & 191 & 764 & 1338 & 2161 & 2163 & 2236 & 2302 \\
\hline Belgium & 149 & 637 & 1345 & 2279 & 2424 & 2607 & 2827 \\
\hline Canada & 294 & 783 & 1737 & 2502 & 2709 & 2843 & 3001 \\
\hline Czech Republic & . & . & 555 & 962 & 1063 & 1187 & 1298 \\
\hline Denmark & 395 (1971) & 955 & 1567 & 2382 & 2556 & 2655 & 2763 \\
\hline Finland & 192 & 592 & 1422 & 1718 & 1857 & 2013 & 2118 \\
\hline France & 210 & 711 & 1568 & 2456 & 2617 & 2762 & 2903 \\
\hline Germany $^{a}$ & 270 & 965 & 1748 (1992) & 2671 & 2784 & 2916 & 2996 \\
\hline Greece & 160 & 487 & 840 & 1617 & 1756 & 1854 & 2011 \\
\hline Hungary & .. & .. & 586 (1991) & 857 & 975 & 1115 & 1269 \\
\hline Iceland & 165 & 708 & 1614 & 2625 & 2742 & 2948 & 3115 \\
\hline Ireland & 117 & 518 & 793 & 1804 & 2089 & 2386 & 2451 \\
\hline Italy & . & . & 1391 & 2049 & 2154 & 2248 & 2258 \\
\hline Japan & 149 & 580 & 1115 & 1971 & 2092 & 2139 & .. \\
\hline Korea & . & 164 (1983) & 377 & 771 & 932 & 975 & 1074 \\
\hline Luxembourg & 163 & 643 & 1547 & 2985 & 3264 & 3729 & 3705 \\
\hline Mexico & . & . & 293 & 499 & 545 & 559 & 583 \\
\hline Netherlands & 330 (1972) & 757 & 1438 & 2259 & 2520 & 2775 & 2976 \\
\hline New Zealand & 211 & 506 & 995 & 1605 & 1701 & 1850 & 1886 \\
\hline Norway & 142 & 667 & 1396 & 3083 & 3287 & 3616 & 3807 \\
\hline Poland & . & . & 296 & 587 & 646 & 734 & 744 \\
\hline Portugal & 51 & 295 & 670 & 1594 & 1693 & 1758 & 1797 \\
\hline Slovak Republic & . & . & . & 597 & 641 & 716 & 777 \\
\hline Spain & 96 & 365 & 875 & 1525 & 1618 & 1728 & 1835 \\
\hline Sweden & 309 & 936 & 1579 & 2273 & 2404 & 2595 & 2703 \\
\hline Switzerland & 352 & 1033 & 2033 & 3182 & 3362 & 3649 & 3781 \\
\hline Turkey & .. & 75 & 166 & 452 & 459 & 467 & 513 \\
\hline United Kingdom & 164 & 482 & 986 & 1833 & 2032 & 2231 & . \\
\hline United States & 347 & 1055 & 2738 & 4539 & 4888 & 5287 & 5635 \\
\hline Average (unweighted) (29) ${ }^{b}$ & & & 1183 & 1988 & 2133 & 2295 & 2394 \\
\hline Average (weighted) $(29)^{b}$ & & & 1416 & 2371 & 2546 & 2719 & 2853 \\
\hline
\end{tabular}

a) Data prior to 1990 refer to West Germany.

b) Excludes Slovak Republic, since expenditure data is only available since 1997. The 2003 average includes 2002 data for Australia, Japan and United Kingdom.

Source: OECD Health Data 2005. 
Table A.3.2. Public expenditure on health, per capita, USD PPP, 1970 to 2003

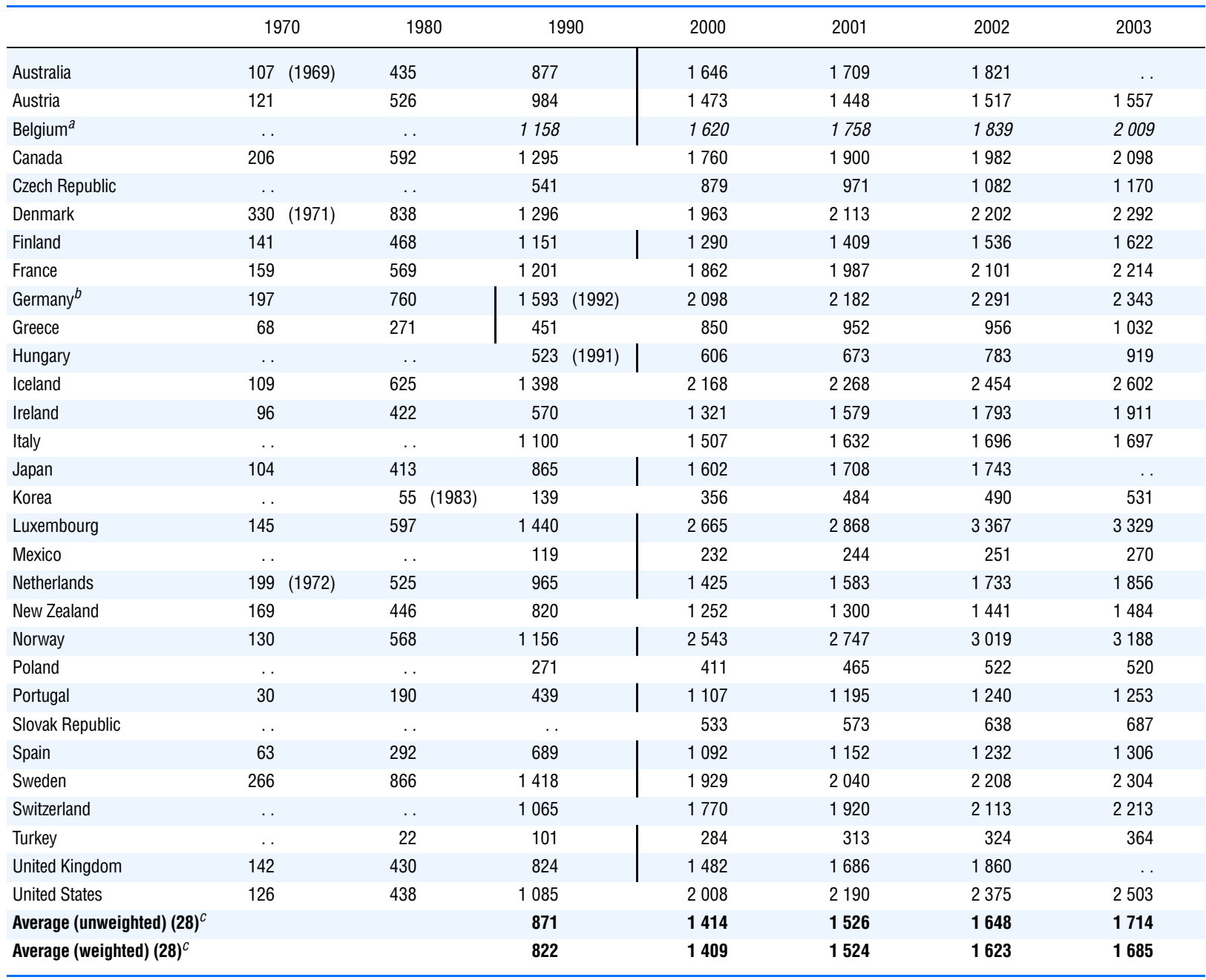

a) Data for Belgium is current public expenditure on health rather than total public expenditure on health.

b) Data prior to 1990 refer to West Germany.

c) Excludes Belgium and Slovak Republic. The 2003 average includes 2002 data for Australia, Japan and United Kingdom.

Source: OECD Health Data 2005. 
Table A.3.3. Growth of total expenditure on health compared to GDP growth, in real terms, 1980 to 2003

\begin{tabular}{|c|c|c|c|c|c|c|c|}
\hline & \multicolumn{2}{|c|}{$1980-2003$} & \multicolumn{2}{|c|}{$1992-1997$} & \multicolumn{2}{|c|}{$1997-2003$} & \multirow{2}{*}{$\begin{array}{c}2003 \text { real per capita } \\
\text { health expenditure } \\
1992=100\end{array}$} \\
\hline & GDP & $\begin{array}{l}\text { Total health } \\
\text { expenditure }\end{array}$ & GDP & $\begin{array}{l}\text { Total health } \\
\text { expenditure }\end{array}$ & GDP & $\begin{array}{l}\text { Total health } \\
\text { expenditure }\end{array}$ & \\
\hline Australia ${ }^{a}$ & 2.0 & 3.3 & 2.9 & 3.9 & 2.4 & 4.3 & 150 \\
\hline Austria & 1.9 & 2.0 & 1.5 & 1.7 & 1.8 & 2.1 & 123 \\
\hline Belgium & 1.7 & 3.5 & 1.6 & 2.6 & 1.7 & 4.0 & 144 \\
\hline Canada & 1.6 & 3.1 & 2.0 & -0.3 & 2.7 & 4.5 & 128 \\
\hline Czech Republic & . & . & 2.3 & 7.9 & 2.1 & 4.2 & 188 \\
\hline Denmark & 1.6 & 1.5 & 2.3 & 1.7 & 1.5 & 3.0 & 130 \\
\hline Finland & 2.0 & 2.7 & 2.8 & -1.6 & 2.9 & 3.3 & 112 \\
\hline France & 1.6 & 3.2 & 0.8 & 1.5 & 1.9 & 3.3 & 131 \\
\hline Germany & 0.9 & 2.0 & 0.7 & 2.2 & 1.2 & 1.7 & 124 \\
\hline Greece & 1.3 & 3.1 & 0.9 & 4.6 & 3.6 & 4.4 & 162 \\
\hline Hungary & . & . & 2.1 & 0.1 & 4.4 & 7.7 & 156 \\
\hline Iceland & 1.5 & 3.9 & 2.2 & 2.1 & 2.4 & 6.5 & 162 \\
\hline Ireland & 4.7 & 4.1 & 6.7 & 4.8 & 6.1 & 8.5 & 207 \\
\hline Italy & . & . & 1.4 & 0.0 & 1.3 & 2.9 & 119 \\
\hline Japan $^{a}$ & 2.1 & 2.9 & 1.4 & 3.6 & 0.2 & 2.8 & 137 \\
\hline Korea $^{b}$ & 5.8 & 7.3 & 5.8 & 5.5 & 3.3 & 7.8 & 204 \\
\hline Luxembourg & 3.9 & 4.5 & 2.8 & 2.0 & 3.8 & 6.5 & 161 \\
\hline Mexico & . & . & 0.6 & -0.6 & 1.5 & 4.2 & 124 \\
\hline Netherlands & 1.7 & 2.9 & 2.1 & 1.5 & 1.5 & 4.7 & 141 \\
\hline New Zealand & 1.5 & 2.9 & 2.7 & 2.4 & 2.3 & 3.8 & 140 \\
\hline Norway & 2.5 & 4.2 & 4.0 & 4.7 & 1.4 & 4.8 & 167 \\
\hline Poland & . & . & 5.6 & 3.9 & 3.4 & 5.5 & 167 \\
\hline Portugal & 2.4 & 4.8 & 1.9 & 5.9 & 1.5 & 3.7 & 165 \\
\hline Slovak Republic & .. & $\ldots$ & .. & .. & 3.4 & 3.7 & .. \\
\hline Spain & 2.3 & 3.8 & 1.9 & 2.6 & 2.4 & 2.9 & 135 \\
\hline Sweden & 1.7 & 1.8 & 1.6 & 1.3 & 2.6 & 4.9 & 142 \\
\hline Switzerland & 0.8 & 2.7 & 0.1 & 1.8 & 0.9 & 3.0 & 131 \\
\hline Turkey & . & . & 2.9 & 5.1 & 0.1 & 10.0 & 226 \\
\hline United Kingdom ${ }^{a}$ & 2.2 & 3.7 & 2.8 & 2.6 & 2.7 & 5.2 & 146 \\
\hline United States & 2.0 & 4.4 & 2.3 & 2.4 & 1.9 & 4.3 & 145 \\
\hline Average $(29)^{C}$ & . & . & 2.4 & 2.6 & 2.3 & 4.6 & 151 \\
\hline Average (23) ${ }^{d}$ & 2.2 & 3.4 & 2.3 & 2.6 & 2.3 & 4.3 & 147 \\
\hline
\end{tabular}

a) Growth rates to 2002 rather than 2003.

b) Growth rate from 1983 rather than 1980.

c) Excludes Slovak Republic.

d) Excludes Czech Republic, Hungary, Italy, Mexico, Poland, Slovak Republic and Turkey.

Source: OECD Health Data 2005. 
Table A.3.4. Growth of public expenditure on health compared to GDP growth, in real terms, 1980 to 2003

\begin{tabular}{|c|c|c|c|c|c|c|c|}
\hline & \multicolumn{2}{|c|}{$1980-2003$} & \multicolumn{2}{|c|}{$1992-1997$} & \multicolumn{2}{|c|}{$1997-2003$} & \multirow{2}{*}{$\begin{array}{c}2003 \text { real per capita } \\
\text { health expenditure } \\
1992=100\end{array}$} \\
\hline & GDP & $\begin{array}{l}\text { Public health } \\
\text { expenditure }\end{array}$ & GDP & $\begin{array}{l}\text { Public health } \\
\text { expenditure }\end{array}$ & GDP & $\begin{array}{l}\text { Public health } \\
\text { expenditure }\end{array}$ & \\
\hline Australia $^{a}$ & 2.0 & 3.7 & 2.9 & 4.3 & 2.4 & 4.3 & 152 \\
\hline Austria & 1.9 & 1.9 & 1.5 & 0.0 & 1.8 & 2.1 & 113 \\
\hline Belgium $^{b}$ & .. & .. & 1.6 & 1.8 & 1.7 & 3.9 & 138 \\
\hline Canada & 1.6 & 2.7 & 2.0 & -1.4 & 2.7 & 4.5 & 121 \\
\hline Czech Republic & $\ldots$ & .. & 2.3 & 7.0 & 2.1 & 3.9 & 177 \\
\hline Denmark & 1.6 & 1.3 & 2.3 & 1.5 & 1.5 & 3.2 & 130 \\
\hline Finland & 2.0 & 2.5 & 2.8 & -2.5 & 2.9 & 3.4 & 108 \\
\hline France & 1.6 & 2.9 & 0.8 & 1.4 & 1.9 & 3.3 & 130 \\
\hline Germany & 0.9 & 2.0 & 0.7 & 1.8 & 1.2 & 1.5 & 120 \\
\hline Greece & 1.3 & 2.7 & 0.9 & 3.9 & 3.6 & 3.9 & 152 \\
\hline Hungary & .. & .. & 2.1 & -1.5 & 4.4 & 5.6 & 129 \\
\hline Iceland & 1.5 & 3.6 & 2.2 & 1.4 & 2.4 & 6.8 & 159 \\
\hline Ireland & 4.7 & 3.9 & 6.7 & 5.7 & 6.1 & 9.3 & 226 \\
\hline Italy & .. & .. & 1.4 & -1.2 & 1.3 & 3.6 & 116 \\
\hline$J^{\prime} a p a n^{b}$ & 2.1 & 3.6 & 1.4 & 4.5 & 0.2 & 2.8 & 143 \\
\hline Korea $^{c}$ & 5.8 & 9.5 & 5.8 & 8.9 & 3.3 & 11.4 & 292 \\
\hline Luxembourg & 3.9 & 4.4 & 2.8 & 1.9 & 3.8 & 5.9 & 156 \\
\hline Mexico & .. & .. & 0.6 & 0.2 & 1.5 & 4.8 & 134 \\
\hline Netherlands & 1.7 & 2.4 & 2.1 & 0.1 & 1.5 & 3.2 & 121 \\
\hline New Zealand & 1.5 & 2.4 & 2.7 & 1.9 & 2.3 & 4.1 & 140 \\
\hline Norway & 2.5 & 4.1 & 4.0 & 3.9 & 1.4 & 5.3 & 165 \\
\hline Poland & $\ldots$ & .. & 5.6 & 2.7 & 3.4 & 4.9 & 153 \\
\hline Portugal & 2.4 & 5.2 & 1.9 & 8.0 & 1.5 & 4.7 & 193 \\
\hline Slovak Republic & .. & .. & .. & .. & 3.4 & 3.1 & . \\
\hline Spain & 2.3 & 3.3 & 1.9 & 1.2 & 2.4 & 2.6 & 124 \\
\hline Sweden & 1.7 & 1.5 & 1.6 & 0.9 & 2.6 & 4.7 & 138 \\
\hline Switzerland & 0.8 & .. & 0.1 & 2.3 & 0.9 & 4.0 & 142 \\
\hline Turkey & .. & . & 2.9 & 6.5 & 0.1 & 9.8 & 237 \\
\hline United Kingdom ${ }^{a}$ & 2.2 & 3.4 & 2.8 & 1.5 & 2.7 & 6.0 & 144 \\
\hline United States & 2.0 & 4.8 & 2.3 & 3.7 & 1.9 & 4.0 & 152 \\
\hline Average (29) ${ }^{d}$ & $\ldots$ & $\ldots$ & 2.4 & 2.4 & 2.3 & 4.7 & 152 \\
\hline Average (22) ${ }^{e}$ & 2.2 & 3.4 & 2.4 & 2.5 & 2.3 & 4.6 & 151 \\
\hline
\end{tabular}

a) Growth rates to 2002 rather than 2003.

b) Data for Belgium refer to current public expenditure on health rather than total public expenditure on health.

c) Growth rate from 1983 rather than 1980.

d) Excludes Slovak Republic.

e) Excludes Belgium, Czech Republic, Hungary, Italy, Mexico, Poland, Slovak Republic and Turkey.

Source: OECD Health Data 2005. 
Table A.3.5. Annual growth rate of total per capita expenditure on health, in real terms, 1992 to 2003

\begin{tabular}{|c|c|c|c|c|c|c|c|c|c|c|c|}
\hline & $1992 / 93$ & $1993 / 94$ & $1994 / 95$ & $1995 / 96$ & $1996 / 97$ & 1997/98 & 1998/99 & $1999 / 2000$ & $2000 / 01$ & $2001 / 02$ & $2002 / 03$ \\
\hline Australia & 3.4 & 3.7 & 3.7 & 4.7 & 4.1 & 5.5 & 4.0 & 4.3 & 3.4 & 4.5 & .. \\
\hline Austria & 5.0 & 2.2 & 11.0 & 3.1 & -11.4 & 6.4 & 3.1 & 1.8 & -1.0 & 1.1 & 1.4 \\
\hline Belgium & 0.2 & 0.2 & 8.9 & 2.7 & 1.1 & 3.0 & 4.8 & 4.6 & 1.9 & 3.8 & 6.0 \\
\hline Canada & 0.0 & -0.2 & -2.0 & -1.8 & 2.4 & 6.3 & 2.9 & 3.7 & 5.8 & 4.9 & 3.6 \\
\hline Czech Republic & 32.1 & 4.3 & 5.8 & 1.2 & -0.7 & -1.3 & 0.9 & 3.8 & 7.1 & 6.3 & 9.1 \\
\hline Denmark & 3.3 & 2.4 & -1.7 & 2.9 & 1.8 & 4.1 & 3.9 & 0.7 & 4.4 & 3.1 & 1.9 \\
\hline Finland & -10.1 & -3.9 & 0.1 & 5.5 & 1.0 & -0.7 & 3.4 & 1.4 & 4.7 & 5.9 & 5.3 \\
\hline France & 3.1 & 1.0 & 2.8 & 0.7 & 0.0 & 2.2 & 2.8 & 3.7 & 3.0 & 3.2 & 4.6 \\
\hline Germany & -1.3 & 4.4 & 5.3 & 3.4 & -0.4 & 1.3 & 2.2 & 2.4 & 2.3 & 1.4 & 0.9 \\
\hline Greece & 9.1 & 10.7 & 0.9 & 1.2 & 1.6 & 1.9 & 6.0 & 7.2 & 6.4 & -0.9 & 6.0 \\
\hline Hungary & -0.1 & 10.5 & -7.9 & -2.2 & 1.2 & 10.6 & 5.0 & 2.3 & 7.5 & 9.4 & 11.4 \\
\hline Iceland & 1.1 & 0.8 & 1.4 & 4.2 & 3.0 & 9.3 & 11.3 & 2.9 & 1.5 & 6.0 & 8.3 \\
\hline Ireland & 1.0 & 5.7 & 6.1 & 4.4 & 7.0 & 3.5 & 11.2 & 9.8 & 13.3 & 11.2 & 2.6 \\
\hline Italy & -3.9 & -1.7 & -2.0 & 2.7 & 5.3 & 1.8 & 2.5 & 7.6 & 3.8 & 2.1 & -0.3 \\
\hline Japan & 4.3 & 4.9 & 3.1 & 5.2 & 0.8 & 2.0 & 3.4 & 4.9 & 3.6 & 0.0 & .. \\
\hline Korea & 0.9 & 5.1 & 8.4 & 10.3 & 2.9 & -3.6 & 16.6 & 4.8 & 18.1 & 4.0 & 8.2 \\
\hline Luxembourg & 4.1 & -0.2 & 4.7 & 2.7 & -1.1 & 3.3 & 13.4 & 5.2 & 8.3 & 11.1 & -1.8 \\
\hline Mexico & 3.8 & 2.7 & -10.1 & -6.0 & 7.9 & 5.4 & 6.7 & 4.5 & 6.6 & -0.2 & 2.4 \\
\hline Netherlands & 1.7 & 0.4 & 2.6 & 1.6 & 1.1 & 4.9 & 4.6 & 1.7 & 5.4 & 7.1 & 4.5 \\
\hline New Zealand & 0.5 & 4.0 & 2.9 & 1.2 & 3.2 & 5.7 & 3.0 & 2.8 & 3.9 & 7.7 & -0.2 \\
\hline Norway & 0.3 & 3.1 & 4.2 & 4.0 & 12.4 & 12.4 & 2.1 & -7.6 & 6.7 & 12.1 & 4.2 \\
\hline Poland & -0.8 & -1.3 & 7.1 & 13.2 & 2.1 & 10.1 & 1.1 & 1.4 & 7.4 & 10.8 & 2.3 \\
\hline Portugal & 2.2 & 1.2 & 16.1 & 6.4 & 4.0 & 3.6 & 7.1 & 8.2 & 3.0 & -0.5 & 0.8 \\
\hline Slovak Republic & $\ldots$ & .. & .. & .. & .. & 1.8 & 2.5 & -2.1 & 4.6 & 6.8 & 9.0 \\
\hline Spain & 3.1 & 0.5 & 5.0 & 2.4 & 1.9 & 4.0 & 4.1 & 2.7 & 2.9 & 1.2 & 2.3 \\
\hline Sweden & 0.4 & -1.4 & 2.9 & 4.0 & 0.4 & 5.1 & 5.8 & 4.2 & 5.1 & 6.4 & 2.7 \\
\hline Switzerland & -0.2 & 1.0 & 2.1 & 4.4 & 1.9 & 4.2 & 2.1 & 2.9 & 5.0 & 1.5 & 2.5 \\
\hline Turkey & 4.2 & -9.5 & -1.8 & 21.6 & 14.1 & 16.1 & 24.8 & 8.6 & 2.8 & 1.8 & 7.5 \\
\hline United Kingdom & 2.4 & 5.1 & 1.8 & 3.1 & 0.4 & 3.4 & 6.5 & 5.1 & 6.9 & 4.1 & . \\
\hline United States & 3.7 & 2.1 & 2.3 & 1.9 & 2.2 & 2.8 & 3.3 & 3.4 & 5.2 & 6.4 & 4.7 \\
\hline Average (29) ${ }^{a}$ & 2.5 & 2.0 & 2.9 & 3.7 & 2.4 & 4.6 & 5.8 & 3.8 & 5.3 & 4.7 & 3.8 \\
\hline
\end{tabular}

a) Excludes the Slovak Republic. The average for 2003 includes 2002 data for Australia, Japan and United Kingdom.

Source: OECD Health Data 2005. 
Table A.3.6. Annual growth rate of public per capita expenditure on health, in real terms, 1992 to 2003

\begin{tabular}{|c|c|c|c|c|c|c|c|c|c|c|c|}
\hline & $1992 / 93$ & $1993 / 94$ & 1994/95 & $1995 / 96$ & 1996/97 & 1997/98 & 1998/99 & 1999/2000 & 2000/01 & 2001/02 & $2002 / 03$ \\
\hline Australia & 2.5 & 3.7 & 5.0 & 3.9 & 6.7 & 5.4 & 6.6 & 3.1 & 2.3 & 4.1 & $\ldots$ \\
\hline Austria & 6.0 & 2.5 & 4.0 & 2.1 & -13.2 & 5.8 & 3.7 & 2.4 & -2.7 & 2.4 & 1.1 \\
\hline Belgium $^{a}$ & -0.7 & -0.7 & 7.2 & 6.2 & -2.6 & 2.7 & 4.3 & 4.7 & 4.0 & 0.9 & 6.8 \\
\hline Canada & -1.9 & -1.1 & -2.9 & -2.5 & 1.3 & 6.9 & 2.5 & 3.8 & 5.4 & 4.2 & 4.0 \\
\hline Czech Republic & 31.2 & 3.2 & 4.4 & 1.1 & -1.6 & -1.1 & 0.5 & 3.7 & 7.1 & 6.0 & 7.9 \\
\hline Denmark & 2.6 & 1.8 & -1.4 & 2.7 & 1.6 & 3.8 & 4.1 & 1.0 & 4.7 & 3.5 & 1.9 \\
\hline Finland & -14.1 & -4.7 & 0.3 & 5.8 & 1.3 & -0.5 & 2.0 & 1.1 & 5.7 & 6.5 & 5.6 \\
\hline France & 3.0 & 0.3 & 3.4 & 0.4 & 0.1 & 1.9 & 2.8 & 3.4 & 3.1 & 3.4 & 4.9 \\
\hline Germany & -2.2 & 4.4 & 5.6 & 3.4 & -2.2 & 0.5 & 2.2 & 2.5 & 2.1 & 1.6 & 0.4 \\
\hline Greece & 8.8 & 1.9 & 4.6 & 3.0 & 1.4 & 0.4 & 8.8 & 5.5 & 9.7 & -5.7 & 5.4 \\
\hline Hungary & -0.8 & 10.4 & -11.5 & -5.0 & 0.8 & 1.8 & 1.7 & 0.0 & 4.8 & 11.4 & 14.8 \\
\hline Iceland & -0.7 & 1.1 & 1.8 & 3.4 & 1.5 & 9.2 & 13.6 & 1.6 & 1.6 & 6.7 & 8.7 \\
\hline Ireland & 3.6 & 3.7 & 5.7 & 4.1 & 11.8 & 6.2 & 5.8 & 10.5 & 16.9 & 10.6 & 6.5 \\
\hline Italy & -4.3 & -4.1 & -5.3 & 2.2 & 5.9 & 1.4 & 3.0 & 9.9 & 7.0 & 1.6 & -0.7 \\
\hline Japan & 5.7 & 4.1 & 8.9 & 4.9 & -0.7 & 1.1 & 3.8 & 5.1 & 4.1 & -0.2 & .. \\
\hline Korea & 3.7 & 1.9 & 11.2 & 19.1 & 9.5 & 5.5 & 16.8 & 8.9 & 32.8 & 0.8 & 6.2 \\
\hline Luxembourg & 4.2 & -1.5 & 5.5 & 3.1 & -1.4 & 3.2 & 10.1 & 4.6 & 6.6 & 14.2 & -2.2 \\
\hline Mexico & 4.1 & 7.0 & -15.9 & -7.6 & 16.5 & 8.5 & 10.8 & 1.8 & 2.7 & 0.0 & 5.7 \\
\hline Netherlands & 2.9 & -0.6 & 0.0 & -5.3 & 3.6 & -0.7 & 2.2 & 2.3 & 4.9 & 6.5 & 4.3 \\
\hline New Zealand & -2.5 & 5.2 & 2.5 & 0.5 & 4.0 & 5.3 & 3.6 & 3.5 & 1.8 & 9.7 & 0.8 \\
\hline Norway & 0.1 & 3.2 & 3.7 & 3.9 & 8.6 & 13.6 & 2.6 & -7.6 & 8.1 & 12.0 & 4.5 \\
\hline Poland & -4.2 & -2.6 & 7.3 & 14.0 & 0.1 & 0.0 & 10.0 & -0.1 & 10.3 & 9.6 & 0.5 \\
\hline Portugal & 8.2 & 1.7 & 14.7 & 10.9 & 4.7 & 5.9 & 7.8 & 11.3 & 4.7 & -0.5 & -0.3 \\
\hline Slovak Republic & $\ldots$ & .. & .. & .. & .. & 1.6 & 0.4 & -2.4 & 4.5 & 6.6 & 8.0 \\
\hline Spain & 2.1 & -0.9 & 0.3 & 2.7 & 2.0 & 3.6 & 3.8 & 2.1 & 2.3 & 1.4 & 2.1 \\
\hline Sweden & 0.6 & -1.8 & 2.5 & 4.4 & -0.8 & 5.0 & 5.8 & 3.1 & 5.0 & 6.7 & 2.8 \\
\hline Switzerland & 0.8 & 0.8 & 1.3 & 6.2 & 2.8 & 3.6 & 2.9 & 3.4 & 7.8 & 2.9 & 3.6 \\
\hline Turkey & 3.3 & -6.1 & 0.3 & 19.6 & 18.1 & 16.6 & 6.0 & 11.8 & 11.4 & 3.6 & 9.8 \\
\hline United Kingdom & 3.1 & 3.6 & 1.8 & 2.0 & -2.7 & 3.4 & 6.8 & 5.5 & 9.7 & 4.6 & .. \\
\hline United States & 5.3 & 6.1 & 3.5 & 2.6 & 1.2 & 0.8 & 2.8 & 3.7 & 6.5 & 6.7 & 3.5 \\
\hline Average (29) ${ }^{b}$ & 2.4 & 1.5 & 2.4 & 3.9 & 2.7 & 4.1 & 5.4 & 3.9 & 6.6 & 4.7 & 4.0 \\
\hline
\end{tabular}

a) Data for Belgium refer to current public expenditure on health rather than total public expenditure on health.

b) Excludes Slovak Republic. The average for 2003 includes 2002 data for Australia, Japan and United Kingdom.

Source: OECD Health Data 2005. 
Table A.3.7. Total expenditure on health, share of Gross Domestic Product, 1970 to 2003

\begin{tabular}{|c|c|c|c|c|c|c|c|}
\hline & 1970 & 1980 & 1990 & 2000 & 2001 & 2002 & 2003 \\
\hline Australia & 4.6 (1969) & 7.0 & 7.8 & 9.0 & 9.1 & 9.3 & . \\
\hline Austria & 5.1 & 7.4 & 7.0 & 7.5 & 7.4 & 7.5 & 7.5 \\
\hline Belgium & 4.0 & 6.4 & 7.4 & 8.7 & 8.8 & 9.1 & 9.6 \\
\hline Canada & 7.0 & 7.1 & 9.0 & 8.9 & 9.4 & 9.6 & 9.9 \\
\hline Czech Republic & $\ldots$ & .. & 4.7 & 6.6 & 6.9 & 7.2 & 7.5 \\
\hline Denmark & 8.0 (1971) & 9.1 & 8.5 & 8.4 & 8.6 & 8.8 & 9.0 \\
\hline Finland & 5.6 & 6.4 & 7.8 & 6.7 & 6.9 & 7.2 & 7.4 \\
\hline France & 5.4 & 7.1 & 8.6 & 9.3 & 9.4 & 9.7 & 10.1 \\
\hline Germany $^{a}$ & 6.2 & 8.7 & 8.5 (1992) & 10.6 & 10.8 & 10.9 & 11.1 \\
\hline Greece & 6.1 & 6.6 & 7.4 & 9.9 & 10.2 & 9.8 & 9.9 \\
\hline Hungary & .. & .. & 7.1 (1991) & 7.1 & 7.4 & 7.8 & 8.4 \\
\hline Iceland & 4.7 & 6.2 & 8.0 & 9.3 & 9.3 & 10.0 & 10.5 \\
\hline Ireland & 5.1 & 8.4 & 6.1 & 6.3 & 6.9 & 7.3 & 7.4 \\
\hline Italy & .. & .. & 7.9 & 8.1 & 8.2 & 8.4 & 8.4 \\
\hline Japan & 4.5 & 6.5 & 5.9 & 7.6 & 7.8 & 7.9 & .. \\
\hline Korea & .. & 4.2 (1983) & 4.5 & 4.7 & 5.4 & 5.3 & 5.6 \\
\hline Luxembourg & 3.6 & 5.9 & 6.1 & 6.0 & 6.5 & 7.2 & 6.9 \\
\hline Mexico & $\ldots$ & .. & 4.8 & 5.6 & 6.0 & 6.0 & 6.2 \\
\hline Netherlands & 6.9 (1972) & 7.5 & 8.0 & 8.3 & 8.7 & 9.3 & 9.8 \\
\hline New Zealand & 5.1 & 5.9 & 6.9 & 7.8 & 7.9 & 8.2 & 8.1 \\
\hline Norway & 4.4 & 7.0 & 7.7 & 8.5 & 8.9 & 9.9 & 10.3 \\
\hline Poland & .. & .. & 4.9 & 5.7 & 6.0 & 6.6 & 6.5 \\
\hline Portugal & 2.6 & 5.6 & 6.2 & 9.2 & 9.4 & 9.3 & 9.6 \\
\hline Slovak Republic & .. & .. & .. & 5.5 & 5.6 & 5.7 & 5.9 \\
\hline Spain & 3.6 & 5.4 & 6.7 & 7.4 & 7.5 & 7.6 & 7.7 \\
\hline Sweden & 6.9 & 9.1 & 8.4 & 8.4 & 8.8 & 9.2 & 9.4 \\
\hline Switzerland & 5.5 & 7.4 & 8.3 & 10.4 & 10.9 & 11.1 & 11.5 \\
\hline Turkey & .. & 3.3 & 3.6 & 6.6 & 7.5 & 7.2 & 7.4 \\
\hline United Kingdom & 4.5 & 5.6 & 6.0 & 7.3 & 7.5 & 7.7 & . \\
\hline United States & 6.9 & 8.7 & 11.9 & 13.1 & 13.8 & 14.6 & 15.0 \\
\hline Average (unweighted) (29) ${ }^{b}$ & & & 7.1 & 8.0 & 8.3 & 8.6 & 8.8 \\
\hline Average (weighted) $(29)^{b}$ & & & 8.6 & 9.9 & 10.3 & 10.6 & 10.9 \\
\hline
\end{tabular}

a) Data prior to 1990 refer to West Germany.

b) Excludes Slovak Republic, since data is only available from 1997. The 2003 average includes 2002 data for Australia, Japan and United Kingdom.

Source: OECD Health Data 2005. 
Table A.3.8. Public expenditure on health, share of Gross Domestic Product, 1970 to 2003

\begin{tabular}{|c|c|c|c|c|c|c|c|}
\hline & 1970 & 1980 & 1990 & 2000 & 2001 & 2002 & 2003 \\
\hline Australia & 2.6 (1969) & 4.4 & 5.2 & 6.2 & 6.2 & 6.3 & . \\
\hline Austria & 3.2 & 5.1 & 5.1 & 5.1 & 5.0 & 5.1 & 5.1 \\
\hline Belgium $^{a}$ & .. & .. & 5.9 (1992) & 6.2 & 6.4 & 6.8 & 6.8 \\
\hline Canada & 4.9 & 5.4 & 6.7 & 6.3 & 6.6 & 6.7 & 6.9 \\
\hline Czech Republic & .. & .. & 4.6 & 6.0 & 6.3 & 6.5 & 6.8 \\
\hline Denmark & 6.7 (1971) & 8.0 & 7.0 & 6.9 & 7.1 & 7.3 & 7.5 \\
\hline Finland & 4.1 & 5.0 & 6.3 & 5.0 & 5.3 & 5.5 & 5.7 \\
\hline France & 4.1 & 5.7 & 6.6 & 7.1 & 7.2 & 7.4 & 7.7 \\
\hline Germany $^{b}$ & 4.5 & 6.8 & 6.5 (1992) & 8.3 & 8.5 & 8.6 & 8.6 \\
\hline Greece & 2.6 & 3.7 & 4.0 & 5.2 & 5.5 & 5.0 & 5.1 \\
\hline Hungary & .. & .. & 6.4 (1991) & 5.0 & 5.1 & 5.5 & 6.1 \\
\hline Iceland & 3.1 & 5.5 & 6.9 & 7.7 & 7.7 & 8.3 & 8.8 \\
\hline Ireland & 4.2 & 6.8 & 4.4 & 4.7 & 5.2 & 5.5 & 5.8 \\
\hline Italy & .. & .. & 6.3 & 5.9 & 6.2 & 6.3 & 6.3 \\
\hline Japan & 3.2 & 4.6 & 4.6 & 6.1 & 6.4 & 6.4 & . \\
\hline Korea & .. & 1.4 (1983) & 1.7 & 2.2 & 2.8 & 2.7 & 2.8 \\
\hline Luxembourg & 3.2 & 5.5 & 5.7 & 5.4 & 5.7 & 6.5 & 6.2 \\
\hline Mexico & $\ldots$ & .. & 2.0 & 2.6 & 2.7 & 2.7 & 2.9 \\
\hline Netherlands & 4.1 (1972) & 5.2 & 5.4 & 5.2 & 5.4 & 5.8 & 6.1 \\
\hline New Zealand & 4.1 & 5.2 & 5.7 & 6.1 & 6.0 & 6.4 & 6.3 \\
\hline Norway & 4.0 & 5.9 & 6.4 & 7.0 & 7.4 & 8.2 & 8.6 \\
\hline Poland & .. & .. & 4.5 & 4.0 & 4.3 & 4.7 & 4.5 \\
\hline Portugal & 1.6 & 3.6 & 4.1 & 6.4 & 6.6 & 6.6 & 6.7 \\
\hline Slovak Republic & .. & .. & & 4.9 & 5.0 & 5.1 & 5.2 \\
\hline Spain & 2.3 & 4.3 & 5.3 & 5.3 & 5.4 & 5.4 & 5.5 \\
\hline Sweden & 5.9 & 8.4 & 7.5 & 7.2 & 7.5 & 7.8 & 8.0 \\
\hline Switzerland & . & .. & 4.3 & 5.8 & 6.2 & 6.4 & 6.7 \\
\hline Turkey & .. & 1.0 & 2.2 & 4.2 & 5.1 & 5.0 & 5.2 \\
\hline United Kingdom & 3.9 & 5.0 & 5.0 & 5.9 & 6.2 & 6.4 & . \\
\hline United States & 2.5 & 3.6 & 4.7 & 5.8 & 6.2 & 6.6 & 6.6 \\
\hline Average (unweighted) $(29)^{c}$ & & & 5.2 & 5.7 & 5.9 & 6.2 & 6.3 \\
\hline Average (weighted) (29) ${ }^{C}$ & & & 5.0 & 5.8 & 6.1 & 6.3 & 6.4 \\
\hline
\end{tabular}

a) Data for Belgium refer to current public expenditure on health rather than total public expenditure on health.

b) Data prior to 1990 refer to West Germany.

c) Excludes the Slovak Republic. The 2003 average includes 2002 data for Australia, Japan and United Kingdom.

Source: OECD Health Data 2005. 
Table A.3.9. Current expenditure on health by function of care, 2003

(c162urrent expenditure on health $=100$ )

\begin{tabular}{|c|c|c|c|c|c|c|c|c|}
\hline & \multirow{2}{*}{$\begin{array}{l}\text { Personal health } \\
\text { services }\end{array}$} & \multicolumn{3}{|c|}{ Of which: } & \multirow{2}{*}{$\begin{array}{l}\text { Medical goods } \\
\text { for out-patients }\end{array}$} & \multirow{2}{*}{$\begin{array}{c}\text { Collective } \\
\text { health }\end{array}$} & \multicolumn{2}{|c|}{ Of which: } \\
\hline & & $\begin{array}{l}\text { Curative- } \\
\text { rehabilitative }\end{array}$ & Long-term care & $\begin{array}{l}\text { Ancillary } \\
\text { services }\end{array}$ & & & $\begin{array}{c}\text { Prevention and } \\
\text { public health }\end{array}$ & $\begin{array}{l}\text { Health admin. } \\
\text { and insurance }\end{array}$ \\
\hline Australia (2001) & 73 & 60 & 8 & 6 & 19 & 8 & 3 & 4 \\
\hline Austria & 70 & . & . & .. & 24 & 6 & 2 & 4 \\
\hline Belgium & $\ldots$ & .. & .. & .. & .. & .. & .. & . . \\
\hline Canada $^{a}$ & 69 & 48 & 14 & 7 & 20 & 11 & 8 & 3 \\
\hline Czech Republic & 67 & . & 2 & 1 & 27 & 6 & 3 & 3 \\
\hline Denmark & 85 & . & $\ldots$ & .. & 12 & 1 & . & 1 \\
\hline Finland & 73 & 64 & 8 & 1 & 20 & 6 & 4 & 2 \\
\hline France & 70 & 62 & 4 & 4 & 25 & 4 & 3 & 2 \\
\hline Germany & 69 & 49 & 14 & 6 & 20 & 11 & 5 & 6 \\
\hline Greece & . & . & . & .. & . & . & . & . \\
\hline Hungary (2002) & 60 & 52 & 2 & 6 & 33 & 7 & 5 & 2 \\
\hline Iceland & 80 & 64 & 15 & 3 & 17 & 3 & 1 & 2 \\
\hline Ireland & . & . & . & . & . & .. & . & .. \\
\hline Italy & 76 & . & . & $\ldots$ & 23 & 1 & 1 & 0 \\
\hline Japan (2002) & 76 & 62 & 13 & 1 & 20 & 5 & 2 & 2 \\
\hline Korea & 62 & 62 & . & . & 33 & 5 & 1 & 4 \\
\hline Luxembourg & 83 & 64 & 13 & 6 & 13 & 3 & 1 & 3 \\
\hline Mexico & 69 & . & . & . & 22 & 8 & 3 & 4 \\
\hline Netherlands & 71 & 57 & 12 & 2 & 18 & 10 & 5 & 4 \\
\hline New Zealand & . & . & . & . & . & $\ldots$ & . & . \\
\hline Norway & 82 & 52 & 25 & 6 & 15 & 3 & 2 & 1 \\
\hline Poland & 61 & 53 & 5 & 3 & 34 & 5 & 3 & 1 \\
\hline Portugal & . & . & . & .. & . & . & . & . \\
\hline Slovak Republic & 52 & . & . & 4 & 46 & 2 & 2 & 0 \\
\hline Spain & 70 & 67 & 2 & 1 & 26 & 4 & 1 & 3 \\
\hline Sweden & 84 & . & . & . & 15 & .. & . & 1 \\
\hline Switzerland & 82 & 59 & 21 & 3 & 13 & 7 & 2 & 5 \\
\hline Turkey $(2000)^{b}$ & 54 & 51 & . & 3 & 29 & 5 & 2 & 2 \\
\hline United Kingdom & . & . & . & . & . & . & . & . \\
\hline United States & 74 & 67 & 7 & 0 & 14 & 11 & 4 & 7 \\
\hline Average $(23)^{c}$ & 72 & . & . & . & 22 & 6 & . & . \\
\hline
\end{tabular}

a) Canadian expenditure on prevention and public health includes the general administrative expenses of provincial/territorial and federal health departments.

b) For Turkey, $12 \%$ of current health expenditure on health cannot be distributed by function.

c) Excludes Belgium, Greece, Ireland, New Zealand, Portugal, Turkey and United Kingdom.

Source: OECD Health Data 2005. 
Table A.3.10. Pharmaceutical expenditure, per capita, 2003, and annual average growth rate, in real terms, 1970 to 2003

\begin{tabular}{|c|c|c|c|c|c|c|}
\hline & \multirow{2}{*}{$\begin{array}{c}\text { Per capita USD PPP } \\
2003\end{array}$} & \multicolumn{4}{|c|}{ Annual average growth rate } & \multirow{2}{*}{$\begin{array}{r}\begin{array}{c}\text { Total health } \\
\text { expenditure }\end{array} \\
1997-2003\end{array}$} \\
\hline & & $1970-1980$ & $1980-1990$ & $1990-2000$ & $1997-2003$ & \\
\hline Australia & 353 (2001) & $-1.9(71-80)$ & 3.9 & 8.8 & $9.1 \quad(97-01)$ & $4.3(97-01)$ \\
\hline Austria & 389 & $\ldots$ & . & .. & 5.3 & $2.1 \quad(97-02)$ \\
\hline Belgium & . & 3.1 & 2.2 & $4.2(90-97)$ & .. & 4.0 \\
\hline Canada & 507 & 0.3 & 7.1 & 5.2 & 6.9 & 4.5 \\
\hline Czech Republic & 284 & $\ldots$ & . & 4.2 & 1.7 & 4.2 \\
\hline Denmark & 272 & . & 3.0 & 3.4 & 4.5 & 3.0 \\
\hline Finland & 339 & 2.9 & 3.4 & 5.0 & 4.6 & 3.3 \\
\hline France & 606 & 1.5 & 4.4 & 4.3 & 5.8 & 3.3 \\
\hline Germany & 436 & 4.2 & 2.5 & $1.2(92-00)$ & 3.7 & 1.7 \\
\hline Greece & 322 & 1.4 & -1.4 & 5.2 & 4.2 & 4.4 \\
\hline Hungary & 308 (2002) & . & . & $3.3(91-01)$ & $8.3 \quad(97-02)$ & $6.9(97-02)$ \\
\hline Iceland & 453 & 7.4 & 2.5 & 4.4 & 5.8 & 6.5 \\
\hline Ireland & 290 & 1.0 & 1.3 & 5.2 & 11.3 & 8.5 \\
\hline Italy & 498 & $\ldots$ & . & 2.2 & 3.3 & 2.9 \\
\hline Japan & 393 (2002) & . & 2.6 & 2.2 & $0.5 \quad(97-02)$ & $2.8 \quad(97-02)$ \\
\hline Korea & 309 & . & $11.6(83-90)$ & 2.3 & 8.6 & 7.8 \\
\hline Luxembourg & 389 & 4.0 & 5.1 & 0.8 & 3.2 & 6.5 \\
\hline Mexico & 125 & .. & . & .. & $7.0 \quad(99-03)$ & 3.3 (99-03) \\
\hline Netherlands & 340 & $-0.1 \quad(72-80)$ & 4.2 & 4.6 & 5.4 & 4.7 \\
\hline New Zealand & $\ldots$ & $2.6 \quad(71-80)$ & 4.4 & $4.1 \quad(90-97)$ & $\ldots$ & 3.8 \\
\hline Norway & 341 (2002) & 10.3 & 1.4 & $2.7 \quad(90-97)$ & $5.7 \quad(97-02)$ & 4.9 (97-02) \\
\hline Poland & 225 & $\ldots$ & . & .. & $\ldots$ & 5.5 \\
\hline Portugal & .. & 16.0 & 6.5 & $5.5 \quad(90-98)$ & .. & 3.7 \\
\hline Slovak Republic & 299 & $\ldots$ & .. & $\ldots$ & $7.7 \quad(99-03)$ & 4.5 (99-03) \\
\hline Spain & 401 & $\ldots$ & 3.0 & 5.3 & 3.7 & 2.9 \\
\hline Sweden & 339 (2002) & 4.3 & 3.2 & 7.5 & 4.9 & 4.9 \\
\hline Switzerland & 398 & . & .. & 3.2 & 3.3 & 3.0 \\
\hline Turkey & 112 (2000) & .. & $13.2(82-90)$ & 10.1 & . & 10.0 \\
\hline United Kingdom & . & 2.7 & 3.7 & $5.9(90-97)$ & .. & $5.2(97-02)$ \\
\hline United States & 728 & 1.3 & 5.7 & 5.7 & 9.5 & 4.3 \\
\hline Average (24) ${ }^{a}$ & 380 & . & . & . & 5.6 & 4.4 \\
\hline Average $(\mathbf{1 3})^{b}$ & 419 & 2.8 & 3.3 & 4.7 & 6.2 & 4.8 \\
\hline
\end{tabular}

a) Excludes Belgium, New Zealand, Poland, Portugal, Turkey and the United Kingdom.

b) Includes Australia, Canada, Finland, France, Germany, Greece, Iceland, Ireland, Luxembourg, Netherlands, Norway, Sweden and United States.

Source: OECD Health Data 2005. 
Table A.3.11. Public share of total expenditure on pharmaceuticals, 1970 to 2003

\begin{tabular}{|c|c|c|c|c|c|c|}
\hline & 1970 & 1980 & 1990 & 2000 & 20 & 03 \\
\hline Australia & 45 (1969) & 44 & 45 & 57 & 52 & (2001) \\
\hline Austria & $\ldots$ & . & .. & 68 & 70 & \\
\hline Belgium & 59 & 57 & 47 & 45 (1997) & & \\
\hline Canada & 2 & 25 & 33 & 35 & 38 & \\
\hline Czech Republic & .. & . & 89 & 78 & 77 & \\
\hline Denmark & $\ldots$ & 50 & 34 & 49 & 49 & \\
\hline Finland & 34 & 47 & 47 & 50 & 54 & \\
\hline France & 67 & 67 & 62 & 65 & 67 & \\
\hline Germany $^{a}$ & 63 & 74 & 73 (1992) & 73 & 75 & \\
\hline Greece & 60 & 60 & 57 & 71 & 74 & \\
\hline Hungary & .. & . & 79 (1991) & 61 & 63 & (2002) \\
\hline Iceland & 43 & 51 & 82 & 61 & 58 & \\
\hline Ireland & 50 & 53 & 65 & 80 & 86 & \\
\hline Italy & . & .. & 63 & 44 & 49 & \\
\hline Japan & $\ldots$ & . & 61 & 66 & 68 & (2002) \\
\hline Korea & .. & 10 (1983) & 12 & 32 & 43 & \\
\hline Luxembourg & 84 & 86 & 85 & 82 & 83 & \\
\hline Mexico & $\ldots$ & . & . & 0 & 11 & \\
\hline Netherlands & 60 (1972) & 67 & 67 & 58 & 57 & \\
\hline New Zealand & 77 (1971) & 81 & 75 & 71 (1997) & & \\
\hline Norway & 36 & 42 & 79 & 58 & 59 & (2002) \\
\hline Poland & . & . & . & 38 & 41 & \\
\hline Portugal & 69 & 69 & 62 & 66 (1997) & & \\
\hline Slovak Republic & .. & . & .. & 83 & 83 & \\
\hline Spain & .. & 64 & 72 & 74 & 74 & \\
\hline Sweden & 63 & 72 & 72 & 69 & 70 & \\
\hline Switzerland & . & $\ldots$ & .. & 61 & 66 & \\
\hline Turkey & .. & 100 & 88 & 63 & .. & \\
\hline United Kingdom & 59 & 68 & 67 & 64 (1997) & & \\
\hline United States & 6 & 8 & 12 & 18 & 21 & \\
\hline Average (25) ${ }^{b}$ & $\ldots$ & $\ldots$ & $\ldots$ & 57 & 59 & \\
\hline Average (13) ${ }^{C}$ & 47 & 53 & 60 & 60 & 61 & \\
\hline
\end{tabular}

a) Data prior to 1990 refer to West Germany.

b) Excludes Belgium, New Zealand, Portugal, Turkey and United Kingdom.

c) Includes Australia, Canada, Finland, France, Germany, Greece, Iceland, Ireland, Luxembourg, Netherlands, Norway, Sweden and United States.

Source: OECD Health Data 2005. 
Table A.3.12. Health expenditure by source of funding, 2003 (total expenditure on health $=100$ )

\begin{tabular}{|c|c|c|c|c|c|c|c|c|c|c|c|c|}
\hline & \multicolumn{6}{|c|}{1990} & \multicolumn{6}{|c|}{2003} \\
\hline & \multirow[b]{2}{*}{$\begin{array}{c}\text { Total } \\
\text { public }\end{array}$} & \multicolumn{2}{|c|}{ of which: } & \multirow[b]{2}{*}{$\begin{array}{c}\text { Total } \\
\text { private }\end{array}$} & \multicolumn{2}{|c|}{ of which: } & \multirow[b]{2}{*}{$\begin{array}{c}\text { Total } \\
\text { public }\end{array}$} & \multicolumn{2}{|c|}{ of which: } & \multirow[b]{2}{*}{$\begin{array}{c}\text { Total } \\
\text { private }\end{array}$} & \multicolumn{2}{|c|}{ of which: } \\
\hline & & $\begin{array}{c}\text { General } \\
\text { government }\end{array}$ & $\begin{array}{c}\text { Social } \\
\text { security } \\
\text { schemes }\end{array}$ & & $\begin{array}{c}\text { Private } \\
\text { insurance }\end{array}$ & $\begin{array}{l}\text { Out-of- } \\
\text { pocket }\end{array}$ & & $\begin{array}{c}\text { General } \\
\text { government }\end{array}$ & $\begin{array}{l}\text { Social } \\
\text { security } \\
\text { schemes }\end{array}$ & & $\begin{array}{c}\text { Private } \\
\text { insurance }\end{array}$ & $\begin{array}{l}\text { Out-of- } \\
\text { pocket }\end{array}$ \\
\hline Australia (2001) & 67 & 67 & 0 & 33 & 11 & 17 & 68 & 68 & 0 & 33 & 8 & 21 \\
\hline Austria & 74 & $\ldots$ & $\ldots$ & 27 & 9 & $\ldots$ & 68 & 23 & 45 & 32 & 8 & 19 \\
\hline Belgium & $\ldots$ & $\ldots$ & . & $\ldots$ & . & $\ldots$ & 75 & $\ldots$ & $\ldots$ & 26 & $\ldots$ & $\ldots$ \\
\hline Canada & 75 & 74 & 1 & 26 & 8 & 14 & 70 & 69 & 2 & 30 & 13 & 15 \\
\hline Czech Republic & 95 & 18 & 77 & 5 & . & 5 & 90 & 13 & 77 & 10 & 0 & 8 \\
\hline Denmark & 83 & 83 & 0 & 17 & 1 & 16 & 83 & 83 & 0 & 17 & 1 & 16 \\
\hline Finland & 81 & 70 & 11 & 19 & 2 & 16 & 77 & 60 & 17 & 24 & 2 & 19 \\
\hline France & 77 & 2 & 74 & 23 & 11 & 11 & 76 & 3 & 74 & 24 & 13 & 10 \\
\hline Germany (2000) & 81 & 15 & 66 & 19 & 10 & 8 & 78 & 10 & 68 & 22 & 9 & 10 \\
\hline Greece & 54 & $\ldots$ & . & 46 & $\ldots$ & $\ldots$ & 51 & $\ldots$ & . & 49 & 2 & 47 \\
\hline Hungary (1992) & 89 & 16 & 73 & 11 & 0 & 11 & 72 & 12 & 60 & 28 & 1 & 25 \\
\hline Iceland & 87 & 53 & 34 & 13 & . & 13 & 84 & 53 & 31 & 17 & 0 & 17 \\
\hline Ireland & 72 & 71 & 1 & 28 & 9 & 17 & 78 & 77 & 1 & 22 & 6 & 13 \\
\hline Italy & 79 & 79 & 0 & 21 & 1 & 15 & 75 & 75 & 0 & 25 & 1 & 21 \\
\hline Japan (2002) & 78 & $\ldots$ & $\ldots$ & 22 & . & & 82 & 16 & 66 & 19 & 0 & 17 \\
\hline Korea & 37 & 10 & 27 & 63 & 1 & 59 & 49 & 9 & 40 & 51 & 2 & 42 \\
\hline Luxembourg & 93 & $\ldots$ & $\ldots$ & 7 & . & 6 & 90 & 12 & 79 & 10 & 1 & 7 \\
\hline Mexico & 40 & 8 & 33 & 60 & 1 & 58 & 46 & 15 & 31 & 54 & 3 & 51 \\
\hline Netherlands & 67 & 5 & 62 & 33 & . & & 62 & 4 & 58 & 38 & 17 & 8 \\
\hline New Zealand & 82 & 82 & 0 & 18 & 3 & 15 & 79 & 79 & 0 & 21 & 6 & 16 \\
\hline Norway & 83 & 83 & 0 & 17 & . & 15 & 84 & 68 & 15 & 16 & 0 & 16 \\
\hline Poland & 92 & 92 & 0 & 8 & . & 8 & 70 & 10 & 60 & 30 & 1 & 26 \\
\hline Portugal & 66 & . & . & 35 & 1 & $\ldots$ & 70 & . & . & 30 & . & $\ldots$ \\
\hline Slovak Republic & . & . & $\ldots$ & & $\ldots$ & $\ldots$ & 88 & 6 & 83 & 12 & 0 & 12 \\
\hline Spain(1991) & 78 & 56 & 22 & 22 & 3 & 19 & 71 & 66 & 5 & 29 & 4 & 24 \\
\hline Sweden & 90 & $\ldots$ & $\ldots$ & 10 & . & $\ldots$ & 85 & $\ldots$ & $\ldots$ & 15 & $\ldots$ & $\ldots$ \\
\hline Switzerland & 52 & 19 & 33 & 48 & 11 & 36 & 59 & 18 & 41 & 42 & 9 & 32 \\
\hline Turkey (2000) & 61 & $\ldots$ & . & 39 & 0 & 31 & 63 & 28 & 35 & 37 & 4 & 28 \\
\hline United Kingdom (2002) & 84 & 84 & 0 & 16 & 3 & 11 & 83 & 83 & 0 & 17 & $\ldots$ & . \\
\hline United States & 40 & 25 & 15 & 60 & 34 & 20 & 44 & 32 & 13 & 56 & 37 & 14 \\
\hline Average $(28)^{a}$ & 73 & & & 27 & & & 72 & & & 28 & & \\
\hline
\end{tabular}

Note: The sum of Private Insurance and Out-of-pocket may not equal Total Private due to Other private funds (not shown).

a) Excluding Belgium and Slovak Republic.

Source: OECD Health Data 2005. 
Table A.3.13. Out-of pocket spending as share of total health expenditure, private expenditure and final household consumption, 1990 and 2003

\begin{tabular}{|c|c|c|c|c|c|c|c|c|}
\hline & \multicolumn{4}{|c|}{1990} & \multicolumn{4}{|c|}{2003} \\
\hline & $\begin{array}{l}\text { Per capita } \\
\text { USD PPP }\end{array}$ & $\begin{array}{c}\% \text { total } \\
\text { expenditure on } \\
\text { health }\end{array}$ & $\begin{array}{c}\% \text { private } \\
\text { expenditure on } \\
\text { health }\end{array}$ & $\begin{array}{c}\% \text { final } \\
\text { household } \\
\text { consumption }\end{array}$ & $\begin{array}{l}\text { Per capita } \\
\text { USD PPP }\end{array}$ & $\begin{array}{l}\% \text { total } \\
\text { expenditure on } \\
\text { health }\end{array}$ & $\begin{array}{c}\% \text { private } \\
\text { expenditure on } \\
\text { health }\end{array}$ & $\begin{array}{c}\% \text { final } \\
\text { household } \\
\text { consumption }\end{array}$ \\
\hline Australia (2001) & 217 & 17 & 51 & 2.2 & 529 & 21 & 65 & 2.8 \\
\hline Austria & .. & . & . & .. & 441 & 19 & 59 & 2.7 \\
\hline Belgium & . & . & . & . & .. & . & . & . \\
\hline Canada & 251 & 14 & 57 & 2.4 & 448 & 15 & 50 & 2.7 \\
\hline Czech Republic & 14 & 3 & 100 & 0.2 & 108 & 8 & 85 & 1.3 \\
\hline Denmark & 251 & 16 & 93 & 2.8 & 436 & 16 & 93 & 3.1 \\
\hline Finland & 221 & 16 & 81 & 2.5 & 403 & 19 & 81 & 2.9 \\
\hline France & 179 & 11 & 49 & 1.8 & 291 & 10 & 42 & 1.8 \\
\hline Germany (1992) & 194 & 10 & 47 & 1.8 & 312 & 10 & 48 & 2.0 \\
\hline Greece & . & .. & . & .. & 935 & 47 & 95 & 6.9 \\
\hline Hungary & 64 & 11 & 100 & 1.4 & 312 & 25 & 89 & 3.9 \\
\hline Iceland & 216 & 13 & 100 & 1.9 & 513 & 17 & 100 & 3.2 \\
\hline Ireland & 131 & 17 & 59 & 1.8 & 327 & 13 & 61 & 2.3 \\
\hline Italy & 215 & 15 & 74 & 2.1 & 468 & 21 & 83 & 2.9 \\
\hline Japan (2002) & . & . & . & .. & 370 & 17 & 93 & 2.4 \\
\hline Korea & 221 & 59 & 93 & 5.4 & 450 & 42 & 83 & 4.4 \\
\hline Luxembourg & 85 & 6 & 80 & 0.7 & 260 & 7 & 70 & 1.2 \\
\hline Mexico & 171 & 58 & 98 & 4.0 & 294 & 51 & 94 & 4.5 \\
\hline Netherlands & . & .. & . . & .. & 233 & 8 & 21 & 1.6 \\
\hline New Zealand & 144 & 15 & 82 & 1.7 & 296 & 16 & 74 & 2.2 \\
\hline Norway & 203 & 15 & 85 & 2.4 & 591 & 16 & 95 & 3.6 \\
\hline Poland & 25 & 8 & 100 & 0.9 & 197 & 26 & 88 & 2.6 \\
\hline Portugal & . & . & . & .. & . & . & .. & . \\
\hline Slovak Republic & . & . & . & .. & 91 & 12 & 100 & 1.2 \\
\hline Spain (1991) & 179 & 19 & 83 & 2.4 & 434 & 24 & 82 & 3.2 \\
\hline Sweden & . & . & . & .. & .. & . & . & . \\
\hline Switzerland & 725 & 36 & 75 & 5.3 & 1192 & 32 & 76 & 6.2 \\
\hline Turkey (1993) & 59 & 31 & 95 & 4.8 & 105 & 20 & 70 & 2.3 \\
\hline United Kingdom & 105 & 11 & 65 & 1.1 & . & .. & .. & .. \\
\hline United States & 550 & 20 & 33 & 3.6 & 793 & 14 & 25 & 3.0 \\
\hline Average $(21)^{a}$ & 205 & 19 & 78 & 2.5 & 417 & 20 & 74 & 3.0 \\
\hline
\end{tabular}

a) Excludes Austria, Belgium, Greece, Japan, Netherlands, Portugal, Slovak Republic, Sweden and United Kingdom. Source: OECD Health Data 2005. 
Table A.4.1. Tobacco consumption, daily smokers, female, male and total population, 15 years and over, 1980 to 2003

\begin{tabular}{|c|c|c|c|c|c|c|c|c|c|c|}
\hline \multirow[b]{3}{*}{ Australia } & \multicolumn{3}{|c|}{1980} & \multicolumn{3}{|c|}{1990} & \multicolumn{4}{|c|}{2003} \\
\hline & \multirow{2}{*}{$\begin{array}{c}\text { Female } \\
31.1\end{array}$} & \multirow{2}{*}{$\begin{array}{l}\text { Male } \\
41.1\end{array}$} & Total & \multirow{2}{*}{$\begin{array}{c}\text { Female } \\
27.0\end{array}$} & \multirow{2}{*}{$\begin{array}{l}\text { Male } \\
30.2\end{array}$} & Total & \multirow{2}{*}{$\begin{array}{c}\text { Female } \\
18.2\end{array}$} & \multirow{2}{*}{$\begin{array}{l}\text { Male } \\
21.4\end{array}$} & \multicolumn{2}{|c|}{ Total } \\
\hline & & & 36.0 & & & 28.6 (1989) & & & 19.8 & (2001) \\
\hline Austria & . & . & $\ldots$ & . & . & $\ldots$ & . & . & . & \\
\hline Belgium & 28.4 & 52.6 & 40.5 (1982) & 26.0 & 38.0 & 32.0 & 25.0 & 30.0 & 27.0 & \\
\hline Canada & 28.9 & 36.7 & 32.8 (1981) & 26.7 & 29.8 & 28.2 & 14.0 & 19.0 & 17.0 & \\
\hline Czech Republic & $\ldots$ & $\ldots$ & $\ldots$ & 21.0 & 31.9 & 26.1 (1993) & 18.1 & 30.9 & 24.1 & (2002) \\
\hline Denmark & 44.0 & 57.0 & 50.5 & 42.0 & 47.0 & 44.5 & 25.0 & 31.0 & 28.0 & \\
\hline Finland & 16.6 & 35.2 & 26.1 & 20.0 & 32.4 & 25.9 & 19.3 & 25.7 & 22.2 & \\
\hline France & 16.0 & 44.0 & 30.0 & 21.0 & 39.0 & 30.0 & 22.0 & 32.0 & 27.0 & \\
\hline Germany & 21.2 & 48.4 & 34.8 (1978) & 17.0 & 30.8 & 23.7 (1992) & 19.1 & 29.8 & 24.3 & \\
\hline Greece & . & $\ldots$ & . & 26.0 & 51.0 & 38.5 & 27.0 & 44.0 & 35.0 & $(2000)$ \\
\hline Hungary & . & . & . & . & . & . & 27.8 & 40.5 & 33.8 & \\
\hline Iceland & $\ldots$ & $\ldots$ & $\ldots$ & 29.9 & 30.8 & 30.3 & 19.6 & 25.4 & 22.4 & \\
\hline Ireland & . & . & . & 29.0 & 31.0 & 30.0 & 26.0 & 28.0 & 27.0 & (2002) \\
\hline Italy & 16.7 & 54.3 & 35.5 & 17.8 & 37.8 & 27.8 & 17.6 & 31.4 & 24.2 & \\
\hline Japan & 14.4 & 70.2 & 42.3 & 14.3 & 60.5 & 37.4 & 13.6 & 48.3 & 30.3 & \\
\hline Korea & . & . & . & 6.4 & 65.7 & 34.6 (1989) & 5.4 & 61.8 & 30.4 & (2001) \\
\hline Luxembourg & . & . & . & 26.0 & 40.0 & 33.0 (1992) & 26.0 & 39.0 & 33.0 & \\
\hline Mexico & . & . & $\ldots$ & 14.4 & 38.3 & 25.8 (1988) & 16.1 & 39.1 & 26.4 & (2002) \\
\hline Netherlands & 34.0 & 52.0 & 43.0 & 32.0 & 43.0 & 37.0 & 28.0 & 36.0 & 32.0 & \\
\hline New Zealand & 29.0 & 35.0 & $32.0 \quad(1981)$ & 27.0 & 28.0 & 28.0 & 25.0 & 25.0 & 25.0 & \\
\hline Norway & 30.0 & 42.0 & 36.0 & 33.0 & 36.0 & 35.0 & 25.0 & 27.0 & 26.0 & \\
\hline Poland & . & . & . & 28.0 & 55.0 & 41.5 (1992) & 19.5 & 37.0 & 27.6 & (2001) \\
\hline Portugal & . & . & . & 5.1 & 33.6 & 19.0 (1987) & $\ldots$ & . & $\ldots$ & \\
\hline Slovak Republic & . & . & . & . & . & $\ldots$ & 22.5 & 25.5 & 24.3 & (2002) \\
\hline Spain & . & . & . & 21.4 & 51.5 & 35.9 (1989) & 22.4 & 34.2 & 28.1 & \\
\hline Sweden & 28.7 & 36.3 & 32.4 & 25.9 & 25.8 & 25.8 & 18.3 & 16.7 & 17.5 & \\
\hline Switzerland & . & $\cdots$ & $\cdots$ & 22.8 & 33.9 & 28.2 (1992) & 22.8 & 31.0 & 26.8 & (2002) \\
\hline Turkey & . & $\cdots$ & . & 24.3 & 62.8 & 43.6 (1989) & 17.8 & 51.1 & 32.1 & \\
\hline United Kingdom & 37.0 & 42.0 & 39.0 & 30.0 & 31.0 & 30.0 & 24.0 & 28.0 & 26.0 & \\
\hline United States & 29.3 & 37.6 & 33.5 & 22.8 & 28.4 & 25.6 & 15.7 & 19.4 & 17.5 & \\
\hline Latest average $^{a}$ & . & . & . & . & . & . & 20.7 & 32.4 & 26.2 & \\
\hline Consistent average $(15)^{b}$ & 27.0 & 45.6 & 36.3 & 25.5 & 35.8 & 30.6 & 20.7 & 28.0 & 24.3 & \\
\hline Median & 28.9 & 42.0 & 35.5 & 25.9 & 36.0 & 30.0 & 20.8 & 31.0 & 26.6 & \\
\hline
\end{tabular}

a) Average comprises all countries for which recent data is available (2000+).

b) Excludes Austria, Czech Republic, Greece, Hungary, Iceland, Ireland, Korea, Luxembourg, Mexico, Poland, Portugal, Slovak Republic, Spain, Switzerland and Turkey.

Source: OECD Health Data 2005. 
Table A.4.2. Alcohol consumption, litres per population aged 15 and over, 1960 to 2003

\begin{tabular}{|c|c|c|c|c|c|c|c|}
\hline & 1960 & 1970 & 1980 & 1990 & 2000 & 200 & 03 \\
\hline Australia & 9.4 & 11.6 & 12.9 & 10.5 & 10.1 & 9.8 & (2002) \\
\hline Austria & 10.9 & 13.9 & 13.8 & 12.6 & 11.1 & 11.1 & \\
\hline Belgium & 8.9 & 12.3 & 14.0 & 12.1 & 10.3 & 10.7 & \\
\hline Canada & 7.0 & 8.8 & 10.7 & 7.4 & 7.7 & 7.8 & (2002) \\
\hline Czech Republic & . & . & 11.8 & 11.3 & 11.8 & 12.1 & \\
\hline Denmark & 5.5 & 8.6 & 11.7 & 11.7 & 11.5 & 11.5 & \\
\hline Finland & 2.7 & 5.8 & 7.9 & 9.5 & 8.6 & 9.3 & \\
\hline France & . & 22.3 & 20.6 & 16.5 & 14.4 & 14.8 & (2002) \\
\hline Germany & 7.5 & 13.4 & $14.2(1982)$ & 13.8 & 10.5 & 10.2 & \\
\hline Greece & . & . & 13.2 & 10.7 & 9.5 & 9.2 & (2002) \\
\hline Hungary & 8.2 & 11.5 & 14.9 & 13.9 & 12.3 & 13.4 & (2002) \\
\hline Iceland & 2.5 (1961) & 3.8 & 4.3 & 5.2 & 6.1 & 6.5 & \\
\hline Ireland & 4.9 & 7.0 & 9.6 & 11.2 & 14.2 & 13.5 & \\
\hline Italy & 16.6 & 18.2 & 13.2 & 10.9 & 9.0 & 8.0 & \\
\hline Japan & 5.0 (1963) & 6.1 & 7.1 & 8.0 & 7.6 & 7.6 & \\
\hline Korea & $\ldots$ & . & $\ldots$ & 9.1 & 8.9 & 9.3 & \\
\hline Luxembourg $^{a}$ & 13.1 & 15.6 & 16.8 (1979) & 14.7 & 15.4 & 15.5 & \\
\hline Mexico & . & . & 3.4 & 4.9 & 4.8 & 4.6 & \\
\hline Netherlands & 3.7 & 7.7 & 11.3 & 9.9 & 10.1 & 9.7 & \\
\hline New Zealand & 5.3 & 9.8 & 11.8 & 10.1 & 8.9 & 8.9 & \\
\hline Norway & 3.4 & 4.7 & 5.3 & 5.0 & 5.7 & 6.0 & \\
\hline Poland & 6.3 (1961) & $8.0(1971)$ & 8.7 (1981) & 8.3 & 8.3 & 8.1 & \\
\hline Portugal & 17.2 (1961) & 17.9 (1969) & 14.8 & 16.3 & 12.9 & 11.4 & \\
\hline Slovak Republic & 6.9 & 12.8 & 14.5 & 13.4 & 8.9 & 7.6 & \\
\hline Spain & 14.6 (1962) & 16.1 & 18.4 & 13.5 & 11.5 & 11.7 & \\
\hline Sweden & 4.8 & 7.2 & 6.7 & 6.4 & 6.2 & 7.0 & \\
\hline Switzerland & 12.1 & 14.2 & 13.5 & 12.9 & 11.2 & 10.8 & \\
\hline Turkey & 0.9 & 1.1 & 1.8 & 1.4 & 1.5 & 1.5 & \\
\hline United Kingdom & . & 7.1 & 9.4 & 9.8 & 10.4 & 11.2 & \\
\hline United States & 7.8 & 9.5 & 10.5 & 9.3 & 8.3 & 8.3 & (2002) \\
\hline Latest average $^{b}$ & . & . & . & . & . & 9.6 & \\
\hline Consistent average $(26)^{c}$ & $\cdots$ & 10.6 & 11.5 & 10.6 & 9.7 & 9.7 & \\
\hline Median & 7.0 & 9.7 & 11.8 & 10.6 & 9.8 & 9.5 & \\
\hline
\end{tabular}

a) In Luxembourg, national sales do not accurately reflect consumption by residents, due to significant levels of consumption by tourists and cross-border traffic of alcoholic beverages.

b) Average consists of the latest available data for all OECD countries.

c) Excludes Czech Republic, Greece, Korea and Mexico.

Source: OECD Health Data 2005. 
Table A.4.3. Total calories consumption per capita, per day, 1961 to 2002

\begin{tabular}{|c|c|c|c|c|c|c|}
\hline & 1961 & 1970 & 1980 & 1990 & 2000 & 2002 \\
\hline Australia $^{a}$ & 3082 & 3243 & 3057 & 3256 & 3088 & 3054 \\
\hline Austria & 3190 & 3232 & 3354 & 3485 & 3761 & 3673 \\
\hline Belgium $^{b}$ & 2942 & 3095 & 3300 & 3533 & 3589 & 3584 \\
\hline Canada & 2819 & 2936 & 2946 & 3017 & 3547 & 3589 \\
\hline Czech Republic & .. & . & . & . & 3065 & 3171 \\
\hline Denmark & 3187 & 3158 & 3127 & 3168 & 3390 & 3439 \\
\hline Finland & 3271 & 3195 & 3124 & 3184 & 3112 & 3100 \\
\hline France & 3194 & 3301 & 3376 & 3512 & 3601 & 3654 \\
\hline Germany & 2889 & 3148 & 3340 & 3310 & 3433 & 3496 \\
\hline Greece & 2820 & 3135 & 3216 & 3524 & 3648 & 3721 \\
\hline Hungary & 3083 & 3330 & 3494 & 3711 & 3487 & 3483 \\
\hline Iceland & 3256 & 3017 & 3252 & 3056 & 3203 & 3249 \\
\hline Ireland & 3352 & 3443 & 3661 & 3645 & 3693 & 3656 \\
\hline Italy & 2914 & 3422 & 3590 & 3591 & 3701 & 3671 \\
\hline Japan & 2468 & 2715 & 2721 & 2823 & 2800 & 2761 \\
\hline Korea & 2147 & 2772 & 2971 & 3035 & 3063 & 3058 \\
\hline Luxembourg & .. & . & .. & . & .. & . \\
\hline Mexico & 2412 & 2660 & 3123 & 3074 & 3161 & 3145 \\
\hline Netherlands & 3058 & 3022 & 3071 & 3289 & 3374 & 3362 \\
\hline New Zealand ${ }^{a}$ & 2917 & 2967 & 3123 & 3259 & 3228 & 3219 \\
\hline Norway & 3004 & 3022 & 3351 & 3144 & 3364 & 3484 \\
\hline Poland & 3282 & 3430 & 3597 & 3343 & 3382 & 3375 \\
\hline Portugal & 2473 & 3002 & 2786 & 3441 & 3751 & 3741 \\
\hline Slovak Republic & .. & .. & .. & . & 2869 & 2889 \\
\hline Spain & 2632 & 2733 & 3063 & 3248 & 3370 & 3371 \\
\hline Sweden & 2836 & 2877 & 2992 & 2975 & 3089 & 3185 \\
\hline Switzerland & 3521 & 3478 & 3491 & 3346 & 3441 & 3526 \\
\hline Turkey & 2881 & 3017 & 3281 & 3539 & 3372 & 3357 \\
\hline United Kingdom & 3290 & 3327 & 3160 & 3267 & 3358 & 3412 \\
\hline United States & 2883 & 3026 & 3155 & 3472 & 3814 & 3774 \\
\hline Latest average $^{C}$ & . & .. & . & . & . & 3386 \\
\hline Consistent average (27) ${ }^{d}$ & 2956 & 3100 & 3212 & 3305 & 3401 & 3413 \\
\hline Median & 2942 & 3095 & 3160 & 3289 & 3374 & 3412 \\
\hline
\end{tabular}

a) Data for Australia and New Zealand are not directly comparable with those from other countries because of the use of a different set of conversion factors, resulting in an under-estimation of about $10 \%$.

b) Belgium includes Luxembourg for 1961, 1970, 1980 and 1990.

c) Average comprises all countries for which recent data is available.

d) Excludes Czech Republic, Luxembourg and Slovak Republic.

Source: OECD Health Data 2005. (The data come from the FAOSTAT Nutrition database. They refer to food available for consumption rather than food actually consumed.) 
Table A.4.4. Sugar consumption per capita, kilos per year, 1961 to 2002

\begin{tabular}{|c|c|c|c|c|c|c|}
\hline & 1961 & 1970 & 1980 & 1990 & 2000 & 2002 \\
\hline Australia & 56.2 & 57.0 & 56.1 & 50.5 & 45.0 & 48.2 \\
\hline Austria & 40.9 & 41.3 & 45.9 & 43.4 & 46.0 & 45.4 \\
\hline Belgium $^{a}$ & 27.7 & 37.1 & 38.0 & 44.9 & 54.3 & 54.3 \\
\hline Canada & 45.4 & 48.6 & 42.7 & 42.3 & 52.8 & 60.6 \\
\hline Czech Republic & .. & .. & .. & .. & 45.3 & 44.1 \\
\hline Denmark & 51.4 & 54.4 & 47.5 & 44.6 & 53.8 & 54.3 \\
\hline Finland & 45.2 & 50.9 & 38.2 & 42.4 & 38.4 & 33.2 \\
\hline France & 30.5 & 39.8 & 33.3 & 36.1 & 39.8 & 40.0 \\
\hline Germany & 34.7 & 39.1 & 43.4 & 35.7 & 42.6 & 44.2 \\
\hline Greece & 15.3 & 22.1 & 26.8 & 31.9 & 33.2 & 34.5 \\
\hline Hungary & 30.2 & 36.7 & 45.0 & 46.4 & 46.9 & 45.1 \\
\hline Iceland & 59.6 & 56.5 & 55.8 & 55.8 & 58.0 & 56.9 \\
\hline Ireland & 53.2 & 55.2 & 49.3 & 47.7 & 42.1 & 42.4 \\
\hline Italy & 24.7 & 30.5 & 35.0 & 30.4 & 31.7 & 31.2 \\
\hline Japan & 17.7 & 34.8 & 33.2 & 33.8 & 28.3 & 29.4 \\
\hline Korea & 1.9 & 7.5 & 15.5 & 32.5 & 34.8 & 37.7 \\
\hline Luxembourg & .. & .. & .. & .. & .. & . \\
\hline Mexico & 26.3 & 38.0 & 47.3 & 53.4 & 49.0 & 49.6 \\
\hline Netherlands & 47.0 & 49.4 & 45.2 & 56.1 & 46.0 & 49.4 \\
\hline New Zealand & 49.1 & 49.9 & 46.7 & 52.5 & 58.5 & 59.1 \\
\hline Norway & 45.4 & 44.7 & 42.3 & 41.3 & 46.1 & 44.8 \\
\hline Poland & 32.5 & 41.6 & 45.1 & 48.1 & 45.1 & 45.2 \\
\hline Portugal & 18.8 & 27.2 & 27.3 & 30.6 & 34.2 & 35.0 \\
\hline Slovak Republic & .. & .. & .. & .. & 36.1 & 32.2 \\
\hline Spain & 20.5 & 29.1 & 30.5 & 27.6 & 34.1 & 34.2 \\
\hline Sweden & 46.2 & 45.6 & 44.8 & 43.1 & 46.7 & 46.3 \\
\hline Switzerland & 52.8 & 53.2 & 46.2 & 49.8 & 56.9 & 58.6 \\
\hline Turkey & 6.9 & 18.7 & 24.3 & 30.5 & 28.4 & 25.8 \\
\hline United Kingdom & 52.7 & 50.0 & 43.9 & 42.1 & 37.5 & 43.7 \\
\hline United States & 52.1 & 56.9 & 57.2 & 63.0 & 71.8 & 71.9 \\
\hline Latest average $^{b}$ & $\ldots$ & . & .. & . & .. & 44.7 \\
\hline Consistent average (27) ${ }^{c}$ & 36.5 & 41.3 & 41.0 & 42.8 & 44.5 & 45.2 \\
\hline Median & 40.9 & 41.6 & 43.9 & 43.1 & 45.1 & 44.8 \\
\hline
\end{tabular}

a) Belgium includes Luxembourg for 1961, 1970, 1980 and 1990.

b) Average comprises all countries for which recent data is available.

c) Excludes Czech Republic, Luxembourg and Slovak Republic.

Source: OECD Health Data 2005. (The data come from the FAOSTAT Nutrition database. They refer to food available for consumption rather than food actually consumed.) 
Table A.4.5. Fruits and vegetables consumption per capita, kilos per year, 1961 to 2002

\begin{tabular}{|c|c|c|c|c|c|c|}
\hline & 1961 & 1970 & 1980 & 1990 & 2000 & 2002 \\
\hline Australia & 139.2 & 155.3 & 159.3 & 179.5 & 189.7 & 185.6 \\
\hline Austria & 200.8 & 182.3 & 210.5 & 206.7 & 209.4 & 225.1 \\
\hline Belgium $^{a}$ & 143.3 & 169.6 & 159.1 & 216.7 & 195.6 & 192.0 \\
\hline Canada & 177.0 & 166.8 & 213.2 & 229.2 & 245.4 & 250.5 \\
\hline Czech Republic & . & . & . & . & 145.3 & 142.0 \\
\hline Finland & 60.1 & 71.6 & 123.9 & 134.8 & 152.2 & 166.9 \\
\hline France & 203.8 & 218.6 & 178.3 & 207.2 & 240.8 & 237.8 \\
\hline Germany & 129.1 & 168.7 & 172.0 & 192.4 & 216.7 & 206.1 \\
\hline Greece & 247.9 & 349.6 & 363.1 & 424.5 & 447.4 & 412.5 \\
\hline Hungary & 148.2 & 163.0 & 162.3 & 161.0 & 200.9 & 176.3 \\
\hline Iceland & 50.9 & 63.8 & 87.1 & 112.5 & 150.2 & 167.7 \\
\hline Italy & 226.4 & 298.8 & 281.5 & 301.5 & 331.1 & 282.2 \\
\hline Japan & 124.3 & 179.5 & 176.8 & 165.1 & 162.6 & 162.8 \\
\hline Korea & 81.1 & 114.5 & 217.2 & 248.4 & 300.0 & 276.0 \\
\hline Luxembourg & . & . & $\ldots$ & . & $\ldots$ & . \\
\hline Mexico & 83.3 & 99.3 & 136.5 & 144.5 & 169.9 & 170.4 \\
\hline Netherlands & 139.2 & 179.3 & 175.4 & 214.6 & 213.8 & 228.5 \\
\hline New Zealand & 146.6 & 153.4 & 178.7 & 205.2 & 249.3 & 253.4 \\
\hline Norway & 110.3 & 128.3 & 146.8 & 155.7 & 166.1 & 182.6 \\
\hline Poland & 109.4 & 141.0 & 142.4 & 152.3 & 175.4 & 147.3 \\
\hline Portugal & 173.6 & 201.5 & 159.6 & 281.3 & 303.0 & 313.4 \\
\hline Slovak Republic & . & $\ldots$ & . & $\ldots$ & 147.4 & 124.3 \\
\hline Spain & 214.0 & 215.6 & 266.0 & 326.0 & 268.5 & 266.2 \\
\hline Sweden & 96.3 & 124.8 & 128.1 & 162.5 & 171.2 & 186.5 \\
\hline United Kingdom & 116.0 & 138.7 & 138.4 & 165.8 & 169.5 & 189.5 \\
\hline United States & 170.5 & 183.1 & 211.5 & 235.0 & 253.9 & 238.0 \\
\hline Latest average $^{b}$ & $\ldots$ & $\ldots$ & . & $\ldots$ & . & 218.4 \\
\hline Consistent average (27) ${ }^{C}$ & 146.0 & 170.5 & 184.7 & 209.3 & 224.7 & 224.7 \\
\hline Median & 139.2 & 166.8 & 172.0 & 205.2 & 200.7 & 192.0 \\
\hline
\end{tabular}

a) Belgium includes Luxembourg for 1961, 1970, 1980 and 1990.

b) Average comprises all countries for which recent data is available.

c) Excludes Czech Republic, Luxembourg and Slovak Republic.

Source: OECD Health Data 2005. (The data come from the FAOSTAT Nutrition database. They refer to food available for consumption rather than food actually consumed.) 
Table A.4.6. Overweight or obesity rate, population aged $15+$, latest year available

\begin{tabular}{|c|c|c|c|c|c|c|c|c|c|c|}
\hline & & \multicolumn{3}{|c|}{$\begin{array}{l}\text { Overweight population } \\
25<\mathrm{BMI}<30\end{array}$} & \multicolumn{3}{|c|}{$\begin{array}{l}\text { Obese population } \\
\quad \text { BMI }>30\end{array}$} & \multicolumn{3}{|c|}{$\begin{array}{l}\text { Overweight and obese pop. } \\
\qquad \text { BMI > } 25\end{array}$} \\
\hline & & Females & Males & Total & Females & Males & Total & Females & Males & Total \\
\hline Australia $^{a}$ & 1999 & 28.2 & 45.3 & 36.7 & 21.4 & 21.9 & 21.7 & 49.6 & 67.2 & 58.4 \\
\hline Austria & 1999 & 21.3 & 54.3 & 37.0 & 9.1 & 9.1 & 9.1 & 30.4 & 63.4 & 46.1 \\
\hline Belgium & 2001 & 25.7 & 39.8 & 32.7 & 12.2 & 11.1 & 11.7 & 37.9 & 50.9 & 44.4 \\
\hline Canada & 2003 & 24.8 & 39.6 & 32.1 & 13.3 & 15.4 & 14.3 & 38.2 & 54.9 & 46.5 \\
\hline Czech Republic & 2002 & 30.7 & 42.5 & 36.2 & 16.1 & 13.4 & 14.8 & 46.7 & 55.9 & 51.1 \\
\hline Denmark & 2000 & 24.9 & 39.8 & 32.3 & 9.1 & 9.8 & 9.5 & 34.0 & 49.6 & 41.7 \\
\hline Finland & 2003 & 26.2 & 39.5 & 32.2 & 11.7 & 14.0 & 12.8 & 37.9 & 53.5 & 45.0 \\
\hline France & 2002 & 22.3 & 34.0 & 28.1 & 9.1 & 9.7 & 9.4 & 31.3 & 43.6 & 37.5 \\
\hline Germany & 2003 & 28.9 & 44.1 & 36.3 & 12.3 & 13.6 & 12.9 & 41.2 & 57.7 & 49.2 \\
\hline Greece & 2003 & 29.9 & 41.1 & 35.2 & 18.2 & 26.0 & 21.9 & 48.1 & 67.1 & 57.1 \\
\hline Hungary & 2003 & 29.8 & 38.7 & 34.0 & 18.0 & 19.6 & 18.8 & 47.8 & 58.3 & 52.8 \\
\hline Iceland & 2002 & 28.0 & 44.7 & 35.9 & 12.4 & 12.4 & 12.4 & 40.4 & 57.1 & 48.8 \\
\hline Ireland & 2002 & 25.0 & 41.0 & 34.0 & 12.0 & 14.0 & 13.0 & 37.0 & 55.0 & 47.0 \\
\hline Italy & 2002 & 25.4 & 42.2 & 33.5 & 8.3 & 8.8 & 8.5 & 33.7 & 51.0 & 42.0 \\
\hline Japan & 2003 & 18.7 & 25.2 & 21.6 & 3.7 & 2.6 & 3.2 & 22.4 & 27.8 & 24.9 \\
\hline Korea & 2001 & 25.9 & 29.6 & 27.4 & 3.5 & 2.8 & 3.2 & 29.4 & 32.4 & 30.6 \\
\hline Luxembourg & 2003 & 25.2 & 40.5 & 34.4 & 18.2 & 18.6 & 18.4 & 43.4 & 59.1 & 52.8 \\
\hline Mexico & 2000 & 35.8 & 40.6 & 38.1 & 28.6 & 19.2 & 24.2 & 64.4 & 59.8 & 62.3 \\
\hline Netherlands & 2002 & 28.0 & 42.0 & 35.0 & 11.0 & 9.0 & 10.0 & 39.0 & 51.0 & 45.0 \\
\hline New Zealand ${ }^{a}$ & 2003 & 28.4 & 42.1 & 35.2 & 21.7 & 20.1 & 20.9 & 50.2 & 62.2 & 56.2 \\
\hline Norway & 2002 & 27.0 & 41.7 & 34.4 & 8.2 & 8.4 & 8.3 & 35.2 & 50.1 & 42.7 \\
\hline Poland & 1996 & 26.5 & 37.5 & 31.7 & 12.4 & 10.3 & 11.4 & 38.8 & 47.8 & 43.1 \\
\hline Portugal & 1999 & 31.8 & 42.3 & 36.8 & 14.0 & 11.4 & 12.8 & 45.8 & 53.7 & 49.6 \\
\hline Slovak Republic & 2002 & 27.9 & 43.9 & 35.2 & 25.4 & 18.8 & 22.4 & 53.3 & 62.7 & 57.6 \\
\hline Spain & 2003 & 27.6 & 43.5 & 35.3 & 13.4 & 12.9 & 13.1 & 41.0 & 56.4 & 48.4 \\
\hline Sweden & 2003 & 26.8 & 39.4 & 33.1 & 9.4 & 10.0 & 9.7 & 36.2 & 49.4 & 42.8 \\
\hline Switzerland & 2002 & 21.8 & 37.5 & 29.4 & 7.5 & 7.9 & 7.7 & 29.3 & 45.4 & 37.1 \\
\hline Turkey & 2003 & 28.9 & 33.6 & 31.6 & 14.5 & 9.7 & 12.0 & 43.4 & 43.3 & 43.4 \\
\hline United Kingdom ${ }^{a}$ & 2003 & 33.4 & 44.4 & 39.0 & 23.4 & 22.9 & 23.0 & 56.8 & 67.3 & 62.0 \\
\hline United States $^{a}$ & 2002 & 28.1 & 42.2 & 35.1 & 33.3 & 27.8 & 30.6 & 61.4 & 70.0 & 65.7 \\
\hline
\end{tabular}

Note: Obesity rates are defined as the percentage of the population with a Body Mass Index (BMI) over 30. Overweight rates are defined as the percentage of the population with a BMI between 25 and 30. The BMI is a single number that evaluates an individual's weight status in relation to height (weight/height ${ }^{2}$, with weight in kilograms and height in metres).

a) For Australia, New Zealand, the United Kingdom and the United States, figures are based on health examinations, rather than selfreported information. Obesity estimates derived from health examinations are generally higher and more reliable than those coming from self-reports, because they preclude any misreporting of people's height and weight. However, health examinations are only conducted regularly in a few countries.

Source: OECD Health Data 2005. 
Table A.5.1. Total population, mid-year, thousands, 1960 to 2003

\begin{tabular}{|c|c|c|c|c|c|c|}
\hline & 1960 & 1970 & 1980 & 1990 & 2000 & 2003 \\
\hline Australia & 10275 & 12507 & 14695 & 17065 & 19153 & 19873 \\
\hline Austria & 7048 & 7467 & 7549 & 7678 & 8012 & 8121 \\
\hline Belgium & 9153 & 9656 & 9859 & 9967 & 10251 & 10376 \\
\hline Canada & 18180 & 21682 & 24516 & 27701 & 30689 & 31660 \\
\hline Czech Republic & 9602 & 9858 & 10304 & 10333 & 10272 & 10207 \\
\hline Finland & 4430 & 4606 & 4780 & 4986 & 5176 & 5220 \\
\hline France & 45684 & 50772 & 53880 & 56709 & 58896 & 59768 \\
\hline Germany $^{a}$ & 55433 & 60651 & 61566 & 63254 & 82212 & 82534 \\
\hline Greece & 8332 & 8793 & 9643 & 10157 & 10917 & 11006 \\
\hline Hungary & 9984 & 10337 & 10707 & 10374 & 10211 & 10130 \\
\hline Iceland & 177 & 204 & 228 & 255 & 281 & 290 \\
\hline Italy & 50200 & 53822 & 56434 & 56719 & 56949 & 57605 \\
\hline Japan & 94302 & 104665 & 117060 & 123611 & 126926 & 127650 \\
\hline Korea & 25012 & 32241 & 38124 & 42869 & 47008 & 47849 \\
\hline Luxembourg & 314 & 339 & 364 & 382 & 436 & 450 \\
\hline Mexico & 38579 & 52775 & 68348 & 84914 & 99927 & 103718 \\
\hline Netherlands & 11487 & 13039 & 14150 & 14952 & 15926 & 16225 \\
\hline New Zealand & 2377 & 2820 & 3144 & 3363 & 3859 & 4009 \\
\hline Norway & 3581 & 3876 & 4086 & 4241 & 4491 & 4565 \\
\hline Poland & 29637 & 32664 & 35574 & 38111 & 38454 & 38205 \\
\hline Portugal & 8858 & 8680 & 9766 & 9945 & 10226 & 10441 \\
\hline Slovak Republic & 4068 & 4538 & 4980 & 5299 & 5389 & 5380 \\
\hline Spain & 30455 & 33753 & 37439 & 38850 & 40169 & 41874 \\
\hline Sweden & 7485 & 8043 & 8310 & 8559 & 8872 & 8958 \\
\hline Turkey & 27368 & 35162 & 44484 & 56124 & 67417 & 70713 \\
\hline United Kingdom & 52377 & 55663 & 56313 & 57572 & 59743 & 59554 \\
\hline United States & 180671 & 205052 & 227727 & 249623 & 282178 & 290810 \\
\hline Total OECD & 757806 & 857732 & 948885 & 1028984 & 1130369 & 1153917 \\
\hline
\end{tabular}

a) Data prior to 1991 refer to West Germany.

Source: OECD Health Data 2005. 
Table A.5.2. Share of the population aged 65 and over, 1960 to 2003

\begin{tabular}{|c|c|c|c|c|c|c|}
\hline & 1960 & 1970 & 1980 & 1990 & 2000 & 2003 \\
\hline Australia & 8.5 & 8.3 & 9.6 & 11.1 & 12.4 & 12.8 \\
\hline Austria & 12.2 & 14.1 & 15.4 & 14.9 & 15.4 & 15.5 \\
\hline Belgium & 12.0 & 13.4 & 14.3 & 14.9 & 16.8 & 17.1 \\
\hline Canada & 7.5 & 7.9 & 9.4 & 11.3 & 12.6 & 12.8 \\
\hline Czech Republic & $\ldots$ & . & 13.5 & 12.6 & 13.8 & 13.9 \\
\hline Denmark & 10.6 & 12.3 & 14.4 & 15.6 & 14.8 & 14.9 \\
\hline Finland & 7.3 & 9.1 & 12.0 & 13.4 & 14.9 & 15.6 \\
\hline France & 11.6 & 12.9 & 13.9 & 14.0 & 16.1 & 16.3 \\
\hline Germany $^{a}$ & . & . & . & 15.0 & 16.4 & 17.7 \\
\hline Greece & 8.1 & 11.1 & 13.1 & 13.8 & 16.6 & 17.4 \\
\hline Hungary & 9.0 & 11.6 & 13.4 & 13.4 & 15.1 & 15.4 \\
\hline Iceland & 8.2 & 8.8 & 10.1 & 10.6 & 11.7 & 11.7 \\
\hline Ireland & 11.1 & 11.1 & 10.7 & 11.4 & 11.2 & 11.1 \\
\hline Italy & 9.3 & 10.9 & 13.1 & 14.9 & 18.3 & 19.1 \\
\hline Japan & 5.7 & 7.1 & 9.1 & 12.1 & 17.4 & 19.0 \\
\hline Korea & . & . & . & . & 7.2 & 8.3 \\
\hline Luxembourg & $\ldots$ & 12.6 & 13.7 & 13.4 & 14.0 & 14.0 \\
\hline Mexico & . & . & 3.8 & 4.0 & 4.9 & 5.3 \\
\hline Netherlands & 9.0 & 10.2 & 11.5 & 12.8 & 13.6 & 13.8 \\
\hline New Zealand & . & . & . & 11.2 & 11.7 & 11.9 \\
\hline Norway & 11.0 & 12.9 & 14.8 & 16.3 & 15.2 & 14.8 \\
\hline Poland & 5.9 & 8.4 & 10.1 & 10.1 & 12.2 & 12.9 \\
\hline Portugal & 7.9 & 9.4 & 11.3 & 13.4 & 16.2 & 16.7 \\
\hline Slovak Republic & 6.8 & 9.1 & 10.5 & 10.2 & 11.4 & 11.5 \\
\hline Spain & & 9.6 & 11.0 & 13.6 & 16.8 & 16.9 \\
\hline Sweden & 11.7 & 13.7 & 16.3 & 17.8 & 17.3 & 17.2 \\
\hline Switzerland & 10.2 & 11.4 & 13.8 & 14.6 & 15.3 & 15.7 \\
\hline Turkey & . & . & . & . & . & 3.9 \\
\hline United Kingdom & 11.7 & 12.8 & 14.9 & 15.6 & 15.6 & 16.0 \\
\hline United States & 9.2 & 9.8 & 11.3 & 12.5 & 12.4 & 12.4 \\
\hline Latest average $^{b}$ & $\ldots$ & . & $\ldots$ & . & . & 14.1 \\
\hline Consistent average $(24)^{C}$ & . & 10.8 & 12.4 & 13.4 & 14.7 & 15.0 \\
\hline Median & 9.1 & 11.0 & 12.6 & 13.4 & 14.9 & 14.9 \\
\hline
\end{tabular}

a) 1990 data for Germany refers to 1991

b) Average of the latest available data for all 30 OECD countries.

c) Excludes Czech Republic, Germany, Korea, Mexico, New Zealand and Turkey.

Source: OECD Health Data 2005. 
Table A.5.3. Share of the population aged 80 and over, 1960 to 2003

\begin{tabular}{|c|c|c|c|c|c|c|}
\hline & 1960 & 1970 & 1980 & 1990 & 2000 & 2003 \\
\hline Australia & 1.2 & 1.4 & 1.7 & 2.2 & 2.9 & 3.3 \\
\hline Austria & 1.8 & 2.1 & 2.7 & 3.6 & 3.5 & 4.0 \\
\hline Belgium & 1.8 & 2.1 & 2.6 & 3.5 & 3.6 & 4.0 \\
\hline Canada & 1.2 & 1.5 & 1.8 & 2.3 & 2.9 & 3.3 \\
\hline Czech Republic & .. & .. & 1.9 & 2.5 & 2.4 & 2.8 \\
\hline Denmark & 1.6 & 2.0 & 2.8 & 3.7 & 4.0 & 4.0 \\
\hline Finland & 0.9 & 1.1 & 1.8 & 2.8 & 3.4 & 3.7 \\
\hline France & 2.0 & 2.3 & 2.8 & 3.7 & 3.7 & 4.3 \\
\hline Germany $^{a}$ & .. & .. & .. & 3.8 & 3.7 & 4.1 \\
\hline Greece & 1.3 & 2.0 & 2.3 & 3.0 & 3.1 & 3.2 \\
\hline Hungary & 1.1 & 1.5 & 2.0 & 2.5 & 2.6 & 3.2 \\
\hline Iceland & 1.6 & 1.5 & 2.2 & 2.4 & 2.8 & 3.1 \\
\hline Ireland & 1.9 & 2.0 & 1.8 & 2.2 & 2.5 & 2.6 \\
\hline Italy & 1.4 & 1.8 & 2.1 & 3.2 & 4.0 & 4.7 \\
\hline Japan & 0.7 & 0.9 & 1.4 & 2.4 & 3.8 & 4.4 \\
\hline Korea & .. & .. & .. & .. & 1.0 & 1.2 \\
\hline Luxembourg & .. & 1.8 & 2.2 & 3.1 & 3.0 & 3.1 \\
\hline Mexico & .. & .. & 0.8 & 0.8 & 1.0 & 1.1 \\
\hline Netherlands & 1.4 & 1.7 & 2.2 & 2.9 & 3.2 & 3.4 \\
\hline New Zealand & .. & .. & .. & 2.3 & 2.8 & 3.0 \\
\hline Norway & 2.0 & 2.2 & 2.9 & 3.7 & 4.3 & 4.5 \\
\hline Poland & 0.7 & 1.0 & 1.4 & 2.0 & 2.0 & 2.3 \\
\hline Portugal & 1.1 & 1.4 & 1.6 & 2.5 & 3.3 & 3.6 \\
\hline Slovak Republic & 1.0 & 1.1 & 1.5 & 2.0 & 1.9 & 2.2 \\
\hline Spain & .. & 1.5 & 1.8 & 2.9 & 3.8 & 4.1 \\
\hline Sweden & 1.9 & 2.3 & 3.1 & 4.3 & 5.0 & 5.3 \\
\hline Switzerland & 1.5 & 1.7 & 2.6 & 3.7 & 4.0 & 4.3 \\
\hline Turkey & .. & .. & .. & .. & .. & .. \\
\hline United Kingdom & 1.9 & 2.2 & 2.7 & 3.6 & 4.0 & 4.3 \\
\hline United States & 1.4 & 1.8 & 2.3 & 2.8 & 3.3 & 3.5 \\
\hline Latest average $^{b}$ & . & .. & . & . & . & 3.5 \\
\hline Consistent average $(24)^{C}$ & . & 1.7 & 2.2 & 3.0 & 3.4 & 3.7 \\
\hline Median & 1.4 & 1.8 & 2.2 & 2.9 & 3.3 & 3.5 \\
\hline
\end{tabular}

a) 1990 data for Germany refers to 1991 .

b) Average comprises all countries for which 2003 data is available.

c) Excludes Czech Republic, Germany, Korea, Mexico, New Zealand and Turkey.

Source: OECD Health Data 2005. 
Table A.5.4. Total fertility rate, number of children per woman aged 15-49, 1960 to 2003

\begin{tabular}{|c|c|c|c|c|c|c|c|}
\hline & 1960 & 1970 & 1980 & 1990 & 2000 & \multicolumn{2}{|c|}{2003} \\
\hline Australia & 3.5 & 2.9 & 1.9 & 1.9 & 1.8 & 1.8 & (2002) \\
\hline Austria & 2.7 & 2.3 & 1.7 & 1.5 & 1.4 & 1.4 & \\
\hline Belgium & 2.6 & 2.3 & 1.7 & 1.6 & 1.7 & 1.6 & \\
\hline Canada & 3.9 & 2.3 & 1.7 & 1.7 & 1.5 & 1.5 & (2002) \\
\hline Czech Republic & 2.1 & 1.9 & 2.1 & 1.9 & 1.1 & 1.2 & \\
\hline Denmark & 2.6 & 2.0 & 1.6 & 1.7 & 1.8 & 1.8 & \\
\hline Finland & 2.7 & 1.8 & 1.6 & 1.8 & 1.7 & 1.8 & \\
\hline France & 2.7 & 2.5 & 2.0 & 1.8 & 1.9 & 1.9 & \\
\hline Germany & 2.4 & 2.0 & 1.6 & 1.5 & 1.4 & 1.3 & \\
\hline Greece & 2.3 & 2.4 & 2.2 & 1.4 & 1.3 & 1.3 & \\
\hline Hungary & 2.0 & 2.0 & 1.9 & 1.9 & 1.3 & 1.3 & \\
\hline Iceland & 4.2 & 2.8 & 2.5 & 2.3 & 2.1 & 2.0 & \\
\hline Ireland & 3.8 & 3.9 & 3.3 & 2.1 & 1.9 & 2.0 & \\
\hline Italy & 2.4 & 2.4 & 1.6 & 1.3 & 1.2 & 1.3 & \\
\hline Japan & 2.0 & 2.1 & 1.8 & 1.5 & 1.4 & 1.3 & \\
\hline Korea & 6.0 & 4.5 & 2.8 & 1.6 & 1.5 & 1.2 & \\
\hline Luxembourg & 2.3 & 2.0 & 1.5 & 1.6 & 1.8 & 1.6 & \\
\hline Mexico & 7.3 & 6.8 & 4.7 & 3.4 & 2.4 & 2.2 & \\
\hline Netherlands & 3.1 & 2.6 & 1.6 & 1.6 & 1.7 & 1.8 & \\
\hline New Zealand & 4.2 (1962) & 3.3 & 2.1 & 2.1 & 2.0 & 1.9 & (2002) \\
\hline Norway & 2.9 & 2.5 & 1.7 & 1.9 & 1.9 & 1.8 & \\
\hline Poland & 3.0 & 2.2 & 2.3 & 2.0 & 1.3 & 1.2 & \\
\hline Portugal & 3.1 & 2.8 & 2.2 & 1.6 & 1.6 & 1.4 & \\
\hline Slovak Republic & 3.1 & 2.4 & 2.3 & 2.1 & 1.3 & 1.2 & \\
\hline Spain & 2.9 & 2.9 & 2.2 & 1.4 & 1.2 & 1.3 & \\
\hline Sweden & 2.2 & 1.9 & 1.7 & 2.1 & 1.5 & 1.7 & \\
\hline Switzerland & 2.4 & 2.1 & 1.6 & 1.6 & 1.5 & 1.4 & \\
\hline Turkey & 6.4 & 5.1 & 4.2 & 2.9 & 2.6 & 2.5 & (2002) \\
\hline United Kingdom & 2.7 & 2.4 & 1.9 & 1.8 & 1.6 & 1.7 & \\
\hline United States & 3.7 & 2.5 & 1.8 & 2.1 & 2.1 & 2.0 & \\
\hline Average (30) & 3.2 & 2.7 & 2.1 & 1.9 & 1.6 & 1.6 & \\
\hline Median & 2.8 & 2.4 & 1.9 & 1.8 & 1.6 & 1.6 & \\
\hline
\end{tabular}

Source: OECD Health Data 2005. (For the 22 European countries, the Eurostat NewCronos database is the main data source.) 
Table A.5.5. GDP per capita, 2003 in USD PPP and annual average growth rates 1970 to 2003

\begin{tabular}{|c|c|c|c|c|c|}
\hline & \multirow{2}{*}{$\frac{\text { GDP per capita USD PPP }}{2003}$} & \multicolumn{4}{|c|}{ Annual average growth rate } \\
\hline & & $1970-1980$ & $1980-1990$ & $1990-2000$ & $2000-2003$ \\
\hline Australia & 30297 & 1.4 & 1.5 & 2.4 & 2.4 \\
\hline Austria & 30550 & 3.5 & 2.1 & 2.1 & 0.4 \\
\hline Belgium & 29513 & 3.2 & 1.9 & 1.9 & 0.6 \\
\hline Canada & 30445 & 2.9 & 1.5 & 1.9 & 1.3 \\
\hline Czech Republic & 17222 & . & . & 0.3 & 2.8 \\
\hline Denmark & 30733 & 1.5 & 1.5 & 1.9 & 0.7 \\
\hline Finland & 28455 & 3.3 & 2.6 & 1.5 & 1.6 \\
\hline France & 28645 & 2.7 & 1.9 & 1.5 & 0.8 \\
\hline Germany & 27094 & 2.6 & 2.0 & 0.1 & 0.1 \\
\hline Greece & 20292 & 3.7 & 0.2 & 1.6 & 3.9 \\
\hline Hungary & 15166 & .. & . & $\ldots$ & 3.7 \\
\hline Iceland & 29716 & 5.2 & 1.6 & 1.6 & 1.0 \\
\hline Ireland & 33162 & 3.2 & 3.3 & 6.3 & 3.6 \\
\hline Italy & 26792 & 3.1 & 2.2 & 1.6 & 0.4 \\
\hline Japan & 28395 & 3.3 & 3.4 & 1.2 & 0.7 \\
\hline Korea & 19274 & 5.6 & 7.4 & 4.9 & 4.0 \\
\hline Luxembourg & 53828 & 1.9 & 4.5 & 4.1 & 1.3 \\
\hline Mexico & 9451 & 4.0 & -0.1 & 1.8 & -0.6 \\
\hline Netherlands & 30315 & 2.1 & 1.7 & 2.3 & -0.3 \\
\hline New Zealand & 23394 & 0.7 & 1.2 & 1.4 & 2.6 \\
\hline Norway & 37017 & 4.2 & 2.2 & 3.1 & 1.0 \\
\hline Poland & 11524 & .. & . & 3.5 & 2.3 \\
\hline Portugal & 18725 & 3.5 & 3.1 & 2.5 & -0.4 \\
\hline Slovak Republic & 13117 & .. & . & $\ldots$ & 4.3 \\
\hline Spain & 23889 & 2.5 & 2.6 & 2.3 & 1.1 \\
\hline Sweden & 28881 & 1.6 & 1.9 & 1.6 & 1.2 \\
\hline Switzerland & 32803 & 1.0 & 1.6 & 0.4 & -0.4 \\
\hline Turkey & 6946 & . & . & 1.7 & 0.2 \\
\hline United Kingdom & 29826 & 1.8 & 2.4 & 2.0 & 2.2 \\
\hline United States & 37658 & 2.2 & 2.3 & 2.0 & 0.9 \\
\hline Latest average $^{a}$ & 26104 & $\ldots$ & .. & .. & 1.4 \\
\hline Consistent average $(25)^{b}$ & 28766 & 2.8 & 2.3 & 2.2 & 1.2 \\
\hline Median & 28550 & 2.9 & 2.0 & 1.9 & 1.1 \\
\hline
\end{tabular}

a) Average of the latest available data for all 30 OECD countries.

b) Excludes Czech Republic, Hungary, Poland, Slovak Republic and Turkey.

Source: OECD Health Data 2005. 


\section{ANNEX B \\ Definition of Health Expenditure and Methodological Notes on Data Comparability}

\section{Definition of health expenditure}

Total expenditure on health measures the final consumption of health care goods and services plus capital investment in health care infrastructure. This includes spending by both public and private sources (including households) on medical services and goods, public health and prevention programmes and administration. Excluded are health-related expenditure such as training, research and environmental health. Total expenditure on health does not include compensation for loss in income due to health problems (sick pay and disability allowances). For a more detailed definition, please see A System of Health Accounts (OECD, 2000a).

The following table presents major expenditure categories used in OECD Health Data 2005 and the tables presented in this publication.

\begin{tabular}{ll}
\hline ICHA Code & Description \\
\hline HC.1; HC. 2 & Services of curative and rehabilitative care (inpatient, outpatient and home care) \\
HC. 3 & Services of long-term nursing care (inpatient and home care) \\
HC. 4 & Ancillary services to health care \\
HC. $1-H C .4$ & Medical services \\
HC.5 & Medical goods dispensed to outpatients \\
HC.1-HC.5 & Total expenditure on personal health \\
HC.6 & Services of prevention and public health \\
HC.7 & Health administration and health insurance \\
HC.6+HC.7 & Total expenditure on collective health \\
HC.1-HC.7 & Total current expenditure on health \\
HC.R.1 & Investment (gross capital formation) in health \\
HC.1-HC.7+ HC.R.1 & TOTAL EXPENDITURE ON HEALTH \\
\hline
\end{tabular}

\section{Comparison of health expenditure across countries}

OECD countries are at varying stages of reporting total expenditure on health according to the boundary of health care proposed in the OECD manual A System of Health Accounts (SHA). This means that data reported in OECD Health Data 2005 are at varying levels of comparability. The comparability of the functional breakdown of health expenditure data in OECD Health Data has gradually improved over the past few years. However, it is still limited (even among those countries where total expenditure is fairly comparable), due to the fact that data reporting is connected to administrative records of 
financing systems. For example, inpatient expenditure does not contain independent billing (office-based) of physicians' fees for inpatient care in Australia, Canada and the United States, while inpatient expenditure includes outpatient care provided in hospitals in Germany and the Netherlands. Different practices regarding the inclusion of long-term care in health or social expenditure are also a major factor affecting data comparability.

Regarding the functional breakdown of health expenditure presented in this publication, ambulatory expenditure is used in a broad sense to cover out-patient care, but also ancillary services and home care, in order to improve data comparability. OECD Health Data 2005 presents a more detailed breakdown (as shown in the table above).

For further information, please see the "Note on General Comparability of Health Expenditure and Finance Data" in OECD Health Data 2005.

\section{Adjustment for differences in national currency}

Health expenditure based on national currency units can be used for comparing some indicators, such as the ratio of health expenditure to GDP and health spending growth rates over time.

However, to make useful comparisons of health expenditure across countries at a given point in time, it is necessary to convert data from national currency units to a common currency, such as the US dollar (USD). It is also useful to take into account differences in the purchasing power of national currencies in each country. To calculate the conversion rate of national currencies into US dollar purchasing power parity (PPP), the same, fixed basket of goods and services across different countries is priced in the national currency, and then converted to US dollars. For example, if an identical basket of goods and services cost 140 Canadian dollars (CAD) in Canada and 100 USD in the United States, then the PPP conversion rate would be 1.4 CAD to one USD. The economy-wide (GDP) PPPs are used as the most available and reliable conversion rates. These are based on a broad basket of goods and services, chosen to be representative of all economic activity. The use of economy-wide PPPs means that the resulting variations in health expenditure across countries will reflect not only variations in the volume of health services, but also any variations in the prices of health services relative to GDP prices, across countries.

Health expenditure converted to USD PPP are not adjusted for price inflation; hence they are not suitable for comparison of real growth rates over time.

\section{Correcting data for price inflation}

To make useful comparison of real growth rates over time, it is necessary to deflate (remove inflation from) nominal health expenditure through the use of a suitable price index, and also to divide by population, to derive real spending per capita. Due to limited availability of reliable health price indices, an economy-wide (GDP) price index is used in this publication (2000 GDP price levels). It should be kept in mind that the health sector usually has a higher inflation than the economy as a whole in most countries. 


\section{ANNEX C \\ List of Variables in OECD Health Data 2005}

Part 1. Health status
Mortality
Life expectancy
Causes of mortality
Maternal and infant mortality
Potential years of life lost
Morbidity
Perceived health status
Infant health
Congenital anomalies
Dental health
Communicable diseases (HIV/AIDS)
Cancer
Injuries
Absence from work due to illness

Part 2. Health care resources

Health employment

In-patient beds

Employment-to-beds ratio

Medical technology

Education in health and welfare

\section{Part 3. Health care utilisation}

Prevention (Immunisation)

Consultations

In-patient utilisation

Average length of stay

Average length of stay: in-patient and acute care

Average length of stay by diagnostic categories

Discharges

Discharge rates by diagnostic categories

Surgical procedures

Total surgical procedures

Surgical procedures by ICD-CM

Transplants and dialyses

Part 4. Expenditure on health

National expenditure on health

Total expenditure on health

Expenditure on personal health care

Expenditure on collective health care

Prevention and public health

Expenditure on health administration and insurance

Expenditure on health-related functions

Expenditure on medical services
Total expenditure on medical services by functions

Expenditure on in-patient care

Expenditure on out-patient care

Expenditure on home care

Expenditure on ancillary services

Medical goods dispensed to out-patients

Total expenditure on medical goods

Pharmaceuticals and other medical non-durables

Therapeutic appliances and other medical durables

Current health expenditure by provider

Price index

Part 5. Health care financing

Health expenditure by sources of funds

Part 6. Social protection

Social expenditure

Health care coverage

Part 7. Pharmaceutical market

Pharmaceutical industry activity

Pharmaceutical consumption

Pharmaceutical sales

Part 8. Non-medical determinants of health

Life styles and behaviour

Food consumption

Alcohol consumption

Tobacco consumption

Body weight and composition

Environment: air quality

Part 9. Demographic references

General demographics

Population age structure

Labour force

Educational leve

\section{Part 10. Economic references}

Macro-economic references

Monetary conversion rates

Other tables

Satisfaction with health care systems

Healthy life expectancy

Disability-free life expectancy

Population covered by private health insurance

Remuneration of health professions

Additional expenditure tables

More information on OECD Health Data 2005 is available at www.oecd.org/health/healthdata. 


\section{Disease and Injury Categories and ICD Codes}

The causes of death presented in OECD Health Data 2005 are listed below with codes according to the Tenth and Ninth revisions of the International Classification of Diseases (ICD).

\begin{tabular}{|c|c|c|}
\hline Disease and injury categories & ICD-10 & ICD-9 \\
\hline 0 . All causes & A00-R99,V01-Y89 & 001-799, E800-E999 \\
\hline 1. Certain infectious and parasitic diseases & A00-B99 & $001-139,042-044$ \\
\hline 2. HIV disease & B20-B24 & $042-044$ \\
\hline 3. Malignant neoplasms (cancer) & $\mathrm{COO}-\mathrm{C} 97$ & $140-208$ \\
\hline 4. Malignant neoplasm of colon, rectum, rectosigmoid junction and anus & C18-C21 & $153-154$ \\
\hline 5. Malignant neoplasm of trachea, bronchus, lung & $\mathrm{C} 33-\mathrm{C} 34$ & 162 \\
\hline 6. Malignant neoplasm of female breast & C50 & 174 \\
\hline 7. Malignant neoplasm of cervix uteri & $\mathrm{C} 53$ & 180 \\
\hline 8. Malignant neoplasm of prostate & $\mathrm{C} 61$ & 185 \\
\hline $\begin{array}{l}\text { 9. Diseases of the blood and blood-forming organs and certain disorders involving the immune } \\
\text { mechanism }\end{array}$ & D50-D89 & $279-289$ \\
\hline 10. Endocrine, nutritional and metabolic diseases & E00-E89 & $240-279$ \\
\hline 11. Diabetes mellitus & E10-E14 & 250 \\
\hline 12. Mental and behavioural disorders & F01-F99 & 290-319 \\
\hline 13. Diseases of the nervous system and sense organs & G00-H95 & $320-389$ \\
\hline 14. Diseases of the circulatory system & $100-199$ & $390-459$ \\
\hline 15. Ischaemic heart disease & $120-125$ & $410-414$ \\
\hline 16. Acute myocardial infarction & $|21| 22$, & 410 \\
\hline 17. Cerebrovascular diseases & $160-169$ & $430-438$ \\
\hline 18. Diseases of the respiratory system & J00-J98 & $460-519$ \\
\hline 19. Influenza and pneumonia & J10-J18 & $480-487$ \\
\hline 20. Bronchitis, emphysema and asthma & $\mathrm{J} 40-\mathrm{J} 43, \mathrm{~J} 45, \mathrm{~J} 46$ & $490-493$ \\
\hline 21. Disease of the digestive system & K00-K92 & $520-579$ \\
\hline 22. Chronic liver disease and cirrhosis & $\mathrm{K} 70, \mathrm{~K} 73, \mathrm{~K} 74, \mathrm{~K} 76$ & 571 \\
\hline 23. Diseases of the skin and subcutaneous tissue & L00-L98 & $680-709$ \\
\hline 24. Diseases of the musculoskeletal system and connective tissue & M00-M99 & $710-739$ \\
\hline 25. Diseases of the genitourinary system & N00-N99 & $580-629$ \\
\hline 26. Pregnancy, childbirth and the puerperium & 000-099 & $630-676$ \\
\hline 27. Certain conditions arising in the perinatal period & P00-P96 & $760-779$ \\
\hline 28. Congenital anomalies & Q00-Q99 & $740-759$ \\
\hline 29. Symptoms, signs and abnormal clinical and laboratory findings, n.e.c. & R00-R99 & $780-799$ \\
\hline 30. External causes of mortality & V01-Y89 & E800-E999 \\
\hline 31. Land Transport Accidents & V01-V89 & E810-E829 \\
\hline 32. Accidental falls & W00-W19 & E880-E888 \\
\hline 33. Intentional self-harm (suicide) & $\mathrm{X} 60-\mathrm{X} 84$ & E950-E959 \\
\hline 34. Assault (homicide) & X85-Y09 & E960-969 \\
\hline 35. Drugs, medicaments and biological substances causing adverse effects in therapeutic use & Y40-Y59 & E930-E949 \\
\hline 36. Misadventures to patients during surgical and medical care & Y60-Y84 & E870-E879 \\
\hline
\end{tabular}




\section{ORDER FORM}

\section{OECD Health Data 2005: Statistics and Indicators for 30 Countries}

YES! Please send me the OECD Health Data 2005 CD-ROM

\section{Enter your delivery details}

Title (Prof./Dr./Mr./Ms.).......... First name Surname

Address Post/ZIP Code

Country Tel. Fax E-mail

\section{Choose the correct price option}

Single-user version (81 2005073 C 1) ISBN 92-64-00876-4

For profit organisations $€ 325$ US\$423£ $£ 219 ¥ 43600$

For non-profit organisations $€ 225$ US\$293 £ $151 ¥ 30200$

Network version (81 2005073 C 5) ISBN 92-64-00877-2

For profit organisations

For non-profit organisations $€ 895$ US\$1 $164 £ 602 ¥ 120000$

\section{Enter method of payment}

Q Cheque/Eurocheque enclosed (please make payable to OECD)

Please invoice me. Purchase order No.

Please charge my credit card: $\square$ AMEX a VISA DMASTERCARD

Card number Expiry date

Today's date Signature.

Please send me details on your related publications

\section{Post, fax or e-mail your order to:}

Turpin Distribution Services Limited Stratton Business Park, Pegasus Drive Biggleswade, Bedfordshire SG18 8QB - UK Tel.: +44 (0)1767 604960 - Fax: +44 (0)1767 604640

E-mail : oecdrow@turpin-distribution.com

The database OECD Health Data 2005 is also available online: go to SourceOECD (http://new.sourceoecd.org/) for more information

Browse OECD titles online at www.oecdbookshop.org

For more information, contact sales@oecd.org

To find out more about health research at OECD, visit www.oecd.org/health/healthdata

Organisation for Economic Co-operation and Development

2, rue André-Pascal, 75775 Paris Cedex 16, France

www.oecd.org 
OECD PUBLICATIONS, 2, rue André-Pascal, 75775 PARIS CEDEX 16 PRINTED IN FRANCE

(81 200517 1 P) ISBN 92-64-01262-1 - No. 542632005 


\section{Health at a Glance OECD INDICATORS 2005}

Progress in health care and the development of new medicines have contributed to the steady improvements in health status that OECD countries have enjoyed in recent decades. At the same time, spending on health care has never been higher, consuming an ever-increasing share of national income. Health expenditure now accounts for an average of almost 9\% of GDP in OECD countries, up from around $7 \%$ in 1990 and just over 5\% in 1970.

In nearly all OECD countries, the public sector finances the greatest share of health spending. Faced with rising health costs, governments in many countries are seeking ways to slow the growth in public-sector spending while at the same time trying to get better value for money.

This third edition of Health at a Glance - OECD Indicators 2005 provides the latest comparable data and trends on different aspects of the performance of health systems in OECD countries. It provides striking evidence of large variations across countries in indicators of health status and health risks, and in the costs, allocation of resources and outputs of health systems. Compared to the previous edition, it contains an expanded set of indicators related to health promotion and disease prevention, reflecting growing policy interest in striking a better balance between spending on prevention and care.

Each indicator in the book is presented in a user-friendly format, consisting of charts illustrating variations across countries and over time, brief commentaries highlighting the key findings conveyed by the data, and a methodological box on the definition of the indicator. In addition, a statistical annex provides additional information for each indicator, often presenting long time series going as far back as 1960.

This publication takes as its basis OECD Health Data 2005, the most comprehensive database on health and health systems across the 30 OECD member countries. OECD Health Data 2005 is available on line at www.SourceOECD.org or on CD-ROM from the OECD's online bookshop (www.oecd.org/bookshop).

The full text of this book is available on line via this link:

http://www.sourceoecd.org/socialissues/9264012621

Those with access to all OECD books on line should use this link: http://www.sourceoecd.org/9264012621

SourceOECD is the OECD's online library of books, periodicals and statistical databases. For more information about this award-winning service and free trials ask your librarian, or write to us at SourceOECD@oecd.org.

\section{www. oecd.org/health}

